\title{
BOUNDARY ELEMENT ANALYSIS OF STRESS CONCENTRATIONS IN BICRYSTALS
}

by

\author{
Adrien Gravelle \\ A Thesis submitted to \\ the Faculty of Graduate Studies and Research \\ in partial fulfilment of \\ the requirements for the degree of \\ Master of Applied Science \\ Ottawa-Carleton Institute for \\ Mechanical and Aerospace Engineering \\ Department of Mechanical and Aerospace Engineering \\ Carleton University \\ Ottawa, Ontario, Canada \\ November 2011
}

Copyright (C)

2011 - Adrien Gravelle 
Library and Archives

Canada

Published Heritage

Branch

395 Wellington Street

Ottawa ON K1A ON4

Canada
Bibliothèque et

Archives Canada

Direction du

Patrimoine de l'édition

395 , rue Wellington

Ottawa ON K1A ON4

Canada
Your file Votre référence

ISBN: 978-0-494-87815-6

Our file Notre référence

ISBN: $978-0-494-87815-6$

\section{NOTICE:}

The author has granted a nonexclusive license allowing Library and Archives Canada to reproduce, publish, archive, preserve, conserve, communicate to the public by telecommunication or on the Internet, loan, distrbute and sell theses worldwide, for commercial or noncommercial purposes, in microform, paper, electronic and/or any other formats.

The author retains copyright ownership and moral rights in this thesis. Neither the thesis nor substantial extracts from it may be printed or otherwise reproduced without the author's permission.
AVIS:

L'auteur a accordé une licence non exclusive permettant à la Bibliothèque et Archives Canada de reproduire, publier, archiver, sauvegarder, conserver, transmettre au public par télécommunication ou par l'Internet, prêter, distribuer et vendre des thèses partout dans le monde, à des fins commerciales ou autres, sur support microforme, papier, électronique et/ou autres formats.

L'auteur conserve la propriété du droit d'auteur et des droits moraux qui protege cette thèse. $\mathrm{Ni}$ la thèse ni des extraits substantiels de celle-ci ne doivent être imprimés ou autrement reproduits sans son autorisation.
In compliance with the Canadian Privacy Act some supporting forms may have been removed from this thesis.

While these forms may be included in the document page count, their removal does not represent any loss of content from the thesis.
Conformément à la loi canadienne sur la protection de la vie privée, quelques formulaires secondaires ont été enlevés de cette thèse.

Bien que ces formulaires aient inclus dans la pagination, il n'y aura aucun contenu manquant. 
The undersigned recommend to the Faculty of Graduate Studies and Research acceptance of the Thesis

\title{
BOUNDARY ELEMENT ANALYSIS OF STRESS CONCENTRATIONS IN BICRYSTALS
}

\author{
Submitted by Adrien Gravelle \\ in partial fulfilment of the requirements for the degree of \\ Master of Applied Science
}

Choon-Lai Tan, Supervisor

Metin I. Yaras, Chair of Department

Carleton University

2011 


\section{Abstract}

Stress concentrations in $\mathrm{Nb}-\mathrm{Al}_{2} \mathrm{O}_{3}$ and $\mathrm{Cu}-\mathrm{Al}_{2} \mathrm{O}_{3}$ bicrystals caused by common geometrical discontinuities are investigated using the boundary element method in threedimensional linear, anisotropic elasticity. The analyses are carried out for a plate with a circular hole and a double U-notch bar in tension; the geometric discontinuities being at the bicrystal interface. The material principal axes of the crystals are rotated independently in a parametric study, and the largest normal and von Mises equivalent stresses are determined a short distance away from the free edges of the interface where weak stress singularities exist. Due to the incompatibility of the elastic constants at the interface, the rotation of the material axes can cause the equivalent stress to increase by $71 \%$ to $134 \%$, relative to the corresponding isotropic homogeneous cases, and by $28 \%$ to $82 \%$, relative to the corresponding isotropic bimaterial cases. The largest increases observed are in the $\mathrm{Cu}-\mathrm{Al}_{2} \mathrm{O}_{3}$ bicrystal, double U-notch bar prob-

lem. It is found as well that rotation of the cubic material principal axis coinciding with the load axis causes very little change in the maximum stresses when compared to other material axis rotations, and rotations of the $\mathrm{Nb}$ and $\mathrm{Cu}$ material principal axes produce opposing trends. The present work also includes an investigation of the effectiveness of introducing auxiliary holes to decrease the stress concentration for the problem of a bicrystal plate with a circular hole. This is carried out for a range of geometrical parameters. It is demonstrated in this study that a significant decrease in the maximum principal stress at the edge of the hole can be achieved. 


\section{Acknowledgments}

I would like to thank my supervisor, Professor C. L. Tan, for his continued guidance and focus throughout the course of this work. I would also like to thank my family for their ongoing support and my partner; she has been a great source of confidence and motivation in helping me complete this thesis. 


\section{Table of Contents}

Abstract $\quad$ iii

Acknowledgments $\quad$ iv

Table of Contents $\quad$ v

List of Tables viii

List of Figures $\quad$ x

$\begin{array}{ll}\text { Nomenclature } & \text { xxii }\end{array}$

1 Introduction 1

1.1 Review of Literature . . . . . . . . . . . . . . . 2

1.2 Proposed Method of Solution . . . . . . . . . . . . . . . . 4

1.3 Outline .......................... 5

2 Review of the Boundary Element Method 6

2.1 Analytical Formulation of the BEM . . . . . . . . . . . . 6

2.2 Numerical Formulation of the BEM . . . . . . . . . . . . . 8

2.3 Numerical Examples . . . . . . . . . . . . . . . . 10

2.3.1 Example $(\mathrm{A}) \ldots \ldots \ldots 10 . \ldots \ldots$

2.3.2 Example (B) . . . . . . . . . . . . . . . 12 
2.3 .3 Example $(\mathrm{C}) \quad \ldots \ldots \ldots \ldots \ldots \ldots$

2.4 Concluding Remarks . . . . . . . . . . . . . . 16

3 Bicrystal Plate with a Circular Hole 32

3.1 Problem Definition . . . . . . . . . . . . . . . . . 32

3.2 Numerical Models . . . . . . . . . . . . . . . . . . . 33

3.3 Results . . . . . . . . . . . . . . . . . . . 34

3.3.1 Effects of the Free Edge Singularity - Some Preliminary Results and Remarks . . . . . . . . . . . . . 34

3.3 .2 Anisotropic Results . . . . . . . . . . . . . . . . 36

3.4 Concluding Remarks $\ldots \ldots \ldots \ldots \ldots$

4 Bicrystal Double U-Notch Bar $\quad 78$

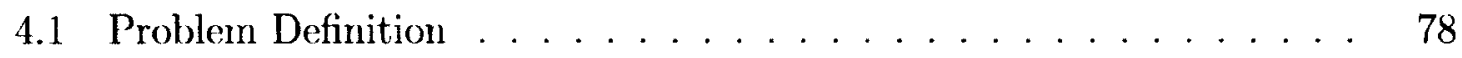

4.2 Numerical Models . . . . . . . . . . . . . . . . . . . . . . . . 79

4.3 Results . . . . . . . . . . . . . . . . . . . . 80

4.3 .1 Preliminary Remarks . . . . . . . . . . . . . . 80

4.3 .2 Anisotropic Results . . . . . . . . . . . . . . . . . 81

4.4 Concluding Remarks $\ldots \ldots \ldots \ldots \ldots \ldots$

5 On the Influence of Auxiliary Holes in a Bicrystal Plate with a $\begin{array}{lr}\text { Primary Circular Hole } & 119\end{array}$

5.1 Problem Review and Definition $\ldots \ldots \ldots \ldots$

5.2 Numerical Models . . . . . . . . . . . . . . . . . . . . . . 121

5.3 Defence Hole System . . . . . . . . . . . . . . . . . . . 121

5.3.1 Homogeneous Plate with a Circular Hole . . . . . . . . . 122

5.3.2 Bimaterial Plate with a Circular Hole . . . . . . . . . . 124

5.4 Concluding Remarks $\ldots \ldots \ldots \ldots \ldots \ldots$ 
6 Conclusions 168

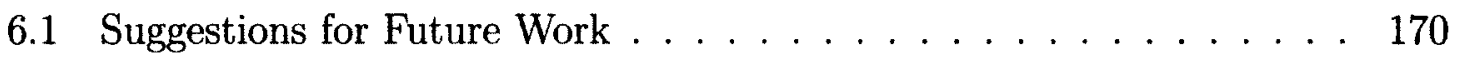

$\begin{array}{ll}\text { List of References } & 172\end{array}$

A Fundamental Solutions of Three Dimensional Anisotropic Elasticity 176

B Quadratic Shape Functions of BEM Elements 180

B.1 Quadrilateral Elements . . . . . . . . . . . . . . . . . 180

B.2 Triangular Elements . . . . . . . . . . . . . . . . . . 181

$\begin{array}{lc}\text { C Numerical Results } & 182\end{array}$ 


\section{List of Tables}

3.1 Mechanical properties of $\mathrm{Nb}, \mathrm{Cu}$, and $\mathrm{Al}_{2} \mathrm{O}_{3} \ldots \ldots \ldots$

3.2 Comparison of stresses at various points from BEM and FEM analyses of the $\mathrm{Nb}-\mathrm{Al}_{2} \mathrm{O}_{3}$ bicrystal plate with a circular hole; $x_{1} / a=0.15$ and

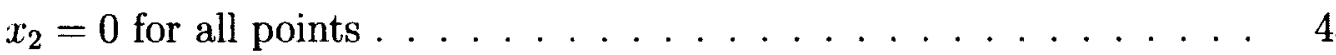

3.3 Comparison of stresses at various points from BEM and FEM analyses of the $\mathrm{Cu}-\mathrm{Al}_{2} \mathrm{O}_{3}$ bicrystal plate with a circular hole; $x_{1} / a=0.15$ and

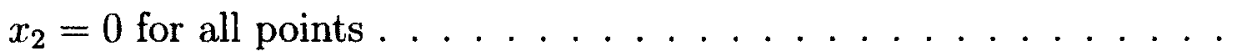

3.4 Stress components along $\overline{A C B}$ in the $\mathrm{Nb}$ material of a $\mathrm{Nb}-\mathrm{Al}_{2} \mathrm{O}_{3}$ bimaterial plate with a circular hole at the interface . . . . . . . . .

3.5 Stress components along $\overline{A C B}$ in the $\mathrm{Cu}$ material of a $\mathrm{Cu}-\mathrm{Al}_{2} \mathrm{O}_{3}$ bimaterial plate with a circular hole at the interface . . . . . . . .

3.6 Stress components at point $\mathrm{F}$ for various material combinations of a plate with a circular hole at the interface; all stresses have been normalized with respect to the applied load, $\sigma_{0} \ldots \ldots \ldots \ldots$

4.1 Comparison of $\sigma_{11} / \sigma_{0}$ at various points from BEM and FEM analyses of the $\mathrm{Nb}-\mathrm{Al}_{2} \mathrm{O}_{3}$ bicrystal bar with double U-notch; $x_{1}=0$ and $x_{2} / H=$

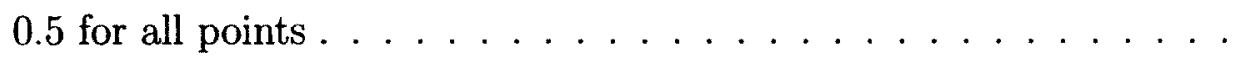

4.2 Comparison of $\sigma_{e q} / \sigma_{0}$ at various points from BEM and FEM analyses of the $\mathrm{Nb}-\mathrm{Al}_{2} \mathrm{O}_{3}$ bicrystal bar with double U-notch; $x_{1}=0$ and $x_{2} / H=$ 0.5 for all points $\ldots \ldots \ldots \ldots \ldots \ldots \ldots$ 
4.3 Comparison of $\sigma_{11} / \sigma_{0}$ at various points from BEM and FEM analyses of the $\mathrm{Cu}-\mathrm{Al}_{2} \mathrm{O}_{3}$ bicrystal bar with double U-notch; $x_{1}=0$ and $x_{2} / H=$

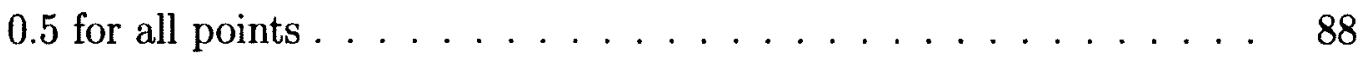

4.4 Comparison of $\sigma_{e q} / \sigma_{0}$ at various points from BEM and FEM analyses of the $\mathrm{Cu}-\mathrm{Al}_{2} \mathrm{O}_{3}$ bicrystal bar with double U-notch ; $x_{1}=0$ and $x_{2} / H=0.5$ for all points $\ldots \ldots \ldots \ldots \ldots \ldots$

4.5 Stress components at point $\mathrm{F}$ for various material combinations of a bar with a double U-notch at the interface; all stresses have been normalized with respect to the applied load, $\sigma_{0} \ldots \ldots \ldots$

5.1 Reference of the various base meshes used to analyse all cases in the parametric study . . . . . . . . . . . . . . 129

5.2 Lowest stress concentrations and the corresponding auxiliary hole parameters . . . . . . . . . . . . . . . . . 130 


\section{List of Figures}

2.1 BEM quadratic isoparametric quadrilateral eight-node surface element 17

2.2 BEM quadratic isoparametric triangular six-node surface element $\ldots 17$

2.3 Plate in tension with a circular hole - Example (A) $\ldots \ldots \ldots$

2.4 Three-dimensional meshes of a plate with a circular hole for isotropic

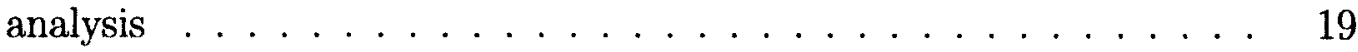

2.5 Variation of stress concentration along $\overline{C A}$, through the thickness of an isotropic plate at a central circular hole . . . . . . . . . .

2.6 Three-dimensional meshes of a plate with circular hole for anisotropic

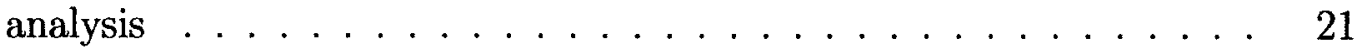

2.7 Variation of stress concentration along $\overline{A B}$, through the thickness of an anisotropic plate at a central circular hole . . . . . . . . . 22

2.8 Bar in tension with double U-notch — Example (B) . . . . . . . 23

2.9 Three-dimensional meshes of a bar with double U-notch for isotropic

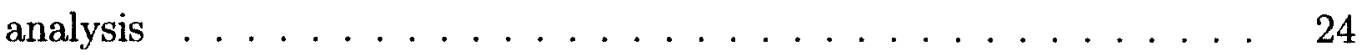

2.10 Variation of stress concentration along the notch at $\overline{C A}$, through the thickness of an isotropic double U-notch bar . . . . . . . . 25

2.11 Three-dimensional meshes of a bar with double U-notch for anisotropic

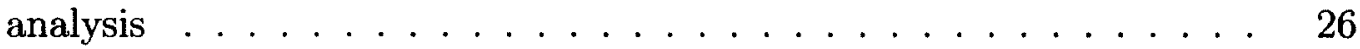

2.12 Variation of $\sigma_{e q} / \sigma_{0}$ along the notch at $\overline{A B}$, through the thickness of an anisotropic double U-notch bar . . . . . . . . . . . . . 
2.13 Bicrystal bar in tension - Example (C) $\ldots \ldots \ldots \ldots 28$

2.14 Three-dimensional meshes of a bicrystal bar in tension $\ldots \ldots \ldots$

2.15 Two dissimilar anisotropic wedges perfectly bonded along the $x_{1}$ axis 30

2.16 Variation of $\sigma_{e q} / \sigma_{0}$ at the interface of a $\mathrm{Nb}-\mathrm{Al}_{2} \mathrm{O}_{3}$ bicrystal bar at point $\mathrm{C}$ for material $x_{1}$ axis rotations of the $\mathrm{Nb}$ crystal $\ldots \ldots \ldots 31$

3.1 Plate in tension with a circular hole; the values of $r / a$ and $h / a$ are both set to $1 / 10 \ldots \ldots \ldots \ldots \ldots \ldots \ldots \ldots \ldots$

3.2 Materials regions of a bimaterial plate with a circular hole $\ldots \ldots 49$

3.3 BEM mesh of the $\mathrm{Nb}-\mathrm{Al}_{2} \mathrm{O}_{3}$ bicrystal plate with a circular hole (284 elements and 828 nodes $) \ldots \ldots \ldots \ldots \ldots$

3.4 BEM interfacial mesh of the $\mathrm{Cu}-\mathrm{Al}_{2} \mathrm{O}_{3}$ bicrystal plate with circular hole (full mesh contains 468 elements and 1368 nodes) $\ldots \ldots \ldots 51$

3.5 FEM mesh of a bimaterial plate with a circular hole (33,300 elements

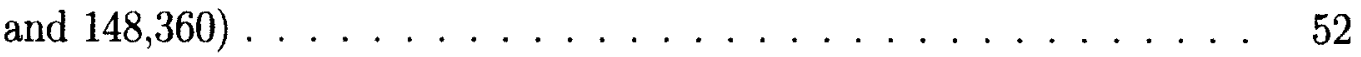

3.6 FEM refined mesh of a bimaterial plate with a circular hole $(70,000$ elements and 302,304$) \ldots \ldots \ldots \ldots \ldots \ldots \ldots \ldots$

3.7 Variation of $\sigma_{e q} / \sigma_{0}$ through the thickness at the interface in the $N b$

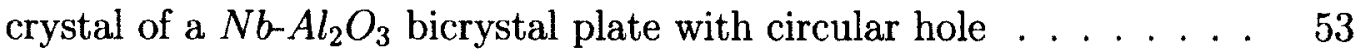

3.8 Variation of $\sigma_{e q} / \sigma_{0}$ through the thickness at the interface in the $\mathrm{Al}_{2} \mathrm{O}_{3}$ crystal of a $\mathrm{Cu}-\mathrm{Al}_{2} \mathrm{O}_{3}$ bicrystal plate with a circular hole $\ldots \ldots . .54$

3.9 Variations of $\sigma_{e q} / \sigma_{0}$ through the thickness at the interface in the $N b$ crystal of a $\mathrm{Nb}-\mathrm{Al}_{2} \mathrm{O}_{3}$ bimaterial plate with circular hole - Isotropic (Iso) and Anisotropic (Ani) $\ldots \ldots \ldots \ldots \ldots$

3.10 Variations of $\sigma_{e q} / \sigma_{0}$ through the thickness at the interface in the $C u$ crystal of a $\mathrm{Cu}-\mathrm{Al}_{2} \mathrm{O}_{3}$ bimaterial plate with circular hole - Isotropic (Iso) and Anisotropic (Ani) $\ldots \ldots \ldots \ldots \ldots$ 
3.11 Variation of $\sigma_{e q} / \sigma_{0}$ at point $\mathrm{C}$ of a $\mathrm{Nb}-\mathrm{Al}_{2} \mathrm{O}_{3}$ bicrystal plate with a circular hole for $x_{1}$-material axis rotations of the $N b$ crystal $\ldots \ldots$

3.12 Variation of $\sigma_{22} / \sigma_{0}$ through the thickness along $\overline{A C B}$ at the interface of a $\mathrm{Nb}-\mathrm{Al}_{2} \mathrm{O}_{3}$ bicrystal plate with circular hole for a $\mathrm{Nb} x_{3}$-material axis rotation of $45^{\circ} \ldots \ldots \ldots \ldots \ldots \ldots$

3.13 Variation of $\sigma_{e q} / \sigma_{0}$ at point $\mathrm{C}$ of a $\mathrm{Nb}-\mathrm{Al}_{2} \mathrm{O}_{3}$ bicrystal plate with a circular hole for $x_{3}$-material axis rotations of the $\mathrm{Al}_{2} \mathrm{O}_{3}$ crystal . . .

3.14 Variation of $\sigma_{e q} / \sigma_{0}$ at point $\mathrm{F}$ of a $\mathrm{Nb}-\mathrm{Al}_{2} \mathrm{O}_{3}$ bicrystal plate with a circular hole for $x_{1}$-material axis rotations of the $\mathrm{Nb}$ crystal $\ldots 60$

3.15 Variation of $\sigma_{e q} / \sigma_{0}$ at point $\mathrm{F}$ of a $\mathrm{Nb}-\mathrm{Al}_{2} \mathrm{O}_{3}$ bicrystal plate with a circular hole for $x_{1}$-material axis rotations of the $\mathrm{Al}_{2} \mathrm{O}_{3}$ crystal $\ldots$.

3.16 Variation of $\sigma_{22} / \sigma_{0}$ at point $\mathrm{C}$ of a $\mathrm{Nb}-\mathrm{Al}_{2} \mathrm{O}_{3}$ bicrystal plate with a circular hole for $x_{1}$-material axis rotations of the $\mathrm{Al}_{2} \mathrm{O}_{3}$ crystal . . . 62

3.17 Variation of $\sigma_{e q} / \sigma_{0}$ at point $\mathrm{C}$ of a $\mathrm{Nb}-\mathrm{Al}_{2} \mathrm{O}_{3}$ bicrystal plate with a circular hole for $x_{1}$-material axis rotations of the $\mathrm{Al}_{2} \mathrm{O}_{3}$ crystal $\ldots$.

3.18 Variation of $\sigma_{e q} / \sigma_{0}$ at point $\mathrm{F}$ in the $\mathrm{Nb}$ crystal of a $\mathrm{Nb}-\mathrm{Al}_{2} \mathrm{O}_{3}$ bicrystal plate with a circular hole for $x_{1}, x_{2}$, and $x_{3}$-material axis rotations . .

3.19 Variation of $\sigma_{e q} / \sigma_{0}$ at point $\mathrm{F}$ in the $\mathrm{Al}_{2} \mathrm{O}_{3}$ crystal of a $\mathrm{Nb}-\mathrm{Al}_{2} \mathrm{O}_{3}$ bicrystal plate with a circular hole for $x_{1}, x_{2}$, and $x_{3}$-material axis

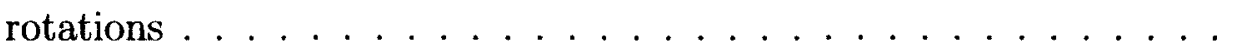

3.20 Variation of $\sigma_{22} / \sigma_{0}$ through the thickness along $\overline{A C B}$ at the interface of a $\mathrm{Nb}-\mathrm{Al}_{2} \mathrm{O}_{3}$ bicrystal plate with circular hole for an $\mathrm{Al}_{2} \mathrm{O}_{3} x_{1}$-material axis rotation of $150^{\circ} \ldots \ldots \ldots \ldots \ldots \ldots$

3.21 Variation of $\sigma_{e q} / \sigma_{0}$ through the thickness along $\overline{A C B}$ at the interface of a $\mathrm{Nb}-\mathrm{Al}_{2} \mathrm{O}_{3}$ bicrystal plate with circular hole for a $\mathrm{Al}_{2} \mathrm{O}_{3} x_{1}$-material axis rotation of $150^{\circ} \ldots \ldots \ldots \ldots \ldots \ldots$ 
3.22 Variation of $\sigma_{e q} / \sigma_{0}$ through the thickness along $\overline{D F E}$ at the interface of a $\mathrm{Nb}-\mathrm{Al}_{2} \mathrm{O}_{3}$ bicrystal plate with circular hole for a $\mathrm{Nb} x_{1}$-material axis rotation of $45^{\circ} \ldots \ldots \ldots \ldots \ldots \ldots$

3.23 Variation of $\sigma_{e q} / \sigma_{0}$ at point $\mathrm{C}$ of a $\mathrm{Cu}-\mathrm{Al}_{2} \mathrm{O}_{3}$ bicrystal plate with a circular hole for $x_{1}$-material axis rotations of the $C u$ crystal $\ldots$.

3.24 Variation of $\sigma_{22} / \sigma_{0}$ at point $\mathrm{C}$ of a $\mathrm{Cu}-\mathrm{Al}_{2} \mathrm{O}_{3}$ bicrystal plate with a circular hole for $x_{3}$-material axis rotations of the $C u$ crystal $\ldots$

3.25 Variation of $\sigma_{e q} / \sigma_{0}$ at point $\mathrm{C}$ of a $\mathrm{Cu}-\mathrm{Al}_{2} \mathrm{O}_{3}$ bicrystal plate with a circular hole for $x_{3}$-material axis rotations of the $C u$ crystal $\ldots$. .

3.26 Stress variation of $\sigma_{22} / \sigma_{0}$ and $\sigma_{e q} / \sigma_{0}$ through the thickness along $\overline{A C B}$ at the interface of a bicrystal plate with a circular hole in the $\mathrm{Al}_{2} \mathrm{O}_{3}$ crystal for an $\mathrm{Al}_{2} \mathrm{O}_{3} x_{1}$-material axis rotation of $150^{\circ} \ldots \ldots$

3.27 Variation of $\sigma_{e q} / \sigma_{0}$ at point $\mathrm{F}$ in the $\mathrm{Cu}$ crystal of a $\mathrm{Cu}-\mathrm{Al}_{2} \mathrm{O}_{3}$ bicrystal plate with a circular hole for $x_{1}, x_{2}$, and $x_{3}$-material axis rotations . .

3.28 Variation of $\sigma_{e q} / \sigma_{0}$ at point $\mathrm{F}$ in the $\mathrm{Al}_{2} \mathrm{O}_{3}$ crystal of a $\mathrm{Cu}-\mathrm{Al}_{2} \mathrm{O}_{3}$ bicrystal plate with a circular hole for $x_{1}, x_{2}$, and $x_{3}$-material axis

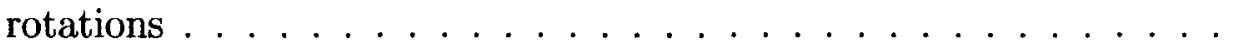

3.29 Variation of $\sigma_{22} / \sigma_{0}$ through the thickness along $\overline{A C B}$ at the interface of a $\mathrm{Cu}-\mathrm{Al}_{2} \mathrm{O}_{3}$ bicrystal plate with circular hole for a $\mathrm{Cu} x_{3}$-material axis rotation of $60^{\circ} \ldots \ldots \ldots \ldots \ldots \ldots$

3.30 Variation of $\sigma_{e q} / \sigma_{0}$ through the thickness along $\overline{A C B}$ at the interface of a $\mathrm{Cu}-\mathrm{Al}_{2} \mathrm{O}_{3}$ bicrystal plate with circular hole for a $\mathrm{Al}_{2} \mathrm{O}_{3} x_{1}$-material axis rotation of $150^{\circ} \ldots \ldots \ldots \ldots$

3.31 Variation of $\sigma_{e q} / \sigma_{0}$ through the thickness along $\overline{D F E}$ at the interface of a $\mathrm{Cu}-\mathrm{Al}_{2} \mathrm{O}_{3}$ bicrystal plate with circular hole for a $\mathrm{Al}_{2} \mathrm{O}_{3} x_{1}$-material axis rotation of $60^{\circ} \ldots \ldots \ldots \ldots \ldots$ 
4.1 Bar with double U-notch in tension; the case analysed has $t / H=$ $r / H=0.2, w / H=1$, and $L / w=4 \ldots \ldots \ldots 91$

4.2 Materials regions of a bimaterial bar with double U-notch . . . . . . . 92

4.3 BEM mesh of the $\mathrm{Nb}-\mathrm{Al}_{2} \mathrm{O}_{3}$ bicrystal bar with double U-notch (380 elements and 1108 nodes $) \ldots \ldots \ldots \ldots \ldots$

4.4 BEM mesh of the $\mathrm{Cu}-\mathrm{Al}_{2} \mathrm{O}_{3}$ bicrystal bar with double U-notch (500 elements and 1468 nodes $) \ldots \ldots \ldots$. . . . . . . . 94

4.5 FEM mesh of a bimaterial bar with double U-notch (36,998 elements and 162,707 nodes $) \ldots \ldots \ldots \ldots \ldots \ldots$

4.6 FEM mesh of a bimaterial bar with double U-notch (51,930 elements and 225,704 nodes $) \ldots \ldots \ldots \ldots \ldots \ldots \ldots$

4.7 Variations of $\sigma_{11} / \sigma_{0}$ through the thickness at the interface of a bimaterial bar with double U-notch - Isotropic (Iso) and Anisotropic (Ani) 97

4.8 Variations of $\sigma_{e q} / \sigma_{0}$ through the thickness at the interface of a bimaterial bar with double U-notch - Isotropic (Iso) and Anisotropic (Ani) 98

4.9 Variation of $\sigma_{e q} / \sigma_{0}$ of a $\mathrm{Nb}-\mathrm{Al}_{2} \mathrm{O}_{3}$ bicrystal bar with double U-notch for $x_{2}$-material axis rotations of the $\mathrm{Nb}$ crystal $\ldots \ldots \ldots \ldots$

4.10 Variation of $\sigma_{11} / \sigma_{0}$ at point $\mathrm{C}$ of a $\mathrm{Nb}-\mathrm{Al}_{2} \mathrm{O}_{3}$ bicrystal bar with double U-notch for $x_{3}$-material axis rotations of the $\mathrm{Nb}$ crystal $\ldots \ldots \ldots 100$

4.11 Variation of $\sigma_{e q} / \sigma_{0}$ of a $\mathrm{Nb}-\mathrm{Al}_{2} \mathrm{O}_{3}$ bicrystal bar with double U-notch for $x_{3}$-material axis rotations of the $\mathrm{Nb}$ crystal $\ldots \ldots \ldots \ldots$

4.12 Variation of $\sigma_{11} / \sigma_{0}$ at point $\mathrm{C}$ of a $\mathrm{Nb}-\mathrm{Al}_{2} \mathrm{O}_{3}$ bicrystal bar with double U-notch for $x_{1}$-material axis rotations of the $N b$ crystal $\ldots \ldots \ldots 102$

4.13 Variation of $\sigma_{e q} / \sigma_{0}$ of a $\mathrm{Nb}-\mathrm{Al}_{2} \mathrm{O}_{3}$ bicrystal bar with double U-notch for $x_{1}$-material axis rotations of the $\mathrm{Al}_{2} \mathrm{O}_{3}$ crystal $\ldots \ldots \ldots$ 
4.14 Variation of $\sigma_{11} / \sigma_{0}$ through the thickness along $\overline{A C B}$ at the interface of a $\mathrm{Nb}-\mathrm{Al}_{2} \mathrm{O}_{3}$ bicrystal bar with double U-notch in the $\mathrm{Al}_{2} \mathrm{O}_{3}$ crystal for an $\mathrm{Al}_{2} \mathrm{O}_{3} x_{2}$-material axis rotation of $60^{\circ}$ and $x_{1}$-material axis rotation of $135^{\circ} \ldots \ldots \ldots \ldots \ldots \ldots \ldots \ldots \ldots$

4.15 Variation of $\sigma_{e q} / \sigma_{0}$ at point $\mathrm{F}$ in the $\mathrm{Nb}$ crystal of a $\mathrm{Nb}-\mathrm{Al}_{2} \mathrm{O}_{3}$ bicrystal bar with a double U-notch for $x_{1}, x_{2}$, and $x_{3}$-material axis rotations .105

4.16 Variation of $\sigma_{e q} / \sigma_{0}$ at point $\mathrm{F}$ in the $\mathrm{Al}_{2} \mathrm{O}_{3}$ crystal of a $\mathrm{Nb}-\mathrm{Al}_{2} \mathrm{O}_{3}$ bicrystal bar with a double $\mathrm{U}$-notch for $x_{1}, x_{2}$, and $x_{3}$-material axis

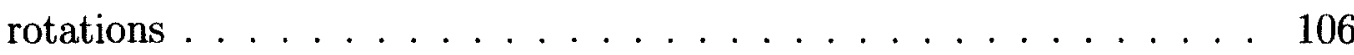

4.17 Variation of $\sigma_{e q} / \sigma_{0}$ through the thickness along $\overline{A C B}$ at the interface of a $\mathrm{Nb}-\mathrm{Al}_{2} \mathrm{O}_{3}$ bicrystal bar with double U-notch for a $\mathrm{Nb} x_{2}$-material axis rotation of $45^{\circ} \ldots \ldots \ldots \ldots \ldots$

4.18 Variation of $\sigma_{11} / \sigma_{0}$ through the thickness along $\overline{A C B}$ at the interface of a $\mathrm{Nb}-\mathrm{Al}_{2} \mathrm{O}_{3}$ bicrystal bar with double U-notch for a $\mathrm{Nb} x_{2}$-material axis rotation of $60^{\circ} \ldots \ldots \ldots \ldots \ldots \ldots \ldots$

4.19 Variation of $\sigma_{e q} / \sigma_{0}$ through the thickness along $\overline{D F E}$ at the interface of a $\mathrm{Nb}-\mathrm{Al}_{2} \mathrm{O}_{3}$ bicrystal bar with double U-notch for a $\mathrm{Nb} x_{2}$-material axis rotation of $45^{\circ} \ldots \ldots \ldots \ldots \ldots$

4.20 Variation of $\sigma_{e q} / \sigma_{0}$ of a $\mathrm{Cu}-\mathrm{Al}_{2} \mathrm{O}_{3}$ bicrystal bar with double U-notch for $x_{2}$-material axis rotations of the $C u$ crystal $\ldots \ldots \ldots \ldots$

4.21 Variation of $\sigma_{11} / \sigma_{0}$ at point $\mathrm{C}$ of a $\mathrm{Cu}-\mathrm{Al}_{2} \mathrm{O}_{3}$ bicrystal bar with double U-notch for $x_{3}$-material axis rotations of the $C u$ crystal $\ldots \ldots \ldots 111$

4.22 Variation of $\sigma_{e q} / \sigma_{0}$ of a $\mathrm{Cu}-\mathrm{Al}_{2} \mathrm{O}_{3}$ bicrystal bar with double U-notch for $x_{3}$-material axis rotations of the $C u$ crystal $\ldots \ldots \ldots 112$

4.23 Variation of $\sigma_{e q} / \sigma_{0}$ at point $\mathrm{F}$ in the $\mathrm{Cu}$ crystal of a $\mathrm{Cu}-\mathrm{Al}_{2} \mathrm{O}_{3}$ bicrystal bar with a double U-notch for $x_{1}, x_{2}$, and $x_{3}$-material axis rotations . 113 
4.24 Variation of $\sigma_{e q} / \sigma_{0}$ at point $\mathrm{F}$ in the $\mathrm{Al}_{2} \mathrm{O}_{3}$ crystal of a $\mathrm{Cu}-\mathrm{Al}_{2} \mathrm{O}_{3}$ bicrystal bar with a double U-notch for $x_{1}, x_{2}$, and $x_{3}$-material axis rotations .

4.25 Variation of $\sigma_{11} / \sigma_{0}$ through the thickness along $\overline{A C B}$ at the interface of a $\mathrm{Cu}-\mathrm{Al}_{2} \mathrm{O}_{3}$ bicrystal bar with double U-notch in the $\mathrm{Al}_{2} \mathrm{O}_{3}$ crystal for $\mathrm{Al}_{2} \mathrm{O}_{3} x_{2}$-material axis rotations of $60^{\circ}$ and $120^{\circ} \ldots \ldots$

4.26 Variation of $\sigma_{11} / \sigma_{0}$ through the thickness along $\overline{A C B}$ at the interface of a $\mathrm{Cu}-\mathrm{Al}_{2} \mathrm{O}_{3}$ bicrystal bar with double U-notch for a $\mathrm{Al}_{2} \mathrm{O}_{3} x_{2}$-material axis rotation of $120^{\circ} \ldots \ldots \ldots \ldots \ldots \ldots \ldots$

4.27 Variation of $\sigma_{e q} / \sigma_{0}$ through the thickness along $\overline{A C B}$ at the interface of a $\mathrm{Cu}-\mathrm{Al}_{2} \mathrm{O}_{3}$ bicrystal bar with double U-notch for a $\mathrm{Al}_{2} \mathrm{O}_{3} x_{2}$-material axis rotation of $120^{\circ} \ldots \ldots \ldots \ldots \ldots \ldots$

4.28 Variation of $\sigma_{e q} / \sigma_{0}$ through the thickness along $\overline{D F E}$ at the interface of a $\mathrm{Cu}-\mathrm{Al}_{2} \mathrm{O}_{3}$ bicrystal bar with double U-notch for a $\mathrm{Cu} x_{1}$-material axis rotation of $75^{\circ} \ldots \ldots \ldots \ldots \ldots \ldots \ldots$

5.1 DHS of a plate with a circular hole in tension $\left(\mathrm{x}_{3}\right.$ dimension not illustrated)

5.2 Bimaterial regioning of a plate with a circular hole at the interface with a DHS

5.3 BEM mesh of plate with a circular hole and DHS (488 elements and 1416 nodes $\ldots \ldots \ldots \ldots \ldots \ldots \ldots$

5.4 BEM mesh of plate with a circular hole and DHS (480 elements and 1384 nodes $) \ldots \ldots \ldots \ldots \ldots \ldots$. . . . . . . . . . . . .

5.5 BEM mesh of plate with a circular hole and DHS (488 elements and

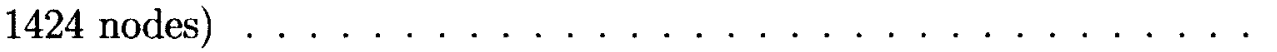

5.6 BEM mesh of plate with a circular hole and DHS (496 elements and 1456 nodes $) \ldots \ldots \ldots \ldots \ldots \ldots \ldots \ldots$ 
5.7 Variation of $\sigma_{1} / \sigma_{0}$ in a homogeneous isotropic plate with a circular hole and DHS, through the thickness along the main, $\overline{A C B}$, and auxiliary, $\overline{A^{\prime} C^{\prime} B^{\prime}}$ and $\overline{A^{\prime \prime} C^{\prime \prime} B^{\prime \prime}}$, holes for $d / r=2.5$ and $b / r=0.7 \ldots \ldots 136$

5.8 Variation of stress concentration with $d / r$ in a homogeneous isotropic plate with a circular hole and DHS, along the main, $\overline{A C B}$, and auxiliary, $\overline{A^{\prime} C^{\prime} B^{\prime}}$ and $\overline{A^{\prime \prime} C^{\prime \prime} B^{\prime \prime}}$, holes . . . . . . . . . . . .

5.9 Variation of stress concentration in a homogeneous isotropic plate with a circular hole and DHS, along the main, $\overline{A C B}$, and auxiliary, $\overline{A^{\prime} C^{\prime} B^{\prime}}$ and $\overline{A^{\prime \prime} C^{\prime \prime} B^{\prime \prime}}$, holes $\ldots \ldots \ldots \ldots \ldots \ldots$

5.10 Variation of stress concentration with $d / r$ in homogeneous anisotropic plates, each with a circular hole and DHS, along the main hole, $\overline{A C B}$

5.11 Variation of $\sigma_{1} / \sigma_{0}$ in a homogeneous anisotropic $N b$ plate with a circular hole and DHS, through the thickness along the main, $\overline{A C B}$, and auxiliary, $\overline{A^{\prime} C^{\prime} B^{\prime}}$ and $\overline{A^{\prime \prime} C^{\prime \prime} B^{\prime \prime}}$, holes for $d / r=2.5$ and $b / r=0.7 \ldots$

5.12 Variation of stress concentration in a homogeneous anisotropic $\mathrm{Nb}$ plate with a circular hole and DHS, along the main, $\overline{A C B}$, and auxiliary, $\overline{A^{\prime} C^{\prime} B^{\prime}}$ and $\overline{A^{\prime \prime} C^{\prime \prime} B^{\prime \prime}}$, holes $\ldots \ldots \ldots \ldots \ldots$

5.13 Variation of $\sigma_{1} / \sigma_{0}$ in a homogeneous anisotropic $C u$ plate with a circular hole and DHS, through the thickness along the main, $\overline{A C B}$, and auxiliary, $\overline{A^{\prime} C^{\prime} B^{\prime}}$ and $\overline{A^{\prime \prime} C^{\prime \prime} B^{\prime \prime}}$, holes for $d / r=2.0$ and $b / r=0.7 \ldots$

5.14 Variation of stress concentration in a homogeneous anisotropic $\mathrm{Cu}$ plate with a circular hole and DHS, along the main, $\overline{A C B}$, and auxiliary, $\overline{A^{\prime} C^{\prime} B^{\prime}}$ and $\overline{A^{\prime \prime} C^{\prime \prime} B^{\prime \prime}}$, holes . . . . . . . . . . . . 143

5.15 Variation of $\sigma_{1} / \sigma_{0}$ in a homogeneous anisotropic $\mathrm{Al}_{2} \mathrm{O}_{3}$ plate with a circular hole and DHS, through the thickness along the main, $\overline{A C B}$, and auxiliary, $\overline{A^{\prime} C^{\prime} B^{\prime}}$ and $\overline{A^{\prime \prime} C^{\prime \prime} B^{\prime \prime}}$, holes for $d / r=2.5$ and $b / r=0.7$ 
5.16 Variation of stress concentration in a homogeneous anisotropic $\mathrm{Al}_{2} \mathrm{O}_{3}$ plate with a circular hole and DHS, along the main, $\overline{A C B}$, and auxiliary, $\overline{A^{\prime} C^{\prime} B^{\prime}}$ and $\overline{A^{\prime \prime} C^{\prime \prime} B^{\prime \prime}}$, holes . . . . . . . . . . . 145

5.17 Variation of $\sigma_{1} / \sigma_{0}$ in the $N b$ material of an isotropic bimaterial $N b$ $\mathrm{Al}_{2} \mathrm{O}_{3}$ plate with a circular hole at the interface and DHS, through the thickness along the main, $\overline{A C B}$, and auxiliary, $\overline{A^{\prime} C^{\prime} B^{\prime}}$, holes for $d / r=2.5$ and $b / r=0.7 \ldots \ldots \ldots \ldots \ldots \ldots$

5.18 Variation of stress concentration with $d / r$ in a $\mathrm{Nb}-\mathrm{Al}_{2} \mathrm{O}_{3}$ bimaterial isotropic plate with a circular hole and DHS, along the main hole, $\overline{A C B} 147$

5.19 Variation of stress concentration in the $\mathrm{Nb}$ material of an isotropic bimaterial $\mathrm{Nb}-\mathrm{Al}_{2} \mathrm{O}_{3}$ plate with a circular hole at the interface and DHS, along the main, $\overline{A C B}$, and auxiliary, $\overline{A^{\prime} C^{\prime} B^{\prime}}$, holes . . . . . 148

5.20 Variation of $\sigma_{1} / \sigma_{0}$ in the $\mathrm{Al}_{2} \mathrm{O}_{3}$ material of an isotropic bimaterial $\mathrm{Nb}$ $\mathrm{Al}_{2} \mathrm{O}_{3}$ plate with a circular hole at the interface and DHS, through the thickness along the main, $\overline{A C B}$, and auxiliary, $\overline{A^{\prime \prime} C^{\prime \prime} B^{\prime \prime}}$, holes for $d / r=2.5$ and $b / r=0.7 \ldots \ldots \ldots \ldots \ldots \ldots \ldots$

5.21 Variation of stress concentration in the $\mathrm{Al}_{2} \mathrm{O}_{3}$ material of an isotropic bimaterial $\mathrm{Nb}-\mathrm{Al}_{2} \mathrm{O}_{3}$ plate with a circular hole at the interface and DHS, along the main, $\overline{A C B}$, and auxiliary, $\overline{A^{\prime \prime} C^{\prime \prime} B^{\prime \prime}}$, holes $\ldots \ldots .150$

5.22 Variation of $\sigma_{1} / \sigma_{0}$ in the $C u$ material of an isotropic bimaterial $C u$ $\mathrm{Al}_{2} \mathrm{O}_{3}$ plate with a circular hole at the interface and DHS, through the thickness along the main, $\overline{A C B}$, and auxiliary, $\overline{A^{\prime} C^{\prime} B^{\prime}}$, holes for $d / r=2.5$ and $b / r=0.7 \ldots \ldots \ldots \ldots \ldots \ldots \ldots$

5.23 Variation of stress concentration with $d / r$ in a $\mathrm{Cu}-\mathrm{Al}_{2} \mathrm{O}_{3}$ bimaterial isotropic plate with a circular hole and DHS, along the main hole, $\overline{A C B} 152$ 
5.24 Variation of stress concentration in the $C u$ material of an isotropic bimaterial $\mathrm{Cu}-\mathrm{Al}_{2} \mathrm{O}_{3}$ plate with a circular hole at the interface and DHS, along the main, $\overline{A C B}$, and auxiliary, $\overline{A^{\prime} C^{\prime} B^{\prime}}$, holes . . . . . 153

5.25 Variation of $\sigma_{1} / \sigma_{0}$ in the $\mathrm{Al}_{2} \mathrm{O}_{3}$ material of an isotropic bimaterial $\mathrm{Cu}$ $\mathrm{Al}_{2} \mathrm{O}_{3}$ plate with a circular hole at the interface and DHS, through the thickness along the main, $\overline{A C B}$, and auxiliary, $\overline{A^{\prime \prime} C^{\prime \prime} B^{\prime \prime}}$, holes for $d / r=2.5$ and $b / r=0.7 \ldots \ldots \ldots \ldots \ldots \ldots$

5.26 Variation of stress concentration in the $\mathrm{Al}_{2} \mathrm{O}_{3}$ material of an isotropic bimaterial $\mathrm{Cu}-\mathrm{Al}_{2} \mathrm{O}_{3}$ plate with a circular hole at the interface and DHS, along the main, $\overline{A C B}$, and auxiliary, $\overline{A^{\prime \prime} C^{\prime \prime} B^{\prime \prime}}$, holes . . . . . 155

5.27 Variation of $\sigma_{1} / \sigma_{0}$ in the $N b$ material of an anisotropic bimaterial $N b$ $\mathrm{Al}_{2} \mathrm{O}_{3}$ plate with a circular hole at the interface and DHS, through the thickness along the main, $\overline{A C B}$, and auxiliary, $\overline{A^{\prime} C^{\prime} B^{\prime}}$, holes for $d / r=2.5$ and $b / r=0.7 \ldots \ldots \ldots \ldots \ldots$

5.28 Variation of stress concentration with $d / r$ in a $\mathrm{Nb}-\mathrm{Al}_{2} \mathrm{O}_{3}$ bimaterial anisotropic plate with a circular hole and DHS, along the main hole,

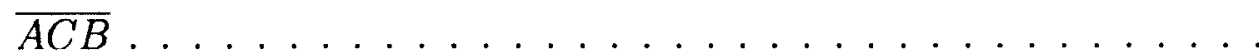

5.29 Variation of stress concentration in the $\mathrm{Nb}$ material of an anisotropic bimaterial $\mathrm{Nb}-\mathrm{Al}_{2} \mathrm{O}_{3}$ plate with a circular hole at the interface and DHS, along the main, $\overline{A C B}$, and auxiliary, $\overline{A^{\prime} C^{\prime} B^{\prime}}$, holes . . . . . 158

5.30 Variation of $\sigma_{1} / \sigma_{0}$ in the $\mathrm{Al}_{2} \mathrm{O}_{3}$ material of an anisotropic bimaterial $\mathrm{Nb}-\mathrm{Al}_{2} \mathrm{O}_{3}$ plate with a circular hole at the interface and DHS, through the thickness along the main, $\overline{A C B}$, and auxiliary, $\overline{A^{\prime \prime} C^{\prime \prime} B^{\prime \prime}}$, holes for $d / r=2.5$ and $b / r=0.7 \ldots \ldots \ldots \ldots \ldots \ldots$ 
5.31 Variation of $\sigma_{1} / \sigma_{0}$ in the $\mathrm{Al}_{2} \mathrm{O}_{3}$ material of an anisotropic bimaterial $\mathrm{Nb}-\mathrm{Al}_{2} \mathrm{O}_{3}$ plate with a circular hole at the interface and DHS, through the thickness along the main, $\overline{A C B}$, and auxiliary, $\overline{A^{\prime \prime} C^{\prime \prime} B^{\prime \prime}}$, holes for $d / r=2.0$ and $b / r=0.3$

5.32 Variation of stress concentration in the $\mathrm{Al}_{2} \mathrm{O}_{3}$ material of an anisotropic bimaterial $\mathrm{Nb}-\mathrm{Al}_{2} \mathrm{O}_{3}$ plate with a circular hole at the interface and DHS, along the main, $\overline{A C B}$, and auxiliary, $\overline{A^{\prime \prime} C^{\prime \prime} B^{\prime \prime}}$, holes . . . . .

5.33 Variation of $\sigma_{1} / \sigma_{0}$ in the $C u$ material of an anisotropic bimaterial $\mathrm{Cu}$ $\mathrm{Al}_{2} \mathrm{O}_{3}$ plate with a circular hole at the interface and DHS, through the thickness along the main, $\overline{A C B}$, and auxiliary, $\overline{A^{\prime} C^{\prime} B^{\prime}}$, holes for $d / r=2.5$ and $b / r=0.7 \ldots \ldots \ldots \ldots \ldots$

5.34 Variation of stress concentration with $d / r$ in a $\mathrm{Cu}-\mathrm{Al}_{2} \mathrm{O}_{3}$ bimaterial isotropic plate with a circular hole and DHS, along the main hole, $\overline{A C B} 163$

5.35 Variation of stress concentration in the $C u$ material of an anisotropic bimaterial $\mathrm{Cu}-\mathrm{Al}_{2} \mathrm{O}_{3}$ plate with a circular hole at the interface and DHS, along the main, $\overline{A C B}$, and auxiliary, $\overline{A^{\prime} C^{\prime} B^{\prime}}$, holes . . . . . 164

5.36 Variation of $\sigma_{1} / \sigma_{0}$ in the $\mathrm{Al}_{2} \mathrm{O}_{3}$ material of an anisotropic bimaterial $\mathrm{Cu}-\mathrm{Al}_{2} \mathrm{O}_{3}$ plate with a circular hole at the interface and DHS, through the thickness along the main, $\overline{A C B}$, and auxiliary, $\overline{A^{\prime \prime} C^{\prime \prime} B^{\prime \prime}}$, holes for $d / r=2.5$ and $b / r=0.7 \ldots \ldots \ldots \ldots \ldots$

5.37 Variation of $\sigma_{1} / \sigma_{0}$ in the $\mathrm{Al}_{2} \mathrm{O}_{3}$ material of an anisotropic bimaterial $\mathrm{Cu}-\mathrm{Al}_{2} \mathrm{O}_{3}$ plate with a circular hole at the interface and DHS, through the thickness along the main, $\overline{A C B}$, and auxiliary, $\overline{A^{\prime \prime} C^{\prime \prime} B^{\prime \prime}}$, holes for $d / r=2.0$ and $b / r=0.3$

5.38 Variation of stress concentration in the $\mathrm{Al}_{2} \mathrm{O}_{3}$ material of an anisotropic bimaterial $\mathrm{Cu}-\mathrm{Al}_{2} \mathrm{O}_{3}$ plate with a circular hole at the interface and DHS, along the main, $\overline{A C B}$, and auxiliary, $\overline{A^{\prime \prime} C^{\prime \prime} B^{\prime \prime}}$, holes . . . . . 
A.1 Definition of the unit vectors $\mathbf{n}$ and $\mathbf{m} \ldots \ldots \ldots \ldots$ 


\section{Nomenclature}

\begin{tabular}{ll}
\hline Symbols & Definition \\
\hline \hline$C_{i j}$ & free term cocficient of boundary integral equation \\
$U_{i j}$ & fundamental solution for displacements \\
$T_{i j}$ & fundamental solution for tractions \\
$u_{i}$ & displacements \\
$t_{i}$ & tractions \\
$x_{i}$ & volumetric domain \\
$P$ & surface of the domain $V$ \\
$P$ & field point in the domain $V$ \\
& source point on the boundary $S$ \\
& field point on the boundary $S$ \\
&
\end{tabular}




\begin{tabular}{|c|c|}
\hline$n_{i}$ & unit outward normal vector \\
\hline$\mu$ & shear modulus \\
\hline$\nu$ & Poisson's ratio \\
\hline$\delta_{i j}$ & Kronecker delta \\
\hline$N^{c}$ & shape function \\
\hline$\zeta_{1}, \zeta_{2}$ & local intrinsic coordinates \\
\hline$J$ & Jacobian of transformation \\
\hline$\sigma_{i j}$ & stress tensor \\
\hline$\sigma_{e q}$ & von Mises equivalent stress \\
\hline$\sigma_{0}$ & applied normal stress \\
\hline$\sigma_{i}, i=1,2,3$ & principal stresses \\
\hline$h$ & half-thickness \\
\hline$a$ & half-width \\
\hline$E$ & Young's modulus \\
\hline$C_{11}, C_{12}, \ldots$ & elastic stiffness coefficients \\
\hline$S_{11}, S_{12}, \ldots$ & elastic compliance coefficients \\
\hline$t$ & notch inset distance \\
\hline$H$ & half-height \\
\hline$w$ & width \\
\hline
\end{tabular}




\begin{tabular}{ll}
$L$ & length \\
$\alpha, \phi$ & wedge angles \\
$(r, \theta)$ & polar coordinates \\
$\lambda$ & eigenvalue \\
$\delta=(\lambda-1)$ & order of stress singularity \\
$f_{i j}$ & eigenfunction \\
$A$ & anisotropic factor \\
$b / r$ & auxiliary-to-main hole radius ratio \\
$d / r$ & ratio of auxiliary-to-main hole distance to main hole radius \\
$\hat{\sigma}_{1}$ & largest value of first principal stress \\
\hline
\end{tabular}




\section{Chapter 1}

\section{Introduction}

Understanding the mechanical interactions of a bicrystal interface is of great importance in determining the performance of materials. Misorientation of the crystallographic axes and the orientation of the grain boundary plane affect the stress fields and create stress concentrations at and near the interface. The large stress gradients near the interface free edges have implications in the strength and fracture of these junctions. Bicrystal interfaces appear in applications such as metal-matrix composites, smart materials, thin-film coatings of turbine blades and machine tools, microelectronics packaging of solid state devices, SQUID magnetometers, bio-medical prostheses, and high pressure sodium lamps. They are also intrinsic to research of grain boundary defects, dislocation nucleation, and superconducting experiments; often involving crystal plasticity theory, cohesive interface modelling, fracture mechanics or molecular dynamics. Without a full understanding and ability to predict the mechanical interactions of these interfaces, design methodology in industry follows a costly and time consuming trial-and-error process when choosing suitable materials with satisfactory performance. The present work focuses on a linear elastic stress analysis of the stress concentrations at a bicrystal interface involving different geometric discontinuities in three dimensions, for changing orientation of the material principal axes. The efficacy of the addition of auxiliary holes to one of the bicrystal 
problems is also studied.

\subsection{Review of Literature}

Much of the research into stress concentrations and the stress field at the interface of anisotropic bicrystals has been conducted for simple prismatic bicrystals in tension with the grain boundary perpendicular to the tensile axis. For example, Gagorik, Queeney \& McKinstry (1971) studied misorientations of plane $\mathrm{Al}_{2} \mathrm{O}_{3}$ bicrystals using direct stiffness calculations and the finite element method (FEM). Qamar \& Husain (1989) investigated the shear stress in the grain boundary plane for cubic bicrystal misorientations by iteratively calculating elastic strains at the interface until compatibility was achieved. Peralta, Schober \& Laird (1993) examined the stress fields at and away from the interface of a 3-D $C u$ bicrystal using the FEM, noting the high stress gradients characterized by the stress singularity at the free edges of the interface. Chen, Li \& Wang (1998) also examined various misorientations of a 3-D $C u$ bicrystal using the FEM to examine the general trends of the strains and resolved shear stresses. Shiah, Tan \& Chen (2009) performed a preliminary study of the interface stress concentrations in a 3-D $\mathrm{Nb}_{-} \mathrm{Al}_{2} \mathrm{O}_{3}$ bicrystal through rotations of the crystallographic axes. No particular attention has been devoted to the calculation of the stress "participation" factor at the free edges of the material interface in any studies thus far; focus has been on the general elevation of stresses at the free edges and the stresses at the interior of the materials.

Gemperlová, Paidar \& Kroupa (1989) calculated the theoretical compatibility stresses within a cubic bicrystal composed of two semi-infinite crystals for elastic and plastic anisotropy of deformation, for various misorientations under tensile or compressive loads. Also, using analytical techniques, Tvergaard \& Hutchinson (1988) analysed the elastic stress fields of 2-D triple-grain junctions within the context of 
crack analysis of grain boundary defects. The strengths of the stress singularities were found to vary with the anisotropic properties and crystallographic orientations of the materials. High stress gradients near grain boundaries were observed by Wan \& Yue (2004) in 3-D bicrystal FEM analysis, and a redistribution of stresses was noted when examining similar crystallographic orientations in a tricrystal. Heinzelmann \& Kalamkarov (2010) calculated the stress concentration factors and weight functions for equi-biaxial anisotropic materials, specifically, within a thin flat plate in tension containing a central hole - one of few studies involving geometric stress concentrations in the anisotropic domain that have been reported in the literature.

As for the stress singularity at the free edges of a bimaterial interface, Bogy (1968) has determined the asymptotic stress fields in the vicinity of two bonded plane, material wedges under general loading conditions with different shear moduli and Poisson's ratio. Reedy (1990) examined a thin elastic layer under plane strain bonded to a rigid material and subjected to either transverse tension or a uniform temperature change and determined the stress intensity factor. Delale (1984) investigated plane, anisotropic material wedge geometries, finding again that the power of singularity is dependent on the elastic properties of the materials. Although the existence of these stress singularities will preclude the determination of the true stress values at the interface free edges in the present study, the values obtained retain their relevance when examined in relation to each other and are useful for qualitative interpretation. Furthermore, the stress results at a very short distance into the interface are expected to be valid as the singularities are of weak power.

The current work investigates the stress concentrations at bicrystal interfaces caused by common geometric discontinuities, such as circular holes and U-notches, through a parametric study of the crystallographic misorientations of the material 
principal axes of the crystals. The technique of adding auxiliary holes within a structure to reduce stress concentrations is introduced in a preliminary study to investigate its effectiveness with anisotropic media. There have been a number of studies related to the addition of auxiliary holes and other geometries to reduce stress concentrations. Many of the studies have focused on uniaxial loading. Haddon (1967) solved the boundary-value problem of two non-intersecting circles within an infinite isotropic region in plane elastostatics. Erickson \& Riley (1978) and Jindal (1983) investigated the effect of auxiliary holes, circular and elliptical, respectively, on the stress concentration in the main circular hole of a thin uniaxially loaded plate using the photoelastic method, accompanied by 2-D FEM analysis in the latter. More recently, Akour, Nayfeh \& Nicholson (2003) investigated a similar plane problem under shear loading using the FEM and photoelasticity, and obtained significant reductions in stress concentrations with the auxiliary holes.

\subsection{Proposed Method of Solution}

Numerical techniques such as the boundary element method (BEM) and FEM are well suited to parametric studies where variables, specifically, the orientation of the crystallographic axes of the bicrystal, are modified incrementally through their respective ranges. The BEM is well established as an efficient numerical tool, and is particularly well suited for problems involving rapidly varying stress fields. The BEM requires only the boundary of the domain to be discretized, as opposed to the full domain in the commonly used FEM. Thus, the numerical model and data preparation are significantly reduced, in turn reducing the solution times and memory required. In this study, the 3-D anisotropic BEM code used is that of which the veracity and efficiency has been tested and demonstrated, see, e.g. Tan, Shiah \& Lin (2009). Where appropriate, the FEM commercial code, Abaqus/Standard (6.8-2), is also employed 
to provide some verification of the numerical results obtained in the BEM analysis.

\subsection{Outline}

Chapter 2 provides a review of the BEM, including its analytical and numerical formulation in 3-D elastic anisotropy. Example problems are also presented with corresponding isotropic and anisotropic analyses to demonstrate the modelling strategies and the veracity of the BEM as a numerical tool. In Chapter 3 , the stresses at the interface of a bicrystal plate with a circular hole in tension are investigated. $\mathrm{Nb}-\mathrm{Al}_{2} \mathrm{O}_{3}$ and $\mathrm{Cu}-\mathrm{Al}_{2} \mathrm{O}_{3}$ bicrystals are chosen throughout this study. The material principal axes of the crystals are rotated independently and the largest stress concentrations and general trends of the normal and von Mises equivalent stresses are reported. A similar investigation follows in Chapter 4, involving a double U-notch bar in tension. The common characteristics, with respect to the material axis rotations, observed throughout these two chapters are also considered. Chapter 5 returns to the physical problem outlined in Chapter 3 and studies the effects of adding auxiliary holes to the surrounding low stress regions to reduce the stress concentration at the main hole. A parametric study is employed to determine the auxiliary hole sizes and locations able to achieve significant stress concentration reductions, and the magnitude of these reductions. Lastly, in Chapter 6 , the work undertaken in this study and the main findings are summarized. 


\section{Chapter 2}

\section{Review of the Boundary Element Method}

The analytical and numerical formulation of the boundary element method (BEM) is briefly reviewed in this chapter. Numerical examples of familiar stress concentration problems, as well as a bicrystal problem, follow. The results are compared with those obtained using the more established finite element method (FEM), and analytical solutions where available. The BEM will be shown here to be an efficient and accurate tool for solving linear elastostatic anisotropic problems, just as has been well recognized for isotropic cases.

\subsection{Analytical Formulation of the BEM}

In the BEM, the governing linear partial differential equation (PDE) of elastostatics is transformed into an integral over the surface of the solution domain. The fundamental solution to the PDE and a reciprocal theorem are required to formulate the boundary integral equation (BIE). In elastostatics, the Navier-Cauchy equilibrium equations and Green's identities are used to construct the integral equation. The fundamental solutions employed are the displacement and traction solutions to Kelvin's problem of a point force in an infinite body. They are used in conjunction with the BettiRayleigh reciprocal work theorem to transform the equation into the BIE. Details of 
this process can be found in, e.g. Cruse (1969). In the absence of body forces, the BIE has the form (Cruse 1969),

$$
C_{j i}(P) u_{i}(P)+\int_{S} u_{i}(Q) T_{j i}(P, Q) d S(Q)=\int_{S} t_{i}(Q) U_{j i}(P, Q) d S(Q),
$$

where $u_{i}$ are the boundary displacements; $t_{i}$ are the boundary tractions; $U_{j i}$ and $T_{j i}$ are the fundamental solutions for the displacements and tractions, respectively; $S$ is the boundary of the domain $V$; and $i, j=1,2,3$ in three dimensions. Also, in equation 2.1, $P$ and $Q$ are the source and field points on the boundary, and $C_{j i}$ is a function of the local surface geometry at $P$. In isotropy, the fundamental solutions are given as (Cruse 1969),

$$
\begin{gathered}
U_{j i}(p, q)=\frac{1}{16 \pi \mu(1-\nu) r}\left[(3-4 \nu) \delta_{i j}+r_{, i} r_{, j}\right], \\
T_{j i}(p, q)=\frac{-(1-2 \nu)}{8 \pi(1-\nu) r^{2}}\left\{\frac{\partial r}{\partial n}\left[\delta_{i j}+\frac{3}{1-2 \nu} r_{, i} r_{, j}\right]-r_{, i} n_{j}+r_{, j} n_{i}\right\},
\end{gathered}
$$

where $\nu$ is the Poisson's ratio, $\mu$ is the shear modulus of the material, $r$ is the distance between the field point $q$ and source point $p$,

$$
r=\sqrt{\left(x_{q i}-x_{p i}\right)\left(x_{q i}-x_{p i}\right)} .
$$

Thus,

$$
r_{, i}=\frac{\partial r}{\partial x_{q i}}=\frac{1}{r}\left(x_{q i}-x_{p i}\right),
$$

and if $n_{i}$ is defined as the unit outward normal vector,

$$
\frac{\partial r}{\partial n}=\frac{\partial r}{\partial x_{i}} n_{i}=\frac{1}{r}\left(x_{q i}-x_{p i}\right) n_{i}
$$


The fundamental solutions for general three dimensional anisotropic elasticity are significantly more complex than those for isotropy. That for displacements, also commonly termed the Green's function, was first derived by Lifshitz \& Rozentsverg (1947), but it is not in explicit, algebraic form. Its implementation for BEM analysis of three dimensional anisotropic bodies was first carried out by Wilson \& Cruse (1978). It was, however, computationally quite demanding and over the years, a number of researchers have built on this work to increase the efficiency, accuracy, and stability of the numerical algorithm to compute the Green's function (see e.g. Sales \& Gray (1998), Phan, Gray \& Kaplan (2004), Wang (1997), and Wang \& Denda (2007)).

A fully explicit, algebraic form of the displacement fundamental solutions for three dimensional anisotropy and its derivatives has been obtained by Ting \& Lee (1997) and Lee (2003), respectively. Although mathematically quite involved, they were shown by Shiah et al. (2008) and Shiah, Tan \& Lee (2008) that they can be numerically evaluated in a relatively straight-forward manner. These solutions were subsequently implemented into an existing BEM code which had originally been developed for three-dimensional isotropy (Tan et al. 2009). As the fundamental solutions are fairly elaborate, notwithstanding their relatively simpler numerical implementation compared to previous formulations mentioned above, they are presented in Appendix A instead. The successful implementation by Tan et al. (2009) makes available an efficient and accurate numerical tool for the stress analysis of three dimensional, anisotropic, elastic bodies. It is the BEM code employed in this study.

\subsection{Numerical Formulation of the BEM}

An exact analytical solution of the governing BIE is not usually obtainable for practical engineering problems. Thus the surface of the domain is discretized into boundary elements. Eight-node quadrilateral and six-node triangular elements, based on the 
quadratic isoparametric formulation, as shown in Figures 2.1 and 2.2, are used to discretize the boundary of the three dimensional solution domain. The global coordinates, displacements, and tractions at any point in the elements, are related to the corresponding nodal values through the shape functions, $N^{c}(\zeta)$, in terms of the intrinsic coordinates $\left(\zeta_{1}, \zeta_{2}\right)$ :

$$
\begin{aligned}
& x_{i}(\zeta)=N^{c}(\zeta) x_{i}^{c} \\
& u_{i}(\zeta)=N^{c}(\zeta) u_{i}^{c} \\
& t_{i}(\zeta)=N^{c}(\zeta) t_{i}^{c}
\end{aligned}
$$

where $c=1,2, \ldots, 8$ for quadrilateral elements and $c=1,2, \ldots, 6$ for triangular elements. The expressions for the quadratic shape functions are given in Appendix B.

Substitution of equation 2.7 into 2.1 gives the discretized form of the BIE, as follows:

$$
\begin{aligned}
C_{j i}\left(P^{a}\right) u_{j}\left(P^{a}\right) & +\sum_{b=1}^{m} \sum_{c=1}^{k} u_{j}\left(P^{d(b, c)}\right) \int_{S} T_{i j}\left(P^{a}, Q(\zeta)\right) N^{c}(\zeta) J(\zeta) d \zeta \\
& =\sum_{b=1}^{m} \sum_{c=1}^{k} t_{j}\left(P^{d(b, c)}\right) \int_{S} U_{i j}\left(P^{a}, Q(\zeta)\right) N^{c}(\zeta) J(\zeta) d \zeta
\end{aligned}
$$

where $m$ is the total number of elements, $k$ is the number of nodes in the $b$ th element, $P^{a}$ represents the $a$ th node of the set of all nodes $1,2, \ldots, q, P^{d(b, c)}$ represents the $d$ th node determined as the $c$ th node of the $b$ th element, and $J(\zeta)$ is the Jacobian of transformation. Equation 2.8 represents a set of linear algebraic equations in terms of the known and unknown displacements and tractions. In three dimensions, there are $6 q$ nodal displacements and tractions, half of which are prescribed, the other half of which are to be calculated. Gaussian quadrature is used to evaluate the integrals 
of the fundamental solutions over each element. Substitution of the known boundary conditions results in a set of $3 q$ algebraic equations for the unknown displacements or tractions at the nodes on the surface of the solution domain.

\subsection{Numerical Examples}

A boundary element analysis (BEA), as well as a finite element analysis (FEA), has been performed for the following linear elastic problems. These analyses are intended to gain familiarity, and confirm the veracity and efficiency of the BEM through comparison to the more familiar FEM for anisotropic elasticity. The results from the BEM program are compared to those from Abaqus/Standard $(6.8-2)$ and analytical solutions where available. Isotropic cases have been run to highlight the differences and complexity which anisotropy introduces. The anisotropic runs require more elements because the stress fields produced have greater variations when compared to the corresponding isotropic problem. Also in anisotropy, geometric symmetry cannot necessarily be used to reduce the modelling domain of a problem.

\subsubsection{Example (A)}

The first case studied was a plate with a circular hole subjected to remote uniaxial stress, $\sigma_{0}$. As shown in Figure 2.3, the dimensions of the radius, half thickness, and half width are represented by $r, h$, and $a$, respectively. The values of $r / a$ and $h / a$ were both set to $1 / 10$. This model geometry is used through all similar subsequent cases.

\section{Isotropy}

The isotropic model material properties were arbitrarily set: Young's modulus was set to $1000 \mathrm{GPa}$, and Poisson's ratio to 0.3 . The physical problem has three planes 
of symmetry. It follows that the numerical problem can be reduced to $18^{\text {th }}$ the size of the original. Figures $2.4 \mathrm{a}$ and $2.4 \mathrm{~b}$ illustrate the differences in mesh refinement and discretizations used with the BEM and FEM. The BEM mesh contains 56 quadratic surface elements and 168 nodes; the FEM mesh contains 2706 quadratic volume elements (C3D20R) and 14,219 nodes.

A mesh refinement study was first performed to further validate the results. Between subsequent mesh refinements, the BEM and FEM results for the normal stress in the load direction along $\overline{C A}$ were found to vary no more than $1 \%$ and $2 \%$, respectively. This implies that the results from both methods have converged to an accurate solution.

The isotropic case of this problem is well understood in the literature. Looking at Figure 2.3, the largest stress concentration is expected to occur at point $\mathrm{C}$ on the edge of the hole in the mid-thickness plane (ie. at $x_{3}=0$ ) and drop off towards the free surface, point A. Hence, this is an area of interest and was chosen for the comparison of results between the BEM and FEM analyses. Normal stress, $\sigma_{22}$, along $\overline{C A}$ from BEM and FEM has been normalized with respect to $\sigma_{0}$ and plotted in Figure 2.5. It can be seen that there is very good agreement between the two sets of results; the difference between the two data sets is less than $2 \%$. The BEM also shows a better correlation to the analytical solution given by Folias \& Wang (1990) than that obtained by FEM.

The veracity of the BEM code used has been demonstrated by its ability to provide an accurate solution, as checked with the FEM analysis, and analytical solution in literature. The relative efficiency of the code is evidenced by only requiring 56 elements to obtain an accurate solution. 


\section{Anisotropy}

A homogeneous anisotropic model was tested using the material properties of single crystal copper $(\mathrm{Cu})$, which is a cubic material with three independent elastic stiffness coefficients:

$$
C_{11}=168.4 \mathrm{GPa}, C_{12}=121.4 \mathrm{GPa}, C_{44}=75.4 \mathrm{GPa}
$$

Although advantage can still be taken of the symmetry of the cubic material axes to model only a fraction of the physical problem, the full model was employed here as the same mesh could be used later on for more general anisotropy. The BEM and FEM mesh designs are shown in Figure 2.6. The model was loaded along one surface of the plate, and fully constrained on the opposite surface. The BEM mesh contained 468 quadratic surface elements and 1368 nodes, and the FEM mesh contained 21,648 elements (C3D20R) and 102,428 nodes.

Similar to the isotropic case, the stresses along $\overline{A B}$ are of the highest interest. Figure 2.7 shows the variation of the normalized direct stress, $\sigma_{22} / \sigma_{0}$, obtained from the BEM and FEM analyses. The stress distribution is symmetric about the midthickness $\left(x_{3}=0\right)$ plane, as expected because of the symmetry of the geometry and material properties when aligned with the global Cartesian axes. The maximum stress concentration was found to be 2.68, in the BEM analysis, and 2.79, in the FEM analysis, as compared to 3.18 and 3.19, in the respective BEM and FEM analyses for the corresponding isotropic problem. In general, there are relatively greater discrepancies between the BEM and FEM results as can be seen in Figure 2.7, but they are still generally well within $5 \%$ of each other.

\subsubsection{Example (B)}

The second example studied was a prismatic bar with opposite U-shaped notches, as shown in Figure 2.8. An axial unit load, $\sigma_{11} \equiv \sigma_{0}$, was applied at the remote ends of 
the bar. Referring to Figure 2.8, the specific case examined was for $t / H=r / H=0.2$, $w / H=1$, and $L / w=4$. This geometry is also used throughout all similar subsequent analyses.

\section{Isotropy}

The same isotropic material properties from the previous model were applied here. Taking advantage of symmetry, only $1 / 8^{\text {th }}$ of the problem was modelled. Figures $2.9 \mathrm{a}$ and $2.9 \mathrm{~b}$ illustrate the differences of the mesh designs; the BEM mesh has 55 elements and 165 nodes, while the FEM mesh has 7048 elements (C3D20R) and 32,828 nodes. The BEM and FEM meshes were tested for validity through another convergence study with finer meshes. Both meshes satisfied the convergence criteria with less than $2 \%$ difference in normal stresses in the loading direction along $\overline{A B}$, where the stress, $\sigma_{11}$, is the largest.

Stress concentrations of the plane problem of this case have been compiled in Pilkey (1997). It was expected that the highest stress concentration would be located at point $\mathrm{C}$, in the centre of the model, due to material constraint. The normal stress, $\sigma_{11}$, in the load direction along $\overline{C A}$ has been normalized with respect to $\sigma_{0}$ and plotted in Figure 2.10. There is a good correlation between the BEM and FEM results where the maximum difference between results is less than $5 \%$, and this difference drops to $2 \%$ in the region of the largest stress concentration at the mid-thickness plane. The corresponding stress concentration factors at these points, $\mathrm{C}$ and $\mathrm{A}$, are 4.20 and 3.46 , respectively from the BEM analysis versus 4.29 and 3.43, from the FEM analysis.

\section{Anisotropy}

A homogeneous anisotropic case of the U-notch bar was run using the material properties of single crystal alumina $\left(\mathrm{Al}_{2} \mathrm{O}_{3}\right)$. Alumina is a trigonal material, with six 
independent elastic stiffness coefficients:

$$
\begin{aligned}
& C_{11}=465 \mathrm{GPa}, C_{12}=124 \mathrm{GPa}, C_{13}=117 \mathrm{GPa}, \\
& C_{33}=563 \mathrm{GPa}, C_{14}=101 \mathrm{GPa}, C_{44}=233 \mathrm{GPa} .
\end{aligned}
$$

The full model of the problem was required to perform the anisotropic analysis here, with the load applied at one end while the other was fully constrained. The BEM mesh has 380 quadratic surface elements and 1108 nodes, while the FEM mesh has 52,860 elements (C3D20R) and 236,424 nodes; they are shown in Figure 2.11.

Due to anisotropy, there are other stress components present along $\overline{A B}$, besides $\sigma_{11}$, caused by the loading. Hence, it is more appropriate to examine the von Mises equivalent stress, $\sigma_{e q}$, here; it is often used for yield criterion and it is defined as

$$
\sigma_{e q}=\frac{1}{2} \sqrt{\left(\sigma_{1}-\sigma_{2}\right)^{2}+\left(\sigma_{2}-\sigma_{3}\right)^{2}+\left(\sigma_{3}-\sigma_{1}\right)^{2}}
$$

where $\sigma_{i}, i=1,2,3$, are the principal stresses.

The von Mises equivalent stresses along $\overline{A B}$ were compared and plotted in Figure 2.12. The differences in the values of $\sigma_{e q} / \sigma_{0}$ along $\overline{A B}$ from the BEM and FEM analyses are all less than $4 \%$ and within $1 \%$ in the vicinity of the largest stress concentration. This is very good agreement between results and demonstrates the validity of the BEM solution.

Unlike the anisotropic model in Example (A), the stress distribution along $\overline{A B}$ is no longer symmetric about the mid-thickness plane, as single crystal alumina is a more anisotropic material than copper crystal. The effects of anisotropy are evident even for this simple homogeneous body. In the next example, a bicrystal is analysed which introduces additional complexities of anisotropy. 


\subsubsection{Example (C)}

Figure 2.13 shows a long, square $\mathrm{Nb}-\mathrm{Al}_{2} \mathrm{O}_{3}$ bicrystal bar constrained at one end, and subjected to remote uniaxial tension, $\sigma_{0}$, at the other end. With reference to the figure, the length to width ratio $(L / w)$ considered was $L / w=6$. Results of the stresses at the interface between the two single crystals are of particular interest due to the differences in their material properties. The material properties of $\mathrm{Al}_{2} \mathrm{O}_{3}$ are the same as those used in the previous example. Single crystal niobium is a cubic material with three elastic stiffness coefficients:

$$
C_{11}=246 \mathrm{GPa}, C_{12}=134 \mathrm{GPa}, C_{44}=28.7 \mathrm{GPa} .
$$

Results were obtained for rotations of the $\mathrm{Nb}$ crystal material principal axes about the $\mathrm{x}_{1}$-axis from $0^{\circ}$ to $90^{\circ}$, beginning with the material axes aligned with the global Cartesian axes.

The BEM and FEM meshes used, are shown in Figures 2.14a and 2.14b, respectively. The BEM mesh, with 472 elements and 1340 nodes, is significantly less refined than the FEM mesh, with 54,000 elements (C3D20R) and 232,562 nodes.

During mesh refinements in both analyses, the stresses at the interface free edges continued to increase; there is a singularity of type $r^{\delta}, \delta<0$, (Bogy 1968) in the stress field at the free edges of dissimilar bonded material wedges. Considering anisotropic wedges, as shown in Figure 2.15, and taking the case of wedge angles $\alpha=90^{\circ}$ and $\phi=$ $90^{\circ}$, it is known that the power of singularity is real, but relatively weak (Delale 1984). The stresses return to finite values at very short distances away from the point of the free edge singularity. For the present purpose, only the results at the interior of the interface are examined, namely, at point $\mathrm{C}$.

Point $\mathrm{C}$ is located at the centre of the bicrystal interface $\left(x_{1}=0, x_{2}=0\right)$. The normalised von Mises equivalent stress, $\sigma_{e q} / \sigma_{0}$, at this point, in both the niobium and 
alumina material, have been plotted in Figure 2.16, for the rotation of the $N b \mathrm{x}_{1}$ material axis. There is excellent agreement between the BEA and FEA results with less than $0.2 \%$ difference. The largest stress concentration at point $\mathrm{C}$ occurs for a $45^{\circ}$ rotation of the material axis. This stress concentration, 1.51 , is in the $\mathrm{Al}_{2} \mathrm{O}_{3}$ crystal, a ceramic material which is considerably stiffer than metallic niobium. The effects of the different material properties at the interface have created a stress concentration in the higher stiffness crystal and a stress reduction in the crystal of lower stiffness.

The largest stress concentration in the bicrystal will occur at the corners of the interface. However, quantitative results cannot be obtained without implicitly treating the singularity in the analytical formulations of both the BEM and FEM analyses. This issue will be discussed further in the chapters that follow.

A significantly coarser mesh was used in the BEM analysis versus the FEM analysis. This greatly reduced the memory required in the former case. The BEM computer run required less than half the real-time than the FEM run while giving the same general accuracy. It is also noted that the BEM code used has not yet been configured to run on multiple computational threads. On the specific system used, four BEM analyses could be run concurrently on the same geometry.

\subsection{Concluding Remarks}

The analytical and numerical formulations of the BEM have been briefly reviewed in this chapter. Numerical examples have been presented that demonstrate the BEM as both an efficient and accurate tool for solving anisotropic problems in elasticity. The BEM results obtained have been compared with those obtained using the FEM, as well as available analytical solutions. One of the examples presented involved a bicrystal problem; stress concentrations in bicrystals with holes and notches are the focus of the study in the next few chapters. 


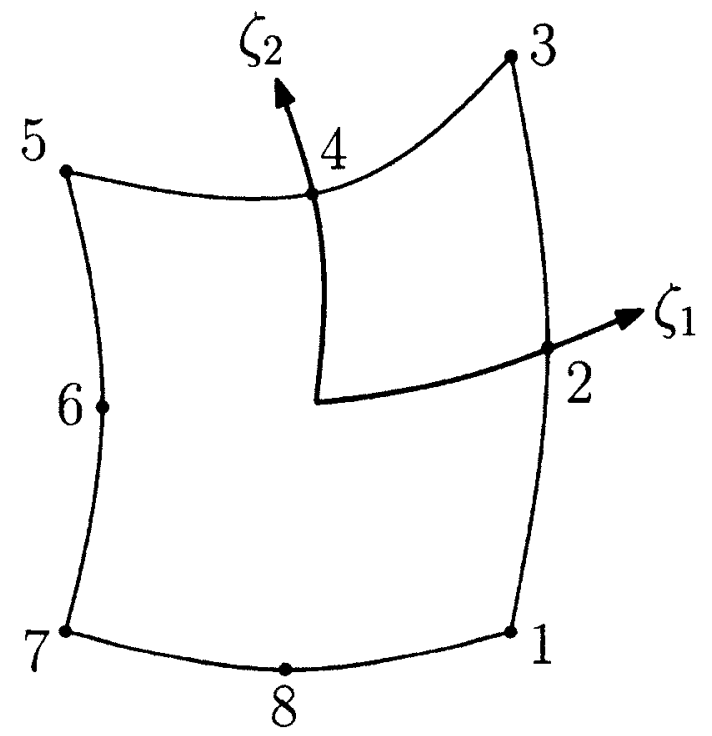

Figure 2.1: BEM quadratic isoparametric quadrilateral eight-node surface element

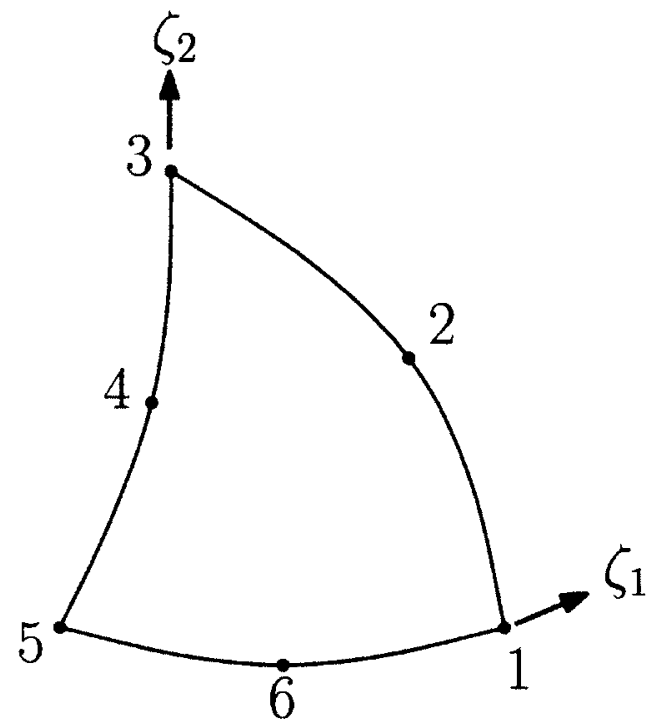

Figure 2.2: BEM quadratic isoparametric triangular six-node surface element 


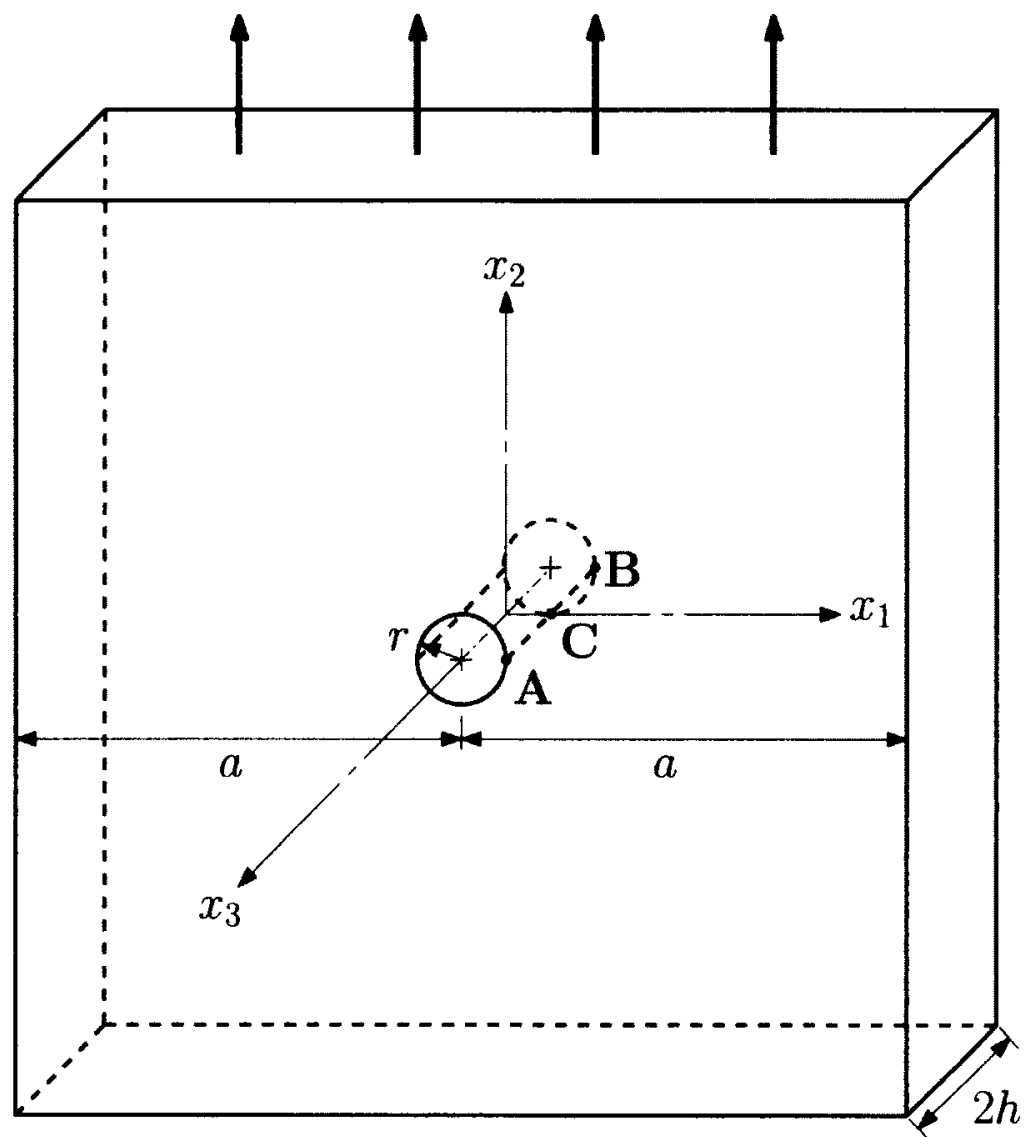

Figure 2.3: Plate in tension with a circular hole - Example (A) 


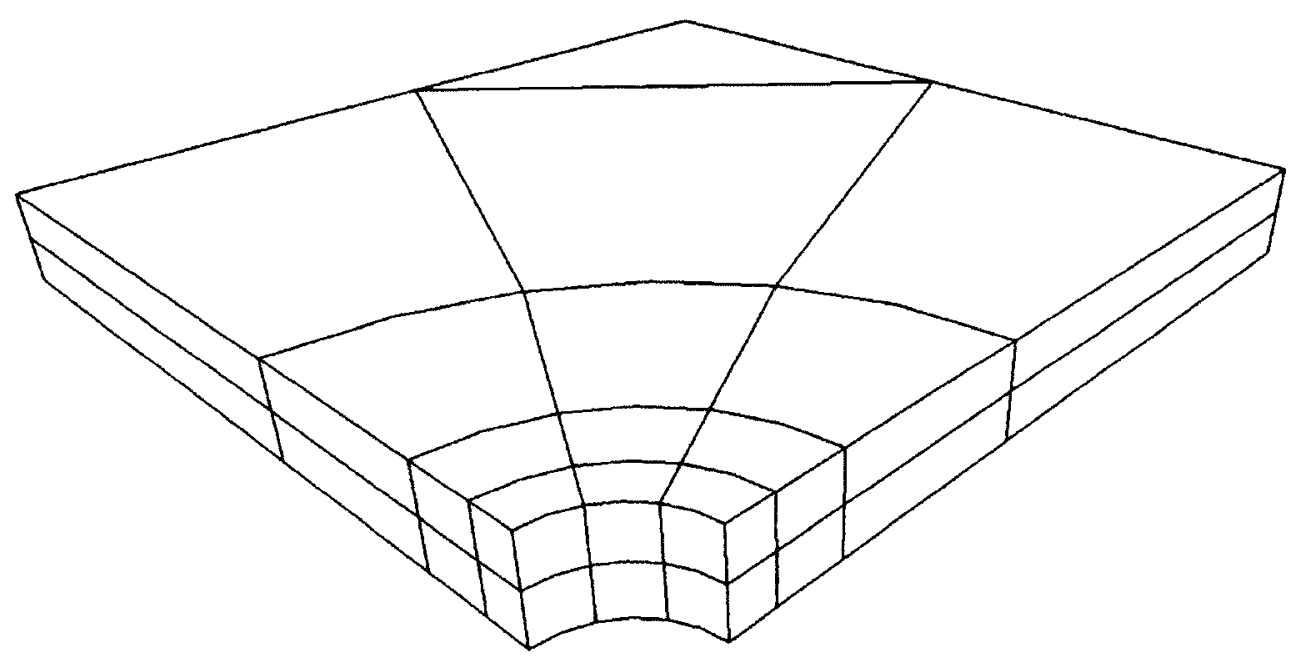

(a) BEM Mesh

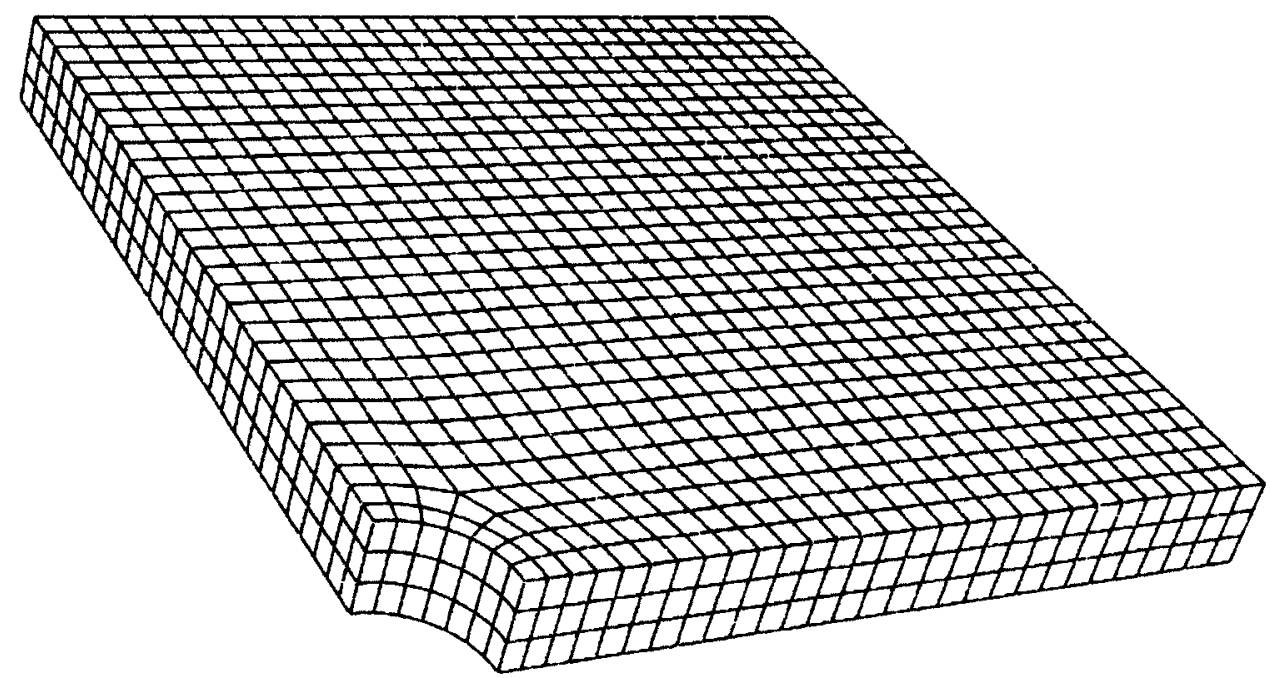

(b) FEM Mesh

Figure 2.4: Three-dimensional meshes of a plate with a circular hole for isotropic analysis 


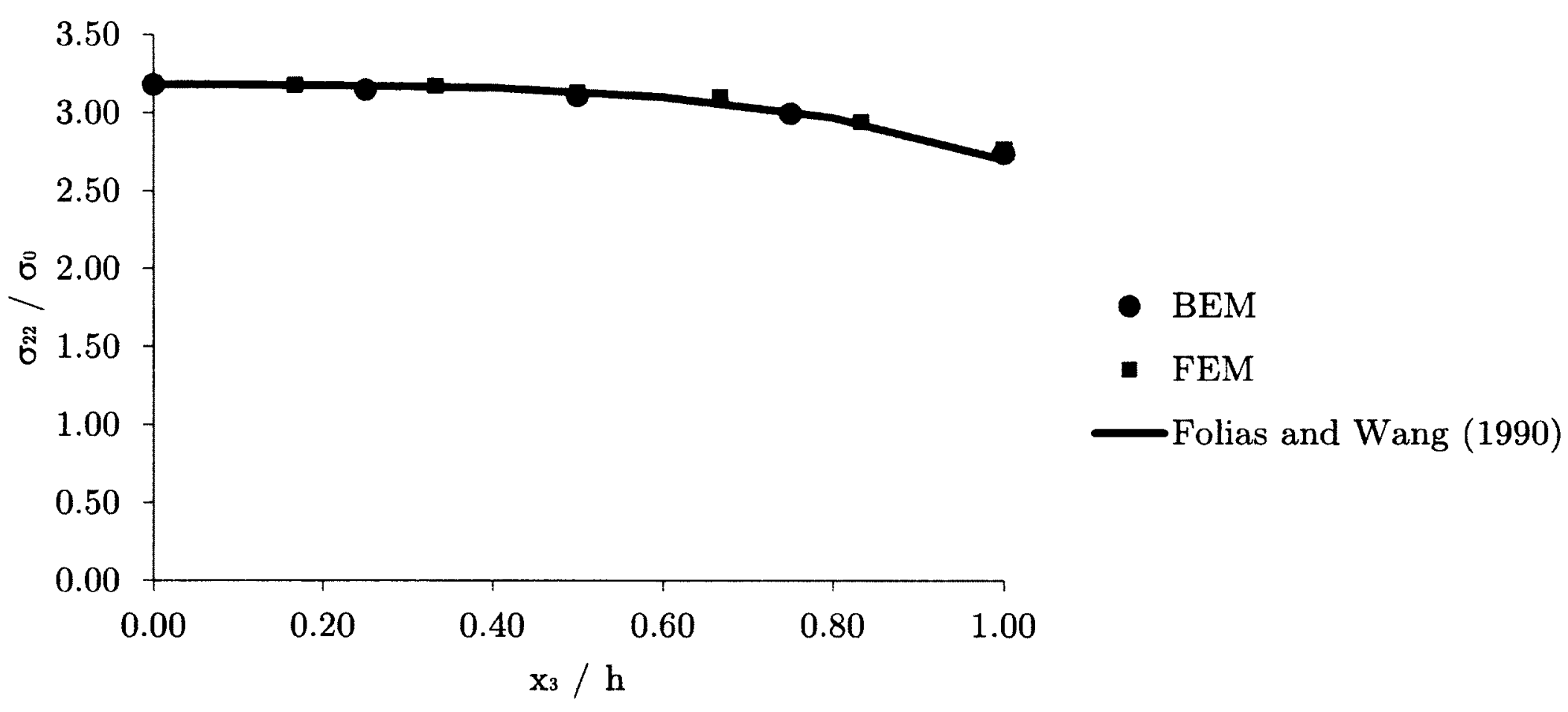

Figure 2.5: Variation of stress concentration along $\overline{C A}$, through the thickness of an isotropic plate at a central circular hole 


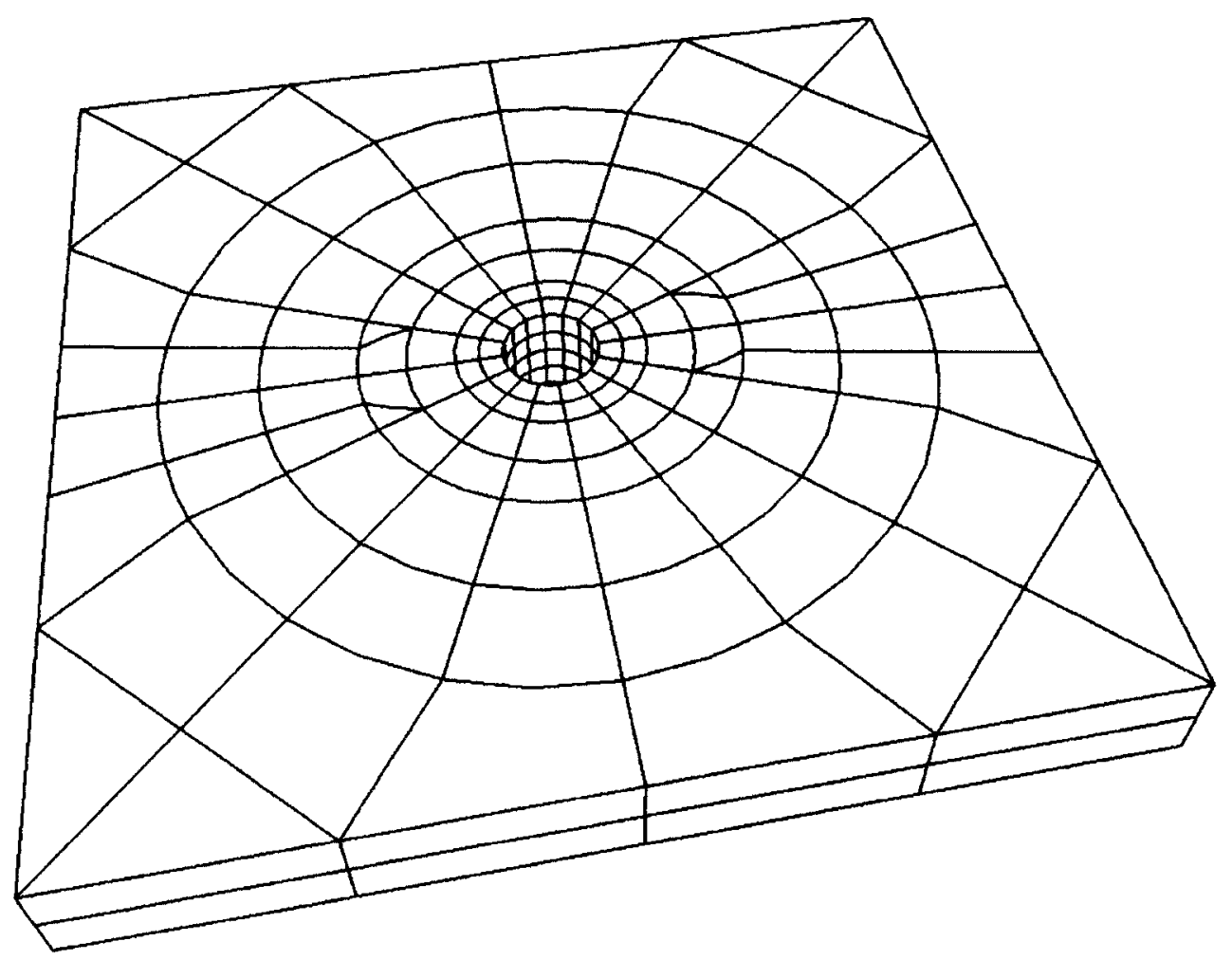

(a) BEM Mesh

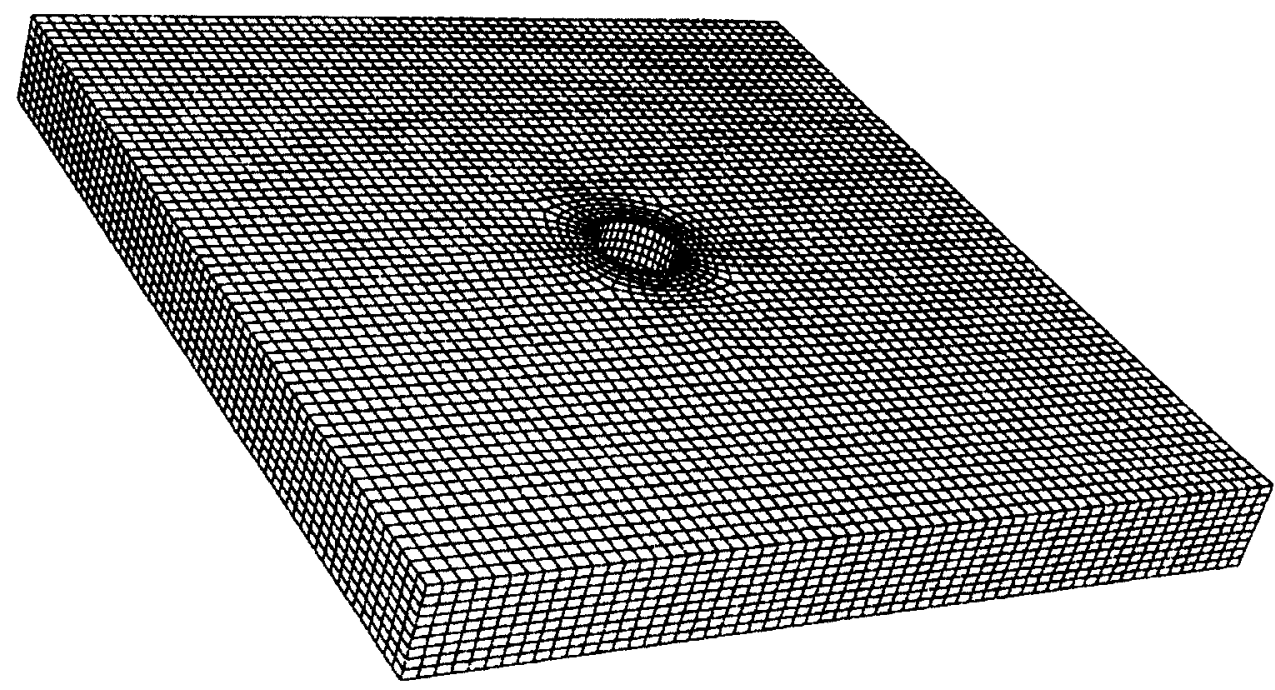

(b) FEM Mesh

Figure 2.6: Three-dimensional meshes of a plate with circular hole for anisotropic analysis 


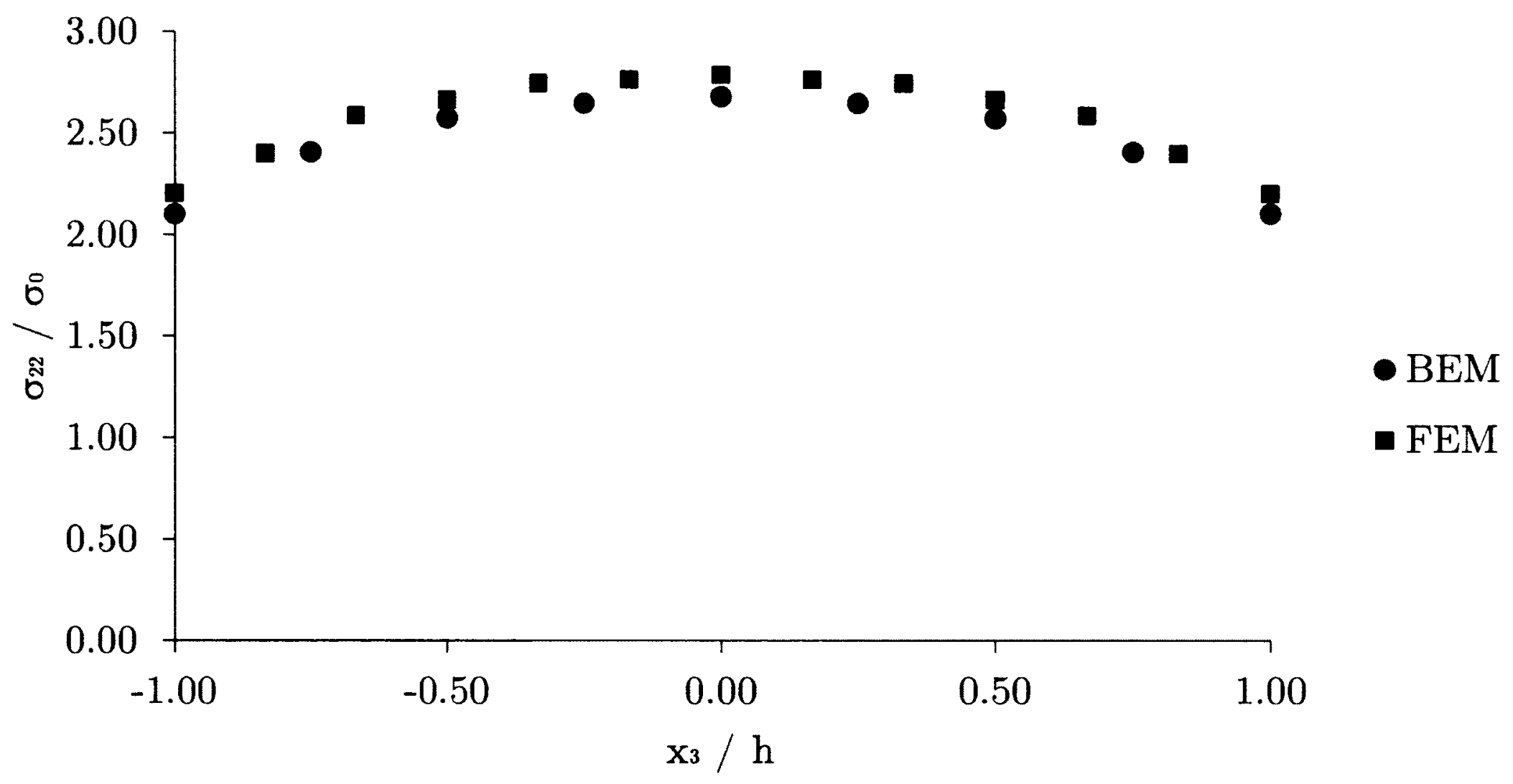

Figure 2.7: Variation of stress concentration along $\overline{A B}$, through the thickness of an anisotropic plate at a central circular hole 


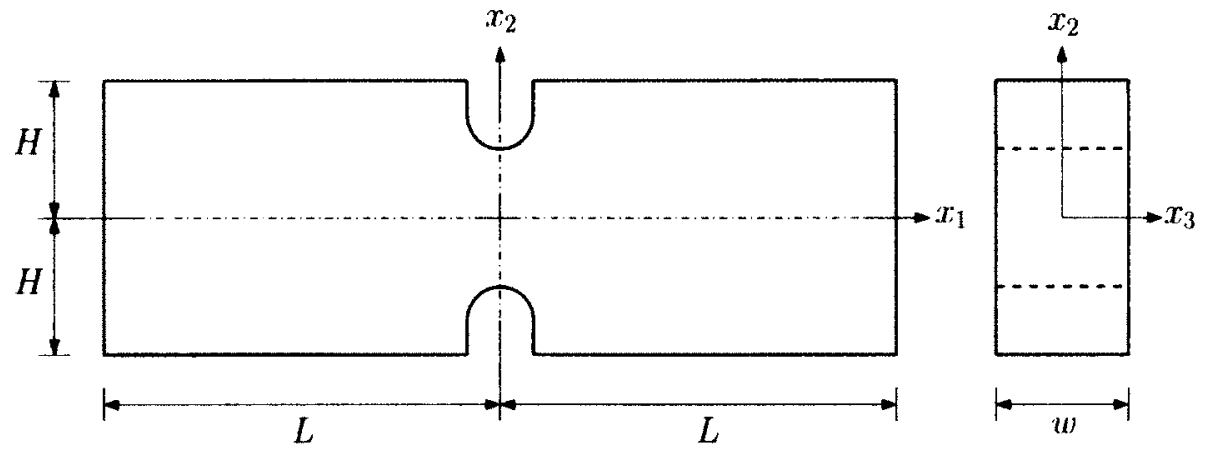

(a)

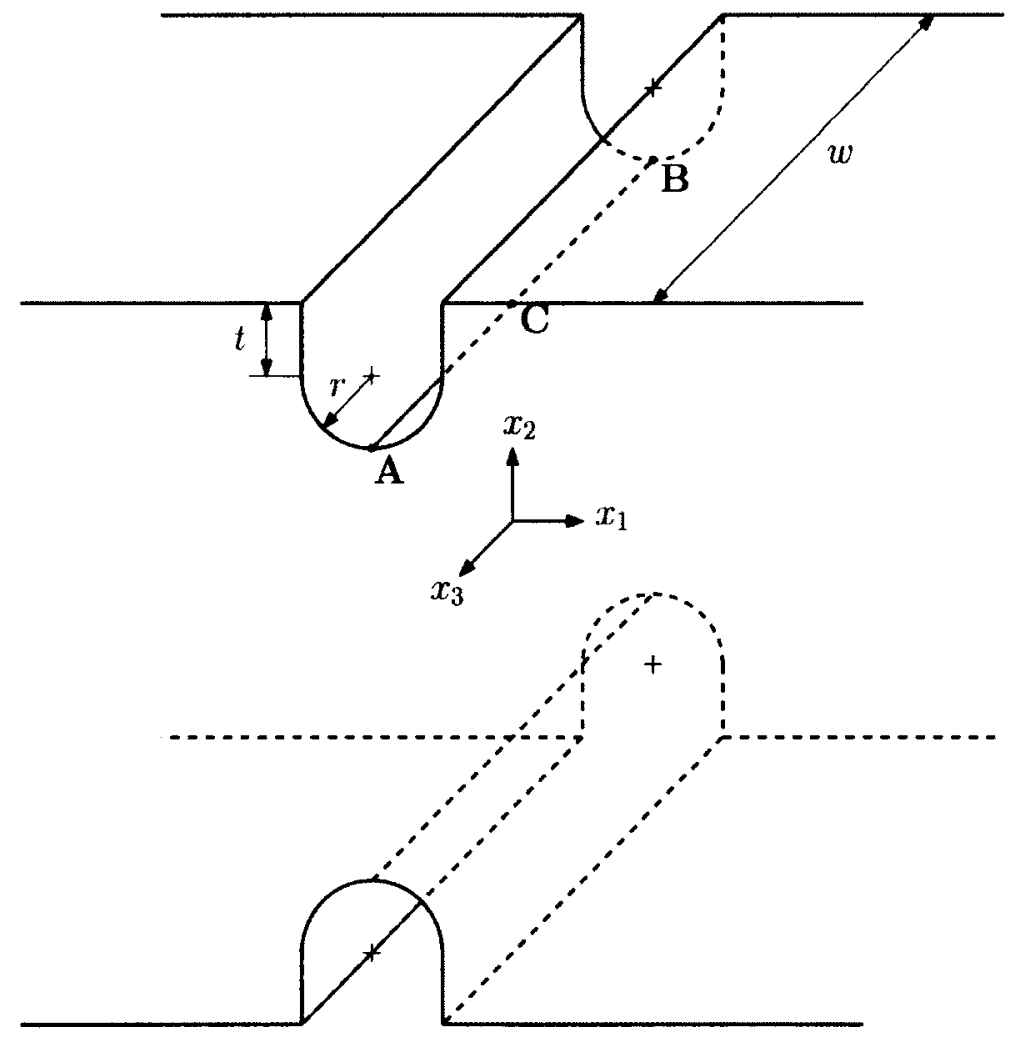

(b)

Figure 2.8: Bar in tension with double U-notch - Example (B) 


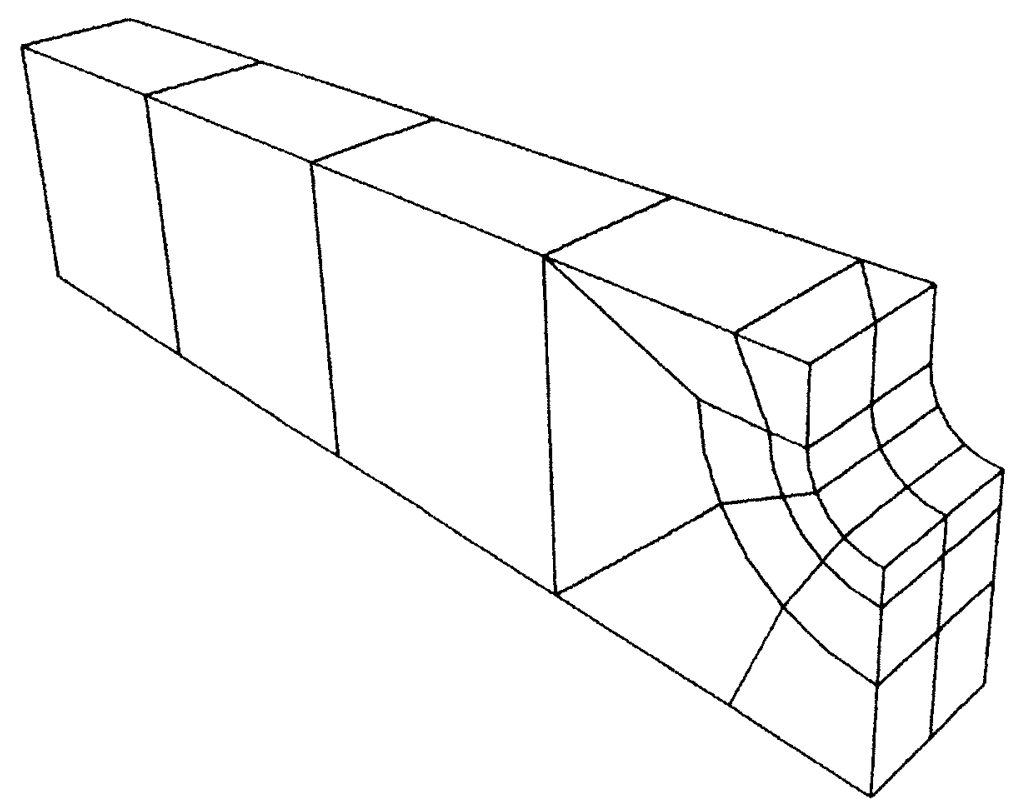

(a) BEM Mesh

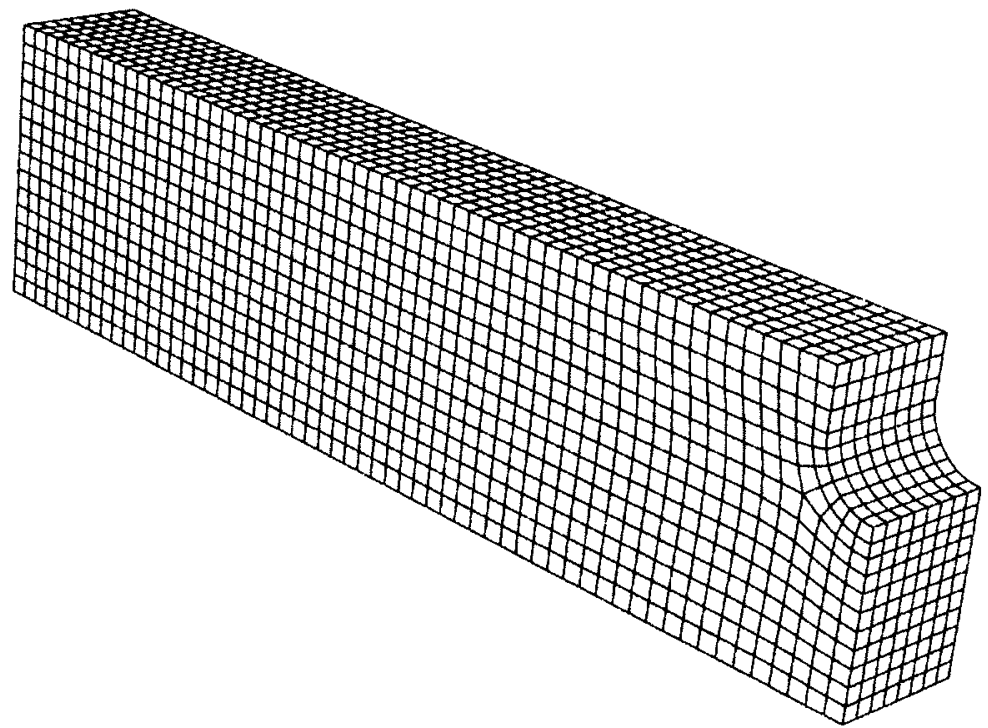

(b) FEM Mesh

Figure 2.9: Three-dimensional meshes of a bar with double U-notch for isotropic analysis 


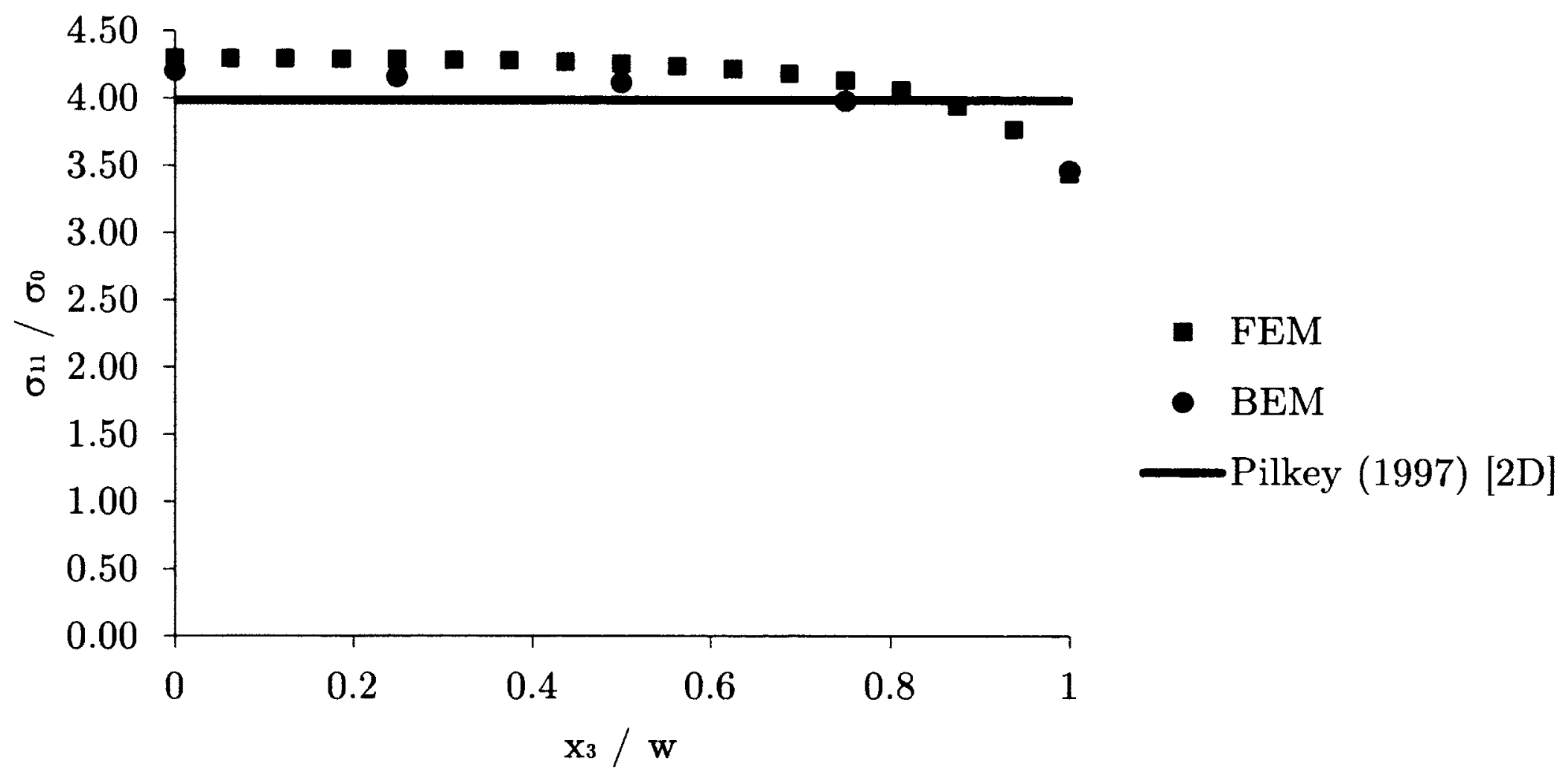

Figure 2.10: Variation of stress concentration along the notch at $\overline{C A}$, through the thickness of an isotropic double U-notch bar 


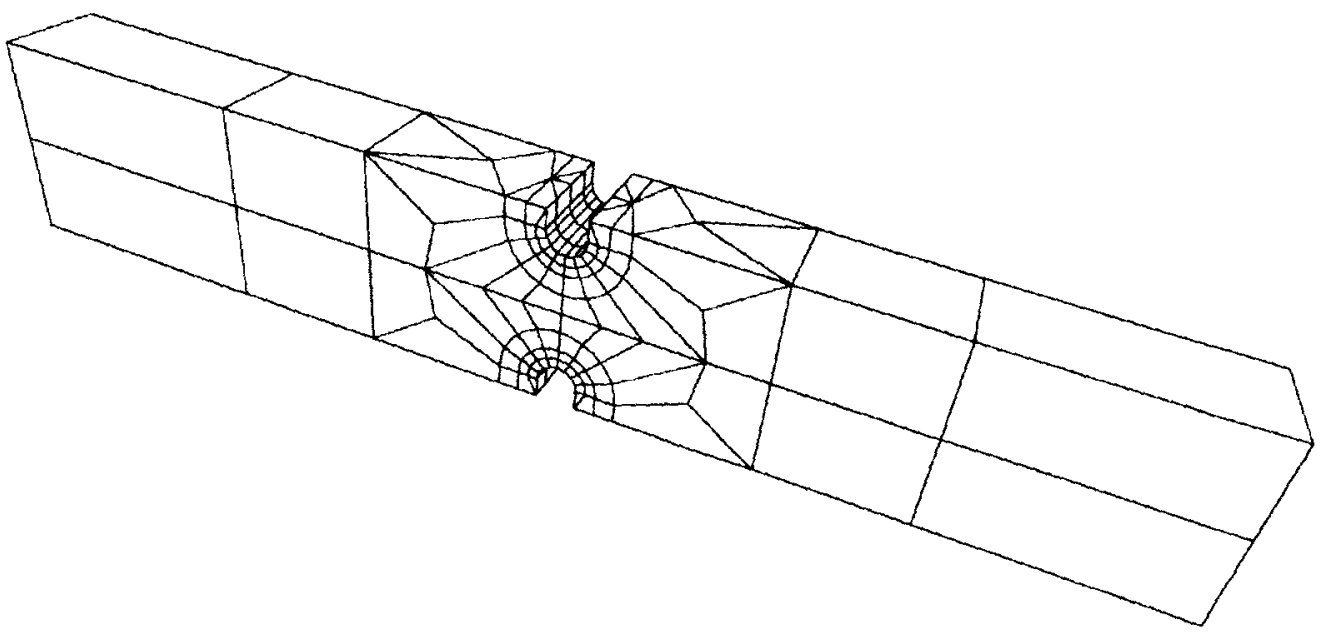

(a) BEM Mesh

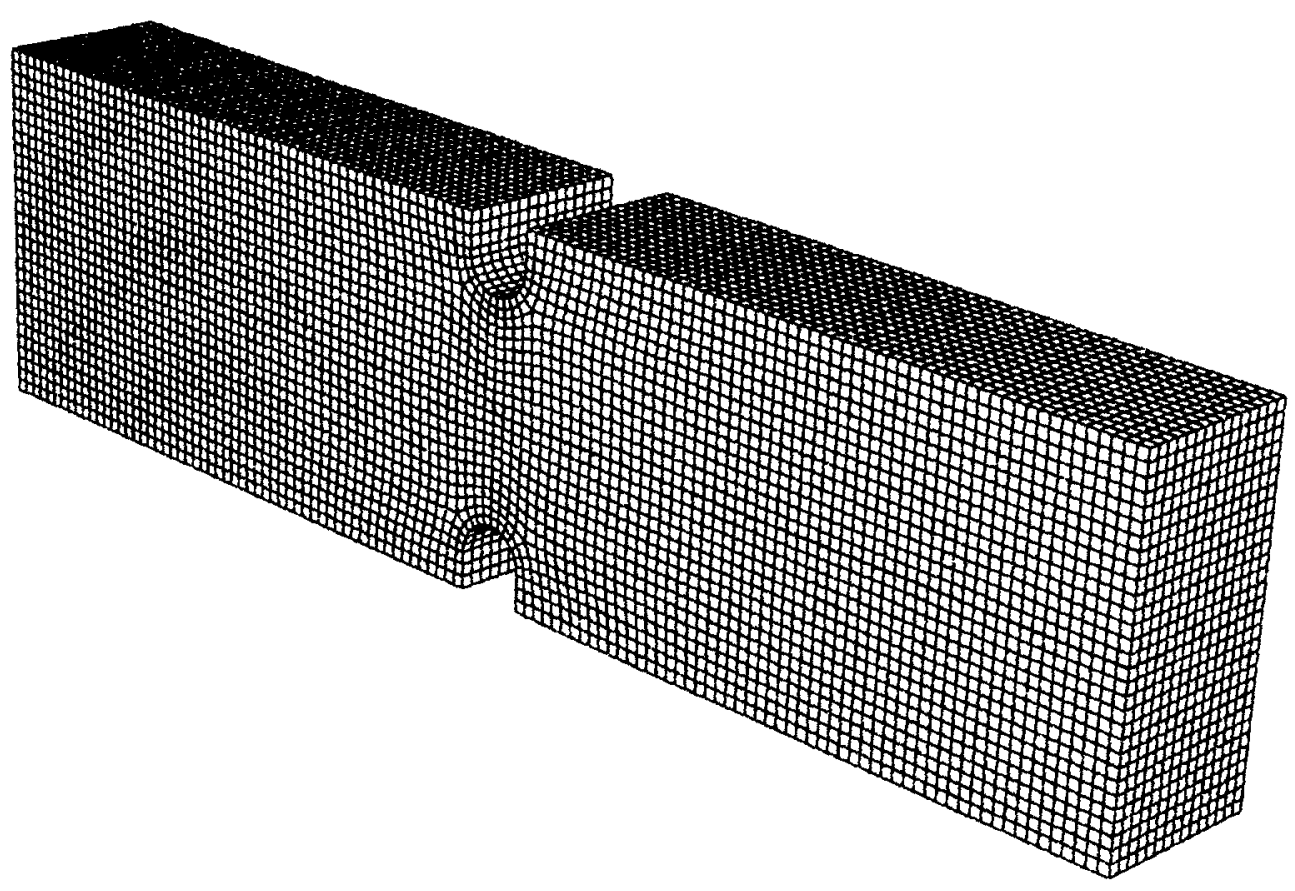

(b) FEM Mesh

Figure 2.11: Three-dimensional meshes of a bar with double U-notch for anisotropic analysis 


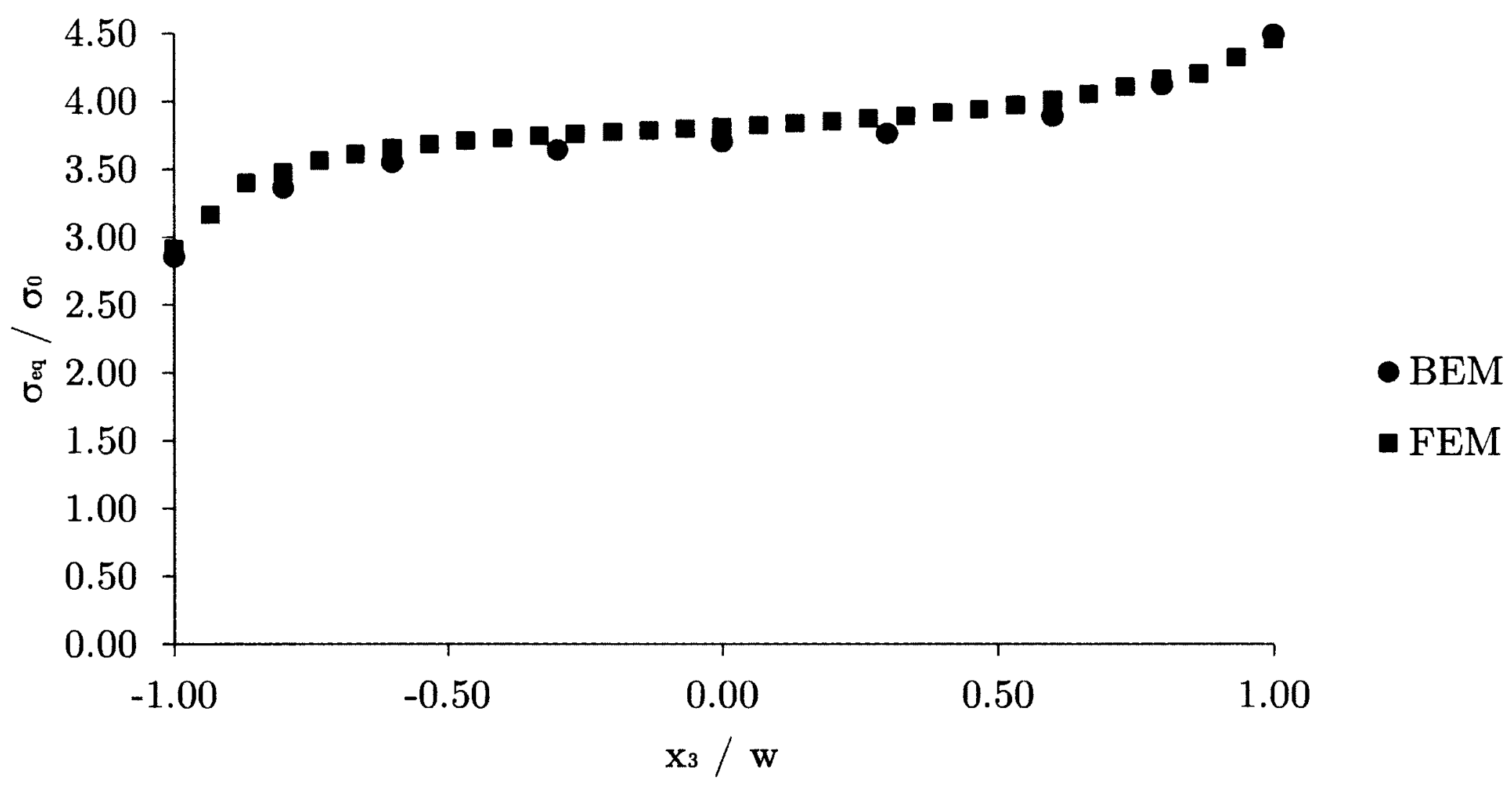

Figure 2.12: Variation of $\sigma_{e q} / \sigma_{0}$ along the notch at $\overline{A B}$, through the thickness of an anisotropic double U-notch bar 


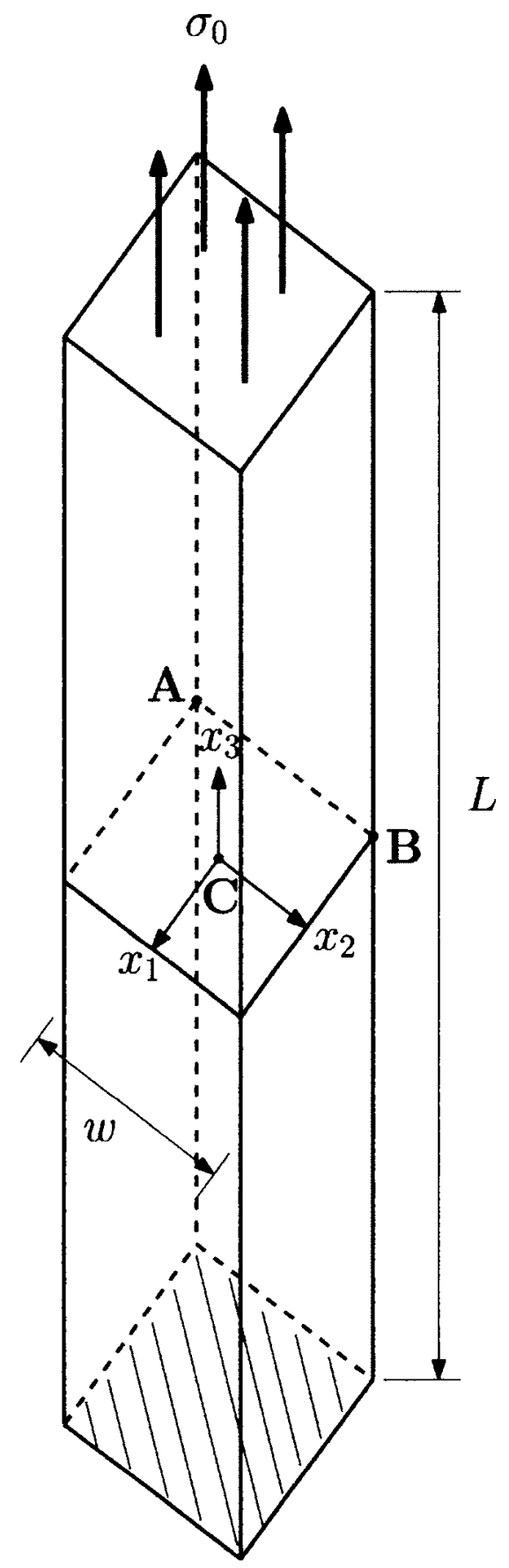

Figure 2.13: Bicrystal bar in tension - Example (C) 


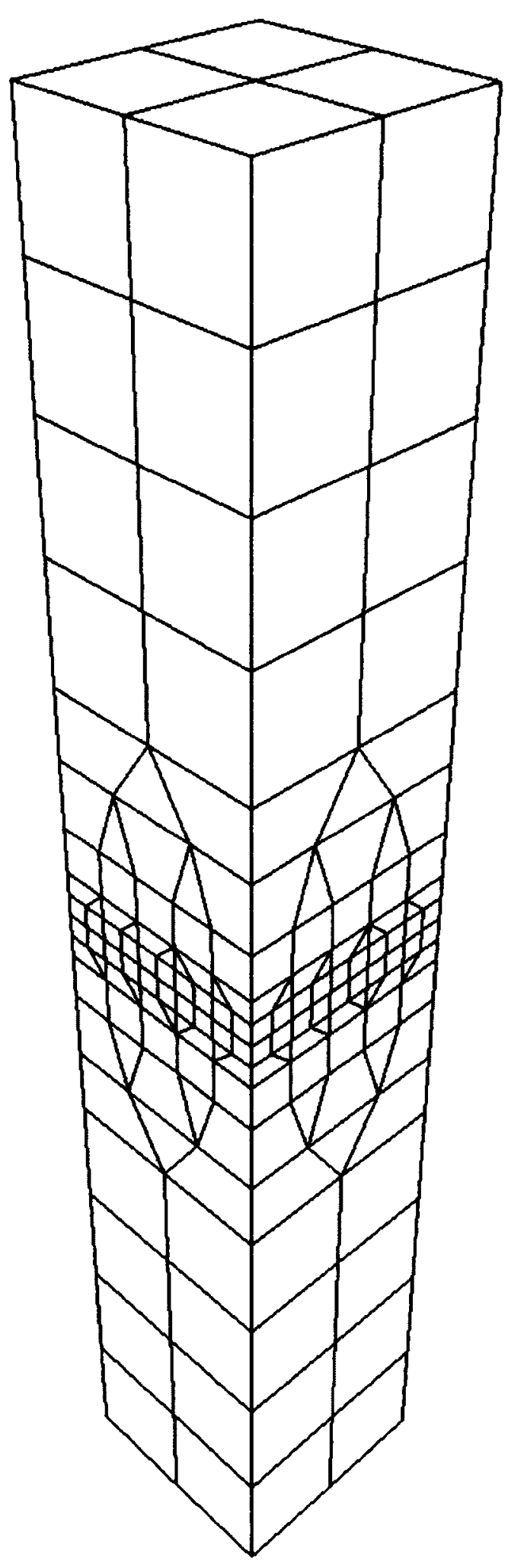

(a) BEM Mesh

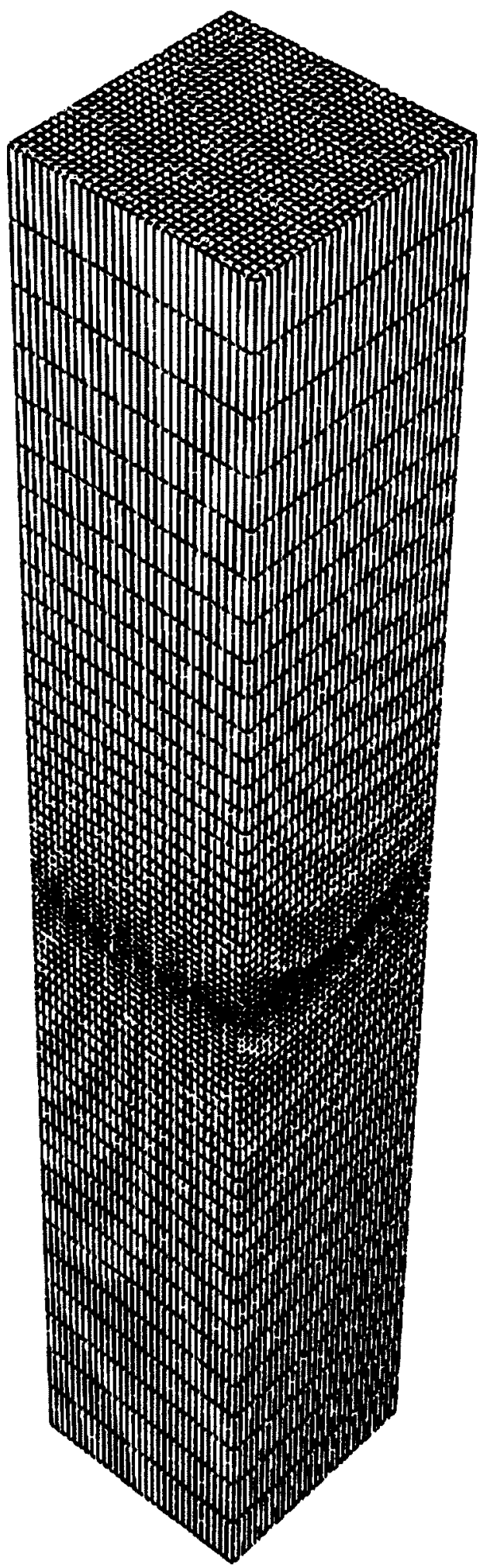

(b) FEM Mesh

Figure 2.14: Three-dimensional meshes of a bicrystal bar in tension 


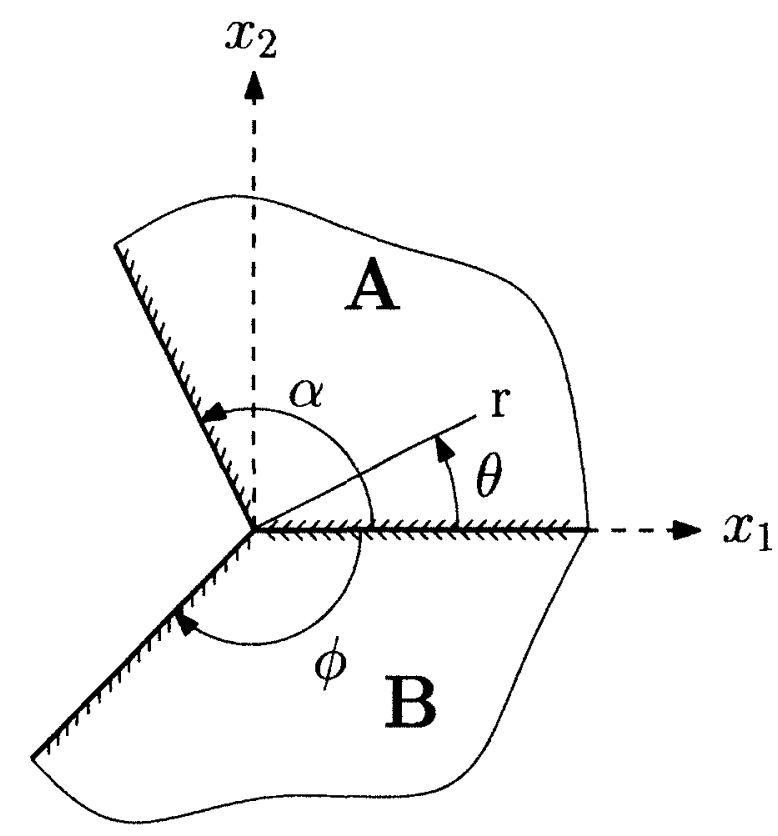

Figure 2.15: Two dissimilar anisotropic wedges perfectly bonded along the $x_{1}$ axis 


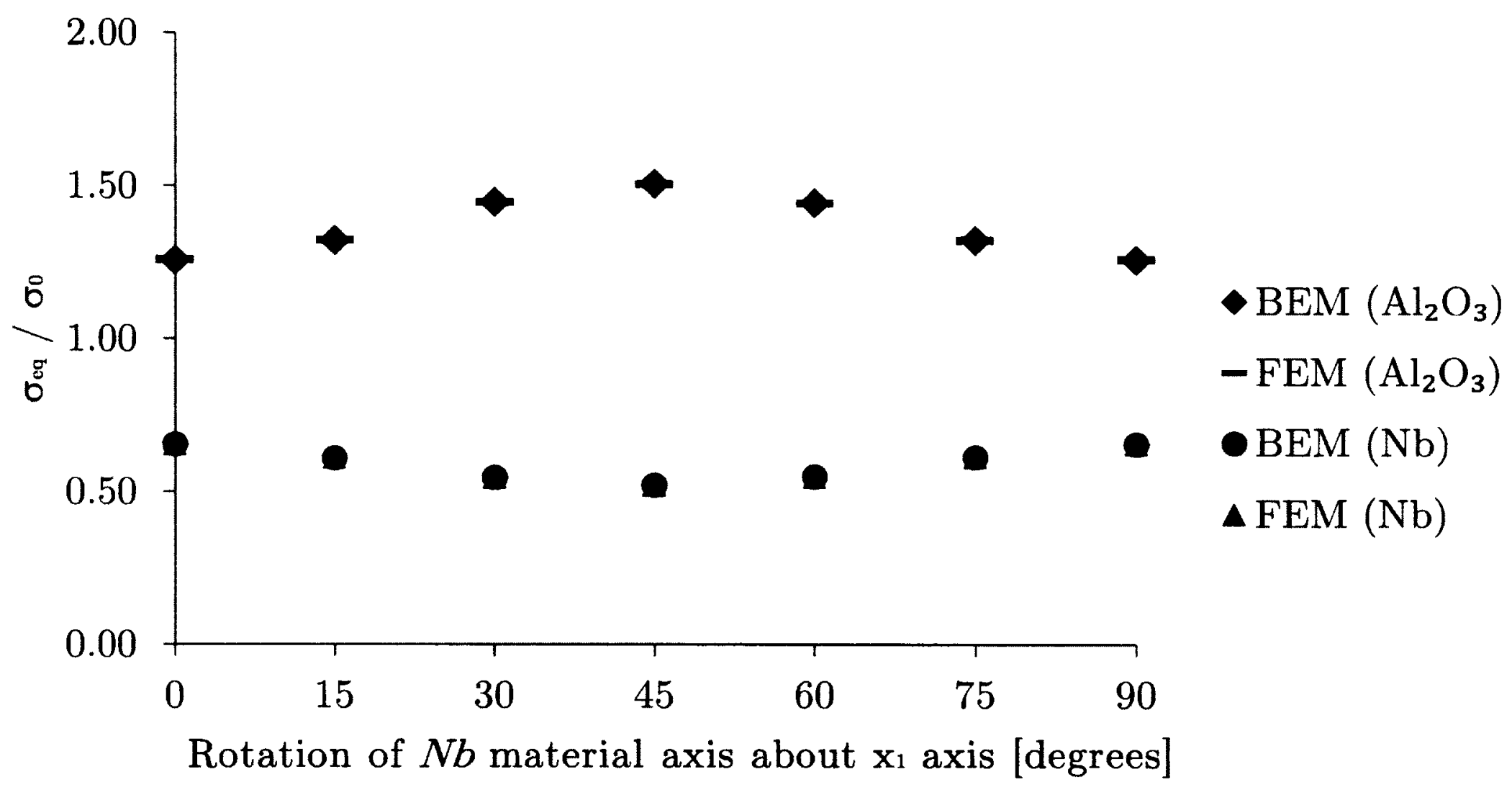

Figure 2.16: Variation of $\sigma_{e q} / \sigma_{0}$ at the interface of a $\mathrm{Nb}-\mathrm{Al}_{2} \mathrm{O}_{3}$ bicrystal bar at point $\mathrm{C}$ for material $x_{1}$ axis rotations of the $N b$ crystal 


\section{Chapter 3}

\section{Bicrystal Plate with a Circular Hole}

The stress concentration of a bicrystal plate with a circular hole in tension is investigated in this chapter. The physical problem is first defined and sample BEM and FEM numerical models of the problem are then introduced. A brief discussion follows of the properties and implications of the stress singularity which occurs at the interface between two crystals. The FEM is employed to verify the accuracy of the BEM results, especially around the singularity, and to compare the anisotropic results to those from a simpler isotropic analysis. Finally, the various trends and notable values of the different material combinations and orientations of the bicrystal problem are presented.

\subsection{Problem Definition}

The physical problem treated has a similar geometry and loading condition to Example (A) from the previous chapter, re-presented in Figure 3.1. However, there are now two homogeneous material regions which are perfectly bonded at an interfacial plane located where the highest stress concentration occurs, as shown in Figure 3.2. Stresses are analysed along $\overline{A C B}$, the interface edge; and $\overline{D F E}, 0.5$ units away from the edge of the hole, noting that the half width of the plate, $a$, is 10 units. Material 
combinations of niobium and alumina, and copper and alumina, were investigated for both isotropic and anisotropic cases. The mechanical properties of these crystals have been given in the previous chapter, but are again reproduced here in Table 3.1 with the corresponding isotropic properties. In anisotropy, all three material principal axes - $\mathrm{x}_{1}, \mathrm{x}_{2}$, and $\mathrm{x}_{3}$ for each crystal - are rotated counter-clockwise individually though $15^{\circ}$ increments until the material symmetry planes realigned.

\subsection{Numerical Models}

Two BEM meshes were used to analyse the different material combinations. The first mesh, containing 284 quadratic surface elements and 828 nodes, is shown in Figure 3.3 ; it was used to analyse rotations of the $\mathrm{Nb}-\mathrm{Al}_{2} \mathrm{O}_{3}$ bicrystal. The second mesh, first shown in Figure 2.6, was used for rotations of the $\mathrm{Cu}-\mathrm{Al}_{2} \mathrm{O}_{3}$ bicrystal and contains 468 elements and 1368 nodes; the interface discretization is shown in Figure 3.4. Two FEM meshes were also used, they contained 33,300 elements (C3D20R) and 148,360 nodes, and 70,000 elements and 302,304 nodes, as shown in Figures 3.5 and 3.6, respectively. These meshes were used in the corresponding isotropic analyses as well. In the models, one end of the plate was fully constrained, and a load, $\sigma_{0}$, was applied at the opposite end. The material interface was treated as being perfectly bonded, allowing no relative movement between two points with the same position on opposite sides of the interface. A comparative study was performed using all meshes for the isotropic and the non-rotated anisotropic bicrystal analyses, with the exception of the $\mathrm{Cu}-\mathrm{Al}_{2} \mathrm{O}_{3}$ bicrystal which produced some unreliable results with the less refined BEM mesh. 


\subsection{Results}

\subsubsection{Effects of the Free Edge Singularity - Some Prelimi- nary Results and Remarks}

In a homogeneous plate with a circular hole of the same geometry as that shown

in Figure 3.1, the elastic stresses at the edge $\overline{A C B}$ are finite and are the largest in magnitude, from which the concept of stress concentration applies. In the case of edge-bonded dissimilar orthogonal wedges under normal (and shear) loading, it is wellknown that the stress field along the interface free edges is singular, the asymptotic solution for which is of the form (Bogy 1968, Delale 1984):

$$
\sigma_{i j}(r, \theta)=r^{\lambda-1} f_{i j}(r, \theta, \lambda)
$$

where $\lambda$ is the eigenvalue, $\delta=(\lambda-1)$ is the order of the stress singularity, $(r, \theta)$ is the polar coordinate system with the origin at the edge and in the plane normal to the edge, and $f_{i j}$ is the eigenfunction. The value of $\lambda$ depends on the material combination of the two adjoining wedges. However, it was determined in Delale (1984), for example, that for two bonded $90^{\circ}$ fully anisotropic wedges, the order of the stress singularity $\delta$ remains relatively small, typically of the order of -0.05 to -0.1 , compared to that of -0.5 at a crack-tip. This implies that its influence on the stresses in its immediate vicinity is relatively small.

Notwithstanding the relatively weak stress singularity at the edge of the plane between the bonded regions, the stresses there are still theoretically infinite. This has implications for numerical stress analysis of such problems using BEM or FEM. Unless the order of singularity is incorporated in the numerical formulation with the use of special elements, such as in Pageau \& Biggers Jr. (1996) and Barroso, Mantič \& 
Paris (2003), the computed values of the stresses at this free edge are, strictly speaking, not meaningful and will vary significantly with the mesh refinement there. Thus, they should be treated with caution. In this regard, it would be more appropriate to deal with the stress intensity or "participation" factor, as in fracture mechanics analysis of cracks (see, e.g. Benthem (1977)). This is outside the scope of the present investigation. Nevertheless, because of the weak singularity and the assumed variations of the tractions and displacements over each element in the numerical analysis, the computed values at the free edge may be treated as "extrapolated" values of the stresses from its vicinity. They are useful for qualitative comparisons only.

A mesh refinement study was performed with the BEM and FEM meshes for both anisotropic cases of the problem with no material principal axis rotation. When the singular stress data are excluded there is good correlation in the $\sigma_{22}$ and equivalent stress results with mesh refinement in the respective analyses: the BEM results agree to within $2 \%$, the FEM results agree to within $1 \%$, and the deviations of the BEM and FEM are less than $4 \%$. These data are presented in Tables 3.2 and 3.3 in which the stresses at points $\mathrm{D}$ and $\mathrm{E}$ are singular and included for reference only. The $\mathrm{BEM}$ results from the less refined mesh for the $\mathrm{Cu}-\mathrm{Al}_{2} \mathrm{O}_{3}$ bicrystal were not included because the mesh produced unreliable results for other material axis orientations; nevertheless, the mesh yielded good results for the same orientations of the $\mathrm{Nb}-\mathrm{Al}_{2} \mathrm{O}_{3}$ bicrystal demonstrating that material properties have an effect on the mesh refinement required. Sample stress profiles from BEM and FEM results along $\overline{A C B}$ and $\overline{D F E}$ are compared in Figures 3.7 and 3.8 .

For a given geometry, changing the material properties affects the order of the stress singularity. The material properties of isotropic $\mathrm{Nb}$ and $\mathrm{Cu}$ are quite similar, but they differ much in anisotropic crystals. The degree of anisotropy of a cubic material can be represented by the anisotropic factor given as (Qamar \& Husain 1989), 


$$
A=2\left(S_{11}-S_{12}\right) / S_{44},
$$

where $S_{i j}$ are coefficients of the material compliance matrix. Factors of 0.512 and 3.21 were obtained for $\mathrm{Nb}$ and $\mathrm{Cu}$, respectively -1 for an isotropic material. Sample results of normal, shear, and equivalent stresses along $\overline{A C B}$ for isotropic and anisotropic analyses are presented in Tables 3.4 and 3.5 for $\mathrm{Nb}-\mathrm{Al}_{2} \mathrm{O}_{3}$ and $\mathrm{Cu}-\mathrm{Al}_{2} \mathrm{O}_{3}$ bimaterials, respectively; they demonstrate the increased shear stresses and variation of stress components of the anisotropic problem over that of isotropy. Figures 3.9 and 3.10 compare the isotropic results with the anisotropic results of the $\mathrm{Nb}-\mathrm{Al}_{2} \mathrm{O}_{3}$ and $\mathrm{Cu}-\mathrm{Al}_{2} \mathrm{O}_{3}$ material pairings, respectively. The isotropic equivalent stress results show symmetric profiles with significantly less variation through the thickness than the anisotropic results. The stress variation between isotropic and anisotropic $\mathrm{Cu}$ $\mathrm{Al}_{2} \mathrm{O}_{3}$ differs much more than the results from $\mathrm{Nb}-\mathrm{Al}_{2} \mathrm{O}_{3}$. Single crystal $\mathrm{Cu}$ is more anisotropic than $\mathrm{Nb}$ crystal.

It is also useful to know if the stresses in the anisotropic problem approach those of a corresponding isotropic plate at the interior of the interface. Table 3.6 shows the normalized normal, shear, and equivalent stresses at point $F$ for isotropic homogeneous, isotropic bimaterial, and anisotropic bimaterial variants of the problem. Notably, the normalized normal stress in the loading direction, $\sigma_{22} / \sigma_{0}$, changes very little through all analyses. However, the magnitude of all other stress components increases with material property complexity. This has significance for yielding as the values of the von Mises equivalent stress will change.

\subsubsection{Anisotropic Results}

As mentioned earlier, a 3-D BEM stress analysis was carried out for each increment of angular rotation of the material principal axes of each crystal in the plate, starting 
with the axes being taken to coincide with the global Cartesian axes. The material principal axes of one of the crystals were fixed while one of the axes of the other set was rotated in $15^{\circ}$ increments counter-clockwise. The complete set of stress results, for each of these axis rotations, along $\overline{A C B}$ and $\overline{D F E}$ are contained in the digital medium (compact disc) in Appendix C. Only the main findings and representative features of these numerical results are discussed here.

At the interface of the bicrystal plate, the von Mises equivalent stress is analysed because its magnitude differs significantly from the direct stress component in the direction of loading, $\sigma_{22}$. This is due to the increased transverse normal and shear stresses caused by the material interface incompatibility of the anisotropic properties. The highest normal stresses are nevertheless also important for studying crack tip opening displacements in fracture mechanics analyses of cracks which are likely to emanate in this plane. All stresses presented are normalized with respect to the applied stress, $\sigma_{0}$.

\section{Niobium-Alumina Bicrystal Results}

Material principal axis rotations of the $\mathrm{Nb}-\mathrm{Al}_{2} \mathrm{O}_{3}$ bicrystal were performed first. Rotating the $\mathrm{Nb} \mathrm{x}_{1}$-material axis increased the equivalent stress in $\mathrm{Al}_{2} \mathrm{O}_{3}$ while decreasing it in $\mathrm{Nb}$; the highest equivalent stress occurred for $45^{\circ}$ of rotation as shown in Figure 3.11. However, $\sigma_{22} / \sigma_{0}$ remained relatively unchanged. Rotation of the $\mathrm{Nb} \mathrm{x}_{3}$-material axis lowered $\sigma_{22} / \sigma_{0}$ in both $\mathrm{Nb}$ and $\mathrm{Al}_{2} \mathrm{O}_{3}$ crystals along the edge $\overline{A C B}$, as shown in Figure 3.12, and subsequently produced low equivalent stress in both crystals with a minimum between $45^{\circ}$ and $60^{\circ}$ of rotation as shown in Figure 3.13. A varying discrepancy of the equivalent stresses arises due to the tensile load causing contracting transverse strain at the interface. The less stiff material, $N b$ or $C u$, induces transverse compressive normal stresses which, combined with the tensile stress in the loading direction and the shear stresses, increases the equivalent stress 
in the stiffer material. The opposite effect occurs in the less stiff material reducing the equivalent stress as shown in Figures 3.14 and 3.15. However, the anisotropy of the materials may alter the effect. Interestingly, rotation of the $\mathrm{Al}_{2} \mathrm{O}_{3} \mathrm{x}_{1}$-material axis produced both low and high values of $\sigma_{22} / \sigma_{0}$ at $45^{\circ}$ and $135^{\circ}$, respectively, in the $\mathrm{Al}_{2} \mathrm{O}_{3}$ crystal and in the $\mathrm{Nb}$ crystal to a lesser extent, as shown in Figure 3.16. Combined with the variation of the transverse normal and shear stresses, this led to low and high equivalent stresses along $\overline{A C B}$ at $30^{\circ}$ and $150^{\circ}$, respectively, in the $\mathrm{Al}_{2} \mathrm{O}_{3}$ crystal, with very little variation in the $\mathrm{Nb}$ crystal, as shown in Figure 3.17. Along $\overline{D F E}$, the variation of equivalent stress was significantly reduced. The results from the rotation of the $\mathrm{Al}_{2} \mathrm{O}_{3} \mathrm{x}_{3}$-material axis were expected to repeat every $120^{\circ}$ since $\mathrm{Al}_{2} \mathrm{O}_{3}$ is trigonal, however due to geometric symmetry the results repeat every $60^{\circ}$ of rotation. For all material axis rotations studied, $\sigma_{22} / \sigma_{0}$ changes an insignificant amount at point $\mathrm{F}$ which indicates that variation of the von Mises equivalent stress, shown in Figures 3.18 and 3.19 for all of these rotations, is caused only by the variation of the transverse normal and shear stresses. Rotation of the other material axes produced no other significant stress variations.

The highest normal and von Mises equivalent stresses occur along $\overline{A C B}$ in the $\mathrm{Al}_{2} \mathrm{O}_{3}$ crystal for a $150^{\circ} \mathrm{x}_{1}$-material axis rotation of the $\mathrm{Al}_{2} \mathrm{O}_{3}$ crystal, as shown in Figures 3.20 and 3.21 , respectively. At point $\mathrm{F}$, the highest equivalent stress, $2.36-$ an increase of $71 \%$ over the corresponding homogeneous isotropic case and $28 \%$ over the corresponding isotropic bimaterial problem - occurs in the $\mathrm{Al}_{2} \mathrm{O}_{3}$ crystal for a $45^{\circ}$ rotation of the $N b \mathrm{x}_{1}$-material axis, of which the normalized equivalent stress profile along $\overline{D F E}$ is shown in Figure 3.22 . 


\section{Copper-Alumina Bicrystal Results}

Material principal axis rotations of the $\mathrm{Cu}-\mathrm{Al}_{2} \mathrm{O}_{3}$ bicrystal were also performed. Rotating the $\mathrm{Cu} \mathrm{x}_{1}$-material axis decreased the equivalent stress in $\mathrm{Al}_{2} \mathrm{O}_{3}$ while increasing it in $\mathrm{Cu}$, reaching a maximum at a $45^{\circ}$ rotation as shown in Figure 3.23, an effect opposite that of the $\mathrm{Nb} \mathrm{x}_{1}$-material axis rotation in the $\mathrm{Nb}-\mathrm{Al}_{2} \mathrm{O}_{3}$ bicrystal. Rotation of the $C u \mathrm{x}_{3}$-material axis also caused an opposite effect to that of the previous bicrystal; $\sigma_{22} / \sigma_{0}$ increased in both $\mathrm{Cu}$ and $\mathrm{Al}_{2} \mathrm{O}_{3}$, reaching a maximum for a $45^{\circ}$ rotation as shown in Figure 3.24, but significantly increased the equivalent stress only in the $\mathrm{Cu}$ crystal, shown in Figure 3.25, an example of the anisotropy of the material altering the general trend of increasing and decreasing equivalent stress on opposite sides of the bicrystal interface. Rotation of the $\mathrm{Al}_{2} \mathrm{O}_{3} \mathrm{x}_{1}$-material axis had a similar effect to the rotation of the same axis in the $\mathrm{Nb}-\mathrm{Al}_{2} \mathrm{O}_{3}$ bicrystal. However, the discrepancy between equivalent stresses in each crystal at the interface is larger for the $\mathrm{Cu}-\mathrm{Al}_{2} \mathrm{O}_{3}$ bicrystal, a trend which was observed in all $\mathrm{Cu}-\mathrm{Al}_{2} \mathrm{O}_{3}$ results; an example of which is shown in Figure 3.26. $\sigma_{22} / \sigma_{0}$ at point $\mathrm{F}$ does not change significantly for any material axis rotation and the equivalent stress for all rotations is shown in Figures 3.27 and 3.28. The rotation of the $\mathrm{x}_{2}$-material axis of both $\mathrm{Nb}$ and $\mathrm{Cu}$ in their respectively bicrystals, has little effect on the stress results which may be related to the $\mathrm{x}_{2}$-axis also being the load axis. This will be further investigated in the next chapter.

Along $\overline{A C B}$, the highest normal stress occurs in the $A l_{2} O_{3}$ crystal for a $60^{\circ} \mathrm{x}_{3^{-}}$ material axis rotation of the $C u$ crystal, as shown in Figure 3.29, and the highest normalized von Mises equivalent stress occurs in the $\mathrm{Al}_{2} \mathrm{O}_{3}$ crystal for a $150^{\circ} \mathrm{x}_{1}$ material axis rotation of the $\mathrm{Al}_{2} \mathrm{O}_{3}$ crystal, as shown in Figure 3.30. At point $\mathrm{F}$, the highest equivalent stress, 2.61 - an increase of $89 \%$ over the corresponding homogeneous isotropic case and $50 \%$ over the corresponding isotropic bimaterial problem

- occurs in the $\mathrm{Al}_{2} \mathrm{O}_{3}$ crystal for a $60^{\circ}$ rotation of the $\mathrm{x}_{1}$-material axis of $\mathrm{Al}_{2} \mathrm{O}_{3}$, for 
which the normalized equivalent stress profile along $\overline{D F E}$ is shown in Figure 3.31.

\subsection{Concluding Remarks}

Two cubic materials, $\mathrm{Nb}$ and $\mathrm{Cu}$, were each paired with a trigonal material, $\mathrm{Al}_{2} \mathrm{O}_{3}$, for multiple material principal axis orientations of a bicrystal plate with a circular hole and studied using the BEM. The stresses at the free edges of the interface are weakly singular. The numerical results there should be treated with caution and useful only for qualitative discussions; they represent extrapolated values relating to the stress "participation" factor. At the interface, a short distance away from the free edge, the stress results from the BEM analysis agree with those of a supplementary FEM analysis, and the normal stress in the loading direction converges to that of isotropy, but the other stress components differ significantly. Rotations of the various axes of the cubic materials produced very different results, relating to the different anisotropic factor of the two materials. Rotation of the $N b \mathrm{x}_{1}$-material axis increased equivalent stress in the $\mathrm{Al}_{2} \mathrm{O}_{3}$ crystal and decreased it in the $\mathrm{Nb}$ crystal, where the same axial rotation of $\mathrm{Cu}$ decreased equivalent stress in $\mathrm{Al}_{2} \mathrm{O}_{3}$ and increased it in $\mathrm{Cu}$. Rotation of the $\mathrm{Nb} \mathrm{x}_{3}$-material axis decreased the highest normal stress component, $\sigma_{22} / \sigma_{0}$, and the equivalent stress in both materials, where these stresses increased for $\mathrm{x}_{3}$-material axis rotations of $\mathrm{Cu}$. Alternatively, rotations of the $\mathrm{Al}_{2} \mathrm{O}_{3}$ crystal $\mathrm{x}_{1}$-material axis produced similar results in both bicrystals, an increase and decrease of $\sigma_{22} / \sigma_{0}$ and equivalent stresses in both materials depending on amount of rotation. The material orientations producing the highest normal and von Mises equivalent stresses were found. A reduction of equivalent stress in the less stiff material generally included an increase of equivalent stress in the stiffer material. This discrepancy is larger in the $\mathrm{Cu}-\mathrm{Al}_{2} \mathrm{O}_{3}$ bicrystal. However, the anisotropy of the materials can greatly change both the normal stresses perpendicular to the load direction and the shear stresses, 
affecting the resulting equivalent stress. The rotation of the cubic material axes in the load direction, $\mathrm{x}_{2}$ here, may have a reduced effect on the stresses. This will be further investigated in the next chapter in which a double U-notch bar in tension is investigated with the same material combinations. 


\begin{tabular}{|c|c|c|}
\hline Material & Young's Modulus [GPa] & Poisson's Ratio \\
\hline Niobium & 103 & 0.38 \\
\hline Copper & 110 & 0.35 \\
\hline Alumina & 370 & 0.22 \\
\hline
\end{tabular}

(a) Isotropy

\begin{tabular}{|c|c|lll|}
\hline Material & Crystal System & \multicolumn{3}{|c|}{ Stiffness Coefficients, $C_{i j}[\mathrm{GPa}]$} \\
\hline Niobium & Cubic & $C_{11}=246$ & $C_{12}=134$ & $C_{44}=28.7$ \\
\hline Copper & Cubic & $C_{11}=168.4$ & $C_{12}=121.4$ & $C_{44}=75.4$ \\
\hline \multirow{2}{*}{ Alumina } & \multirow{2}{*}{ Trigonal } & $C_{11}=465$ & $C_{12}=124$ & $C_{13}=117$ \\
& & $C_{33}=563$ & $C_{14}=101$ & $C_{44}=233$ \\
\hline
\end{tabular}

(b) Anisotropy

Table 3.1: Mechanical properties of $\mathrm{Nb}, \mathrm{Cu}$, and $\mathrm{Al}_{2} \mathrm{O}_{3}$ 


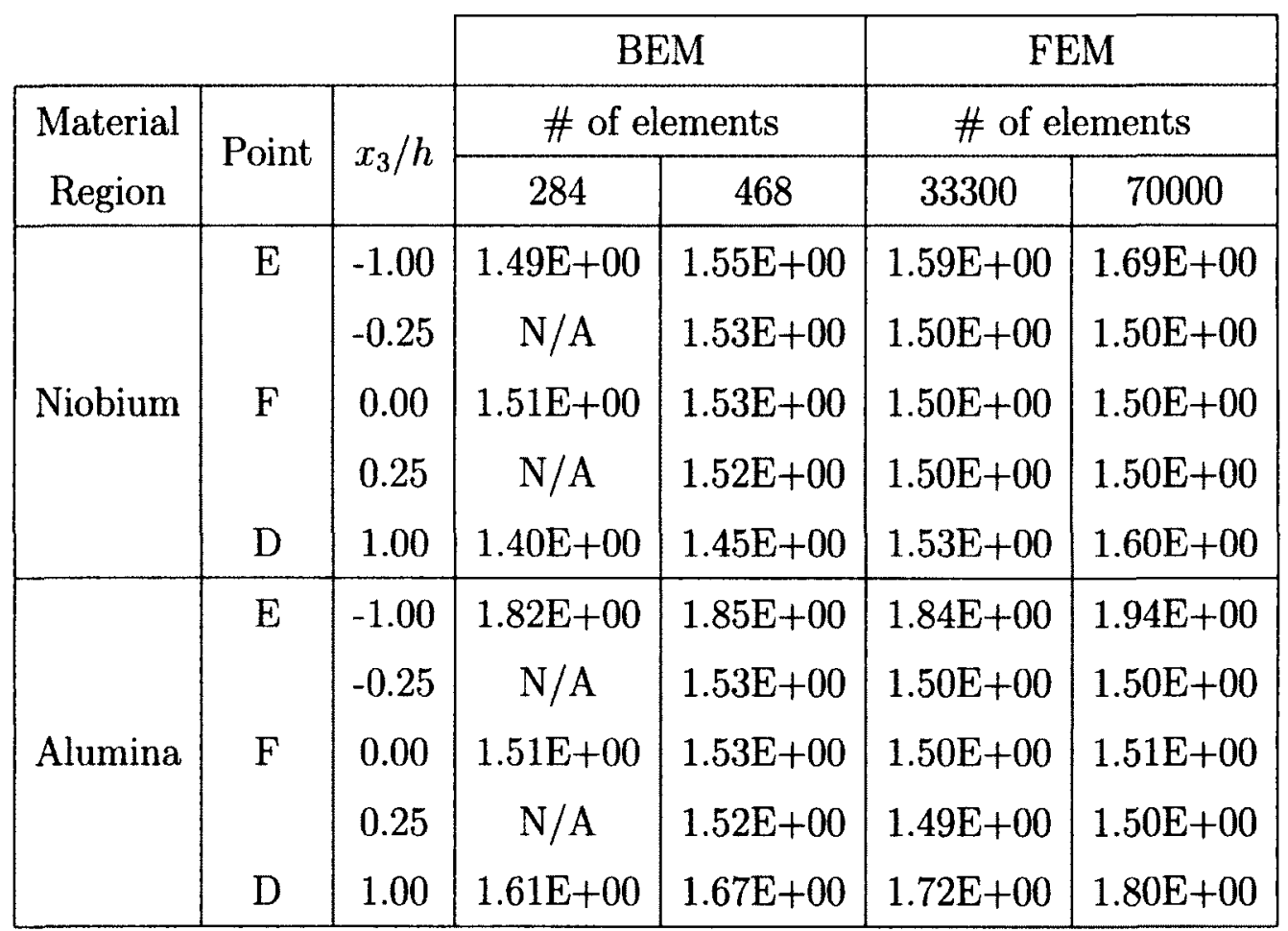

(a) $\sigma_{22} / \sigma_{0}$

\begin{tabular}{|c|c|c|c|c|c|c|}
\hline \\
\hline \multirow{3}{*}{$\begin{array}{l}\text { Material } \\
\text { Region }\end{array}$} & \multirow{3}{*}{ Point } & \multirow{3}{*}{$x_{3} / h$} & \multirow{2}{*}{\multicolumn{2}{|c|}{$\frac{\text { BEM }}{\text { \# of elements }}$}} & \multirow{2}{*}{\multicolumn{2}{|c|}{$\frac{\text { FEM }}{\text { \# of elements }}$}} \\
\hline & & & & & & \\
\hline & & & 284 & 468 & 33300 & 70000 \\
\hline \multirow{5}{*}{ Niobium } & \multirow[t]{2}{*}{$\mathrm{E}$} & -1.00 & $1.15 \mathrm{E}+00$ & $1.18 \mathrm{E}+00$ & $1.23 \mathrm{E}+00$ & $1.30 \mathrm{E}+00$ \\
\hline & & -0.25 & $\mathrm{~N} / \mathrm{A}$ & $9.79 \mathrm{E}-01$ & $1.00 \mathrm{E}+00$ & $9.97 \mathrm{E}-01$ \\
\hline & \multirow[t]{2}{*}{$\mathrm{F}$} & 0.00 & $9.67 \mathrm{E}-01$ & 9.73E-01 & $9.92 \mathrm{E}-01$ & $9.88 \mathrm{E}-01$ \\
\hline & & 0.25 & $\mathrm{~N} / \mathrm{A}$ & $9.68 \mathrm{E}-01$ & $9.91 \mathrm{E}-01$ & $9.86 \mathrm{E}-01$ \\
\hline & $\mathrm{D}$ & 1.00 & $1.10 \mathrm{E}+00$ & $1.13 \mathrm{E}+00$ & $1.19 \mathrm{E}+00$ & $1.24 \mathrm{E}+00$ \\
\hline \multirow{5}{*}{ Alumina } & \multirow[t]{2}{*}{$\mathrm{E}$} & -1.00 & $1.78 \mathrm{E}+00$ & $1.81 \mathrm{E}+00$ & $2.00 \mathrm{E}+00$ & $2.11 E+00$ \\
\hline & & -0.25 & $\mathrm{~N} / \mathrm{A}$ & $1.75 \mathrm{E}+00$ & $1.76 \mathrm{E}+00$ & $1.76 \mathrm{E}+00$ \\
\hline & \multirow[t]{2}{*}{ F } & 0.00 & $1.75 \mathrm{E}+00$ & $1.75 \mathrm{E}+00$ & $1.76 \mathrm{E}+00$ & $1.76 \mathrm{E}+00$ \\
\hline & & 0.25 & $\mathrm{~N} / \mathrm{A}$ & $1.76 \mathrm{E}+00$ & $1.76 \mathrm{E}+00$ & $1.77 \mathrm{E}+00$ \\
\hline & $\mathrm{D}$ & 1.00 & $1.73 \mathrm{E}+00$ & $1.77 \mathrm{E}+00$ & $1.89 \mathrm{E}+00$ & $1.98 \mathrm{E}+00$ \\
\hline
\end{tabular}

(b) $\sigma_{e q} / \sigma_{0}$

Table 3.2: Comparison of stresses at various points from BEM and FEM analyses of the $\mathrm{Nb}-\mathrm{Al}_{2} \mathrm{O}_{3}$ bicrystal plate with a circular hole; $x_{1} / a=0.15$ and $x_{2}=0$ for all points 


\begin{tabular}{|c|c|c|c|c|c|}
\cline { 4 - 6 } \multicolumn{2}{c|}{$\begin{array}{c}\text { Material } \\
\text { Region }\end{array}$} & Point & $x_{3} / h$ & \# of elements & \multicolumn{2}{c|}{ \# of elements } \\
\cline { 4 - 7 } & & & 468 & 33300 & 70000 \\
\hline & $\mathrm{E}$ & -1.00 & $1.72 \mathrm{E}+00$ & $1.97 \mathrm{E}+00$ & $2.17 \mathrm{E}+00$ \\
& & -0.25 & $1.47 \mathrm{E}+00$ & $1.45 \mathrm{E}+00$ & $1.45 \mathrm{E}+00$ \\
Copper & $\mathrm{F}$ & 0.00 & $1.50 \mathrm{E}+00$ & $1.46 \mathrm{E}+00$ & $1.46 \mathrm{E}+00$ \\
& & 0.25 & $1.47 \mathrm{E}+00$ & $1.45 \mathrm{E}+00$ & $1.45 \mathrm{E}+00$ \\
& $\mathrm{D}$ & 1.00 & $1.59 \mathrm{E}+00$ & $1.79 \mathrm{E}+00$ & $1.94 \mathrm{E}+00$ \\
\hline \multirow{4}{*}{ Alumina } & $\mathrm{E}$ & -1.00 & $2.54 \mathrm{E}+00$ & $2.65 \mathrm{E}+00$ & $2.87 \mathrm{E}+00$ \\
& & -0.25 & $1.47 \mathrm{E}+00$ & $1.45 \mathrm{E}+00$ & $1.46 \mathrm{E}+00$ \\
& & 0.00 & $1.50 \mathrm{E}+00$ & $1.46 \mathrm{E}+00$ & $1.47 \mathrm{E}+00$ \\
& & 0.25 & $1.47 \mathrm{E}+00$ & $1.44 \mathrm{E}+00$ & $1.46 \mathrm{E}+00$ \\
& $\mathrm{D}$ & 1.00 & $2.18 \mathrm{E}+00$ & $2.30 \mathrm{E}+00$ & $2.48 \mathrm{E}+00$ \\
\hline
\end{tabular}

(a) $\sigma_{22} / \sigma_{0}$

\begin{tabular}{|c|c|c|c|c|c|}
\hline & & & BEM & & \\
\hline Material & Point & $r_{a} / b$ & \# of elements & $\#$ of $\mathrm{e}$ & ements \\
\hline Region & $10 \mathrm{sin}$ & $x_{3 / n}$ & 468 & 33300 & 70000 \\
\hline & $\mathrm{E}$ & -1.00 & $1.36 \mathrm{E}+00$ & $1.52 \mathrm{E}+00$ & $1.64 \mathrm{E}+00$ \\
\hline & & -0.25 & $7.12 \mathrm{E}-01$ & $7.32 \mathrm{E}-01$ & 7.34E-01 \\
\hline Copper & F & 0.00 & $6.63 \mathrm{E}-01$ & $6.72 \mathrm{E}-01$ & $6.78 \mathrm{E}-01$ \\
\hline & & 0.25 & $6.84 \mathrm{E}-01$ & $6.93 \mathrm{E}-01$ & $6.95 \mathrm{E}-01$ \\
\hline & $\mathrm{D}$ & 1.00 & $1.29 \mathrm{E}+00$ & $1.35 \mathrm{E}+00$ & $1.44 \mathrm{E}+00$ \\
\hline & $\mathrm{E}$ & -1.00 & $2.80 \mathrm{E}+00$ & $3.36 \mathrm{E}+00$ & $3.64 \mathrm{E}+00$ \\
\hline & & -0.25 & $2.39 \mathrm{E}+00$ & $2.37 \mathrm{E}+00$ & $2.38 \mathrm{E}+00$ \\
\hline Alumina & $\mathrm{F}$ & 0.00 & $2.38 \mathrm{E}+00$ & $2.36 \mathrm{E}+00$ & $2.36 \mathrm{E}+00$ \\
\hline & & 0.25 & $2.41 \mathrm{E}+00$ & $2.38 \mathrm{E}+00$ & $2.40 \mathrm{E}+00$ \\
\hline & $\mathrm{D}$ & 1.00 & $2.65 \mathrm{E}+00$ & $2.95 \mathrm{E}+00$ & $3.16 \mathrm{E}+00$ \\
\hline
\end{tabular}

(b) $\sigma_{e q} / \sigma_{0}$

Table 3.3: Comparison of stresses at various points from BEM and FEM analyses of the $\mathrm{Cu}-\mathrm{Al}_{2} \mathrm{O}_{3}$ bicrystal plate with a circular hole; $x_{1} / a=0.15$ and $x_{2}=0$ for all points 


\begin{tabular}{|c|c|c|r|c|c|c|c|}
\hline$x_{3} / \mathrm{h}$ & $\sigma_{11} / \sigma_{0}$ & $\sigma_{22} / \sigma_{0}$ & $\sigma_{33} / \sigma_{0}$ & $\sigma_{12} / \sigma_{0}$ & $\sigma_{23} / \sigma_{0}$ & $\sigma_{31} / \sigma_{0}$ & $\sigma_{e q} / \sigma_{0}$ \\
\hline-1.00 & $6.63 \mathrm{E}-01$ & $2.70 \mathrm{E}+00$ & $6.13 \mathrm{E}-01$ & $1.98 \mathrm{E}-01$ & $4.23 \mathrm{E}-01$ & $-5.35 \mathrm{E}-03$ & $2.22 \mathrm{E}+00$ \\
-0.75 & $6.13 \mathrm{E}-01$ & $2.81 \mathrm{E}+00$ & $9.33 \mathrm{E}-01$ & $3.77 \mathrm{E}-01$ & $3.05 \mathrm{E}-01$ & $-6.18 \mathrm{E}-04$ & $2.22 \mathrm{E}+00$ \\
-0.50 & $6.66 \mathrm{E}-01$ & $2.88 \mathrm{E}+00$ & $1.03 \mathrm{E}+00$ & $3.72 \mathrm{E}-01$ & $2.52 \mathrm{E}-01$ & $1.71 \mathrm{E}-03$ & $2.20 \mathrm{E}+00$ \\
0.00 & $6.75 \mathrm{E}-01$ & $2.90 \mathrm{E}+00$ & $1.06 \mathrm{E}+00$ & $4.02 \mathrm{E}-01$ & $-1.79 \mathrm{E}-06$ & $-1.64 \mathrm{E}-06$ & $2.17 \mathrm{E}+00$ \\
0.50 & $6.66 \mathrm{E}-01$ & $2.88 \mathrm{E}+00$ & $1.03 \mathrm{E}+00$ & $3.72 \mathrm{E}-01$ & $-2.52 \mathrm{E}-01$ & $-1.71 \mathrm{E}-03$ & $2.20 \mathrm{E}+00$ \\
0.75 & $6.13 \mathrm{E}-01$ & $2.81 \mathrm{E}+00$ & $9.33 \mathrm{E}-01$ & $3.77 \mathrm{E}-01$ & $-3.05 \mathrm{E}-01$ & $6.10 \mathrm{E}-04$ & $2.22 \mathrm{E}+00$ \\
1.00 & $6.63 \mathrm{E}-01$ & $2.70 \mathrm{E}+00$ & $6.13 \mathrm{E}-01$ & $1.98 \mathrm{E}-01$ & $-4.23 \mathrm{E}-01$ & $5.34 \mathrm{E}-03$ & $2.22 \mathrm{E}+00$ \\
\hline
\end{tabular}

(a) Isotropic

\begin{tabular}{|c|c|c|r|c|c|c|c|}
\hline$x_{3} / \mathrm{h}$ & $\sigma_{11} / \sigma_{0}$ & $\sigma_{22} / \sigma_{0}$ & $\sigma_{33} / \sigma_{0}$ & $\sigma_{12} / \sigma_{0}$ & $\sigma_{23} / \sigma_{0}$ & $\sigma_{31} / \sigma_{0}$ & $\sigma_{e q} / \sigma_{0}$ \\
\hline-1.00 & $4.95 \mathrm{E}-01$ & $3.27 \mathrm{E}+00$ & $6.36 \mathrm{E}-01$ & $5.20 \mathrm{E}-02$ & $3.57 \mathrm{E}-01$ & $-1.30 \mathrm{E}-02$ & $2.78 \mathrm{E}+00$ \\
-0.75 & $4.50 \mathrm{E}-01$ & $3.32 \mathrm{E}+00$ & $9.74 \mathrm{E}-01$ & $1.74 \mathrm{E}-01$ & $1.94 \mathrm{E}-01$ & $-1.96 \mathrm{E}-02$ & $2.68 \mathrm{E}+00$ \\
-0.50 & $5.09 \mathrm{E}-01$ & $3.36 \mathrm{E}+00$ & $1.07 \mathrm{E}+00$ & $1.75 \mathrm{E}-01$ & $1.24 \mathrm{E}-01$ & $-2.25 \mathrm{E}-02$ & $2.64 \mathrm{E}+00$ \\
0.00 & $5.37 \mathrm{E}-01$ & $3.38 \mathrm{E}+00$ & $1.11 \mathrm{E}+00$ & $2.03 \mathrm{E}-01$ & $-6.01 \mathrm{E}-02$ & $-2.35 \mathrm{E}-02$ & $2.63 \mathrm{E}+00$ \\
0.50 & $5.43 \mathrm{E}-01$ & $3.36 \mathrm{E}+00$ & $1.07 \mathrm{E}+00$ & $1.97 \mathrm{E}-01$ & $-2.44 \mathrm{E}-01$ & $-2.51 \mathrm{E}-02$ & $2.65 \mathrm{E}+00$ \\
0.75 & $5.12 \mathrm{E}-01$ & $3.23 \mathrm{E}+00$ & $9.51 \mathrm{E}-01$ & $1.98 \mathrm{E}-01$ & $-2.69 \mathrm{E}-01$ & $-1.67 \mathrm{E}-02$ & $2.59 \mathrm{E}+00$ \\
1.00 & $4.91 \mathrm{E}-01$ & $2.89 \mathrm{E}+00$ & $5.37 \mathrm{E}-01$ & $4.15 \mathrm{E}-02$ & $-3.27 \mathrm{E}-01$ & $-2.81 \mathrm{E}-03$ & $2.45 \mathrm{E}+00$ \\
\hline
\end{tabular}

(b) Anisotropic

Table 3.4: Stress components along $\overline{A C B}$ in the $\mathrm{Nb}$ material of a $\mathrm{Nb}-\mathrm{Al}_{2} \mathrm{O}_{3}$ bimaterial plate with a circular hole at the interface 


\begin{tabular}{|c|c|c|c|c|c|c|c|}
\hline$x_{3} / \mathrm{h}$ & $\sigma_{11} / \sigma_{0}$ & $\sigma_{22} / \sigma_{0}$ & $\sigma_{33} / \sigma_{0}$ & $\sigma_{12} / \sigma_{0}$ & $\sigma_{23} / \sigma_{0}$ & $\sigma_{31} / \sigma_{0}$ & $\sigma_{e q} / \sigma_{0}$ \\
\hline-1.00 & $5.63 \mathrm{E}-01$ & $2.80 \mathrm{E}+00$ & $5.08 \mathrm{E}-01$ & $1.66 \mathrm{E}-01$ & $3.66 \mathrm{E}-01$ & $-4.80 \mathrm{E}-03$ & $2.37 \mathrm{E}+00$ \\
-0.75 & $4.98 \mathrm{E}-01$ & $2.87 \mathrm{E}+00$ & $7.85 \mathrm{E}-01$ & $2.95 \mathrm{E}-01$ & $2.77 \mathrm{E}-01$ & $-3.03 \mathrm{E}-04$ & $2.35 \mathrm{E}+00$ \\
-0.50 & $5.35 \mathrm{E}-01$ & $2.89 \mathrm{E}+00$ & $8.48 \mathrm{E}-01$ & $2.91 \mathrm{E}-01$ & $2.23 \mathrm{E}-01$ & $1.75 \mathrm{E}-03$ & $2.31 \mathrm{E}+00$ \\
-0.25 & $5.39 \mathrm{E}-01$ & $2.91 \mathrm{E}+00$ & $8.84 \mathrm{E}-01$ & $3.09 \mathrm{E}-01$ & $8.96 \mathrm{E}-02$ & $7.43 \mathrm{E}-04$ & $2.28 \mathrm{E}+00$ \\
0.00 & $5.43 \mathrm{E}-01$ & $2.92 \mathrm{E}+00$ & $9.06 \mathrm{E}-01$ & $3.06 \mathrm{E}-01$ & $1.41 \mathrm{E}-06$ & $1.61 \mathrm{E}-06$ & $2.28 \mathrm{E}+00$ \\
0.25 & $5.39 \mathrm{E}-01$ & $2.91 \mathrm{E}+00$ & $8.84 \mathrm{E}-01$ & $3.09 \mathrm{E}-01$ & $-8.96 \mathrm{E}-02$ & $-7.37 \mathrm{E}-04$ & $2.28 \mathrm{E}+00$ \\
0.50 & $5.35 \mathrm{E}-01$ & $2.89 \mathrm{E}+00$ & $8.48 \mathrm{E}-01$ & $2.91 \mathrm{E}-01$ & $-2.23 \mathrm{E}-01$ & $-1.74 \mathrm{E}-03$ & $2.31 \mathrm{E}+00$ \\
0.75 & $4.98 \mathrm{E}-01$ & $2.87 \mathrm{E}+00$ & $7.85 \mathrm{E}-01$ & $2.95 \mathrm{E}-01$ & $-2.77 \mathrm{E}-01$ & $3.07 \mathrm{E}-04$ & $2.35 \mathrm{E}+00$ \\
1.00 & $5.63 \mathrm{E}-01$ & $2.80 \mathrm{E}+00$ & $5.08 \mathrm{E}-01$ & $1.66 \mathrm{E}-01$ & $-3.66 \mathrm{E}-01$ & $4.81 \mathrm{E}-03$ & $2.37 \mathrm{E}+00$ \\
\hline
\end{tabular}

(a) Isotropic

\begin{tabular}{|c|c|c|c|c|c|c|c|}
\hline$x_{3} / \mathrm{h}$ & $\sigma_{11} / \sigma_{0}$ & $\sigma_{22} / \sigma_{0}$ & $\sigma_{33} / \sigma_{0}$ & $\sigma_{12} / \sigma_{0}$ & $\sigma_{23} / \sigma_{0}$ & $\sigma_{31} / \sigma_{0}$ & $\sigma_{e q} / \sigma_{0}$ \\
\hline-1.00 & $6.88 \mathrm{E}-01$ & $2.61 \mathrm{E}+00$ & $8.40 \mathrm{E}-01$ & $2.97 \mathrm{E}-01$ & $8.46 \mathrm{E}-01$ & $-3.61 \mathrm{E}-02$ & $2.42 \mathrm{E}+00$ \\
-0.75 & $5.50 \mathrm{E}-01$ & $2.31 \mathrm{E}+00$ & $9.55 \mathrm{E}-01$ & $5.39 \mathrm{E}-01$ & $5.72 \mathrm{E}-01$ & $-4.10 \mathrm{E}-02$ & $2.10 \mathrm{E}+00$ \\
-0.50 & $6.47 \mathrm{E}-01$ & $2.25 \mathrm{E}+00$ & $9.78 \mathrm{E}-01$ & $5.06 \mathrm{E}-01$ & $3.46 \mathrm{E}-01$ & $-4.15 \mathrm{E}-02$ & $1.81 \mathrm{E}+00$ \\
-0.25 & $6.63 \mathrm{E}-01$ & $2.27 \mathrm{E}+00$ & $1.01 \mathrm{E}+00$ & $5.62 \mathrm{E}-01$ & $5.43 \mathrm{E}-02$ & $-5.75 \mathrm{E}-02$ & $1.77 \mathrm{E}+00$ \\
0.00 & $7.03 \mathrm{E}-01$ & $2.33 \mathrm{E}+00$ & $1.06 \mathrm{E}+00$ & $5.71 \mathrm{E}-01$ & $-1.53 \mathrm{E}-01$ & $-6.19 \mathrm{E}-02$ & $1.80 \mathrm{E}+00$ \\
0.25 & $7.14 \mathrm{E}-01$ & $2.33 \mathrm{E}+00$ & $1.06 \mathrm{E}+00$ & $6.00 \mathrm{E}-01$ & $-3.51 \mathrm{E}-01$ & $-6.50 \mathrm{E}-02$ & $1.91 \mathrm{E}+00$ \\
0.50 & $7.37 \mathrm{E}-01$ & $2.35 \mathrm{E}+00$ & $1.06 \mathrm{E}+00$ & $5.75 \mathrm{E}-01$ & $-6.61 \mathrm{E}-01$ & $-7.19 \mathrm{E}-02$ & $2.12 \mathrm{E}+00$ \\
0.75 & $6.91 \mathrm{E}-01$ & $2.40 \mathrm{E}+00$ & $1.04 \mathrm{E}+00$ & $6.16 \mathrm{E}-01$ & $-7.42 \mathrm{E}-01$ & $-6.00 \mathrm{E}-02$ & $2.29 \mathrm{E}+00$ \\
1.00 & $7.74 \mathrm{E}-01$ & $2.47 \mathrm{E}+00$ & $8.08 \mathrm{E}-01$ & $3.82 \mathrm{E}-01$ & $-8.03 \mathrm{E}-01$ & $-2.39 \mathrm{E}-02$ & $2.28 \mathrm{E}+00$ \\
\hline
\end{tabular}

(b) Anisotropic

Table 3.5: Stress components along $\overline{A C B}$ in the $C u$ material of a $C u-A l_{2} \mathrm{O}_{3}$ bimaterial plate with a circular hole at the interface 


\begin{tabular}{|c|c|c|c|c|c|c|c|c|}
\cline { 3 - 8 } \multicolumn{2}{c|}{} & $\sigma_{11}$ & $\sigma_{22}$ & $\sigma_{33}$ & $\sigma_{12}$ & $\sigma_{23}$ & $\sigma_{31}$ & $\sigma_{e q}$ \\
\hline $\begin{array}{c}\text { Isotropic } \\
\text { Homogeneous }\end{array}$ & $\begin{array}{c}E=1000 \mathrm{GPa} \\
\nu=0.3\end{array}$ & $4.65 \mathrm{E}-01$ & $1.59 \mathrm{E}+00$ & $5.15 \mathrm{E}-02$ & $4.63 \mathrm{E}-03$ & $0.00 \mathrm{E}+00$ & $1.05 \mathrm{E}-03$ & $1.38 \mathrm{E}+00$ \\
\hline $\begin{array}{c}\text { Isotropic } \\
\text { Bimaterial }\end{array}$ & $\mathrm{Cu}$ & $6.67 \mathrm{E}-01$ & $1.51 \mathrm{E}+00$ & $4.90 \mathrm{E}-01$ & $9.93 \mathrm{E}-03$ & $5.73 \mathrm{E}-06$ & $-2.75 \mathrm{E}-06$ & $9.42 \mathrm{E}-01$ \\
\hline & $\mathrm{Al}_{2} \mathrm{O}_{3}$ & $1.89 \mathrm{E}-01$ & $1.51 \mathrm{E}+00$ & $-4.66 \mathrm{E}-01$ & $9.93 \mathrm{E}-03$ & $5.73 \mathrm{E}-06$ & $-1.02 \mathrm{E}-05$ & $1.74 \mathrm{E}+00$ \\
\hline $\begin{array}{c}\text { Anisotropic } \\
\text { Bimaterial }\end{array}$ & $\mathrm{Cu}$ & $8.82 \mathrm{E}-01$ & $1.50 \mathrm{E}+00$ & $7.98 \mathrm{E}-01$ & $-2.73 \mathrm{E}-02$ & $1.94 \mathrm{E}-02$ & $-1.16 \mathrm{E}-02$ & $6.63 \mathrm{E}-01$ \\
\cline { 2 - 9 } & $\mathrm{Al}_{2} \mathrm{O}_{3}$ & $-2.19 \mathrm{E}-02$ & $1.50 \mathrm{E}+00$ & $-1.25 \mathrm{E}+00$ & $-2.73 \mathrm{E}-02$ & $1.94 \mathrm{E}-02$ & $-4.27 \mathrm{E}-02$ & $2.38 \mathrm{E}+00$ \\
\hline
\end{tabular}

Table 3.6: Stress components at point $F$ for various material combinations of a plate with a circular hole at the interface; all stresses have been normalized with respect to the applied load, $\sigma_{0}$ 


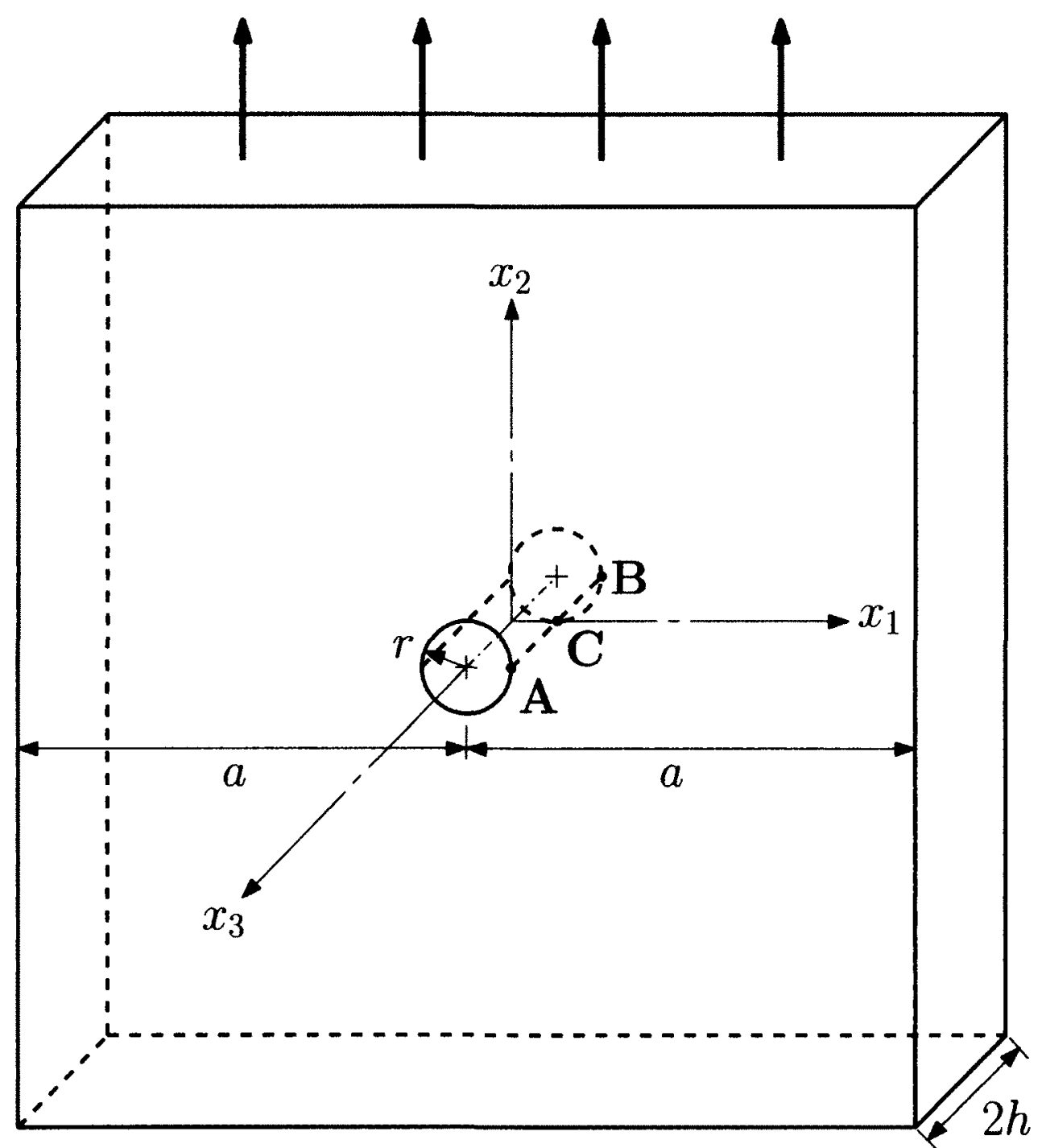

Figure 3.1: Plate in tension with a circular hole; the values of $r / a$ and $h / a$ are both set to $1 / 10$ 


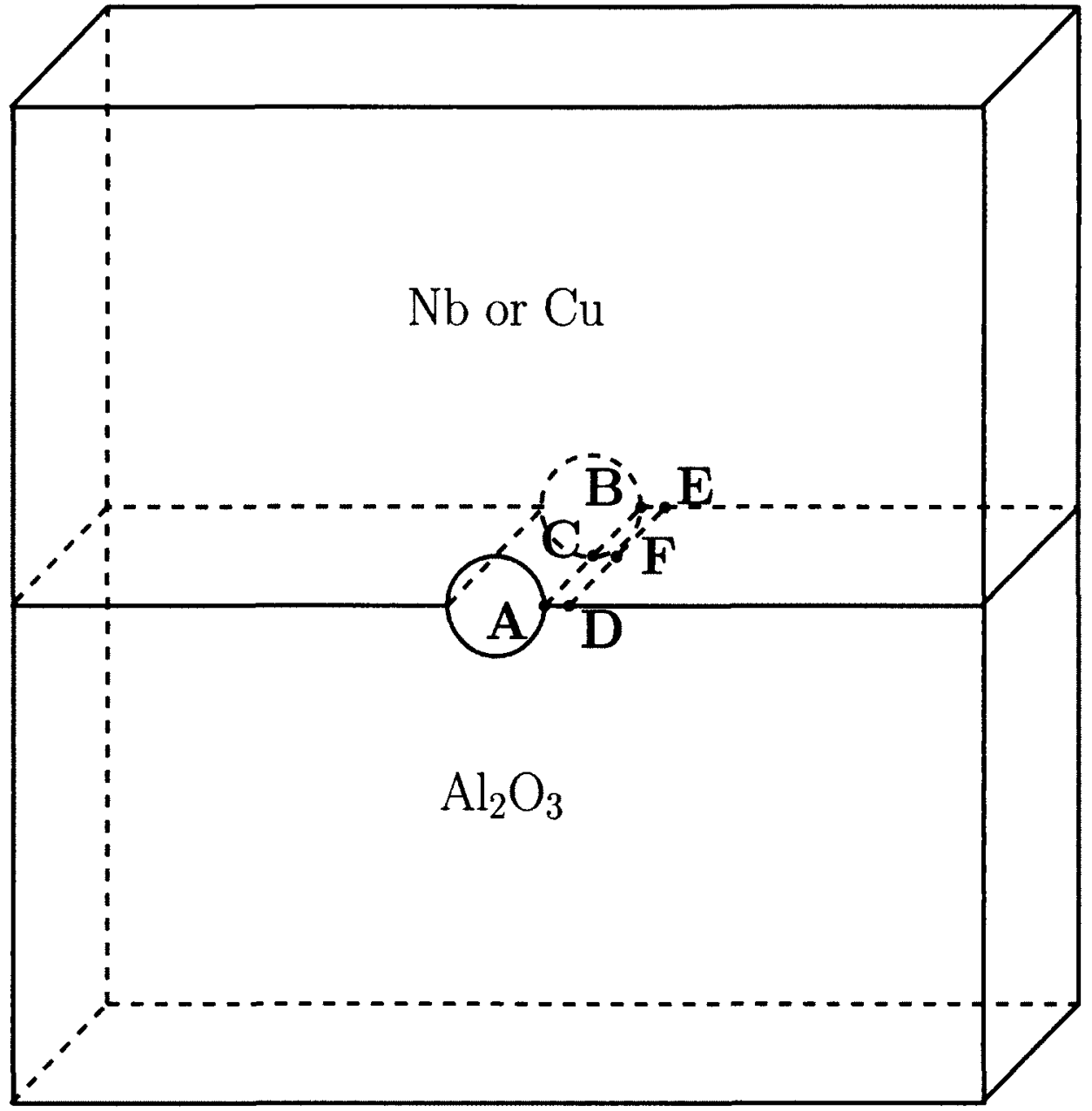

Figure 3.2: Materials regions of a bimaterial plate with a circular hole 


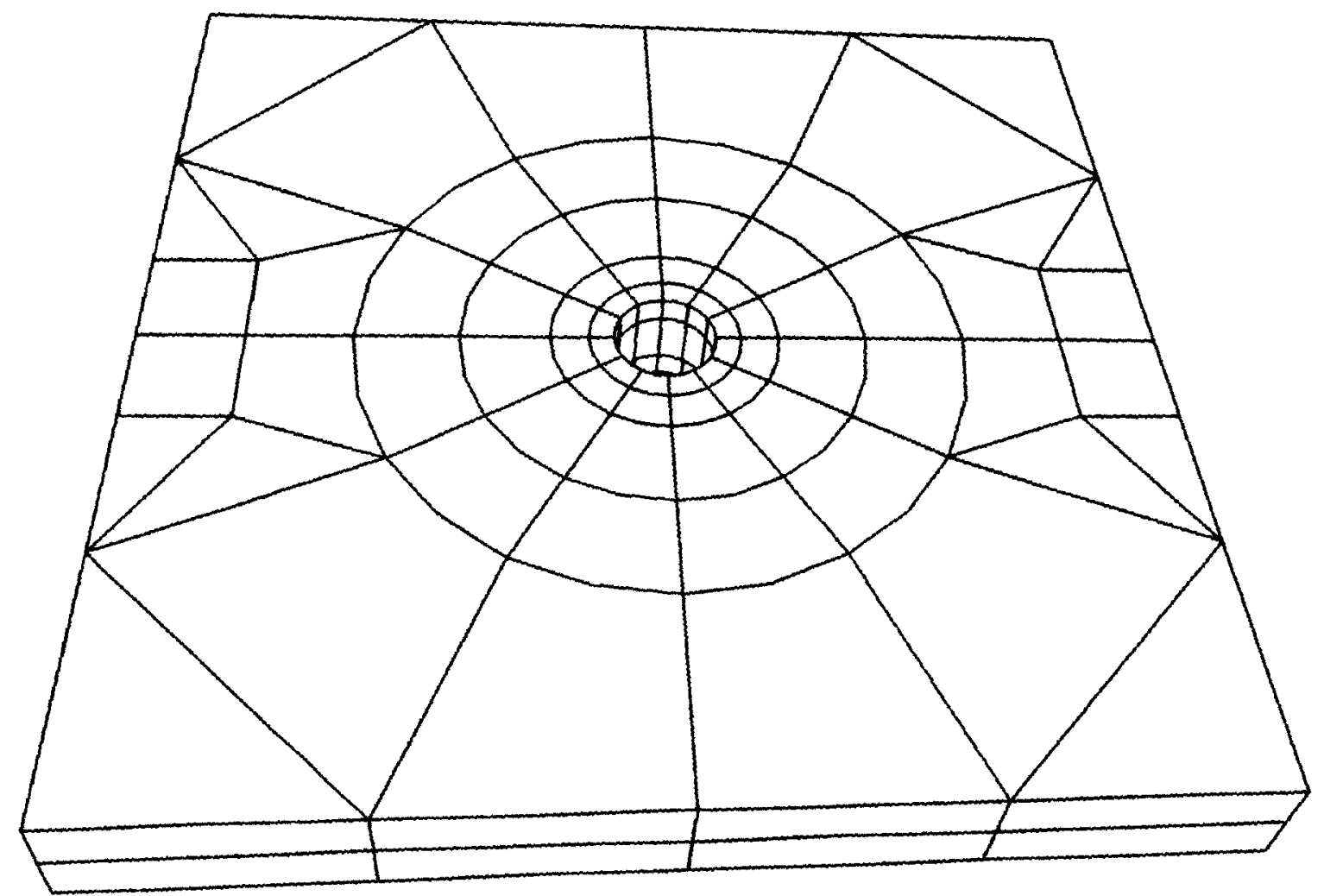

(a) Full Mesh

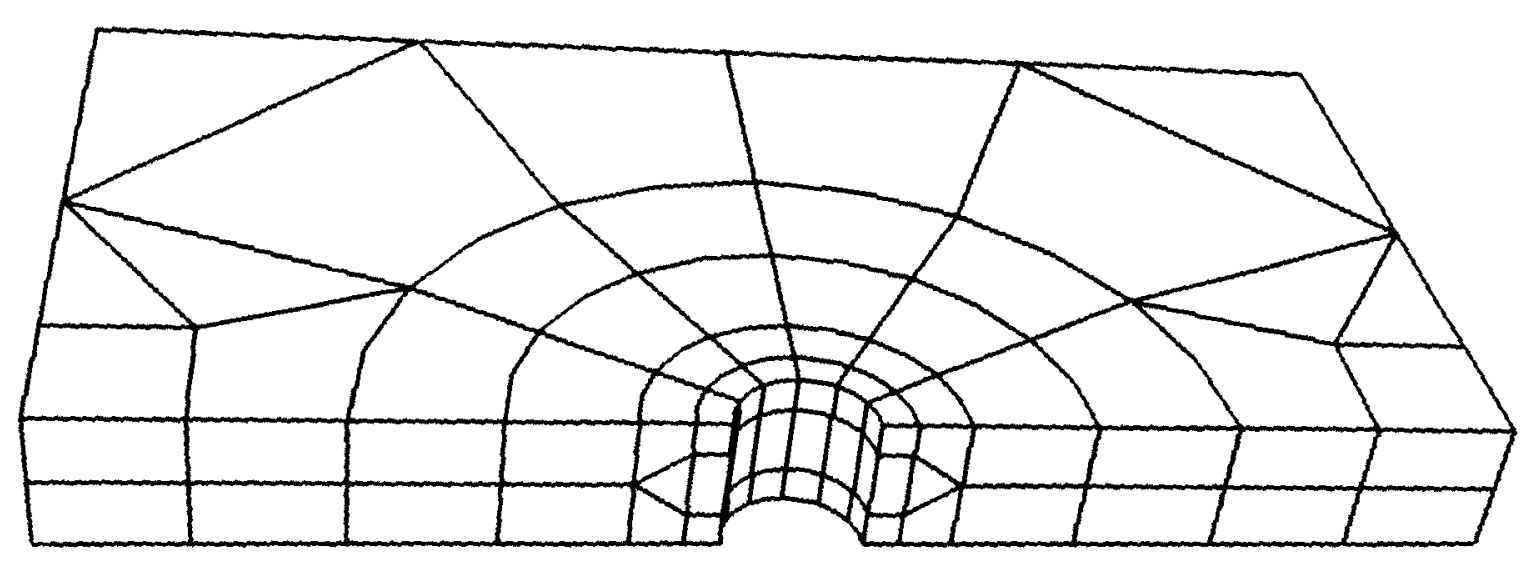

Figure 3.3: $B E M$ mesh (b) Interfacial Mesh elements and 828 nodes) $\mathrm{Nb}_{-} \mathrm{Al}_{2} \mathrm{O}_{3}$ bicrystal plate with a circular hole (284 


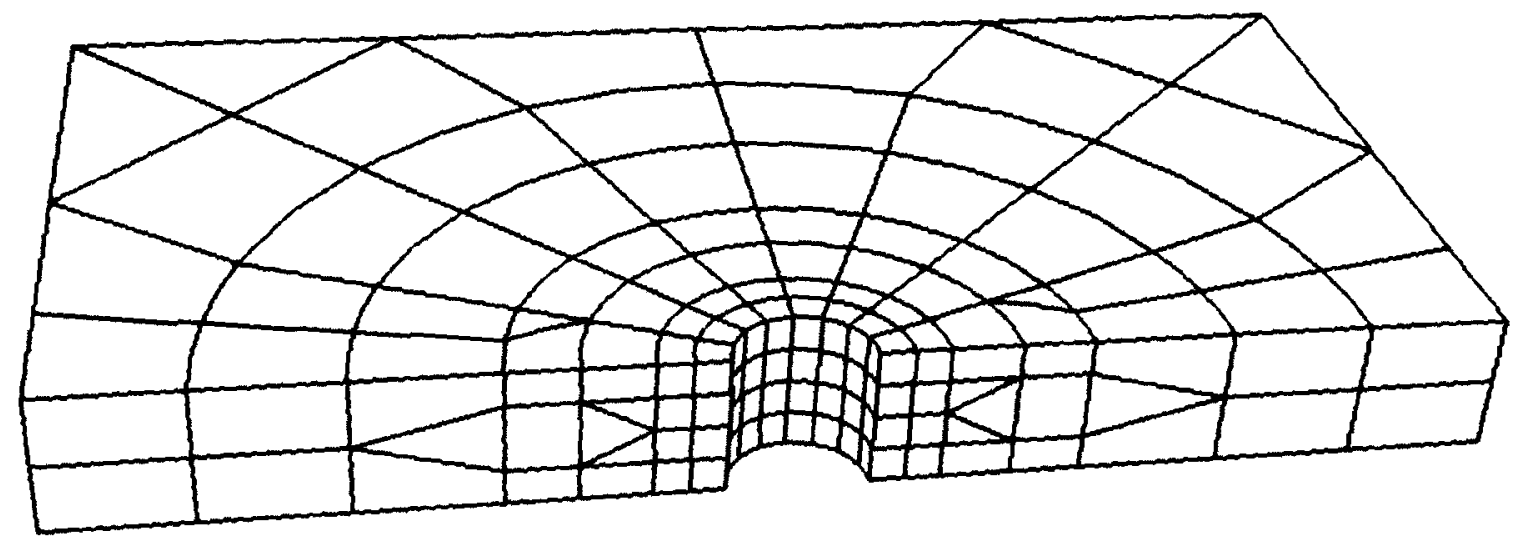

Figure 3.4: $B E M$ interfacial mesh of the $C u-A l_{2}$

(full mesh contains 468 elements and 1368 nodes) 


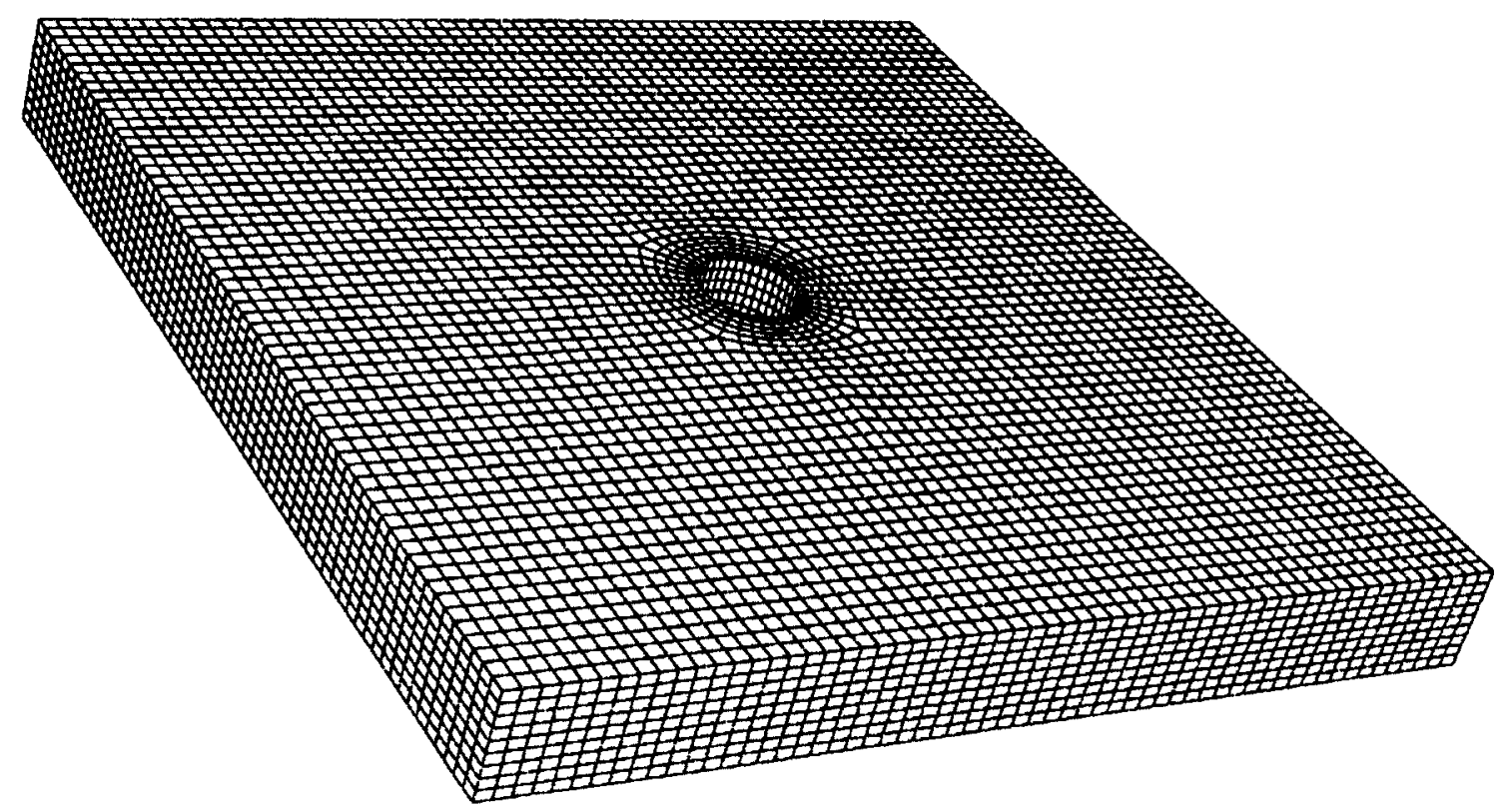

Figure 3.5: FEM mesh of a bimaterial plate with a circular hole (33,300 elements and 148,360$)$

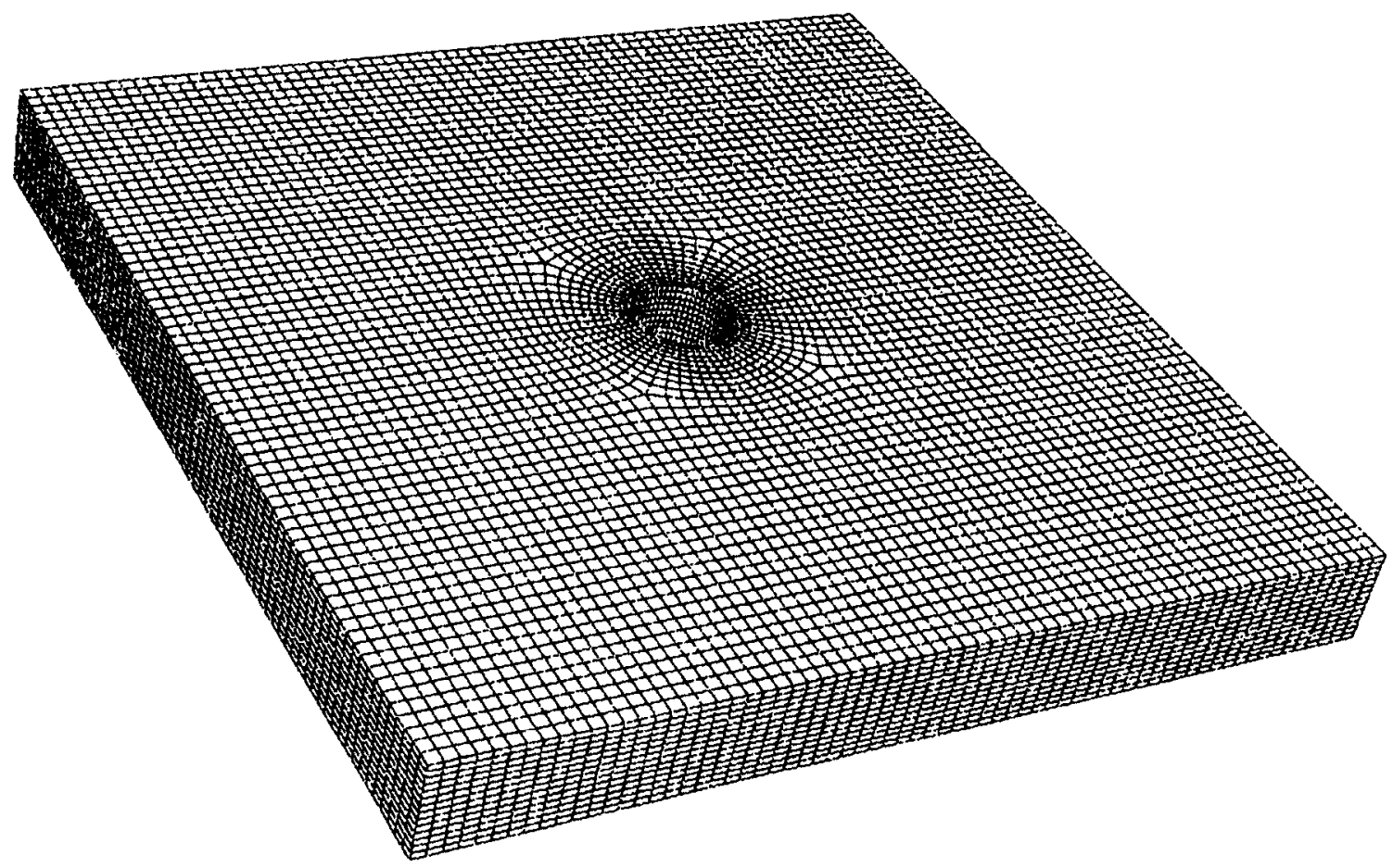

Figure 3.6: FEM refined mesh of a bimaterial plate with a circular hole $(70,000$ elements and 302,304 ) 


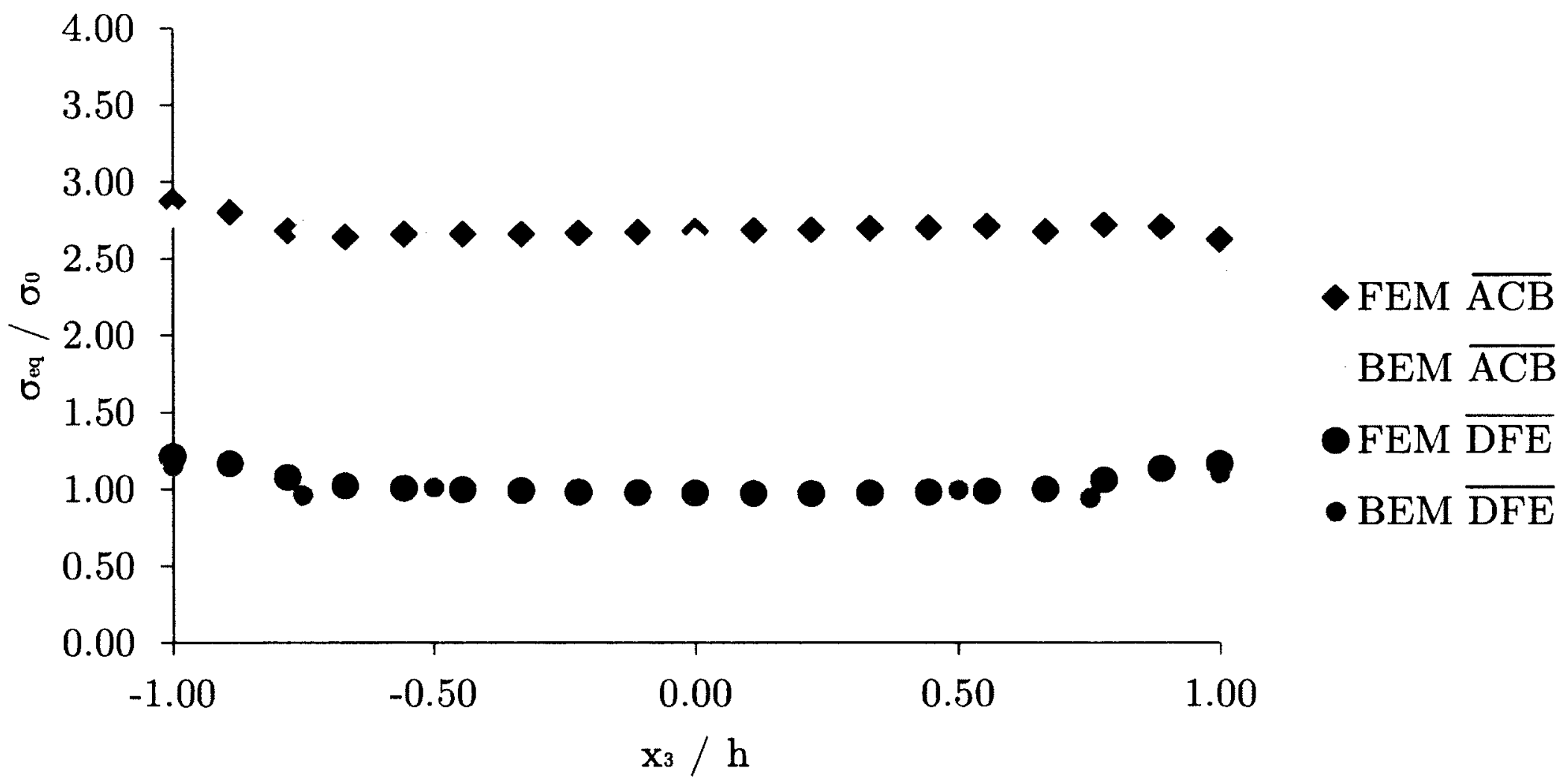

Figure 3.7: Variation of $\sigma_{e q} / \sigma_{0}$ through the thickness at the interface in the $\mathrm{Nb}$ crystal of a $\mathrm{Nb}-\mathrm{Al}_{2} \mathrm{O}_{3}$ bicrystal plate with circular hole 


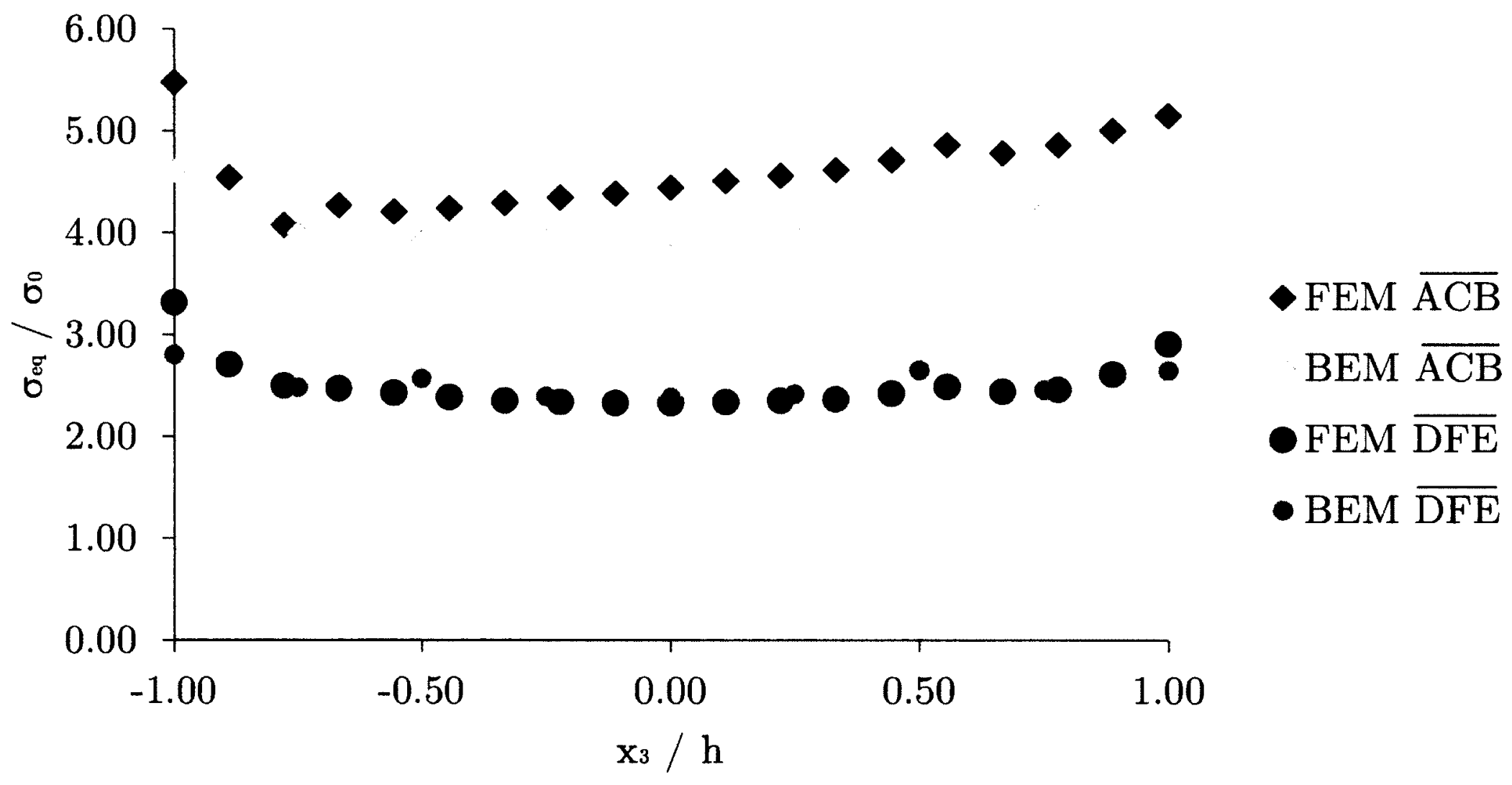

Figure 3.8: Variation of $\sigma_{e q} / \sigma_{0}$ through the thickness at the interface in the $\mathrm{Al}_{2} \mathrm{O}_{3}$ crystal of a $\mathrm{Cu}-\mathrm{Al}_{2} \mathrm{O}_{3}$ bicrystal plate with a circular hole 


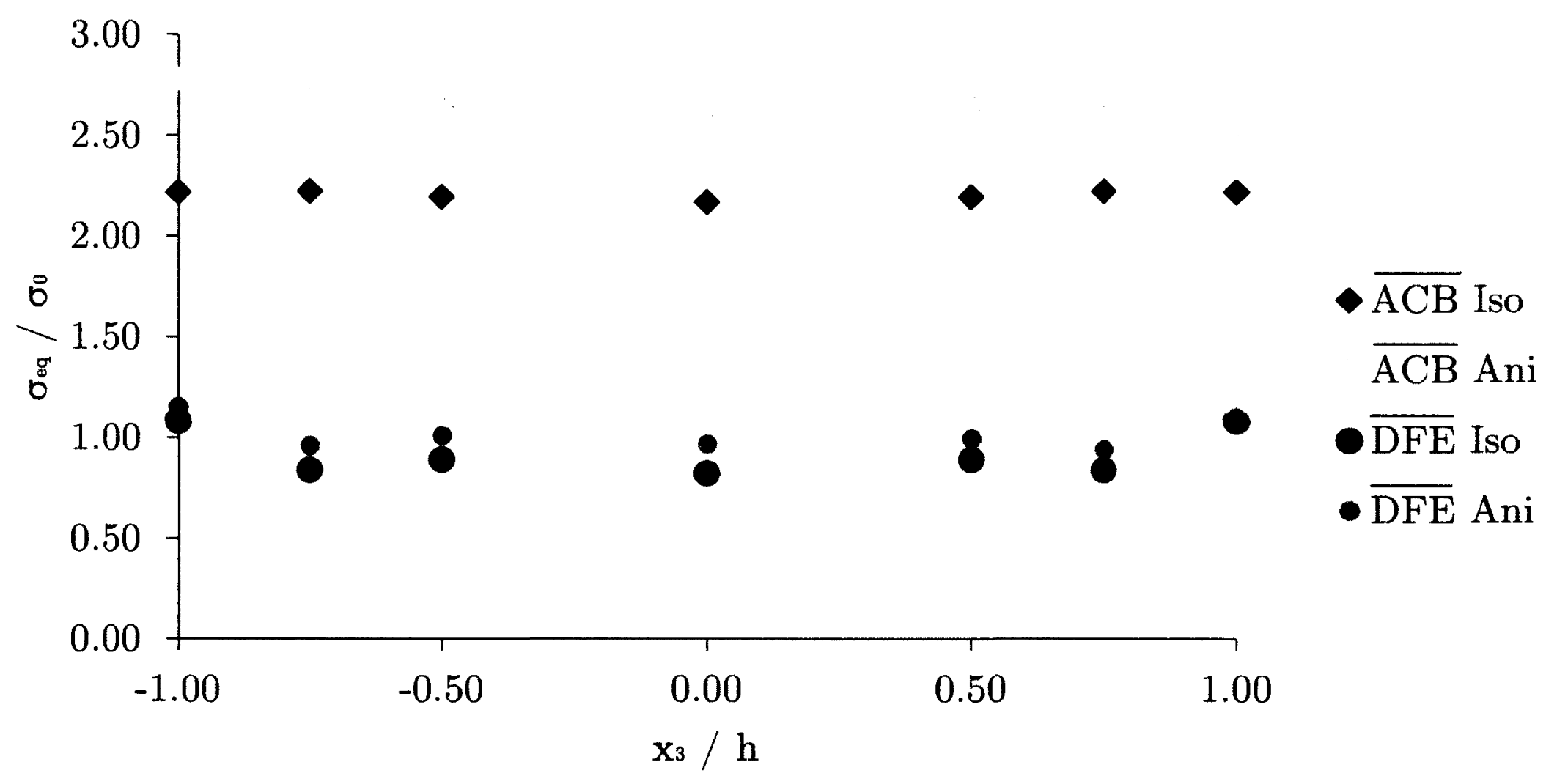

Figure 3.9: Variations of $\sigma_{e q} / \sigma_{0}$ through the thickness at the interface in the $\mathrm{Nb}$ crystal of a $\mathrm{Nb}_{-} \mathrm{Al}_{2} \mathrm{O}_{3}$ bimaterial plate with circular hole - Isotropic (Iso) and Anisotropic (Ani) 


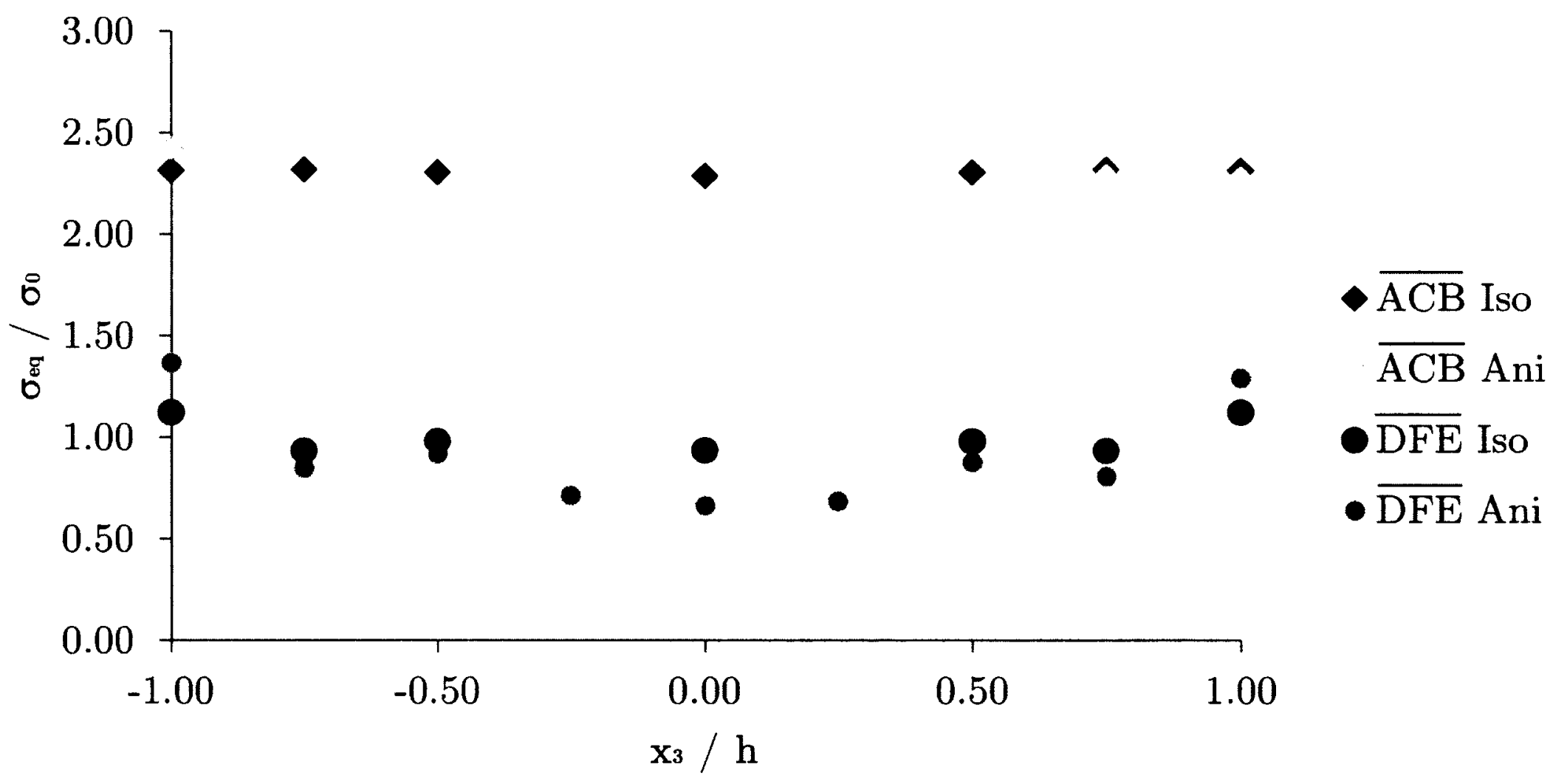

Figure 3.10: Variations of $\sigma_{e q} / \sigma_{0}$ through the thickness at the interface in the $\mathrm{Cu}$ crystal of a $\mathrm{Cu}-\mathrm{Al}_{2} \mathrm{O}_{3}$ bimaterial plate with circular hole - Isotropic (Iso) and Anisotropic (Ani) 


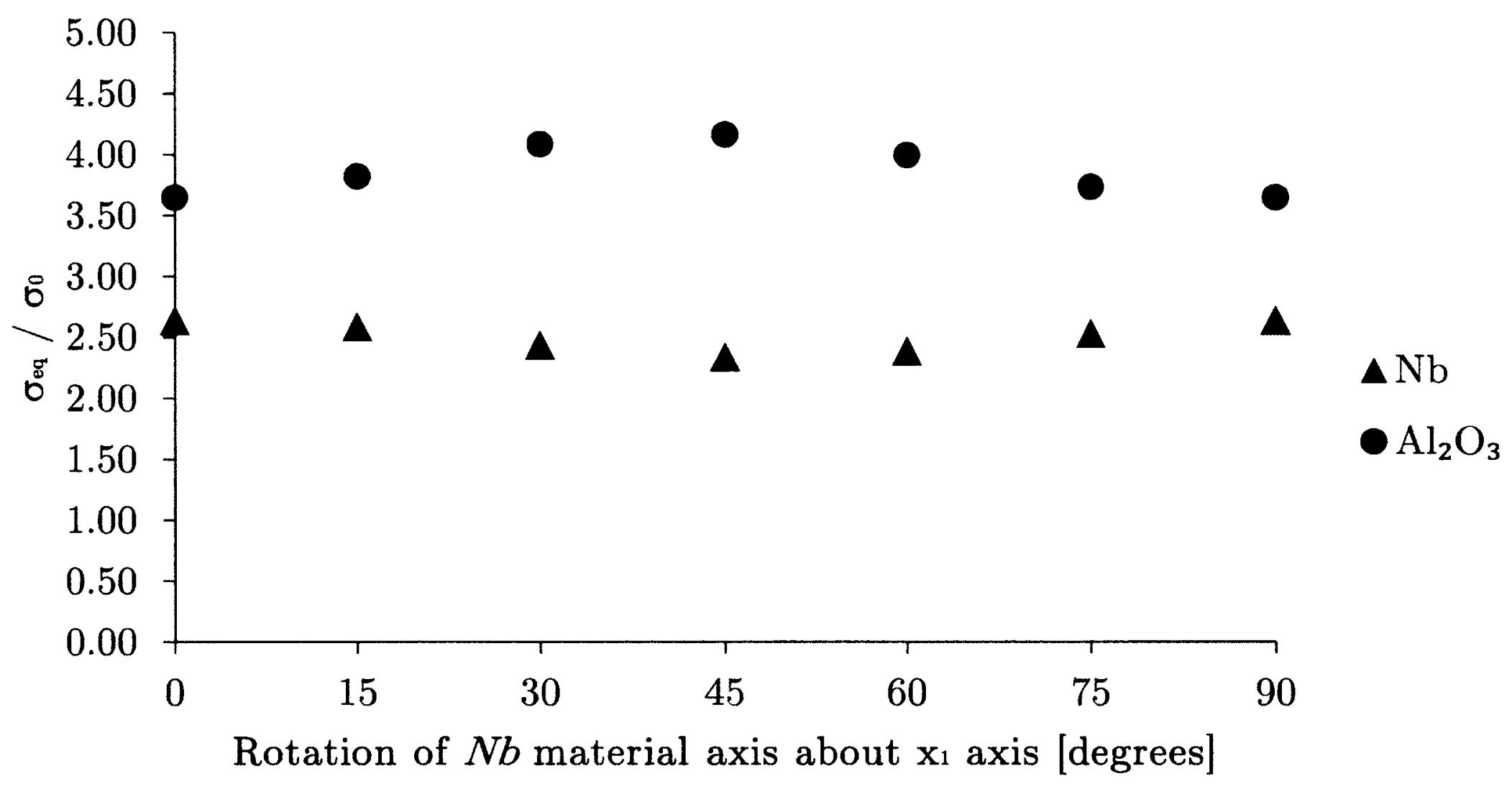

Figure 3.11: Variation of $\sigma_{e q} / \sigma_{0}$ at point $\mathrm{C}$ of a $\mathrm{Nb}-\mathrm{Al}_{2} \mathrm{O}_{3}$ bicrystal plate with a circular hole for $x_{1}$-material axis rotations of the $\mathrm{Nb}$ crystal 


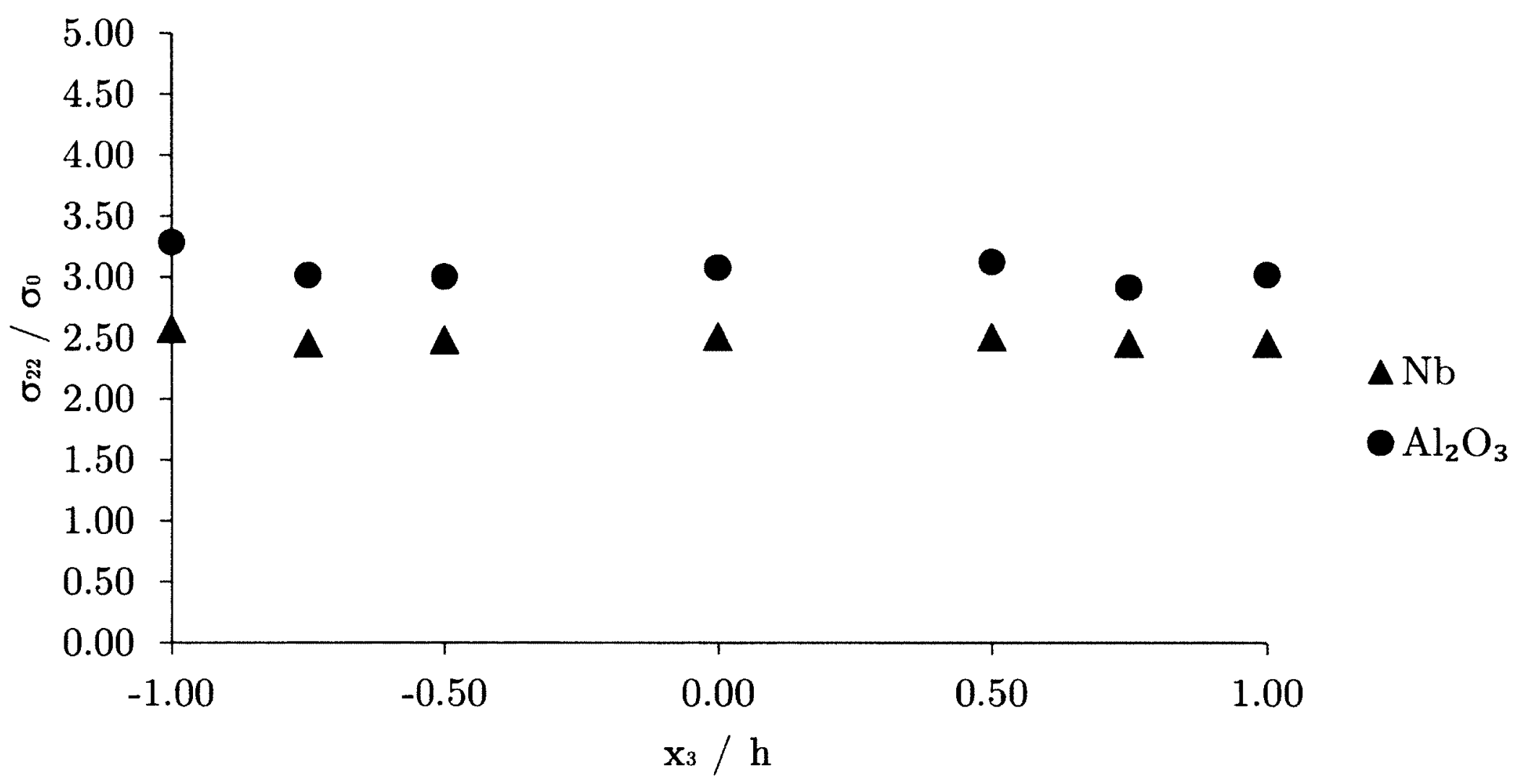

Figure 3.12: Variation of $\sigma_{22} / \sigma_{0}$ through the thickness along $\overline{\mathrm{ACB}}$ at the interface of a $\mathrm{Nb}-\mathrm{Al}_{2} \mathrm{O}_{3}$ bicrystal plate with circular hole for a $\mathrm{Nb} x_{3}$-material axis rotation of $45^{\circ}$ 


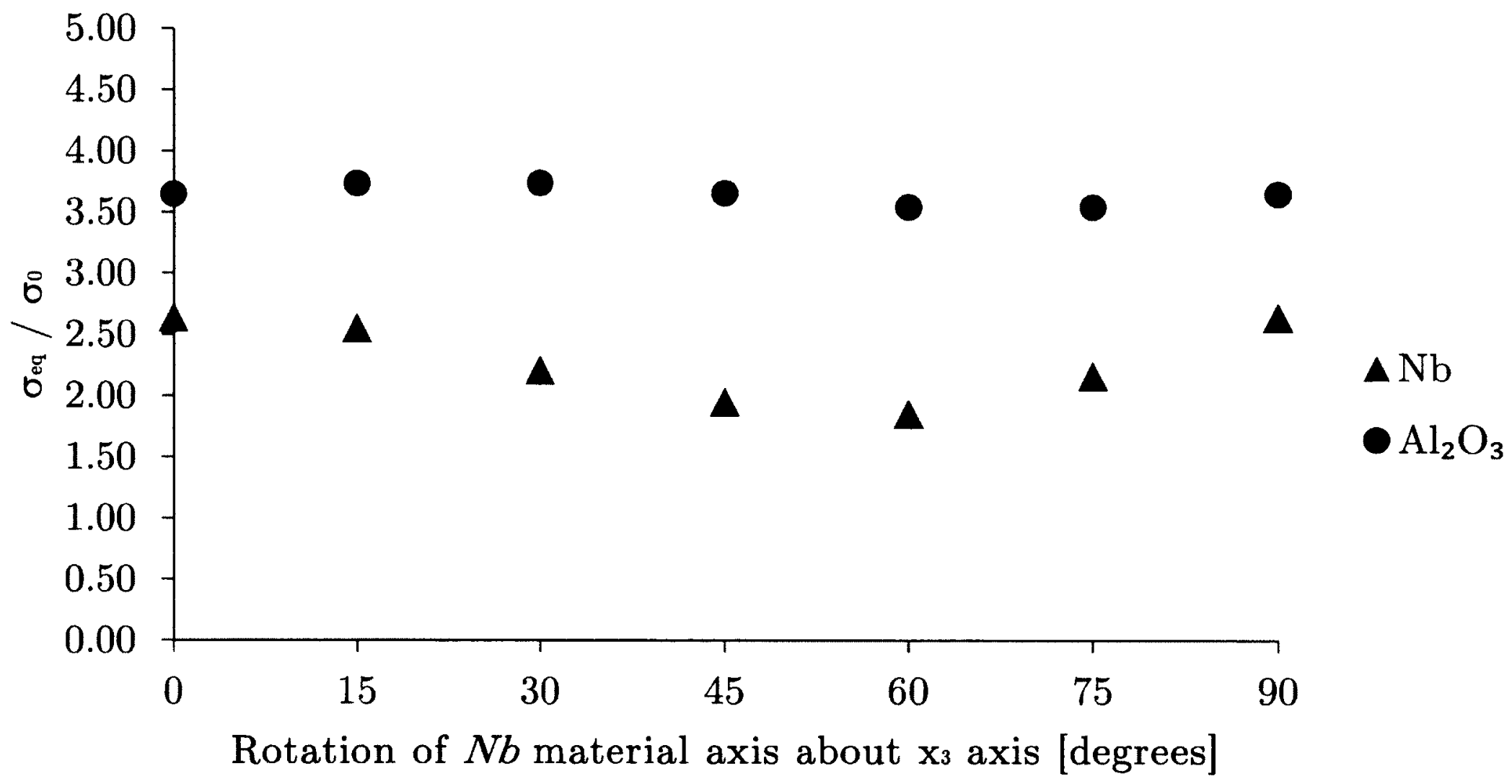

Figure 3.13: Variation of $\sigma_{e q} / \sigma_{0}$ at point $\mathrm{C}$ of a $\mathrm{Nb}-\mathrm{Al}_{2} \mathrm{O}_{3}$ bicrystal plate with a circular hole for $x_{3}$-material axis rotations of the $\mathrm{Al}_{2} \mathrm{O}_{3}$ crystal 


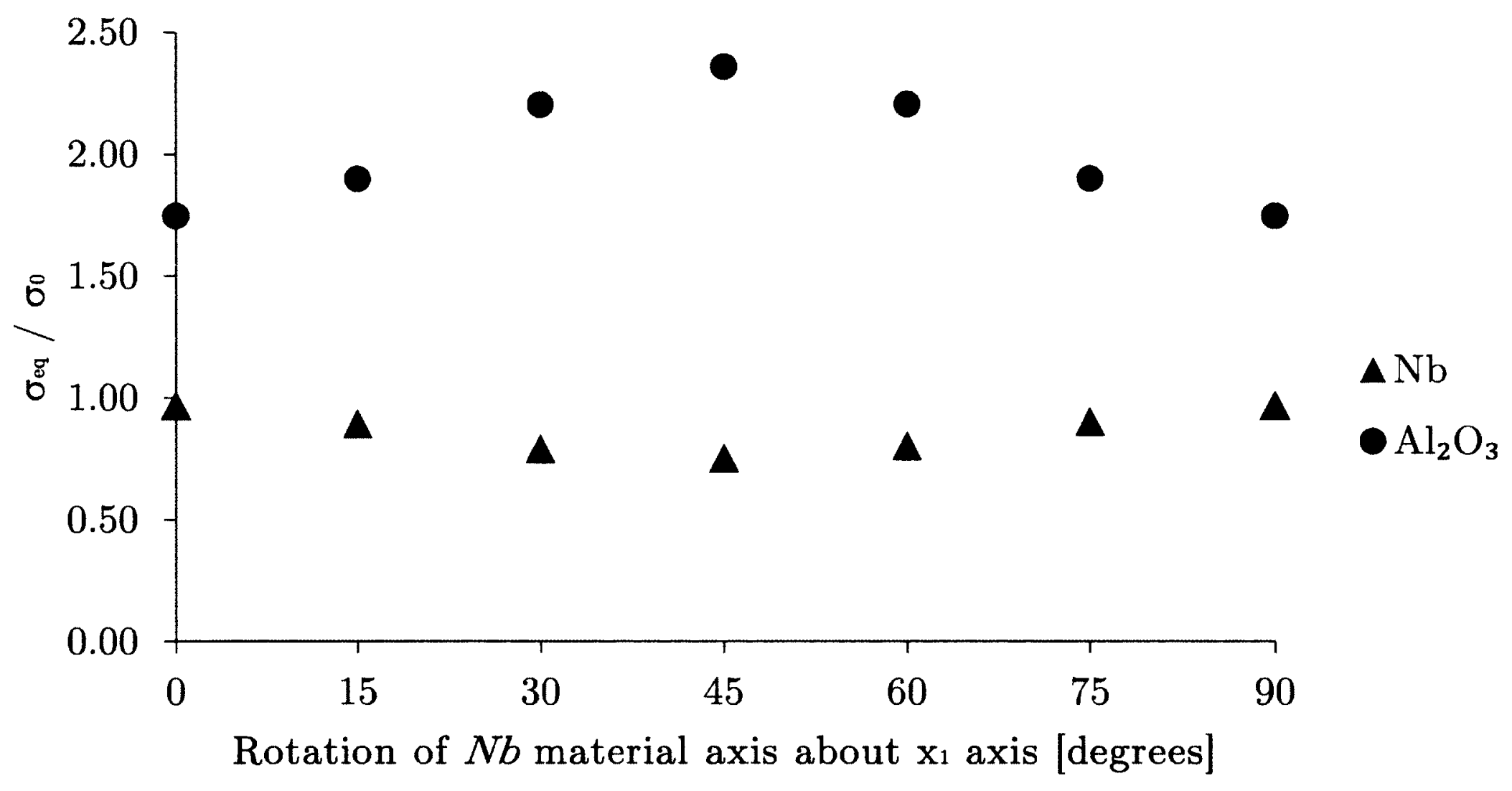

Figure 3.14: Variation of $\sigma_{e q} / \sigma_{0}$ at point $\mathrm{F}$ of a $\mathrm{Nb}-\mathrm{Al}_{2} \mathrm{O}_{3}$ bicrystal plate with a circular hole for $x_{1}$-material axis rotations of the $N b$ crystal 


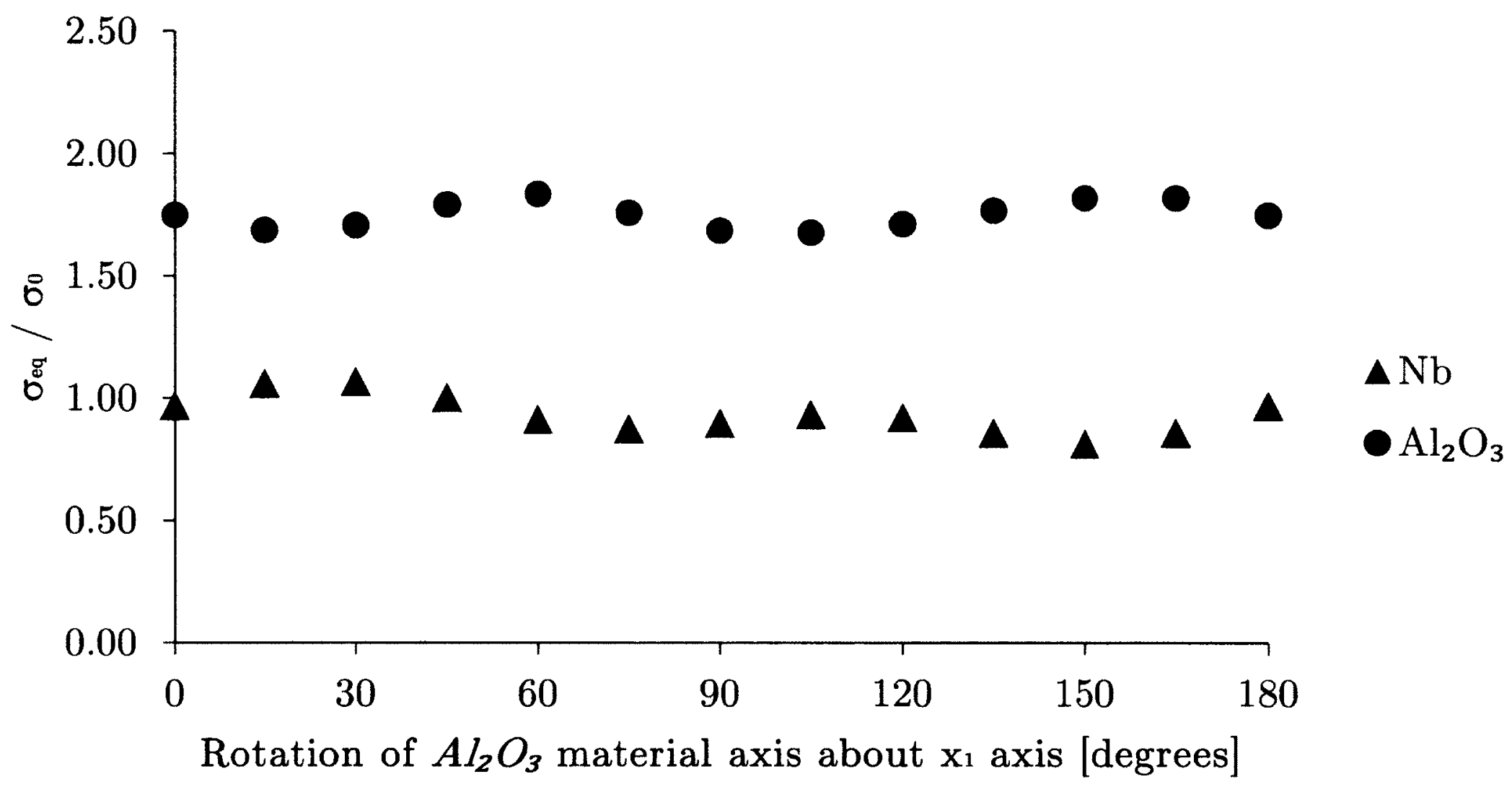

Figure 3.15: Variation of $\sigma_{e q} / \sigma_{0}$ at point $\mathrm{F}$ of a $\mathrm{Nb}-\mathrm{Al}_{2} \mathrm{O}_{3}$ bicrystal plate with a circular hole for $x_{1}$-material axis rotations of the $\mathrm{Al}_{2} \mathrm{O}_{3}$ crystal 


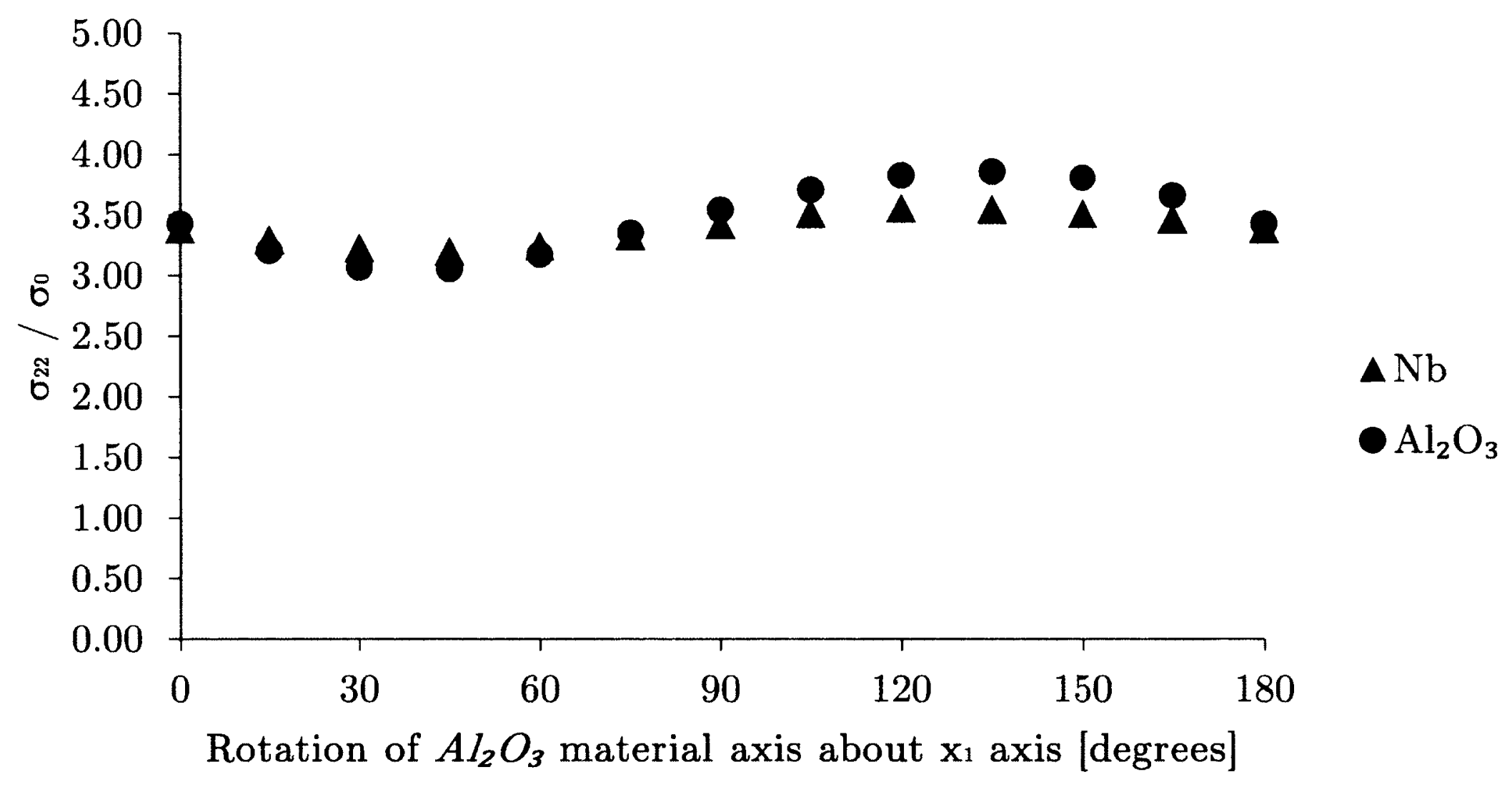

Figure 3.16: Variation of $\sigma_{22} / \sigma_{0}$ at point $\mathrm{C}$ of a $\mathrm{Nb}-\mathrm{Al}_{2} \mathrm{O}_{3}$ bicrystal plate with a circular hole for $x_{1}$-material axis rotations of the $\mathrm{Al}_{2} \mathrm{O}_{3}$ crystal 


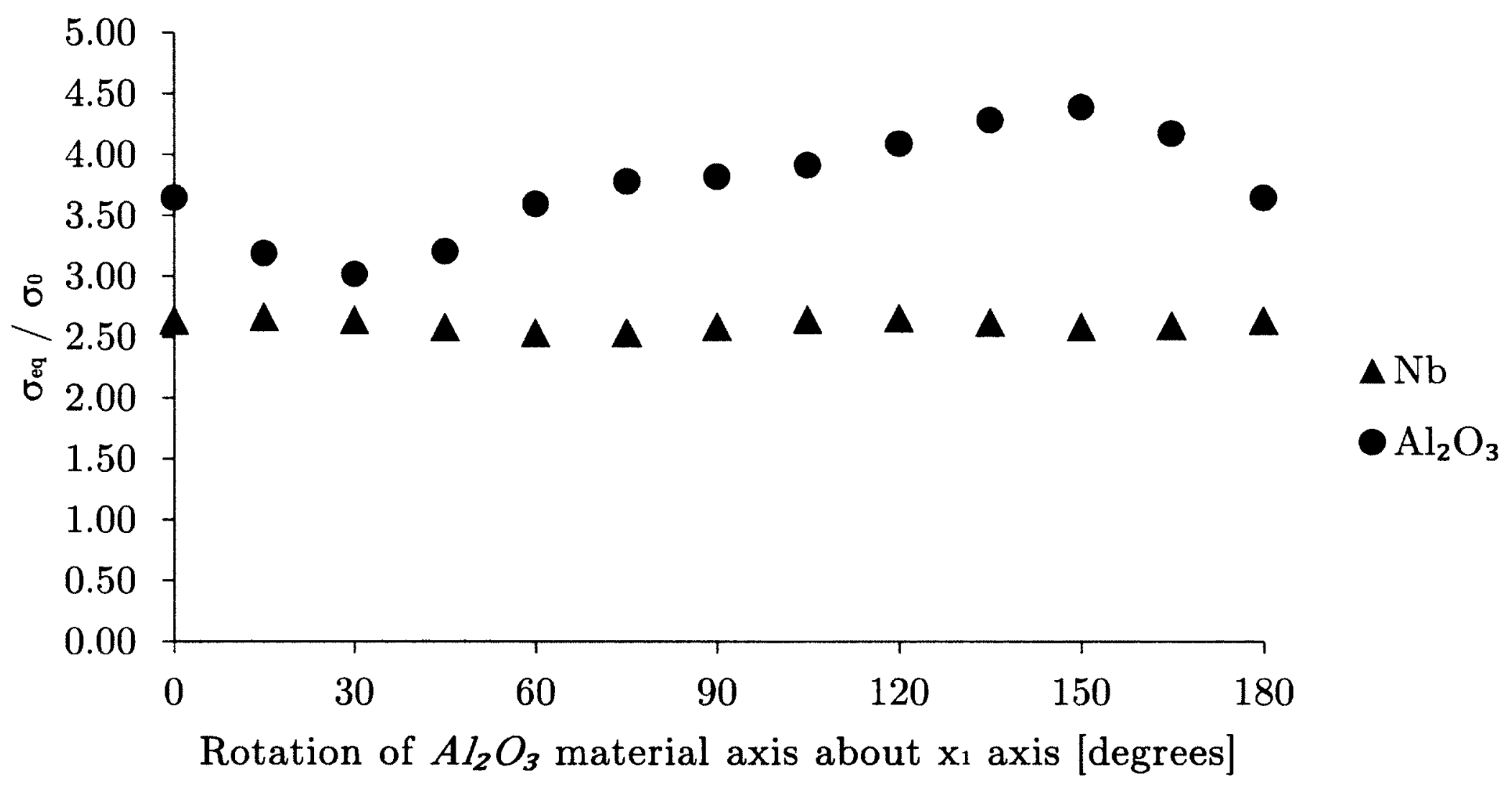

Figure 3.17: Variation of $\sigma_{e q} / \sigma_{0}$ at point $\mathrm{C}$ of a $\mathrm{Nb}-\mathrm{Al}_{2} \mathrm{O}_{3}$ bicrystal plate with a circular hole for $x_{1}$-material axis rotations of the $\mathrm{Al}_{2} \mathrm{O}_{3}$ crystal 


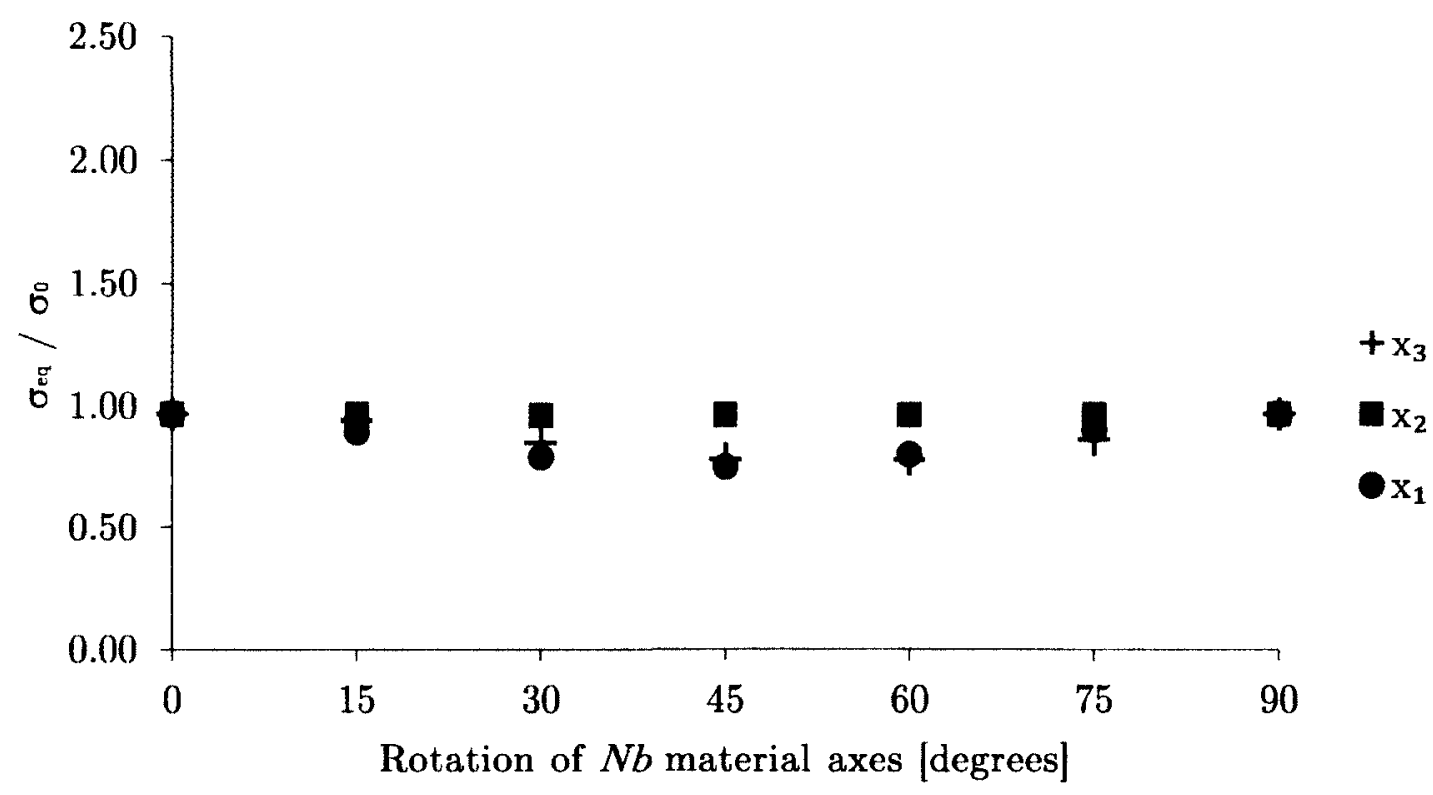

(a) Rotations of the $N b$ crystal

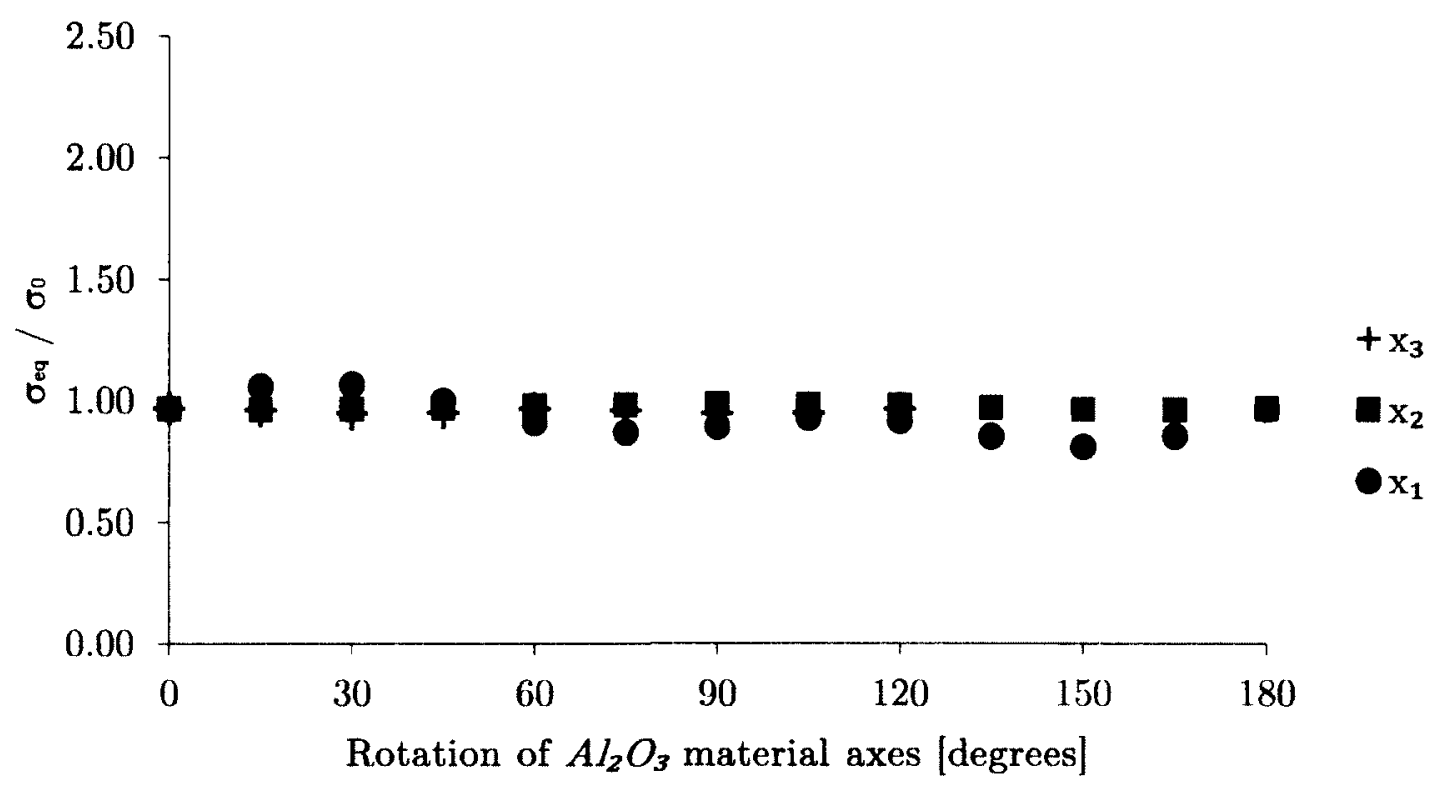

(b) Rotations of the $\mathrm{Al}_{2} \mathrm{O}_{3}$ crystal

Figure 3.18: Variation of $\sigma_{e q} / \sigma_{0}$ at point $\mathrm{F}$ in the $\mathrm{Nb}$ crystal of a $\mathrm{Nb}-\mathrm{Al}_{2} \mathrm{O}_{3}$ bicrystal plate with a circular hole for $x_{1}, x_{2}$, and $x_{3}$-material axis rotations 


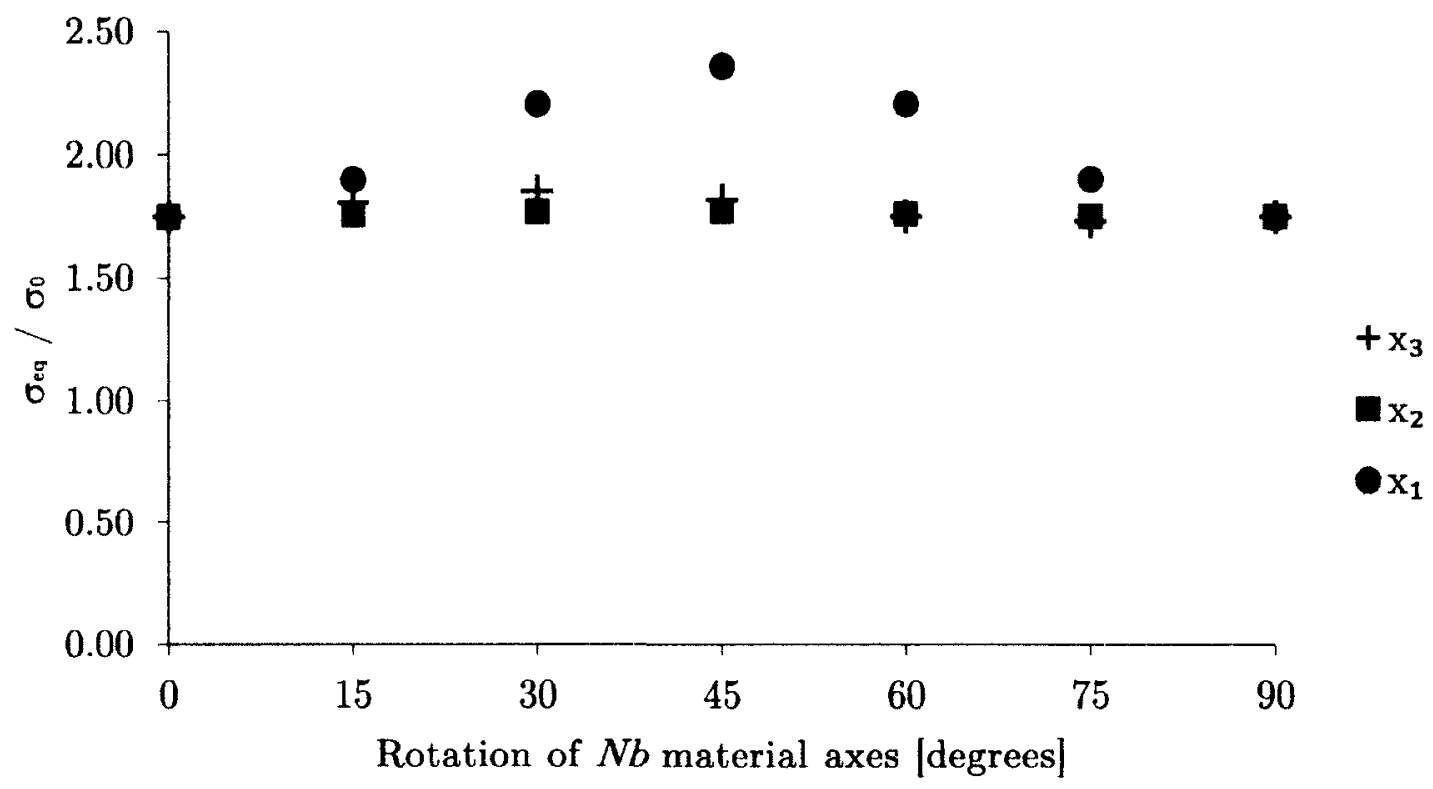

(a) Rotations of the $N b$ crystal

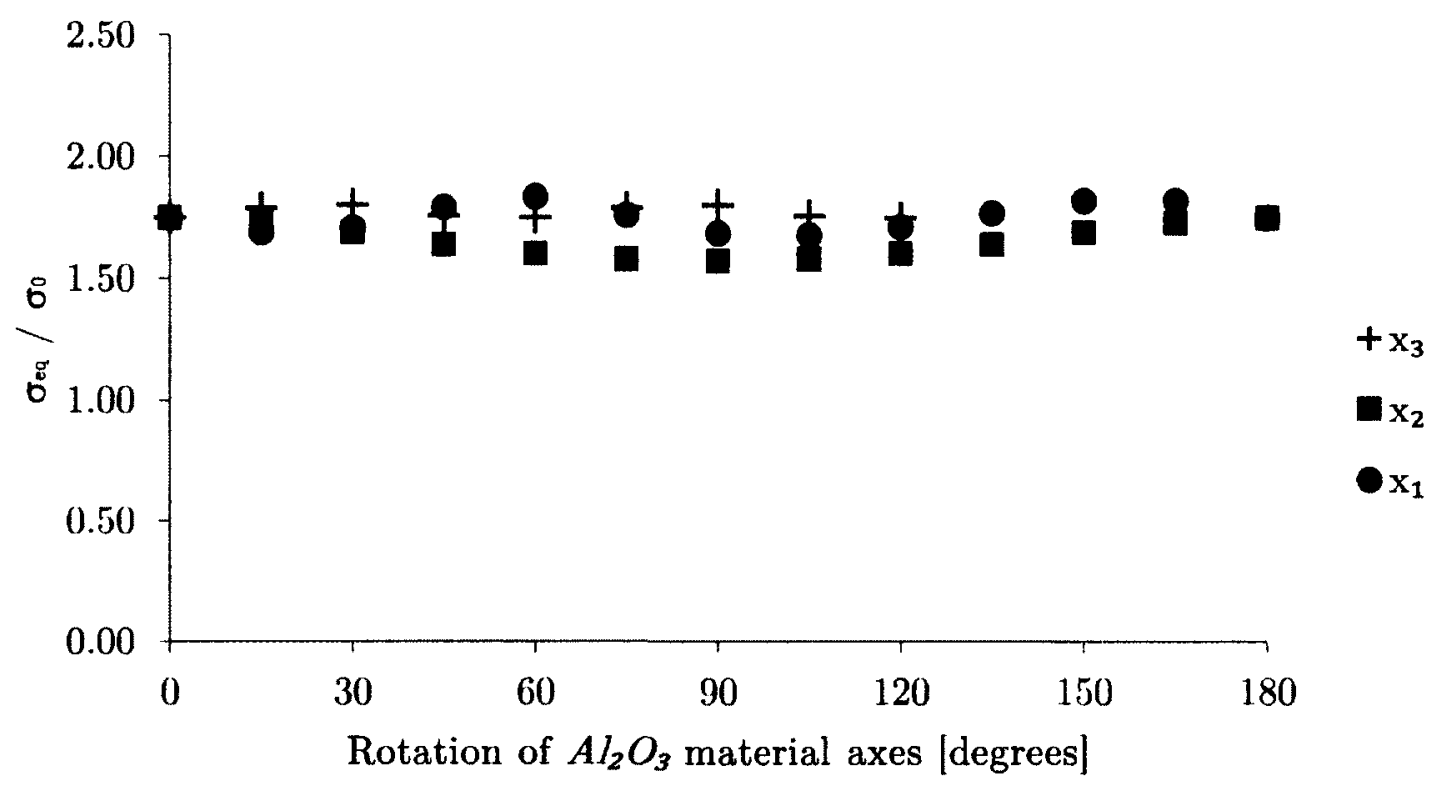

(b) Rotations of the $\mathrm{Al}_{2} \mathrm{O}_{3}$ crystal

Figure 3.19: Variation of $\sigma_{e q} / \sigma_{0}$ at point $\mathrm{F}$ in the $\mathrm{Al}_{2} \mathrm{O}_{3}$ crystal of a $\mathrm{Nb}-\mathrm{Al}_{2} \mathrm{O}_{3}$ bicrystal plate with a circular hole for $x_{1}, x_{2}$, and $x_{3}$-material axis rotations 


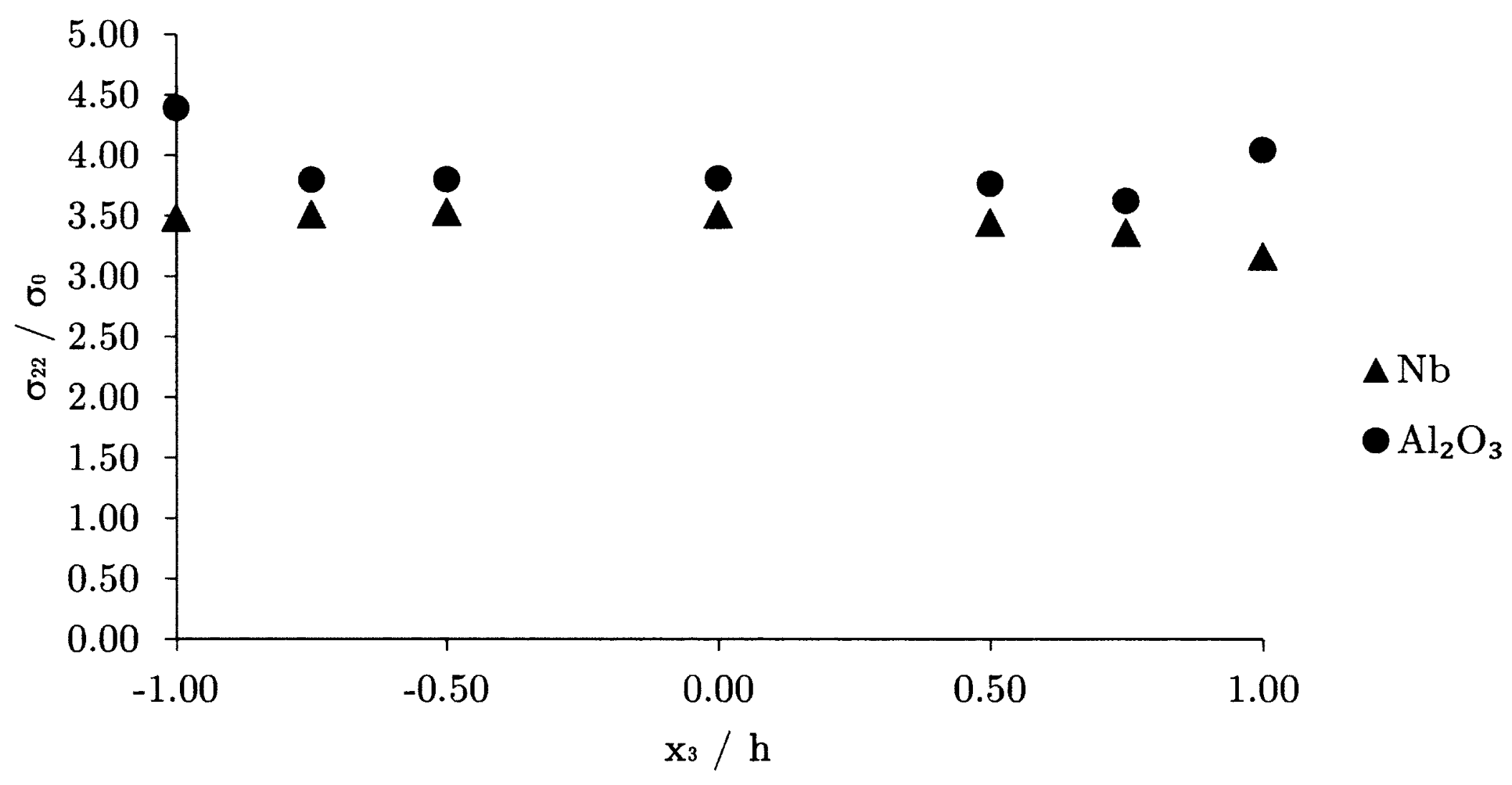

Figure 3.20: Variation of $\sigma_{22} / \sigma_{0}$ through the thickness along $\overline{A C B}$ at the interface of a $\mathrm{Nb}_{-} \mathrm{Al}_{2} \mathrm{O}_{3}$ bicrystal plate with circular hole for an $\mathrm{Al}_{2} \mathrm{O}_{3} x_{1}$-material axis rotation of $150^{\circ}$ 


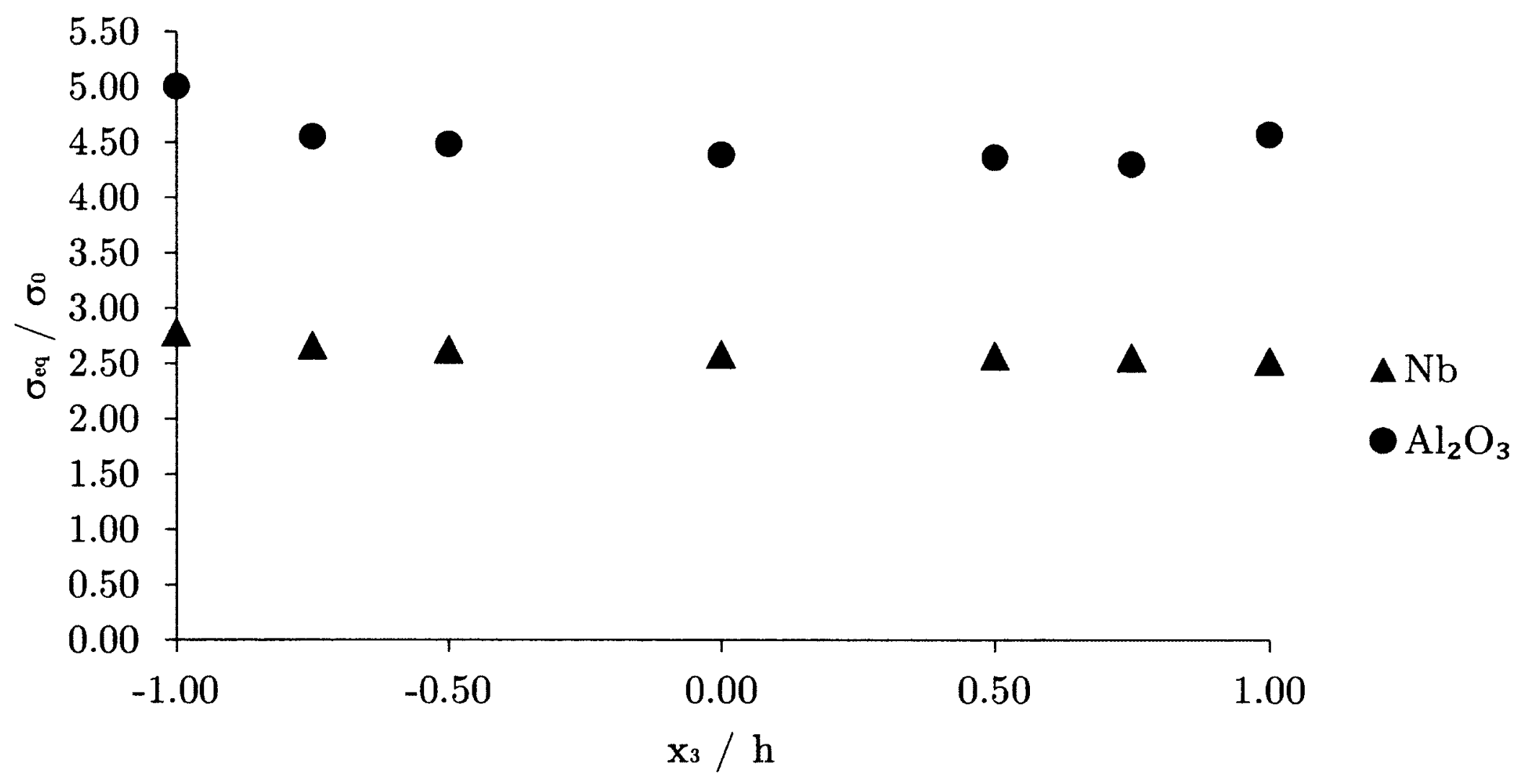

Figure 3.21: Variation of $\sigma_{e q} / \sigma_{0}$ through the thickness along $\overline{A C B}$ at the interface of a $\mathrm{Nb}_{-} \mathrm{Al}_{2} \mathrm{O}_{3}$ bicrystal plate with circular hole for a $\mathrm{Al}_{2} \mathrm{O}_{3} x_{1}$-material axis rotation of $150^{\circ}$ 


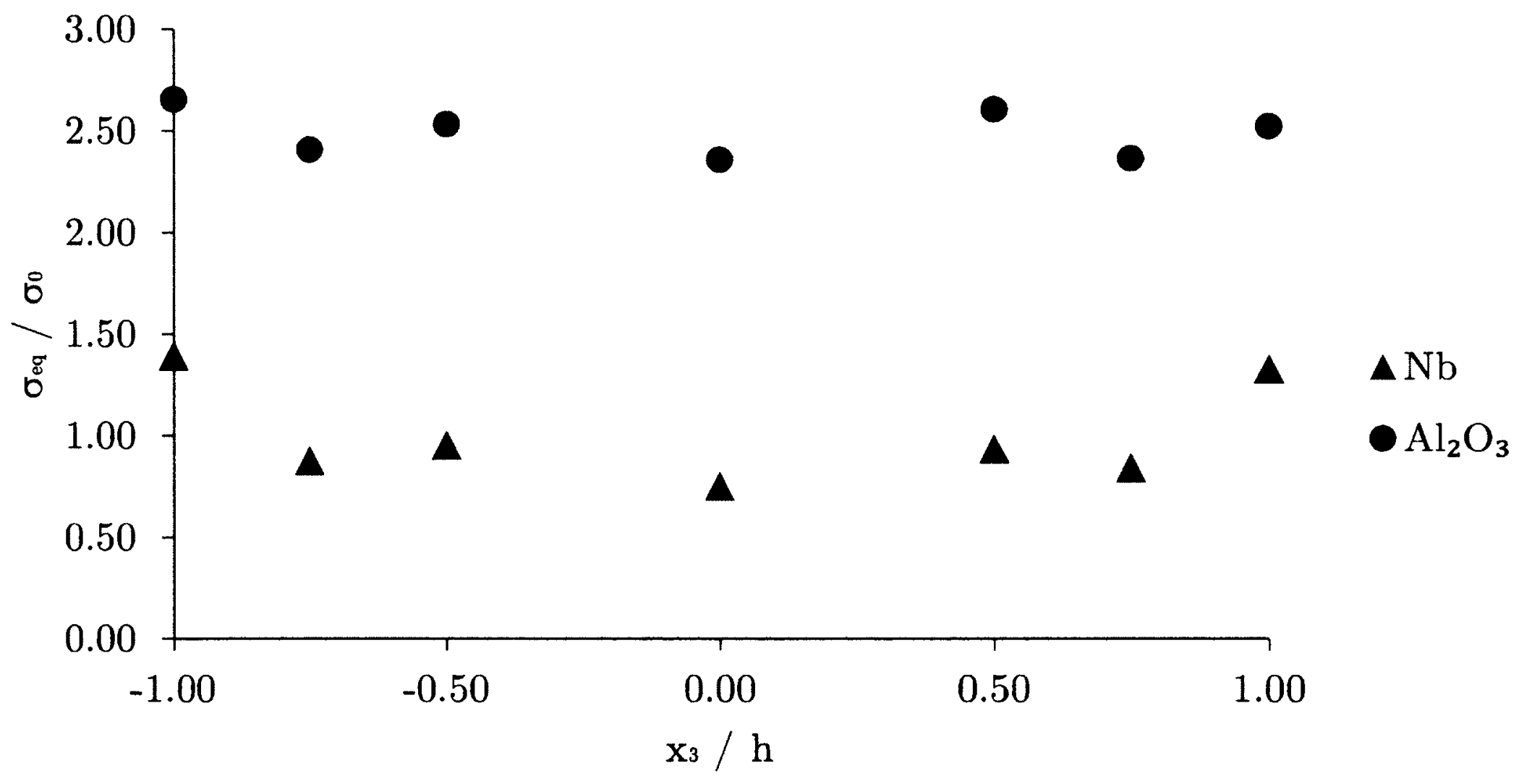

Figure 3.22: Variation of $\sigma_{e q} / \sigma_{0}$ through the thickness along $\overline{D F E}$ at the interface of a $\mathrm{Nb}_{-} \mathrm{Al}_{2} \mathrm{O}_{3}$ bicrystal plate with circular hole for a $N b x_{1}$-material axis rotation of $45^{\circ}$ 


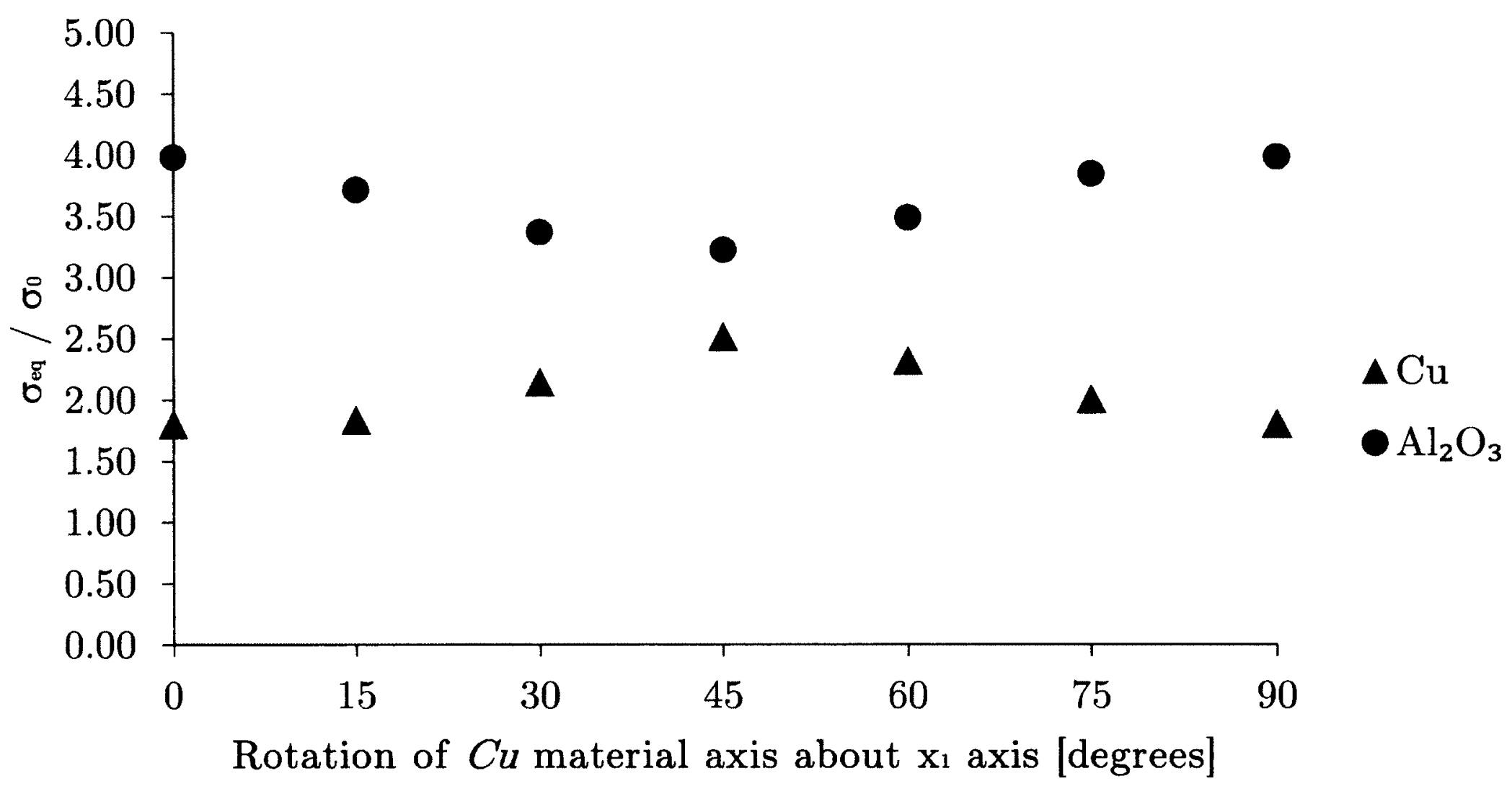

Figure 3.23: Variation of $\sigma_{e q} / \sigma_{0}$ at point $\mathrm{C}$ of a $\mathrm{Cu}-\mathrm{Al}_{2} \mathrm{O}_{3}$ bicrystal plate with a circular hole for $x_{1}$-material axis rotations of the $C u$ crystal 


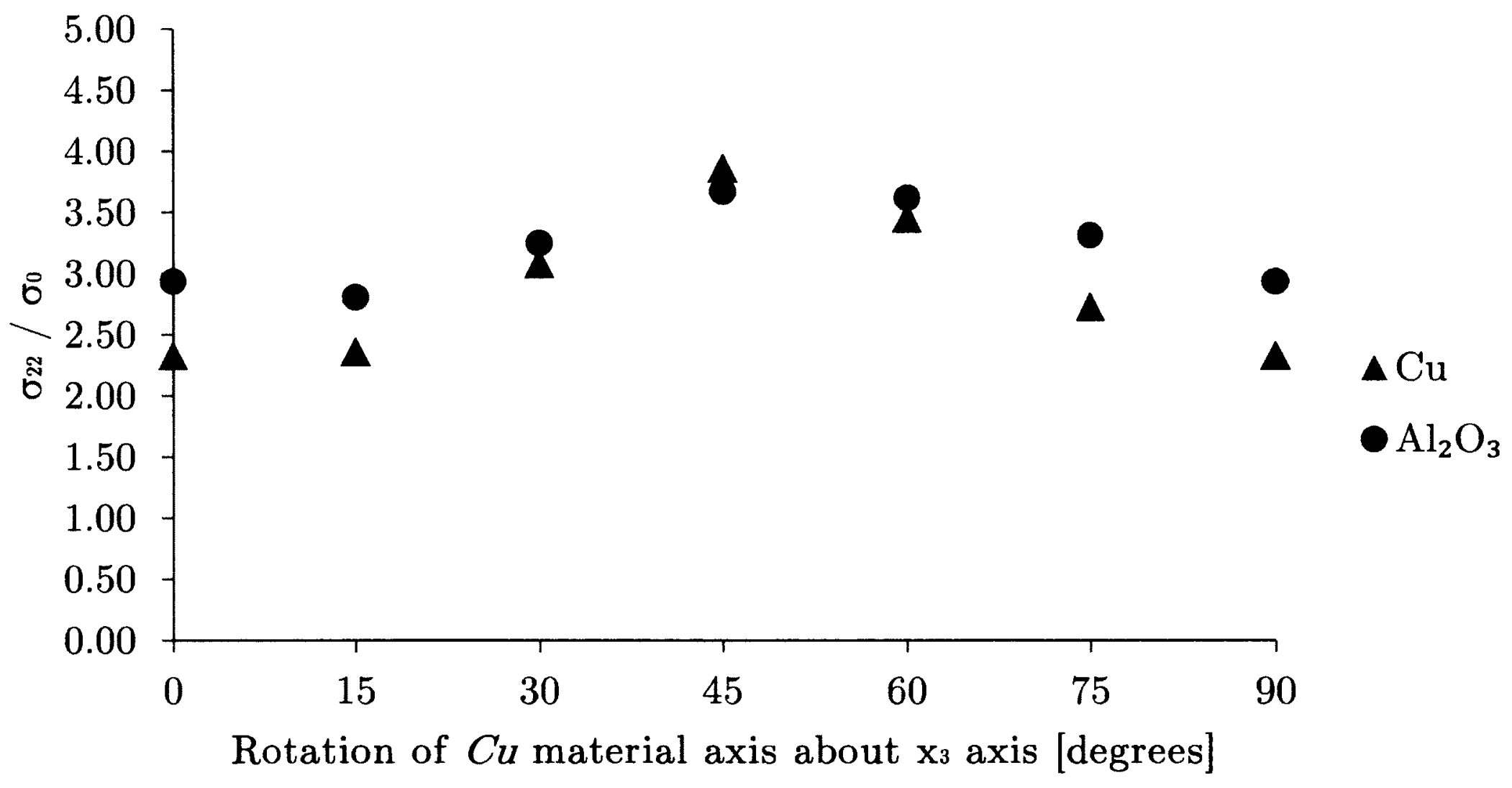

Figure 3.24: Variation of $\sigma_{22} / \sigma_{0}$ at point $\mathrm{C}$ of a $\mathrm{Cu}-\mathrm{Al}_{2} \mathrm{O}_{3}$ bicrystal plate with a circular hole for $x_{3}$-material axis rotations of the $C u$ crystal 


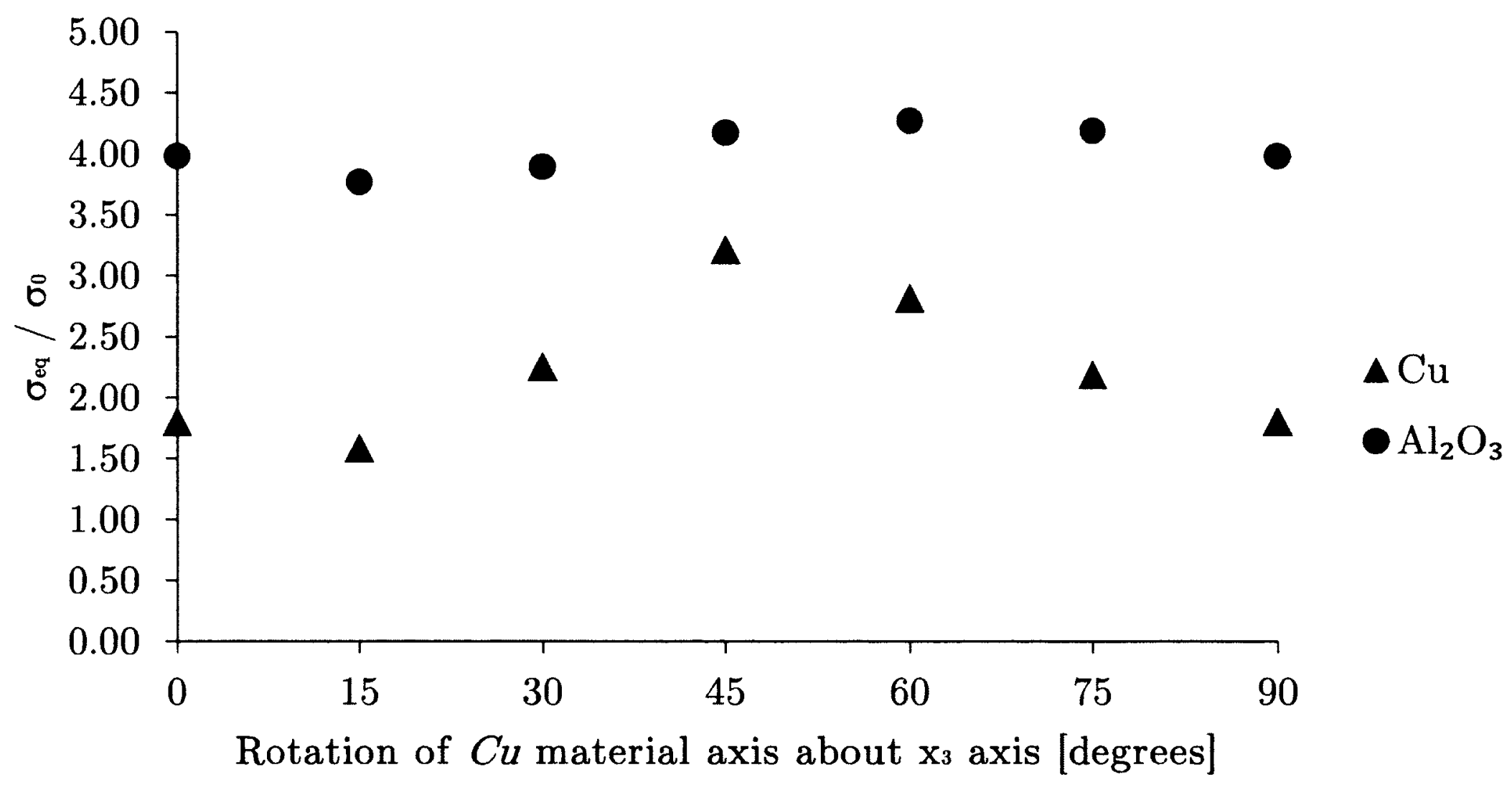

Figure 3.25: Variation of $\sigma_{e q} / \sigma_{0}$ at point $\mathrm{C}$ of a $\mathrm{Cu}-\mathrm{Al}_{2} \mathrm{O}_{3}$ bicrystal plate with a circular hole for $x_{3}$-material axis rotations of the $C u$ crystal 


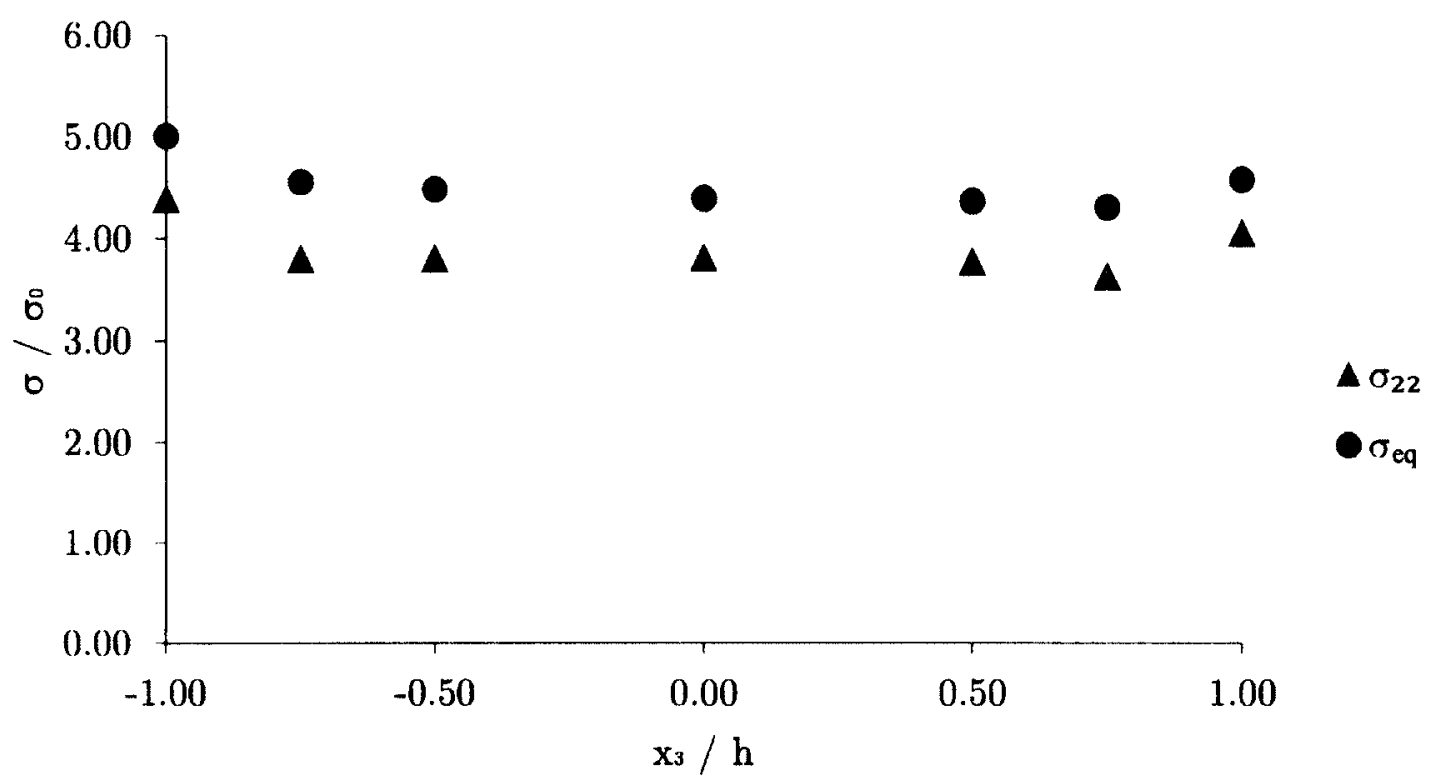

(a) $\mathrm{Nb}-\mathrm{Al}_{2} \mathrm{O}_{3}$ Bicrystal

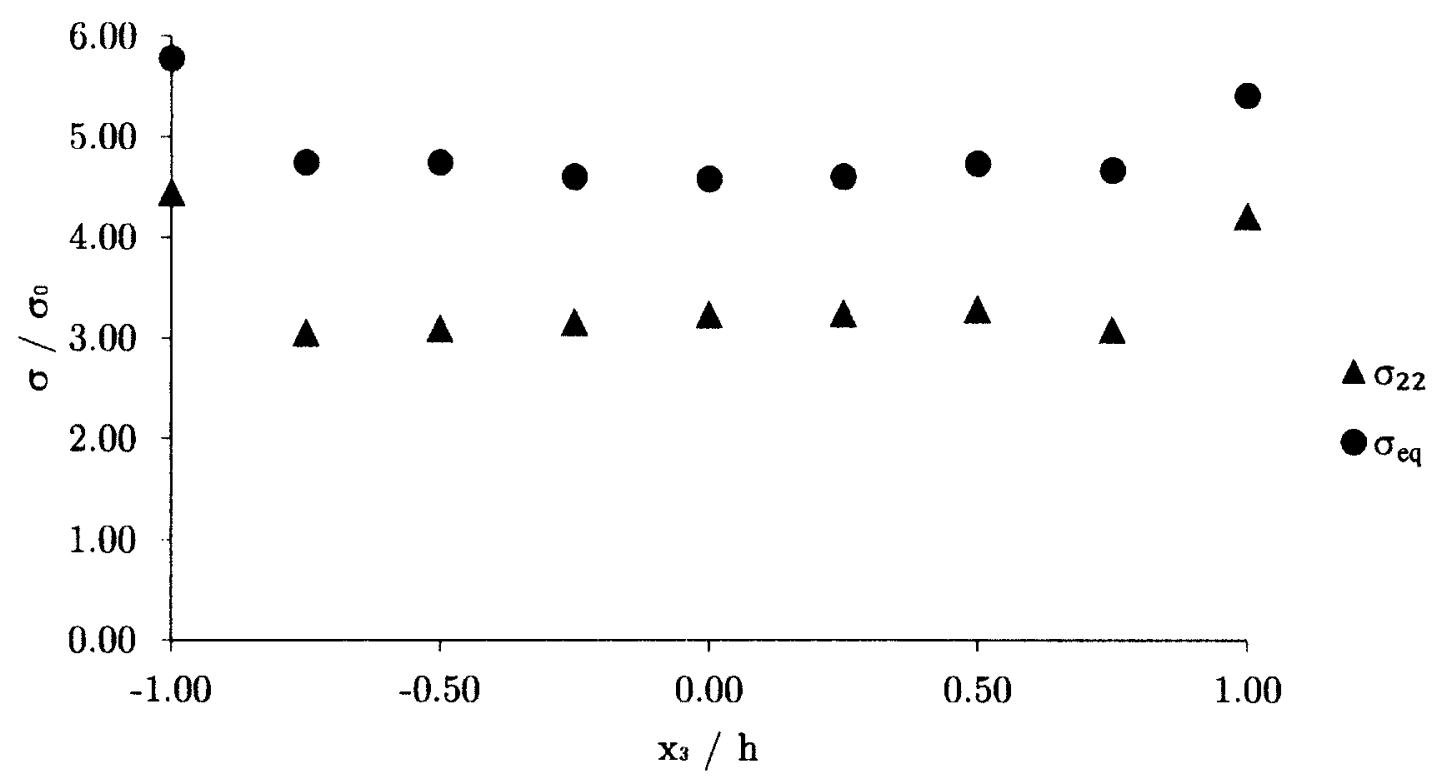

(b) $\mathrm{Cu}-\mathrm{Al}_{2} \mathrm{O}_{3}$ Bicrystal

Figure 3.26: Stress variation of $\sigma_{22} / \sigma_{0}$ and $\sigma_{e q} / \sigma_{0}$ through the thickness along $\overline{A C B}$ at the interface of a bicrystal plate with a circular hole in the $\mathrm{Al}_{2} \mathrm{O}_{3}$ crystal for an $\mathrm{Al}_{2} \mathrm{O}_{3} x_{1}$-material axis rotation of $150^{\circ}$ 


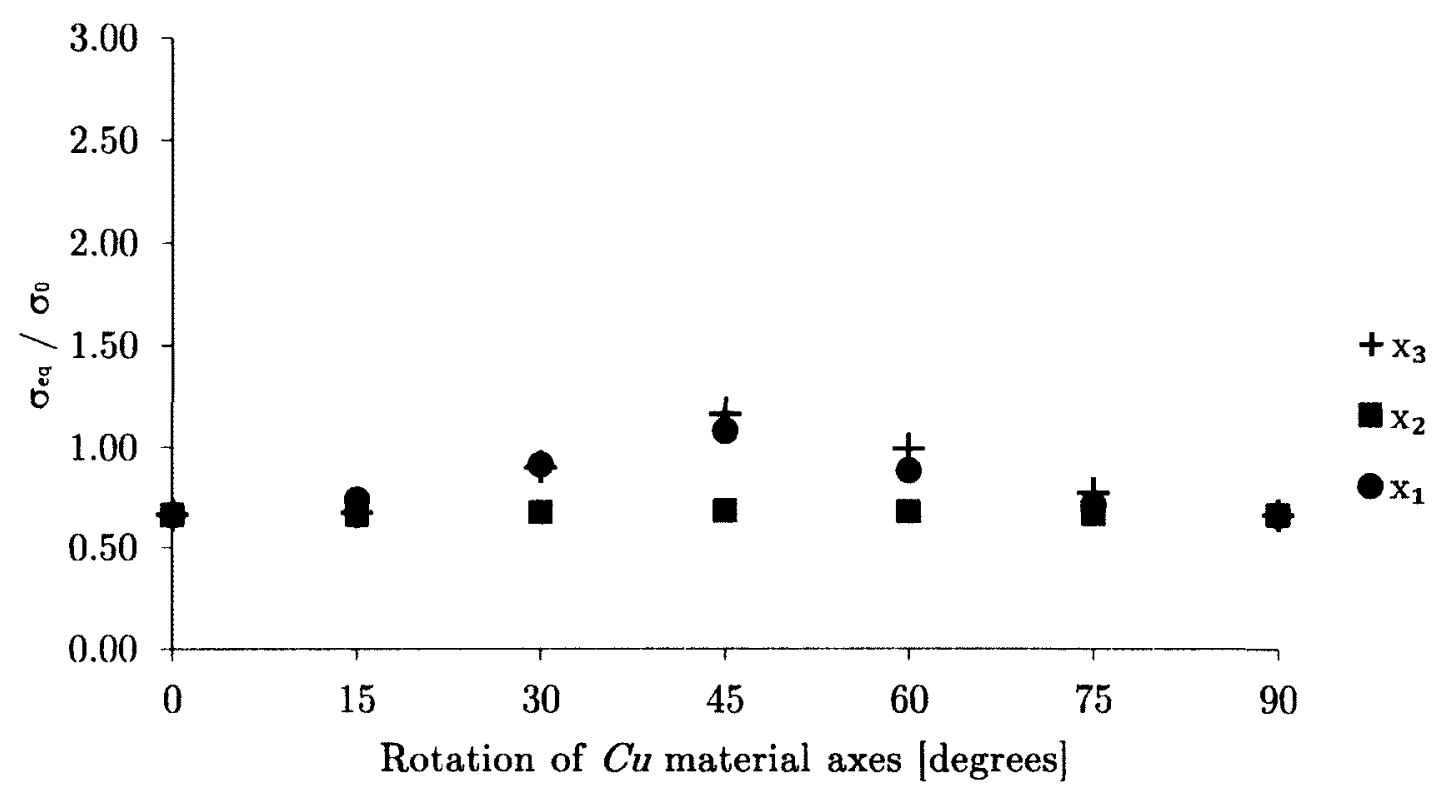

(a) Rotations of the $C u$ crystal

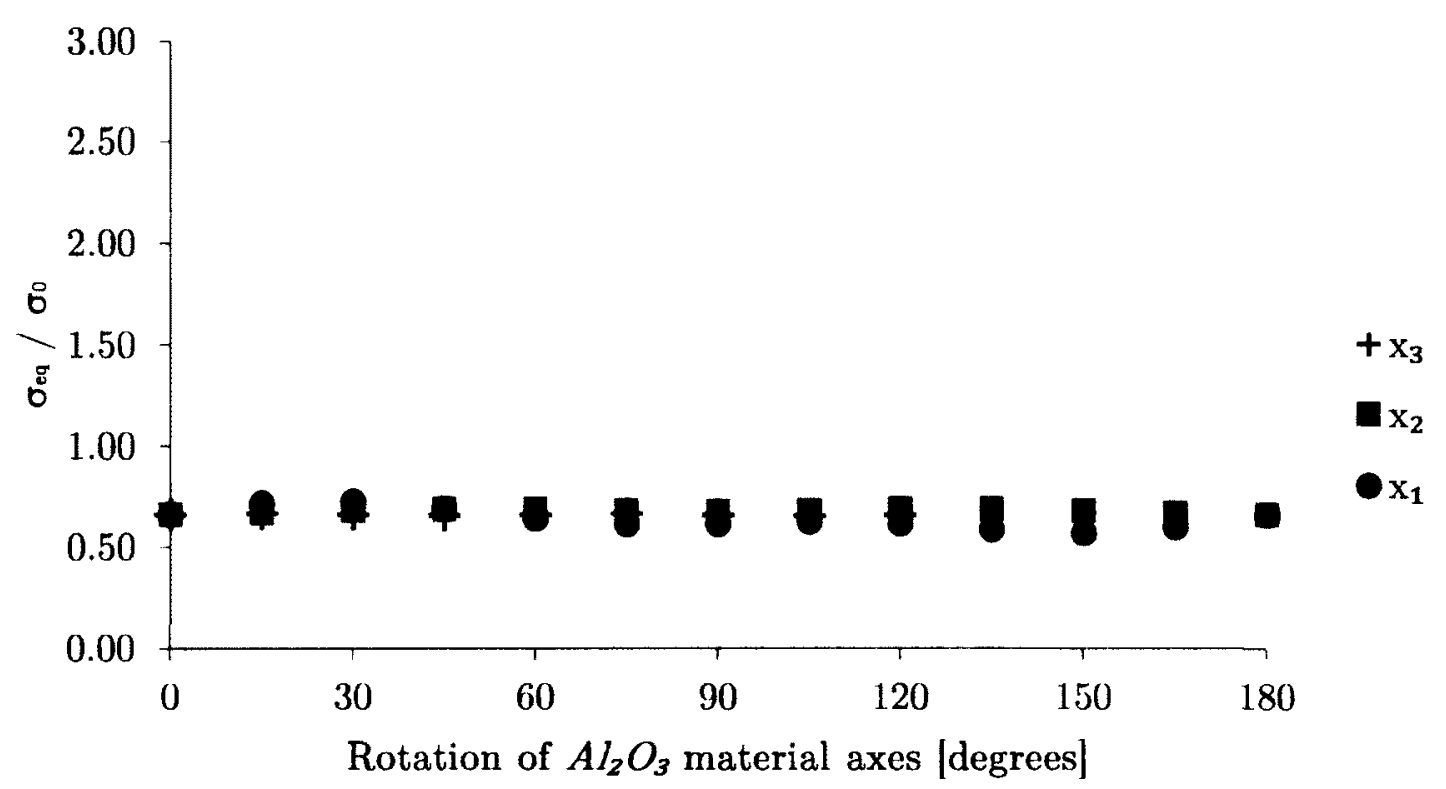

(b) Rotations of the $\mathrm{Al}_{2} \mathrm{O}_{3}$ crystal

Figure 3.27: Variation of $\sigma_{e q} / \sigma_{0}$ at point $\mathrm{F}$ in the $\mathrm{Cu}$ crystal of a $\mathrm{Cu}-\mathrm{Al}_{2} \mathrm{O}_{3}$ bicrystal plate with a circular hole for $x_{1}, x_{2}$, and $x_{3}$-material axis rotations 


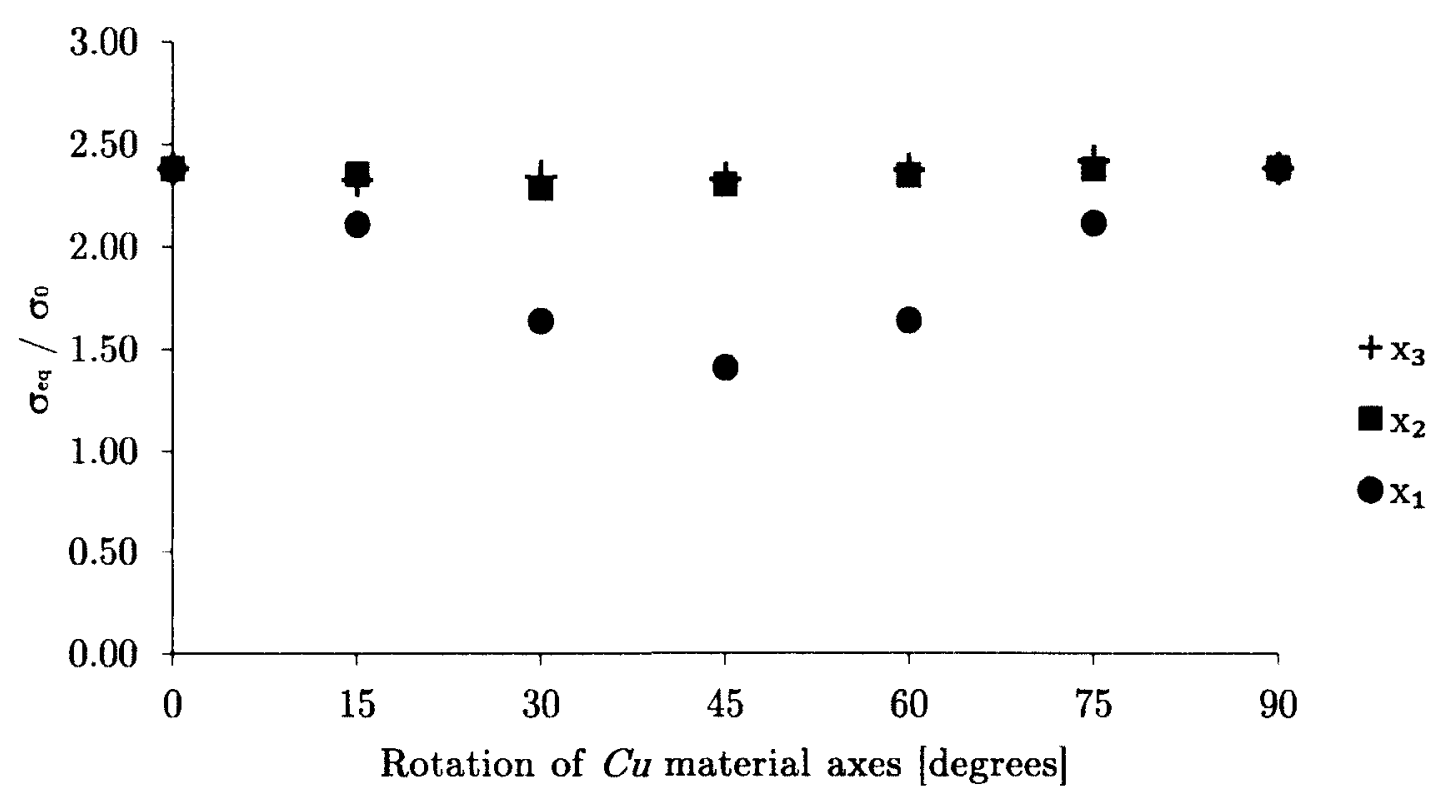

(a) Rotations of the $\mathrm{Cu}$ crystal

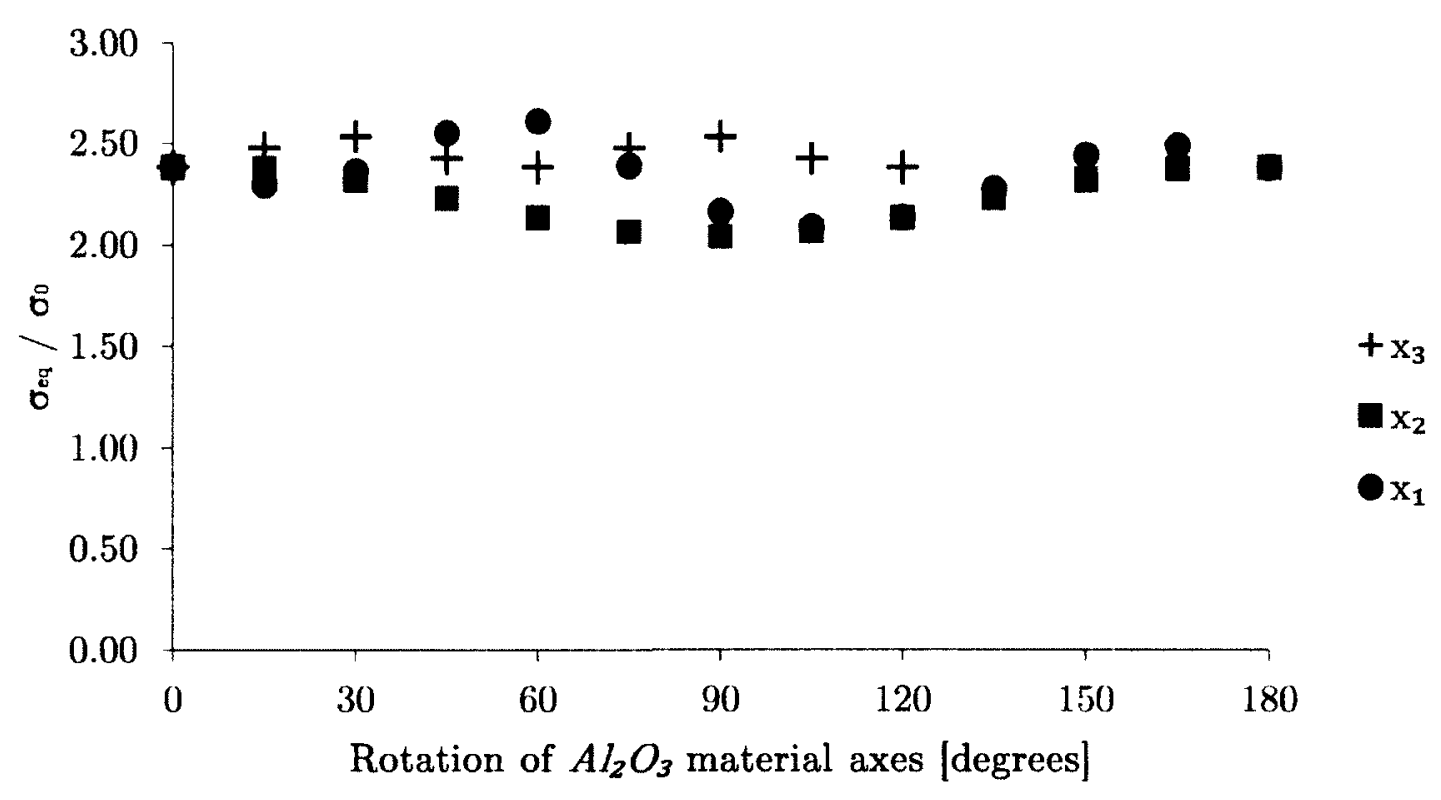

(b) Rotations of the $\mathrm{Al}_{2} \mathrm{O}_{3}$ crystal

Figure 3.28: Variation of $\sigma_{e q} / \sigma_{0}$ at point $\mathrm{F}$ in the $\mathrm{Al}_{2} \mathrm{O}_{3}$ crystal of a $\mathrm{Cu}-\mathrm{Al}_{2} \mathrm{O}_{3}$ bicrystal plate with a circular hole for $x_{1}, x_{2}$, and $x_{3}$-material axis rotations 


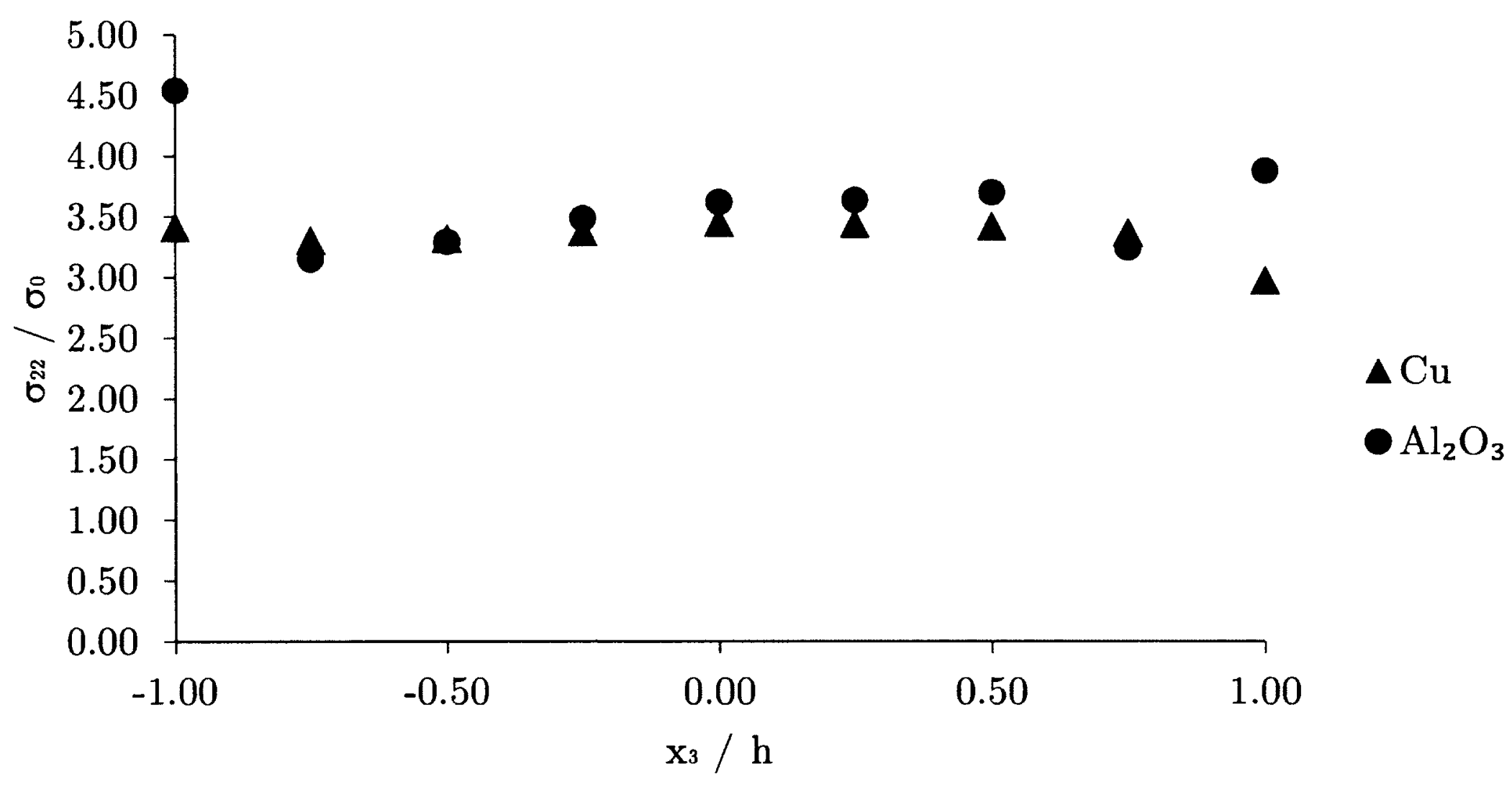

Figure 3.29: Variation of $\sigma_{22} / \sigma_{0}$ through the thickness along $\overline{A C B}$ at the interface of a $\mathrm{Cu}-\mathrm{Al}_{2} \mathrm{O}_{3}$ bicrystal plate with circular hole for a $\mathrm{Cu} x_{3}$-material axis rotation of $60^{\circ}$ 


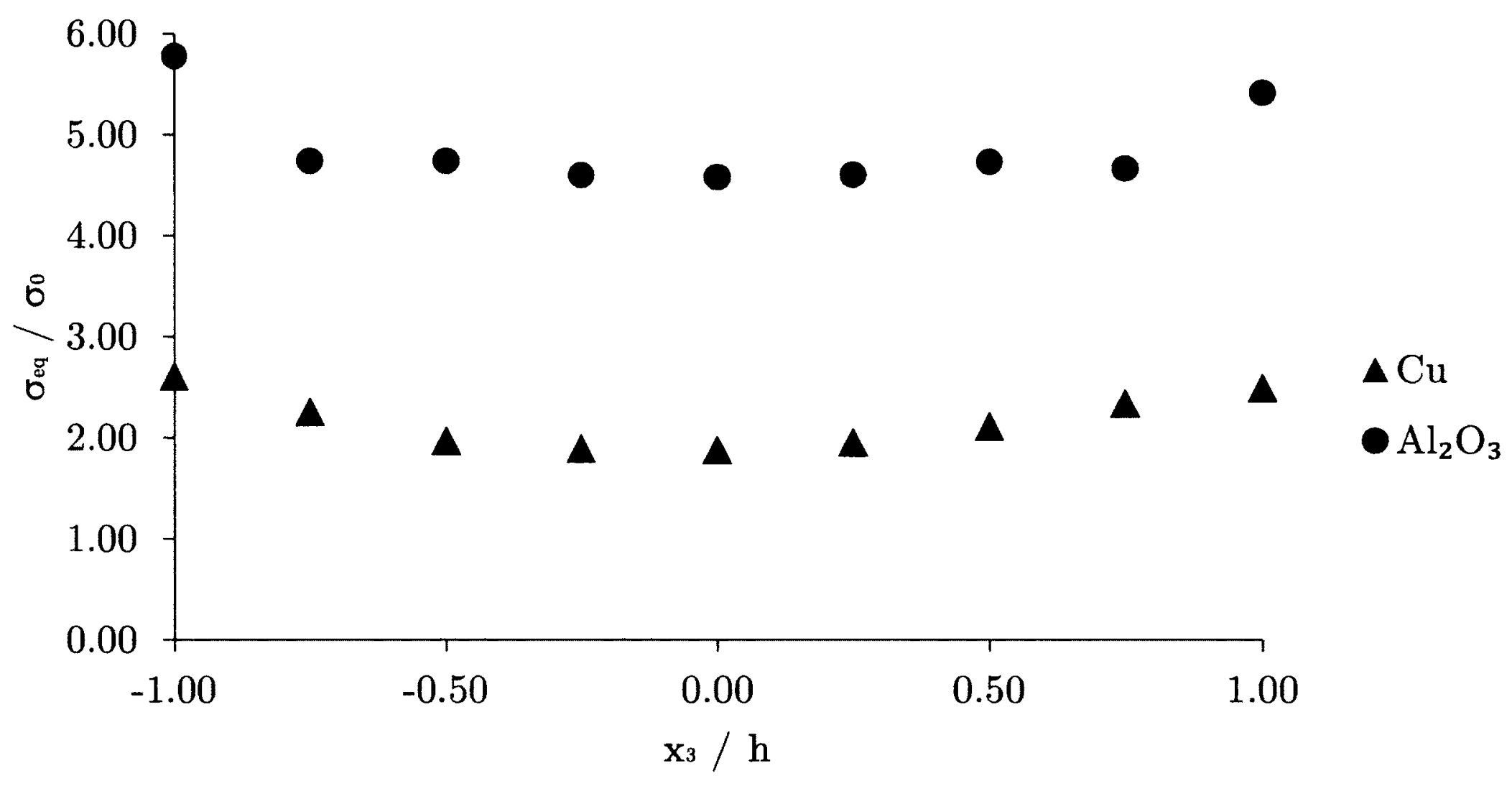

Figure 3.30: Variation of $\sigma_{e q} / \sigma_{0}$ through the thickness along $\overline{A C B}$ at the interface of a $\mathrm{Cu}-\mathrm{Al}_{2} \mathrm{O}_{3}$ bicrystal plate with circular hole for a $\mathrm{Al}_{2} \mathrm{O}_{3} x_{1}$-material axis rotation of $150^{\circ}$ 


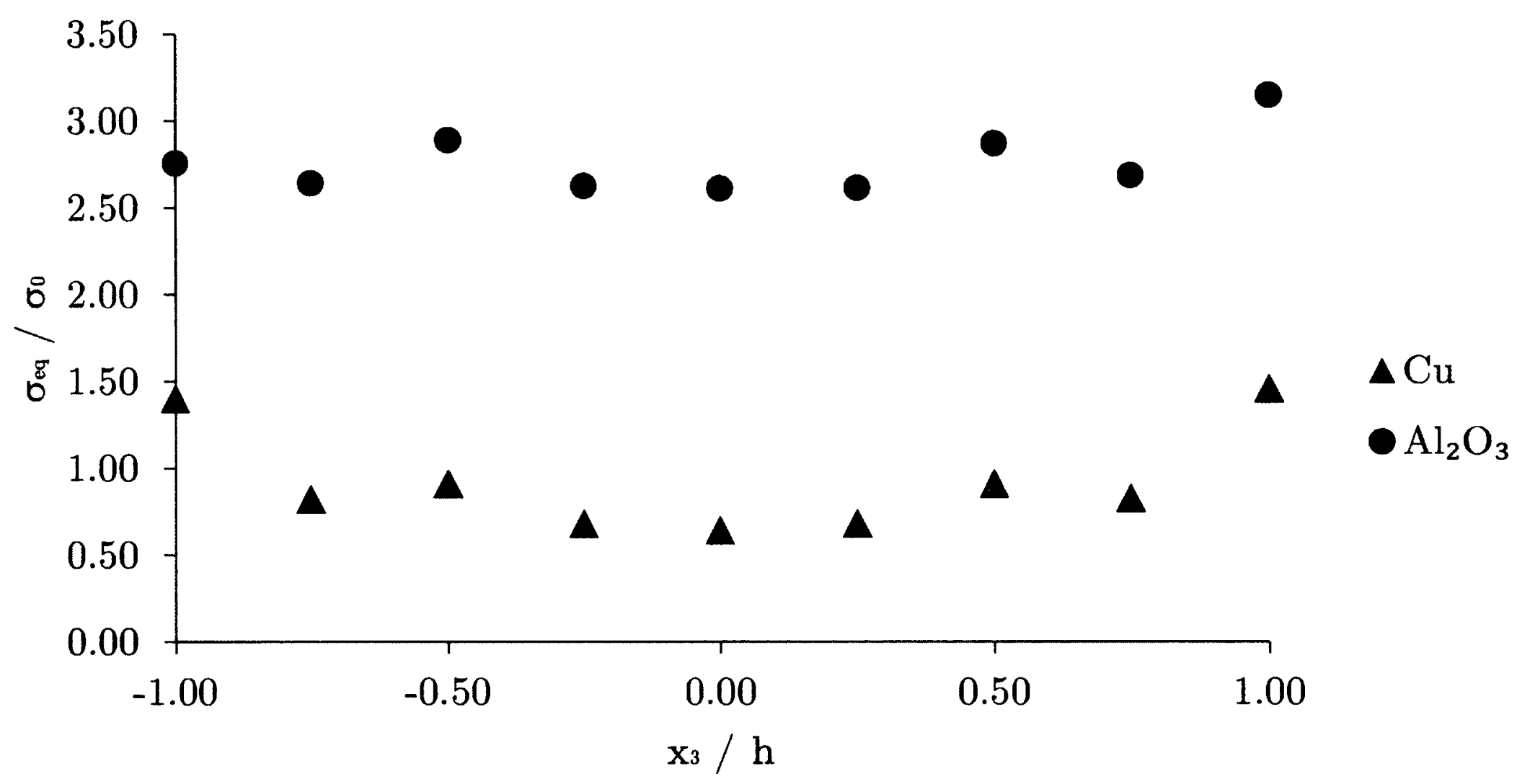

Figure 3.31: Variation of $\sigma_{e q} / \sigma_{0}$ through the thickness along $\overline{D F E}$ at the interface of a $\mathrm{Cu}-\mathrm{Al}_{2} \mathrm{O}_{3}$ bicrystal plate with circular hole for a $\mathrm{Al}_{2} \mathrm{O}_{3} x_{1}$-material axis rotation of $60^{\circ}$ 


\section{Chapter 4}

\section{Bicrystal Double U-Notch Bar}

In this chapter, the stresses are investigated of another bicrystal problem, namely, a double U-notch bar in tension. First, the physical problem is defined along with the BEM and FEM numerical models used to treat the problem. The FEM results confirm the veracity and efficiency of the BEM results and the stresses are briefly compared to those from the corresponding isotropic case of the problem. The material principal axes of the crystals were independently rotated and the noteworthy trends and values of stresses in the region of the stress concentration are reported and compared with those of the same axis rotations and materials from the previous chapter where possible.

\subsection{Problem Definition}

The physical problem is similar to that encountered in Example (B) from Chapter 2 in both geometry and loading condition, re-presented in Figure 4.1. The geometry is split into two material regions with the interfacial plane located at $\mathrm{x}_{1}=0$, bisecting the model at the stress concentration of the double U-notch, as shown in Figure 4.2. Stresses are analysed along the U-notch interface edge, $\overline{A C B}$, and 0.5 units away from the edge, where the half-height of the bar, $H$, is 5 units. Material combinations 
identical to those used in the previous chapter; niobium and alumina, and copper and alumina; were used in the analysis. Again in anisotropy, all three material principal axes, $\mathrm{x}_{1}, \mathrm{x}_{2}$, and $\mathrm{x}_{3}$ for each crystal, were rotated counter-clockwise individually through $15^{\circ}$ increments until the material symmetry planes realigned. The crystals are bonded together along the $x_{1}=0$ plane, instead of the $x_{2}=0$ plane as in the previous chapter.

\subsection{Numerical Models}

Two BEM and two FEM meshes were used to analyse the differing material combinations. The first BEM mesh, used to analyse material axis rotations of the $\mathrm{Nb}-\mathrm{Al}_{2} \mathrm{O}_{3}$ bicrystal, contains 380 quadratic surface elements and 1108 nodes, and is shown in Figure 4.3. The second mesh, being more refined, was used to analyse the $\mathrm{Cu}-\mathrm{Al}_{2} \mathrm{O}_{3}$ bicrystal as the less refined BEM mesh produced less reliable results for certain material axis orientations as mentioned in the previous chapter. The second mesh contains 500 elements and 1468 nodes, and is shown in Figure 4.4. The two FEM meshes contain 36,998 elements (C3D20R) and 162,707 nodes, and 51,930 elements and 225,704 nodes; they are shown in Figures 4.5 and 4.6, respectively. The meshes were also used in the corresponding isotropic problem. In the model, one remote end of the bar was fully constrained while a load, $\sigma_{0}$, was applied at the opposing end. Similar to the plate with a circular hole problem in the previous chapter, the materials were treated as perfectly bonded along the interfacial plane. 


\subsection{Results}

\subsubsection{Preliminary Remarks}

Along the free edges of the material interface in the double U-notch bar, the same type of relatively weak stress singularity exists, as has been discussed in the previous chapter. The stress results along these edges must again be taken with caution. A mesh refinement study performed with the BEM and FEM meshes, shows the results converging along $\overline{D F E}$, a very short distance into the material interface plane. The study was performed with both anisotropic bicrystals, with no rotation of the material principal axes. The normal stress in the loading direction, $\sigma_{11}$, and the von Mises equivalent stress correlated well between mesh refinements: the BEM results agreed within $2 \%$ discrepancy, and the FEM results agreed to within $5 \%$ discrepancy, while BEM and FEM results of the refined meshes agreed to within $5 \%$ discrepancy. These data are given in Tables $4.1-4.4$, noting that the stresses at points $\mathrm{D}$ and $\mathrm{E}$ are singular and included for reference only. As in the previous chapter, the less refined BEM mesh produced unreliable results of lesser accuracy for certain material orientations of the $\mathrm{Cu}-\mathrm{Al}_{2} \mathrm{O}_{3}$ bicrystal and are not included. It reinforces the notion that material properties must be taken into account along with geometry when creating a suitable mesh in anisotropic stress analyses.

Comparison of the results from the isotropic and anisotropic material combinations highlights the changes that occur when a problem is considered to be anisotropic. Figure 4.7 shows $\sigma_{11} / \sigma_{0}$ on one side of the interface, $N b$ or $C u$, along $\overline{A C B}$ and $\overline{D F E}$; anisotropic results from the $\mathrm{Cu}-\mathrm{Al}_{2} \mathrm{O}_{3}$ bar diverge from the corresponding isotropic results more than the $\mathrm{Nb}-\mathrm{Al}_{2} \mathrm{O}_{3}$ results. The effect is much more pronounced in the normalized equivalent stress on the opposite side of the interface in the $\mathrm{Al}_{2} \mathrm{O}_{3}$ material, as shown in Figure 4.8. The stresses at the free edge, related to the stress 
participation factor, and the stresses at the interior of the interface increase significantly in the anisotropic problem. The normal, shear, and equivalent stresses at point $\mathrm{F}$, of these bimaterial analyses have been compared with those from a corresponding homogeneous isotropic analysis, shown in Table 4.5. As observed in the previous chapter, throughout the analyses, the stress in the loading direction, $\sigma_{11}$, changes very little along $\overline{D F E}$, a short distance into the interfacial plane. Nevertheless, the other stress components, including the equivalent stress, increase in magnitude with increasing material complexity and diverge from the homogeneous isotropic analysis.

\subsubsection{Anisotropic Results}

The 3-D BEM stress investigation of the bicrystal bar with double U-notch followed the same procedure described in the previous chapter where all material principal axes of each crystal were rotated counter-clockwise in $15^{\circ}$ increments, independently of each other. The complete set of stress results, for each axis rotation, along $\overline{A C B}$ and $\overline{D F E}$ are contained in the digital medium (compact disc) in Appendix C. Only the main findings and representative features of these numerical results are discussed here. The stress results reported here have been normalized with respect to the applied stress, $\sigma_{0}$.

\section{Niobium-Alumina Bicrystal Results}

Material principal axis rotations were performed first with the $\mathrm{Nb}-\mathrm{Al}_{2} \mathrm{O}_{3}$ bicrystal bar. Rotation of the $\mathrm{Nb} \mathrm{x}_{2}$-material axis produced insignificant change of $\sigma_{11} / \sigma_{0}$ and a small increase in von Mises equivalent stress in the $\mathrm{Al}_{2} \mathrm{O}_{3}$ crystal, as shown in Figure 4.9, and produced very little change in the $\mathrm{Nb}$ crystal. Rotation of the $\mathrm{Nb} \mathrm{x}_{3^{-}}$ material axis decreased $\sigma_{11} / \sigma_{0}$ and the equivalent stresses in $N b$ at $30^{\circ}$ and increased the stresses in $\mathrm{Al}_{2} \mathrm{O}_{3}$ at $60^{\circ}$, as shown in Figures 4.10 and 4.11. Rotation of the $\mathrm{Al}_{2} \mathrm{O}_{3} \mathrm{x}_{1}$-material axis lowered $\sigma_{11} / \sigma_{0}$ near $60^{\circ}$, and increased it, reaching a maximum 
between $120^{\circ}$ and $135^{\circ}$, in $\mathrm{Al}_{2} \mathrm{O}_{3}$, and $\mathrm{Nb}$ to a lesser extent, as shown in Figure 4.12. The equivalent stress behaves similarly, however, a local maximum exists near $30^{\circ}$ of rotation, shown in Figure 4.13a, since the transverse normal and shear stresses do not follow the same trend as the stress component in the direction of loading, $\sigma_{11} / \sigma_{0}$, as can be seen at point $\mathrm{F}$ in Figure $4.13 \mathrm{~b}$. Rotation of the $\mathrm{Al}_{2} \mathrm{O}_{3} \mathrm{x}_{2}$-material axis causes a small increase in $\sigma_{11} / \sigma_{0}$ and the equivalent stresses which remains relatively uniform from $60^{\circ}$ to $120^{\circ}$. Interestingly, $\sigma_{11} / \sigma_{0}$ along $\overline{A C B}$ reaches a maximum value at different locations through the thickness depending on the orientation of the material axes; Figure 4.14 shows two profiles with maximum values in different locations. As with the previous bicrystal geometry, for all rotations, the normal stress coinciding with the direction of loading, $\sigma_{11} / \sigma_{0}$, changes an insignificant amount at the interior of the interface. Thus, the von Mises equivalent stress at point F, shown in Figures 4.15 and 4.16, demonstrate the general combined effects of the transverse normal and shear stresses. Results from $0^{\circ}$ to $180^{\circ}$ of rotation of the $\mathrm{Al}_{2} \mathrm{O}_{3}$ x $\mathrm{x}_{2}$-material axis are symmetric about $90^{\circ}$ of rotation. Rotation of the other material axes produced no other significant stress variations.

The highest normalized von Mises equivalent stress along $\overline{A C B}$ occurred for a $45^{\circ}$ rotation of the $\mathrm{Nb}$ crystal $\mathrm{x}_{2}$-material axis, shown in Figure 4.17, and the highest normal stress occurred at $60^{\circ}$ rotation of the same axis, shown in Figure 4.18. Along $\overline{D F E}$, the highest normalized equivalent stress, not affected by the singularity, is 3.08 ; it occurs for a $45^{\circ}$ rotation of the $\mathrm{Nb}$ crystal $\mathrm{x}_{2}$-material axis, shown in Figure 4.19. This value is $82 \%$ larger than that found in the corresponding homogeneous isotropic problem and $33 \%$ larger than that found in the corresponding isotropic bimaterial problem. 


\section{Copper-Alumina Bicrystal Results}

Material principal axis rotations of the $\mathrm{Cu}-\mathrm{Al}_{2} \mathrm{O}_{3}$ bicrystal were also performed. Rotation of the $C u \mathrm{x}_{2}$-material axis produced no significant change in $\sigma_{11} / \sigma_{0}$ while reducing equivalent stress in the $\mathrm{Al}_{2} \mathrm{O}_{3}$ crystal and increasing it in the $\mathrm{Cu}$ crystal, as shown in Figure 4.20. This is an effect opposite to that of the same axis rotation of $\mathrm{Nb}$ in the previous bicrystal, which is part of the overall pattern governed by the differing anisotropic factors of $N b$ and $C u$. Rotation of the $C u \mathrm{x}_{3}$-material axis decreased $\sigma_{11} / \sigma_{0}$ and equivalent stresses in $C u$ at $75^{\circ}$ and increased them in $\mathrm{Al}_{2} \mathrm{O}_{3}$ at $15^{\circ}$, as shown in Figures 4.21 and $4.22 ; 45^{\circ}$ out of phase with respect to the corresponding $\mathrm{Nb}$ material axis rotations in the previous bicrystal. The discrepancies in the behaviour of the two cubic materials are explained by the changing stiffness coefficients. The $C_{44}, C_{55}$, and $C_{66}$ stiffness coefficients of the non-rotated $C u$ crystal are nearly 3 times larger than those of the non-rotated $N b$ crystal. When, for example, the $\mathrm{x}_{3}$-material axis is rotated in both crystals, the $C_{66}$ coefficient in $\mathrm{Cu}$ is lowered and the material becomes more comparable in value with $\mathrm{Al}_{2} \mathrm{O}_{3}$ crystal since the corresponding coefficient in $\mathrm{Al}_{2} \mathrm{O}_{3}$ is lower to begin with. Alternatively, the $C_{66}$ coefficient of $\mathrm{Nb}$ is initially comparable with that in $\mathrm{Al}_{2} \mathrm{O}_{3}$, but the rotation causes the $C_{66}$ coefficient to increase. This in turn results in higher shear stresses at the interface. It is expected that the anisotropic factors of the cubic materials can be used to determine how the coefficients change with rotation of the material axes. Rotations of the $\mathrm{Al}_{2} \mathrm{O}_{3}$ crystal yielded similar trends to those of the $\mathrm{Al}_{2} \mathrm{O}_{3}$ rotations in the previous bicrystal, an effect similar to that found in the two bicrystals analysed in the previous chapter. Again, $\sigma_{11} / \sigma_{0}$ does not change significantly at the interior of the bicrystal interface for any material axis rotation, and the equivalent stress at point $\mathrm{F}$, for all rotations, is included in Figures 4.23 and 4.24. Furthermore, results are symmetric about $90^{\circ}$ of rotation of the $\mathrm{Al}_{2} \mathrm{O}_{3} \mathrm{x}_{2}$-material axis; demonstrated in 
Figure 4.25. As noted in the previous chapter for the $\mathrm{x}_{2}$-axis, it is again observed that rotation of the material principal axis, of $\mathrm{Nb}$ or $\mathrm{Cu}$, which coincides with the load axis, $x_{1}$ in this case, yields significantly reduced stress variation. No other significant stress variations were produced by other material axis rotations.

For both a $60^{\circ}$ and $120^{\circ}$ rotation of the $\mathrm{Al}_{2} \mathrm{O}_{3} \quad \mathrm{x}_{2}$-material principal axis, the highest $\sigma_{11} / \sigma_{0}$ and normalized von Mises equivalent stresses occur along $\overline{A C B}$ in the $\mathrm{Al}_{2} \mathrm{O}_{3}$ crystal, as shown in Figures 4.26 and 4.27, respectively. The highest normalized equivalent stress, not affected by the singularity, was found along $\overline{D F E}$ and has a value of 3.95 in the $\mathrm{Al}_{2} \mathrm{O}_{3}$ crystal for an $\mathrm{Al}_{2} \mathrm{O}_{3} \mathrm{x}_{1}$-material axis rotation of $75^{\circ}$; this is shown in Figure 4.28 and is $134 \%$ larger than the stress in the corresponding homogenous isotropic case and $82 \%$ larger than the stress in the corresponding isotropic bimaterial case. Overall, the discrepancy between $\sigma_{11}$ and equivalent stresses on either side of the interface of the $\mathrm{Cu}-\mathrm{Al}_{2} \mathrm{O}_{3}$ bicrystal are higher than in the $\mathrm{Nb}-\mathrm{Al}_{2} \mathrm{O}_{3}$ bicrystal. Although isotropic $N b$ and $C u$ are very similar in material properties, the stiffness coefficients linked to normal stresses in anisotropic $\mathrm{Nb}$ crystal are higher relative to those linked to shear stresses; the converse is true for anisotropic $C u$ crystal. Since the problem investigated was subject to a normal stress loading condition, and $\mathrm{Al}_{2} \mathrm{O}_{3}$ is stiffer than $\mathrm{Nb}$ and $\mathrm{Cu}$ with respect to stiffness in the normal direction, there is generally greater incompatibility of normal stresses, notably the transverse normal stresses, at the interface of the $\mathrm{Cu}-\mathrm{Al}_{2} \mathrm{O}_{3}$ bicrystal.

\subsection{Concluding Remarks}

Two cubic materials, $\mathrm{Nb}$ and $\mathrm{Cu}$, were each paired with a trigonal material, $\mathrm{Al}_{2} \mathrm{O}_{3}$, for multiple material principal axis orientations of a bicrystal bar with double U-notch in tension and analysed using the BEM. As before, the stresses at the free edges of the interface are weakly singular; thus, the numerical results there should be taken 
with caution. A short distance into the bicrystal interface, the stresses from the BEM and FEM analysis agree very well with each other, and the normal stress in the direction of loading, $\sigma_{11} / \sigma_{0}$, approaches that of the corresponding case in isotropy; however, the other stress components differ significantly. The differing anisotropic factor of $\mathrm{Nb}$ and $\mathrm{Cu}$ produces significantly different results for similar material axis rotations of these materials. The material orientations producing the highest normal and von Mises equivalent stresses were found. Rotation of the $\mathrm{Nb} \mathrm{x}_{2}$-material axis increased equivalent stress in the $\mathrm{Al}_{2} \mathrm{O}_{3}$ crystal and slightly lowered it in the $\mathrm{Nb}$ crystal, whereas rotation of the same axis of the $C u$ crystal lowered equivalent stress in $\mathrm{Al}_{2} \mathrm{O}_{3}$ crystal and increased it in $\mathrm{Cu}$. Rotation of the $\mathrm{Nb} \mathrm{x}_{3}$-material axis increased $\sigma_{11}$ and equivalent stresses in $\mathrm{Al}_{2} \mathrm{O}_{3}$ and lowered them in $\mathrm{Nb}$, and rotation of the same material axis of $\mathrm{Cu}$ produced similar results $45^{\circ}$ out of phase with those of the $\mathrm{Nb}$ crystal rotations. Rather, rotation of the $\mathrm{Al}_{2} \mathrm{O}_{3} \mathrm{x}_{1}$-material axis produced similar trends for both bicrystals, increasing and decreasing the $\sigma_{11}$ and equivalent stresses depending on rotation. This effect was also observed for $\mathrm{Al}_{2} \mathrm{O}_{3}$ material axis rotations in the previous chapter. Stress variation with rotation of the cubic material axis which coincides with the load axis seems to be significantly reduced - as observed in the previous chapter. Both of these effects may be helpful in understanding anisotropic bicrystal problems and require further study. The following chapter returns to the problem of a bicrystal plate with a circular hole. However, the investigation shifts from the study of material orientations to a brief look at the effects of introducing additional holes to reduce the stress concentration. 


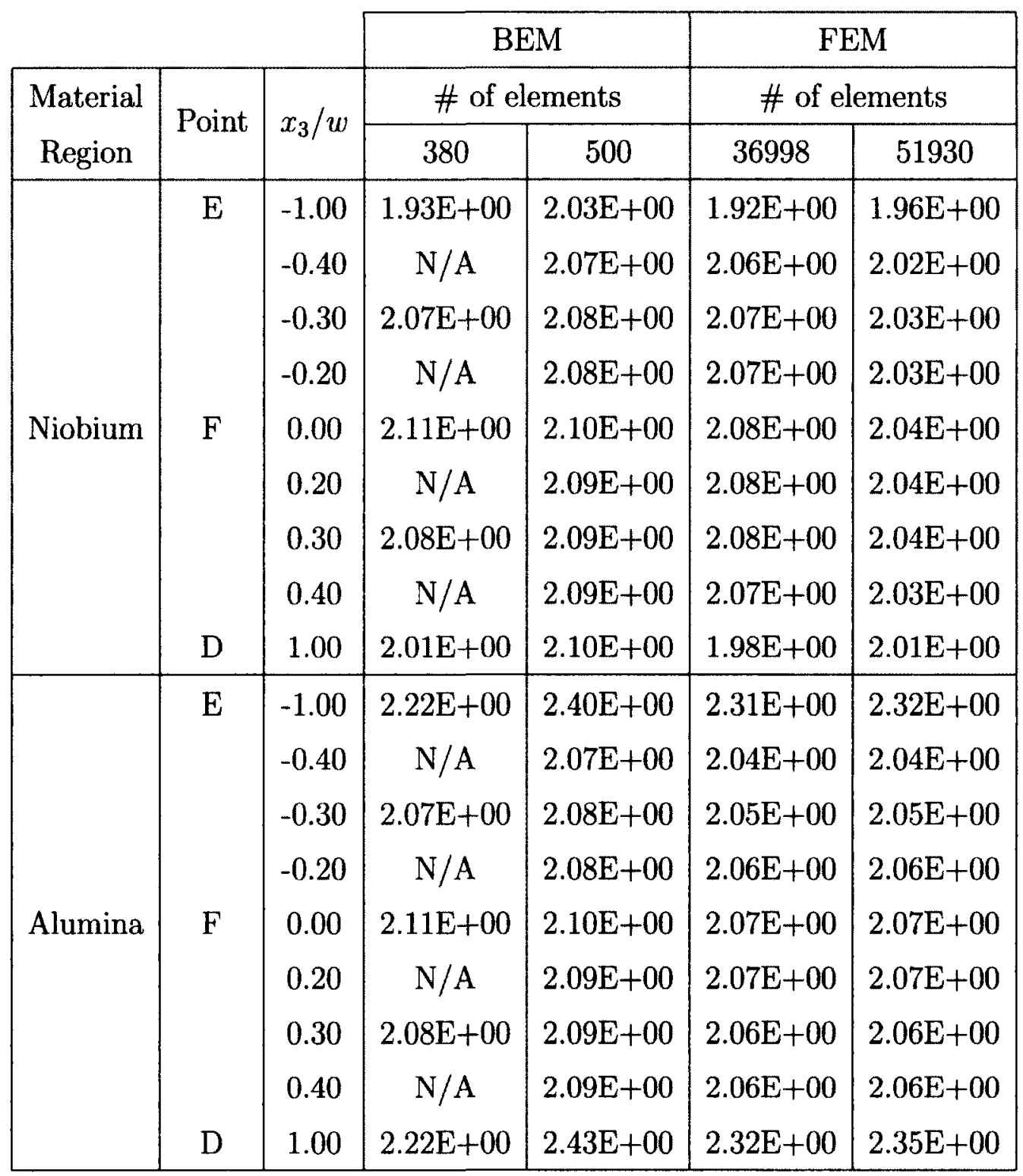

Table 4.1: Comparison of $\sigma_{11} / \sigma_{0}$ at various points from BEM and FEM analyses of the $\mathrm{Nb}-\mathrm{Al}_{2} \mathrm{O}_{3}$ bicrystal bar with double U-notch; $x_{1}=0$ and $x_{2} / H=0.5$ for all points 


\begin{tabular}{|c|c|c|c|c|c|c|}
\hline & & & & & \multirow{3}{*}{\multicolumn{2}{|c|}{$\frac{\text { FEM }}{\text { tof elements }}$}} \\
\hline & \multirow{2}{*}{\multicolumn{2}{|c|}{$\frac{\text { BEM }}{\text { \# of elements }}$}} & & \\
\hline \multirow{2}{*}{$\begin{array}{l}\text { Material } \\
\text { Region }\end{array}$} & \multirow{2}{*}{ Point } & \multirow{2}{*}{$x_{3} / w$} & & & & \\
\hline & & & 380 & 500 & 36998 & 51930 \\
\hline \multirow{9}{*}{ Niobium } & \multirow[t]{4}{*}{$\mathrm{E}$} & -1.00 & $1.54 \mathrm{E}+00$ & $1.61 \mathrm{E}+00$ & $1.56 \mathrm{E}+00$ & $1.59 \mathrm{E}+00$ \\
\hline & & -0.40 & $\mathrm{~N} / \mathrm{A}$ & $1.21 \mathrm{E}+00$ & $1.29 \mathrm{E}+00$ & $1.27 \mathrm{E}+00$ \\
\hline & & -0.30 & $1.21 \mathrm{E}+00$ & $1.20 \mathrm{E}+00$ & $1.28 \mathrm{E}+00$ & $1.26 \mathrm{E}+00$ \\
\hline & & -0.20 & $\mathrm{~N} / \mathrm{A}$ & $1.20 \mathrm{E}+00$ & $1.28 \mathrm{E}+00$ & $1.26 \mathrm{E}+00$ \\
\hline & \multirow[t]{4}{*}{$F$} & 0.00 & $1.22 \mathrm{E}+00$ & $1.20 \mathrm{E}+00$ & $1.28 \mathrm{E}+00$ & $1.26 \mathrm{E}+00$ \\
\hline & & 0.20 & $\mathrm{~N} / \mathrm{A}$ & $1.22 \mathrm{E}+00$ & $1.30 \mathrm{E}+00$ & $1.27 \mathrm{E}+00$ \\
\hline & & 0.30 & $1.24 \mathrm{E}+00$ & $1.23 \mathrm{E}+00$ & $1.31 \mathrm{E}+00$ & $1.28 \mathrm{E}+00$ \\
\hline & & 0.40 & $\mathrm{~N} / \mathrm{A}$ & $1.25 \mathrm{E}+00$ & $1.32 \mathrm{E}+00$ & $1.30 \mathrm{E}+00$ \\
\hline & D & 1.00 & $1.50 \mathrm{E}+00$ & $1.57 \mathrm{E}+00$ & $1.53 \mathrm{E}+00$ & $1.54 \mathrm{E}+00$ \\
\hline \multirow{9}{*}{ Alumina } & \multirow[t]{4}{*}{$\mathrm{E}$} & -1.00 & $2.35 \mathrm{E}+00$ & $2.49 \mathrm{E}+00$ & $2.51 \mathrm{E}+00$ & $2.58 \mathrm{E}+00$ \\
\hline & & -0.40 & $\mathrm{~N} / \mathrm{A}$ & $2.33 \mathrm{E}+00$ & $2.28 \mathrm{E}+00$ & $2.29 \mathrm{E}+00$ \\
\hline & & -0.30 & $2.32 \mathrm{E}+00$ & $2.32 \mathrm{E}+00$ & $2.27 \mathrm{E}+00$ & $2.28 \mathrm{E}+00$ \\
\hline & & -0.20 & $\mathrm{~N} / \mathrm{A}$ & $2.32 \mathrm{E}+00$ & $2.26 \mathrm{E}+00$ & $2.27 \mathrm{E}+00$ \\
\hline & \multirow[t]{4}{*}{$\mathrm{F}$} & 0.00 & $2.34 \mathrm{E}+00$ & $2.32 \mathrm{E}+00$ & $2.27 \mathrm{E}+00$ & $2.28 \mathrm{E}+00$ \\
\hline & & 0.20 & $\mathrm{~N} / \mathrm{A}$ & $2.35 \mathrm{E}+00$ & $2.30 \mathrm{E}+00$ & $2.30 \mathrm{E}+00$ \\
\hline & & 0.30 & $2.38 \mathrm{E}+00$ & $2.38 \mathrm{E}+00$ & $2.33 \mathrm{E}+00$ & $2.33 \mathrm{E}+00$ \\
\hline & & 0.40 & $\mathrm{~N} / \mathrm{A}$ & $2.41 \mathrm{E}+00$ & $2.35 \mathrm{E}+00$ & $2.36 \mathrm{E}+00$ \\
\hline & D & 1.00 & $2.27 \mathrm{E}+00$ & $2.44 \mathrm{E}+00$ & $2.46 \mathrm{E}+00$ & $2.56 \mathrm{E}+00$ \\
\hline
\end{tabular}

Table 4.2: Comparison of $\sigma_{e q} / \sigma_{0}$ at various points from BEM and FEM analyses of the $\mathrm{Nb}-\mathrm{Al}_{2} \mathrm{O}_{3}$ bicrystal bar with double U-notch; $x_{1}=0$ and $x_{2} / \mathrm{H}=0.5$ for all points 


\begin{tabular}{|c|c|c|c|c|c|}
\hline & \multirow{2}{*}{$\frac{\text { BEM }}{\text { \# of elements }}$} & \multirow{2}{*}{\multicolumn{2}{|c|}{$\frac{\text { FEM }}{\# \text { of elements }}$}} \\
\hline \multirow{2}{*}{$\begin{array}{c}\text { Material } \\
\text { Region }\end{array}$} & \multirow{2}{*}{ Point } & \multirow{2}{*}{$x_{3} / w$} & & & \\
\hline & & & 500 & 36998 & 51930 \\
\hline \multirow{9}{*}{ Copper } & \multirow[t]{4}{*}{$\mathrm{E}$} & -1.00 & $2.37 \mathrm{E}+00$ & $2.29 \mathrm{E}+00$ & $2.37 \mathrm{E}+00$ \\
\hline & & -0.40 & $2.26 \mathrm{E}+00$ & $2.27 \mathrm{E}+00$ & $2.18 \mathrm{E}+00$ \\
\hline & & -0.30 & $2.28 \mathrm{E}+00$ & $2.29 \mathrm{E}+00$ & $2.19 \mathrm{E}+00$ \\
\hline & & -0.20 & $2.29 \mathrm{E}+00$ & $2.30 \mathrm{E}+00$ & $2.20 \mathrm{E}+00$ \\
\hline & \multirow[t]{4}{*}{$\mathrm{F}$} & 0.00 & $2.30 \mathrm{E}+00$ & $2.31 \mathrm{E}+00$ & $2.21 \mathrm{E}+00$ \\
\hline & & 0.20 & $2.30 \mathrm{E}+00$ & $2.31 \mathrm{E}+00$ & $2.21 \mathrm{E}+00$ \\
\hline & & 0.30 & $2.30 \mathrm{E}+00$ & $2.30 \mathrm{E}+00$ & $2.21 E+00$ \\
\hline & & 0.40 & $2.29 \mathrm{E}+00$ & $2.29 \mathrm{E}+00$ & $2.20 \mathrm{E}+00$ \\
\hline & $\mathrm{D}$ & 1.00 & $2.41 \mathrm{E}+00$ & $2.34 \mathrm{E}+00$ & $2.39 \mathrm{E}+00$ \\
\hline \multirow{9}{*}{ Alumina } & \multirow[t]{4}{*}{$\mathrm{E}$} & -1.00 & $3.34 \mathrm{E}+00$ & $3.28 \mathrm{E}+00$ & $3.36 \mathrm{E}+00$ \\
\hline & & -0.40 & $2.26 \mathrm{E}+00$ & $2.23 \mathrm{E}+00$ & $2.25 \mathrm{E}+00$ \\
\hline & & -0.30 & $2.28 \mathrm{E}+00$ & $2.24 \mathrm{E}+00$ & $2.27 \mathrm{E}+00$ \\
\hline & & -0.20 & $2.29 \mathrm{E}+00$ & $2.25 \mathrm{E}+00$ & $2.28 \mathrm{E}+00$ \\
\hline & \multirow[t]{4}{*}{ F } & 0.00 & $2.30 \mathrm{E}+00$ & $2.27 \mathrm{E}+00$ & $2.29 \mathrm{E}+00$ \\
\hline & & 0.20 & $2.30 \mathrm{E}+00$ & $2.26 \mathrm{E}+00$ & $2.29 \mathrm{E}+00$ \\
\hline & & 0.30 & $2.30 \mathrm{E}+00$ & $2.26 \mathrm{E}+00$ & $2.28 \mathrm{E}+00$ \\
\hline & & 0.40 & $2.29 \mathrm{E}+00$ & $2.25 \mathrm{E}+00$ & $2.28 \mathrm{E}+00$ \\
\hline & $\mathrm{D}$ & 1.00 & $3.43 \mathrm{E}+00$ & $3.32 \mathrm{E}+00$ & $3.39 \mathrm{E}+00$ \\
\hline
\end{tabular}

Table 4.3: Comparison of $\sigma_{11} / \sigma_{0}$ at various points from BEM and FEM analyses of the $\mathrm{Cu}-\mathrm{Al}_{2} \mathrm{O}_{3}$ bicrystal bar with double U-notch; $x_{1}=0$ and $x_{2} / H=0.5$ for all points 


\begin{tabular}{|c|c|c|c|c|c|}
\hline & & & BEM & & \\
\hline Material & Point & $x_{0} / \mu$ & \# of elements & $\#$ of $\mathrm{e}$ & ements \\
\hline Region & $10 \mathrm{t}$ & $\alpha_{3 / \omega}$ & 500 & 36998 & 51930 \\
\hline & $\mathrm{E}$ & -1.00 & $2.01 \mathrm{E}+00$ & $1.98 \mathrm{E}+00$ & $2.05 \mathrm{E}+00$ \\
\hline & & -0.40 & $9.32 \mathrm{E}-01$ & $9.43 \mathrm{E}-01$ & $9.27 \mathrm{E}-01$ \\
\hline & & -0.30 & $9.02 \mathrm{E}-01$ & $9.07 \mathrm{E}-01$ & $8.92 \mathrm{E}-01$ \\
\hline & & -0.20 & $8.84 \mathrm{E}-01$ & $8.87 \mathrm{E}-01$ & $8.71 \mathrm{E}-01$ \\
\hline Copper & $\mathrm{F}$ & 0.00 & $8.83 \mathrm{E}-01$ & $8.83 \mathrm{E}-01$ & $8.68 \mathrm{E}-01$ \\
\hline & & 0.20 & $9.31 \mathrm{E}-01$ & $9.22 \mathrm{E}-01$ & $9.06 \mathrm{E}-01$ \\
\hline & & 0.30 & $9.73 \mathrm{E}-01$ & $9.57 \mathrm{E}-01$ & $9.42 \mathrm{E}-01$ \\
\hline & & 0.40 & $1.03 \mathrm{E}+00$ & $1.01 \mathrm{E}+00$ & $9.89 \mathrm{E}-01$ \\
\hline & $\mathrm{D}$ & 1.00 & $2.05 \mathrm{E}+00$ & $1.92 \mathrm{E}+00$ & $1.92 \mathrm{E}+00$ \\
\hline & $\mathrm{E}$ & -1.00 & $3.97 \mathrm{E}+00$ & $4.13 \mathrm{E}+00$ & $4.36 \mathrm{E}+00$ \\
\hline & & -0.40 & $3.26 \mathrm{E}+00$ & $3.15 \mathrm{E}+00$ & $3.20 \mathrm{E}+00$ \\
\hline & & -0.30 & $3.25 \mathrm{E}+00$ & $3.12 \mathrm{E}+00$ & $3.17 \mathrm{E}+00$ \\
\hline & & -0.20 & $3.24 \mathrm{E}+00$ & $3.11 \mathrm{E}+00$ & $3.15 \mathrm{E}+00$ \\
\hline Alumina & $\mathrm{F}$ & 0.00 & $3.22 \mathrm{E}+00$ & $3.12 \mathrm{E}+00$ & $3.16 \mathrm{E}+00$ \\
\hline & & 0.20 & $3.29 \mathrm{E}+00$ & $3.18 \mathrm{E}+00$ & $3.21 \mathrm{E}+00$ \\
\hline & & 0.30 & $3.34 \mathrm{E}+00$ & $3.23 \mathrm{E}+00$ & $3.26 \mathrm{E}+00$ \\
\hline & & 0.40 & $3.39 \mathrm{E}+00$ & $3.29 \mathrm{E}+00$ & $3.33 \mathrm{E}+00$ \\
\hline & D & 1.00 & $4.03 \mathrm{E}+00$ & $4.09 \mathrm{E}+00$ & $4.32 \mathrm{E}+00$ \\
\hline
\end{tabular}

Table 4.4: Comparison of $\sigma_{e q} / \sigma_{0}$ at various points from BEM and FEM analyses of the $\mathrm{Cu}-\mathrm{Al}_{2} \mathrm{O}_{3}$ bicrystal bar with double U-notch ; $x_{1}=0$ and $x_{2} / H=0.5$ for all points 


\begin{tabular}{|c|c|c|c|c|c|c|c|c|}
\cline { 2 - 8 } \multicolumn{2}{c}{} & $\sigma_{11}$ & $\sigma_{22}$ & $\sigma_{33}$ & $\sigma_{12}$ & $\sigma_{23}$ & $\sigma_{31}$ & $\sigma_{e q}$ \\
\hline $\begin{array}{c}\text { Isotropic } \\
\text { Homogeneous }\end{array}$ & $\begin{array}{c}E=1000 \mathrm{GPa} \\
\nu=0.3\end{array}$ & $2.17 \mathrm{E}+00$ & $7.84 \mathrm{E}-01$ & $2.89 \mathrm{E}-01$ & $4.47 \mathrm{E}-03$ & $1.22 \mathrm{E}-03$ & $0.00 \mathrm{E}+00$ & $1.69 \mathrm{E}+00$ \\
\hline $\begin{array}{c}\text { Isotropic } \\
\text { Bimaterial }\end{array}$ & $\mathrm{Cu}$ & $2.14 \mathrm{E}+00$ & $1.03 \mathrm{E}+00$ & $8.14 \mathrm{E}-01$ & $4.05 \mathrm{E}-02$ & $1.81 \mathrm{E}-05$ & $3.65 \mathrm{E}-05$ & $1.24 \mathrm{E}+00$ \\
\cline { 2 - 10 } & $\mathrm{Al}_{2} \mathrm{O}_{3}$ & $2.14 \mathrm{E}+00$ & $4.78 \mathrm{E}-01$ & $-3.12 \mathrm{E}-01$ & $4.05 \mathrm{E}-02$ & $6.68 \mathrm{E}-05$ & $3.65 \mathrm{E}-05$ & $2.17 \mathrm{E}+00$ \\
\hline $\begin{array}{c}\text { Anisotropic } \\
\text { Bimaterial }\end{array}$ & $\mathrm{Cu}$ & $2.30 \mathrm{E}+00$ & $1.48 \mathrm{E}+00$ & $1.38 \mathrm{E}+00$ & $3.27 \mathrm{E}-02$ & $-2.33 \mathrm{E}-02$ & $-5.58 \mathrm{E}-02$ & $8.83 \mathrm{E}-01$ \\
\cline { 2 - 10 } & $\mathrm{Al}_{2} \mathrm{O}_{3}$ & $2.30 \mathrm{E}+00$ & $-2.22 \mathrm{E}-02$ & $-1.12 \mathrm{E}+00$ & $3.27 \mathrm{E}-02$ & $6.34 \mathrm{E}-01$ & $-5.58 \mathrm{E}-02$ & $3.22 \mathrm{E}+00$ \\
\hline
\end{tabular}

Table 4.5: Stress components at point $F$ for various material combinations of a bar with a double U-notch at the interface; all stresses have been normalized with respect to the applied load, $\sigma_{0}$ 


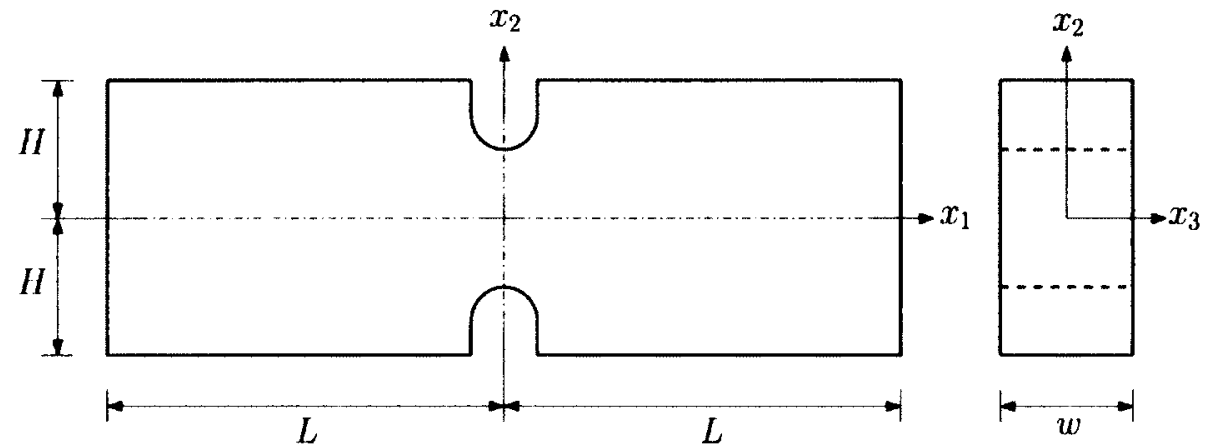

(a)

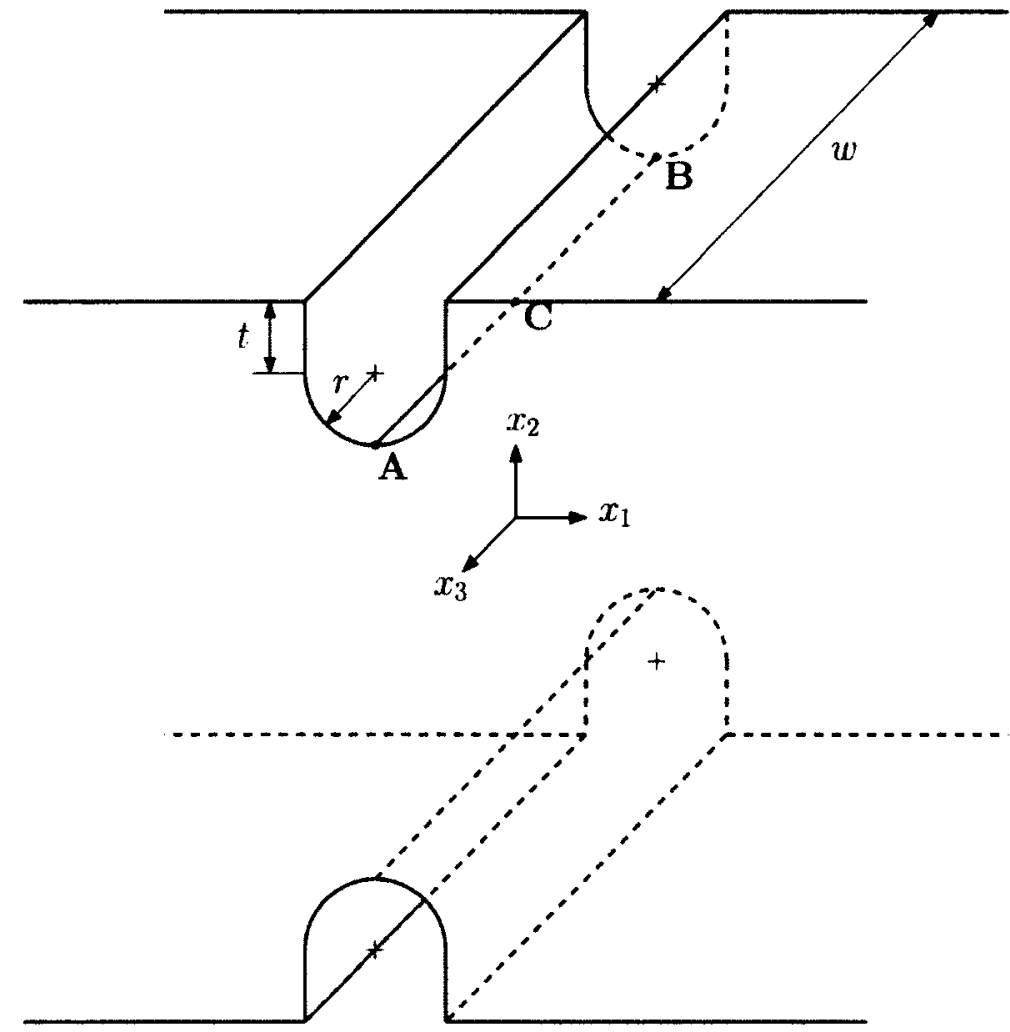

(b)

Figure 4.1: Bar with double U-notch in tension; the case analysed has $t / H=r / H=$ $0.2, w / H=1$, and $L / w=4$ 


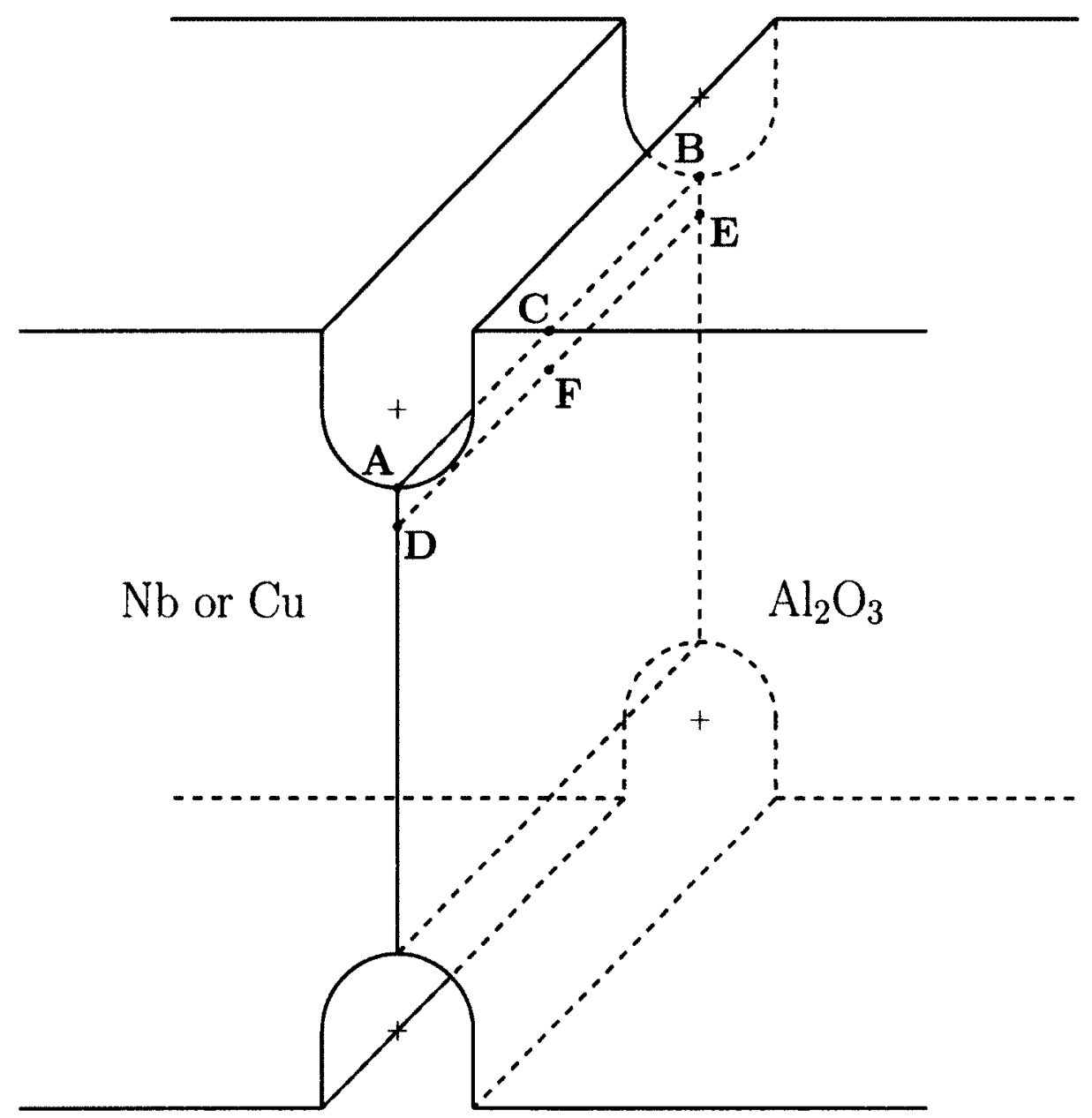

Figure 4.2: Materials regions of a bimaterial bar with double U-notch 


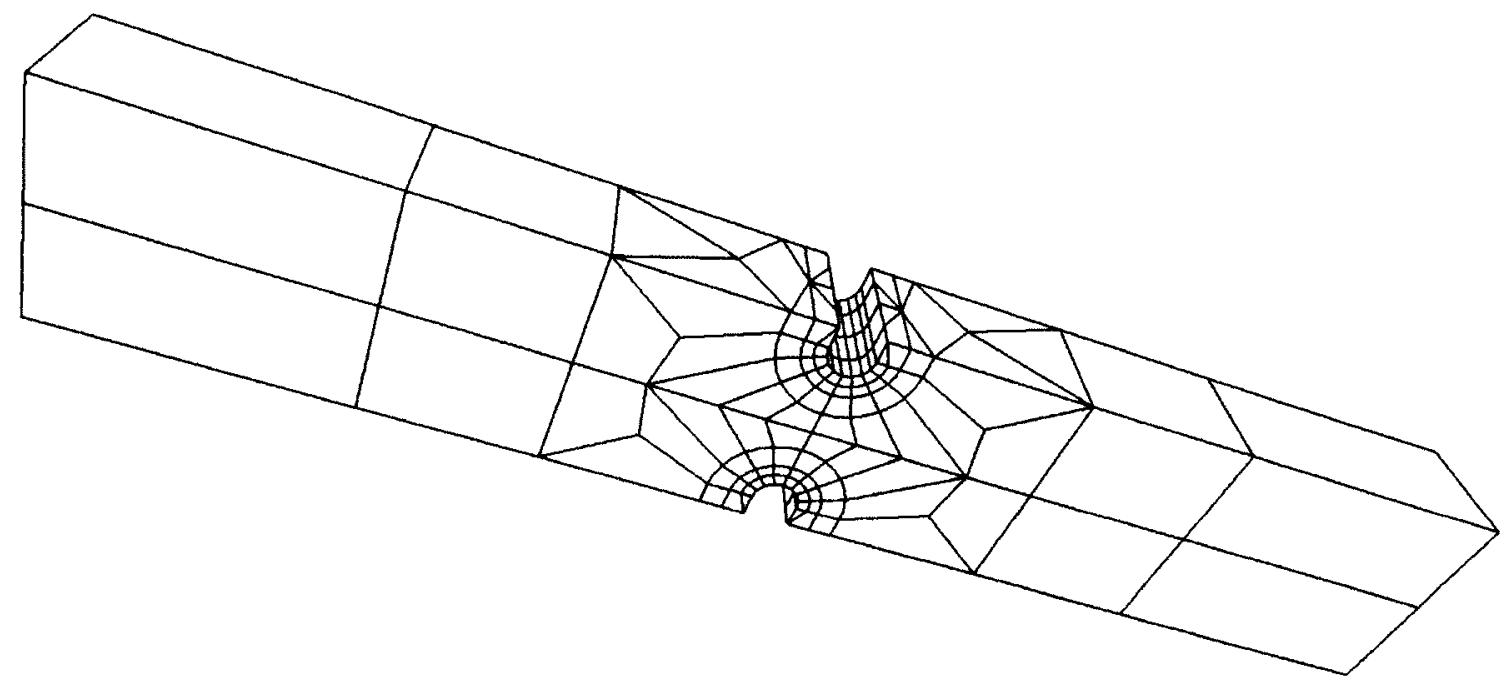

(a) Full Mesh

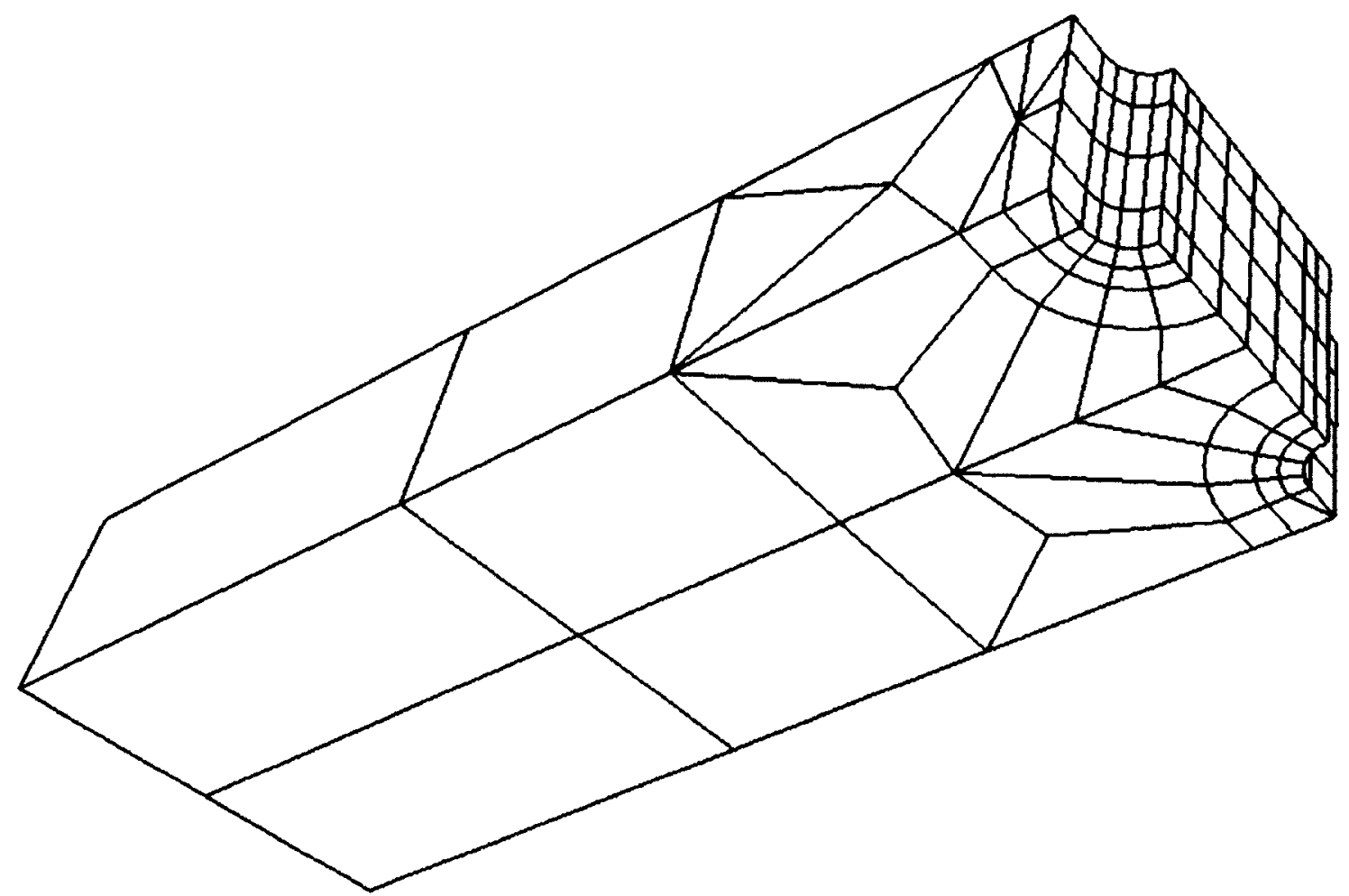

(b) Interfacial Mesh

Figure 4.3: $\mathrm{BEM}$ mesh of the $\mathrm{Nb}-\mathrm{Al}_{2} \mathrm{O}_{3}$ bicrystal bar with double U-notch (380 elements and 1108 nodes) 

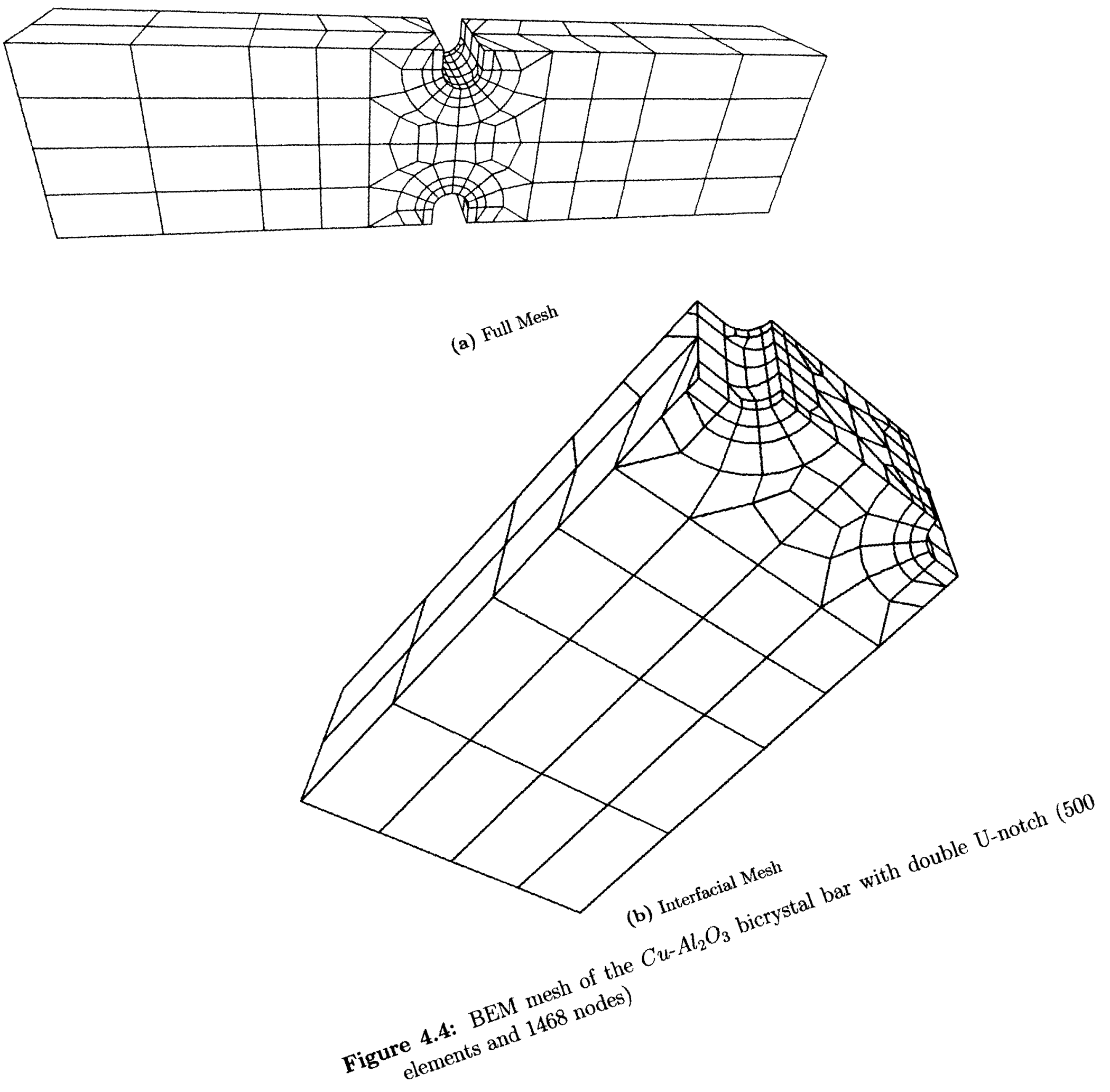


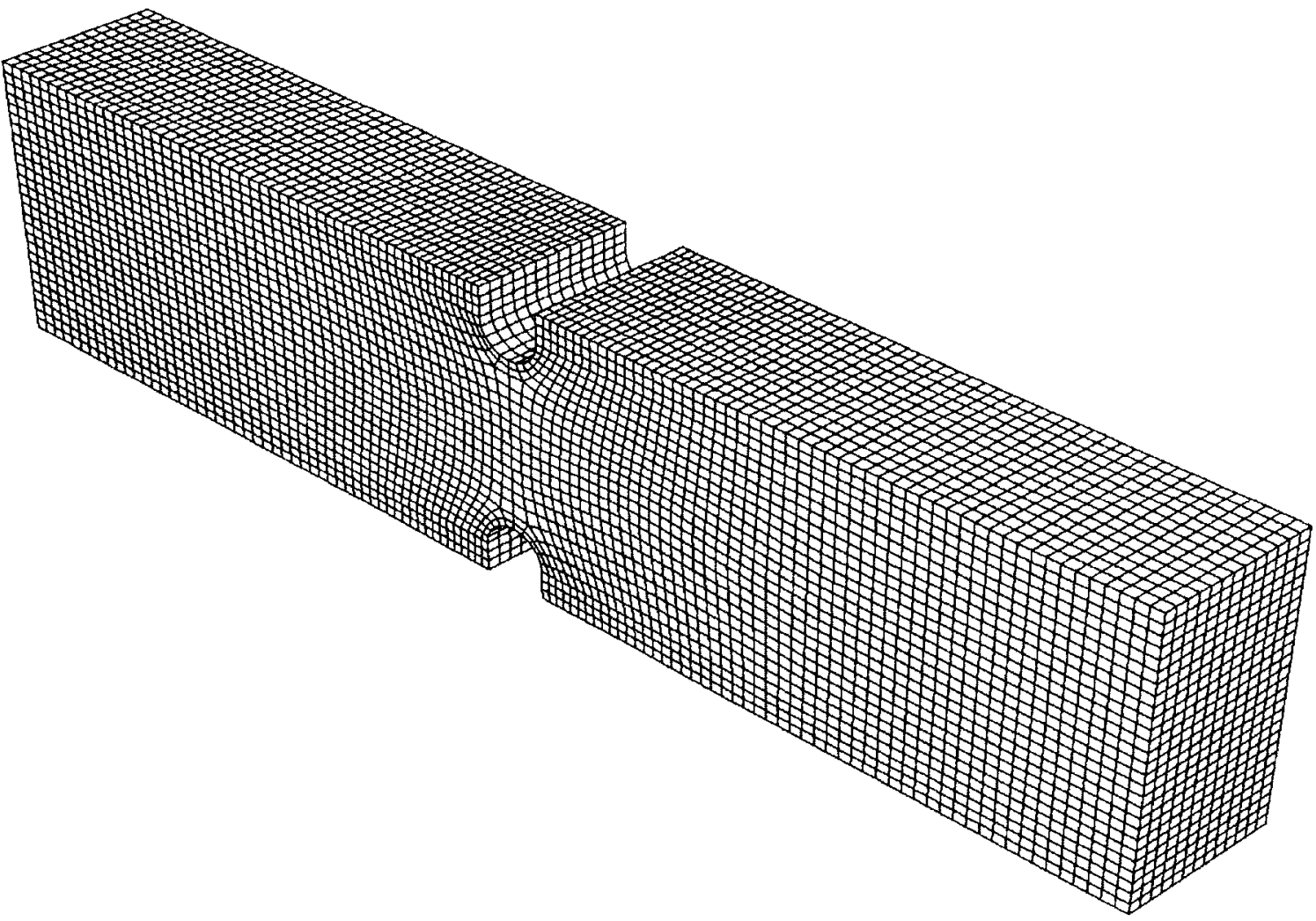

Figure 4.5: FEM mesh of a bimaterial bar with double U-notch $(36,998$ elements and 162,707 nodes) 


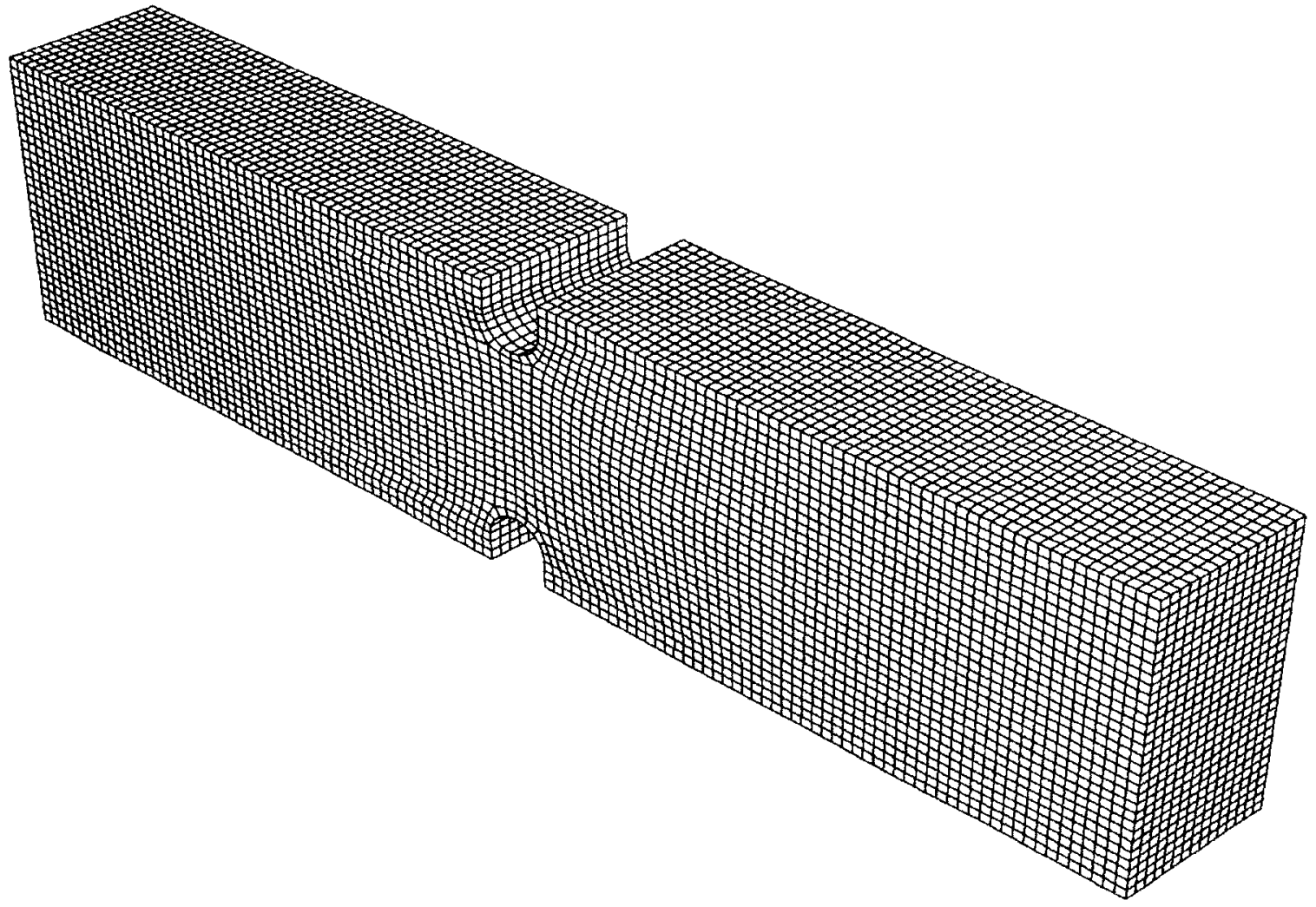

Figure 4.6: FEM mesh of a bimaterial bar with double U-notch (51,930 elements and 225,704 nodes) 


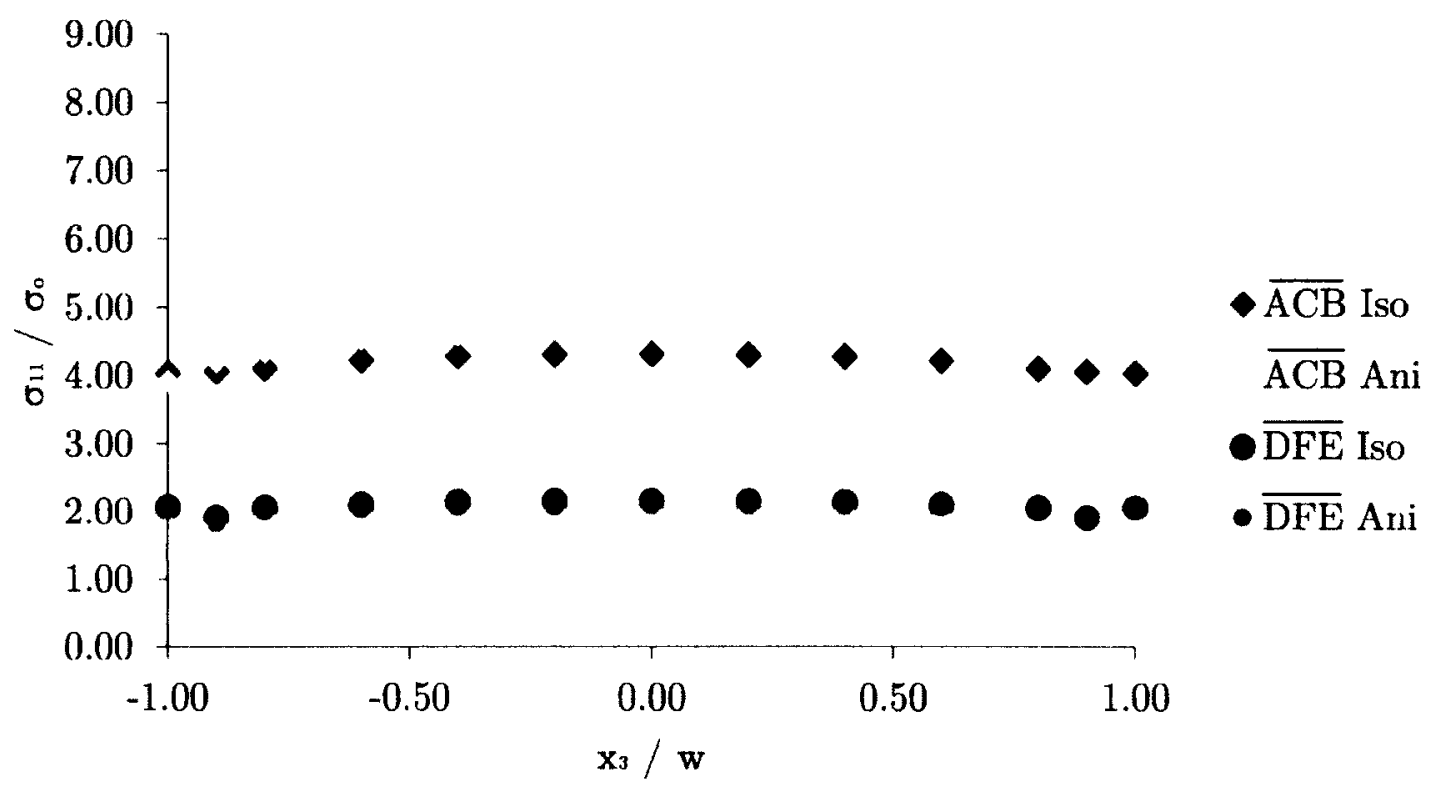

(a) In the $\mathrm{Nb}$ crystal of the $\mathrm{Nb}-\mathrm{Al}_{2} \mathrm{O}_{3}$ interface

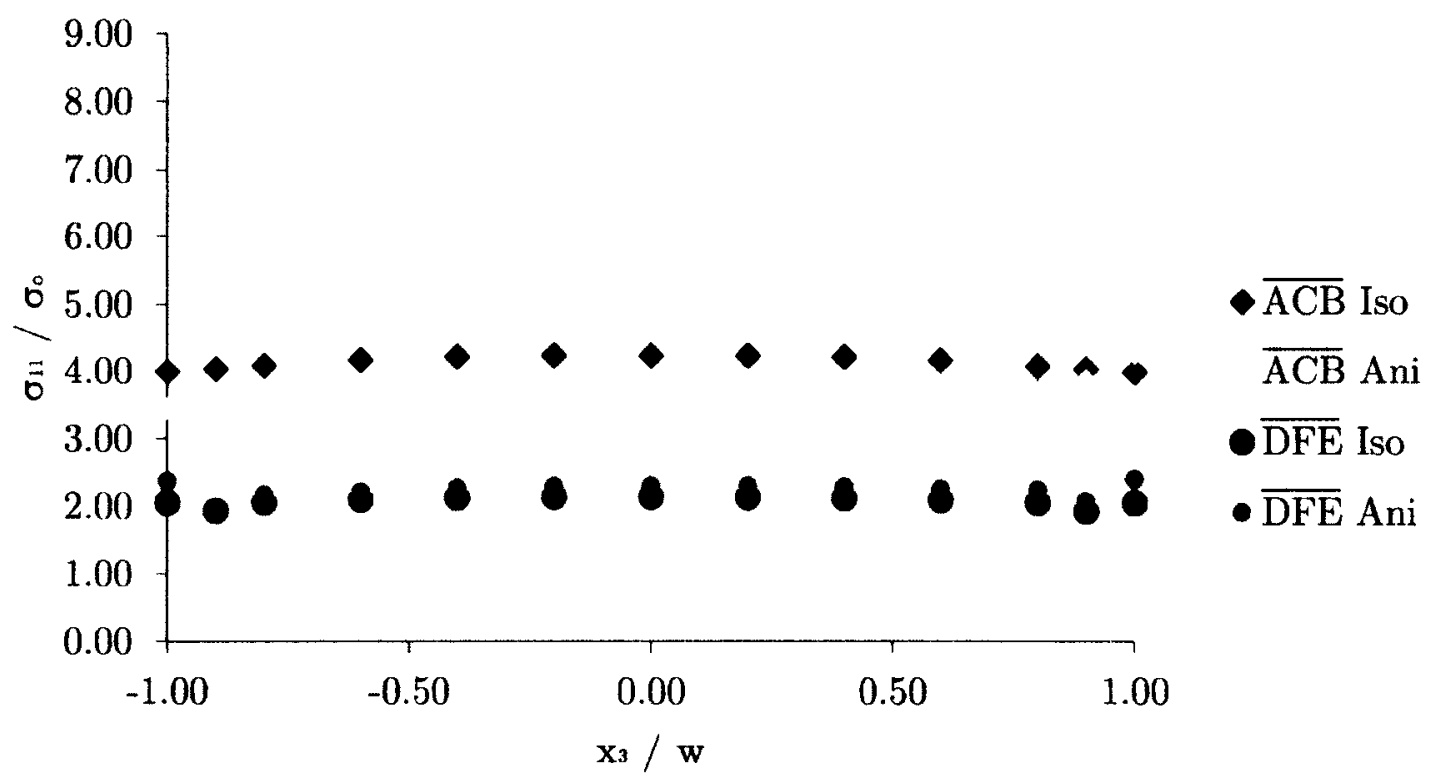

(b) In the $\mathrm{Cu}$ crystal of the $\mathrm{Cu}-\mathrm{Al}_{2} \mathrm{O}_{3}$ interface

Figure 4.7: Variations of $\sigma_{11} / \sigma_{0}$ through the thickness at the interface of a bimaterial bar with double U-notch - Isotropic (Iso) and Anisotropic (Ani) 


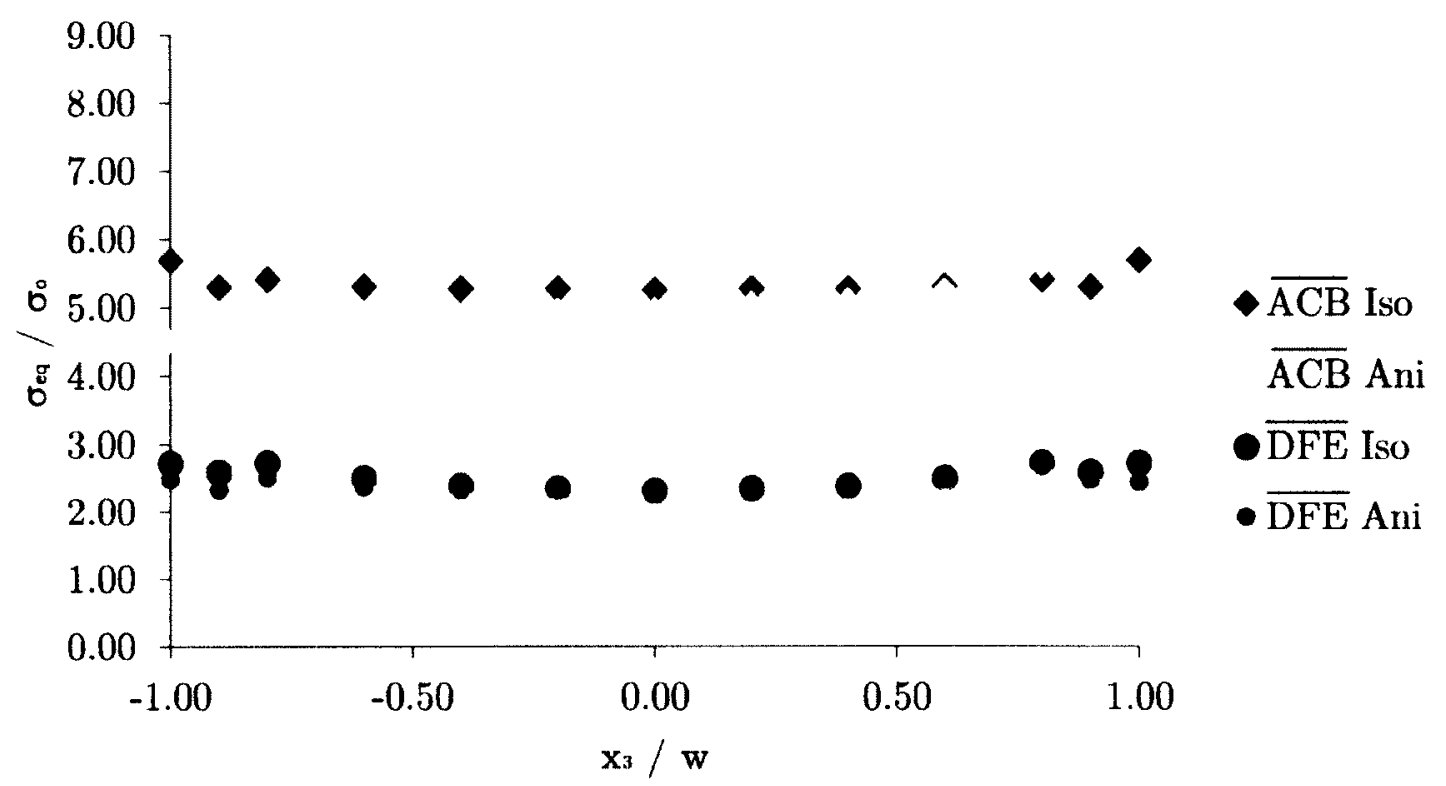

(a) In the $\mathrm{Al}_{2} \mathrm{O}_{3}$ crystal of the $\mathrm{Nb}-\mathrm{Al}_{2} \mathrm{O}_{3}$ interface

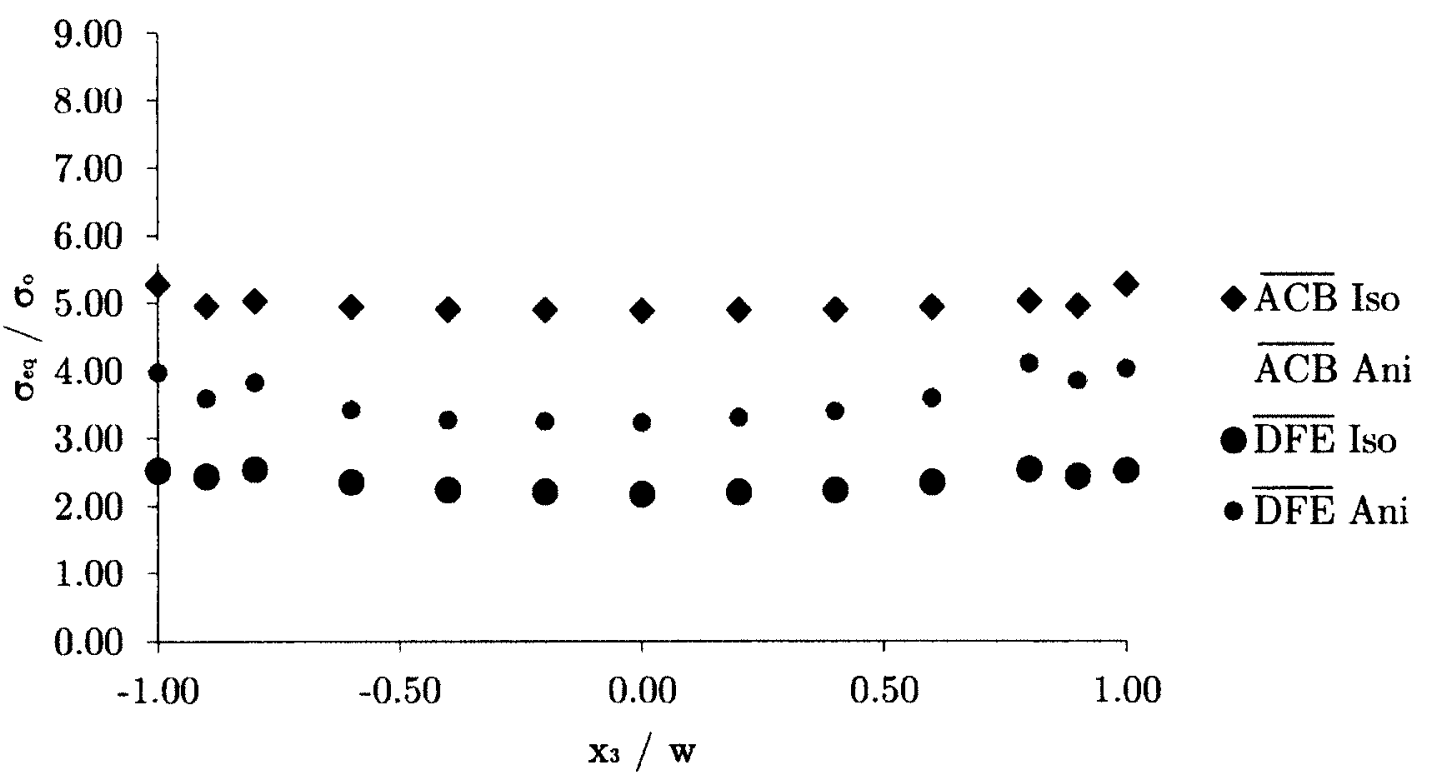

(b) In the $\mathrm{Al}_{2} \mathrm{O}_{3}$ crystal of the $\mathrm{Cu}-\mathrm{Al}_{2} \mathrm{O}_{3}$ interface

Figure 4.8: Variations of $\sigma_{e q} / \sigma_{0}$ through the thickness at the interface of a bimaterial bar with double U-notch - Isotropic (Iso) and Anisotropic (Ani) 


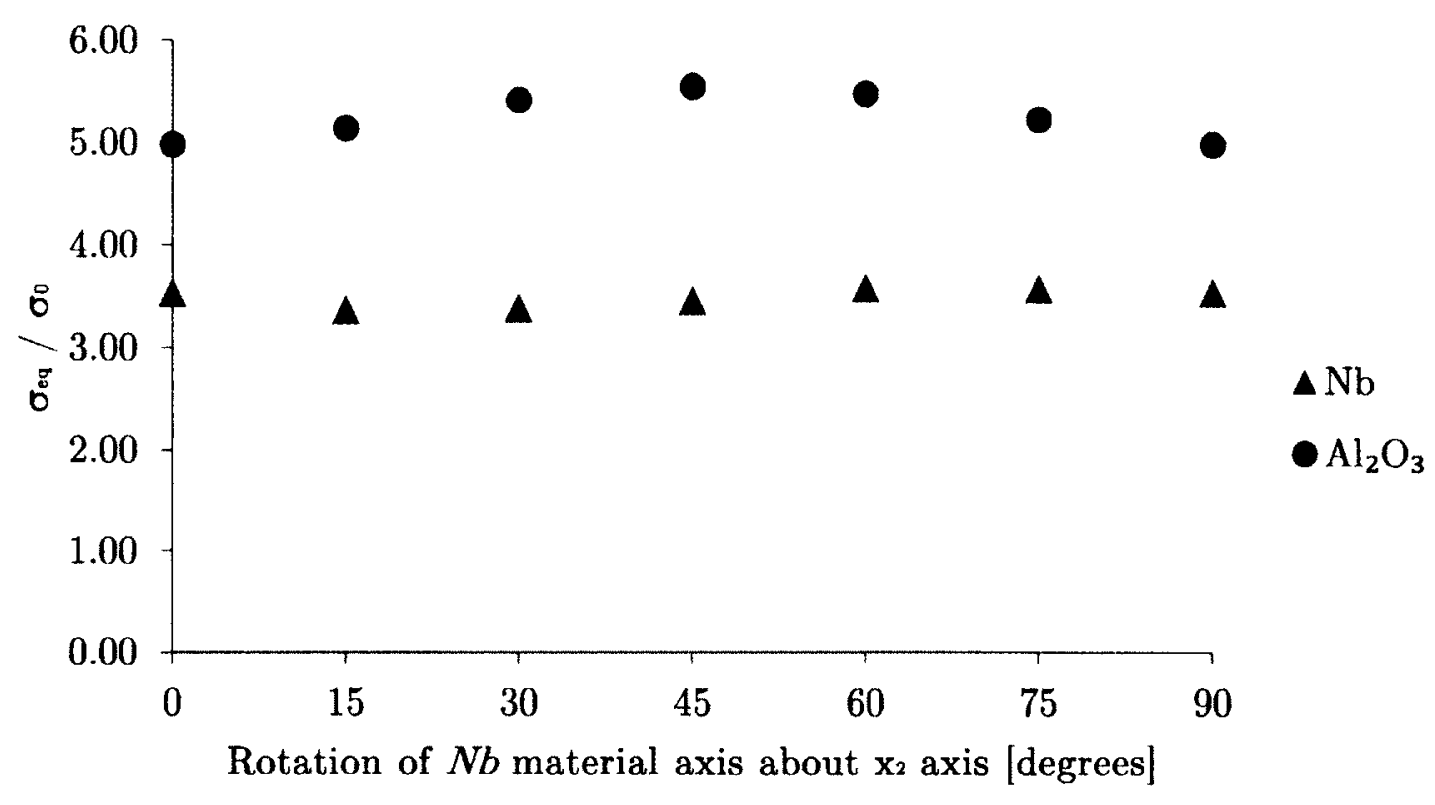

(a) At point $\mathrm{C}$

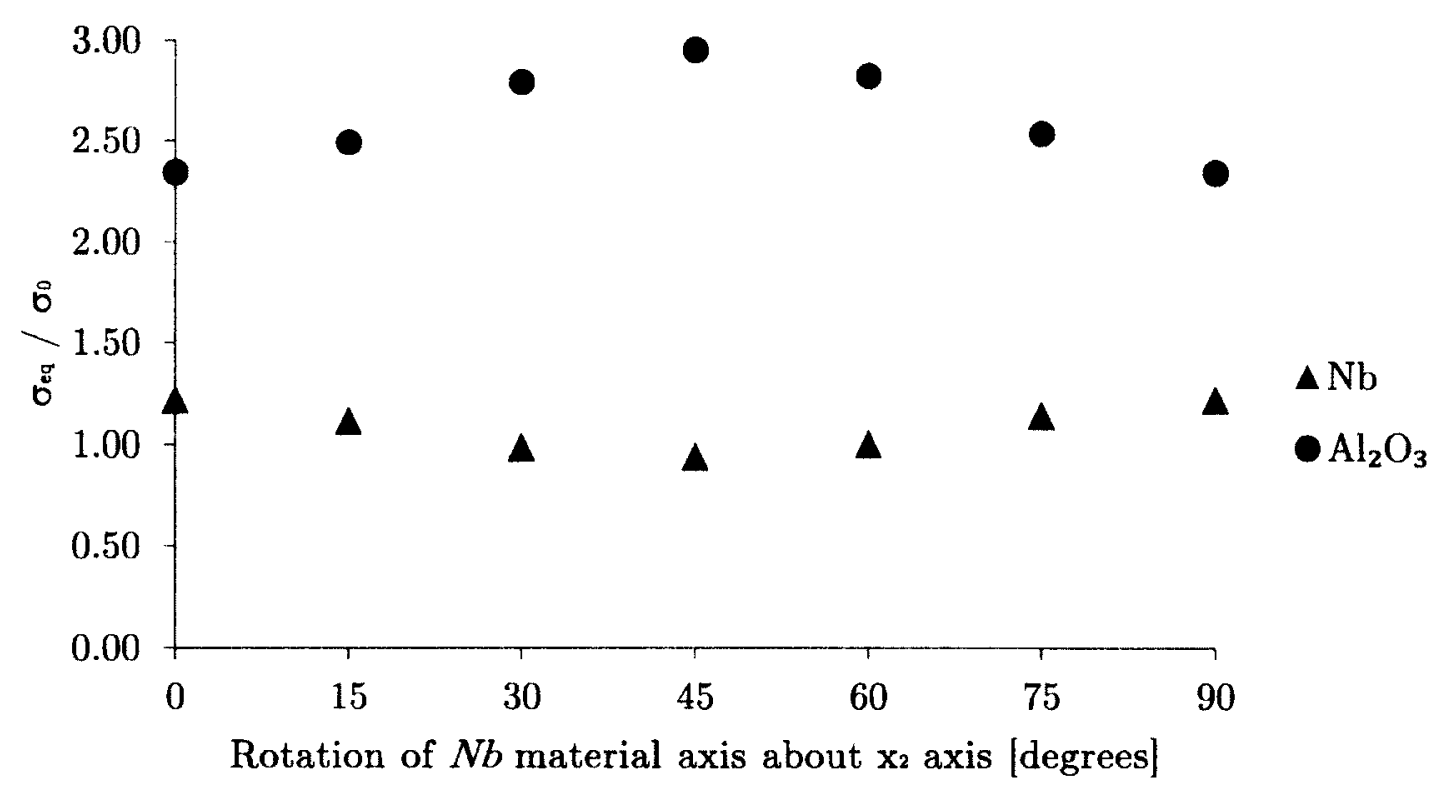

(b) At point $\mathrm{F}$

Figure 4.9: Variation of $\sigma_{e q} / \sigma_{0}$ of a $\mathrm{Nb}-\mathrm{Al}_{2} \mathrm{O}_{3}$ bicrystal bar with double U-notch for $x_{2}$-material axis rotations of the $\mathrm{Nb}$ crystal 


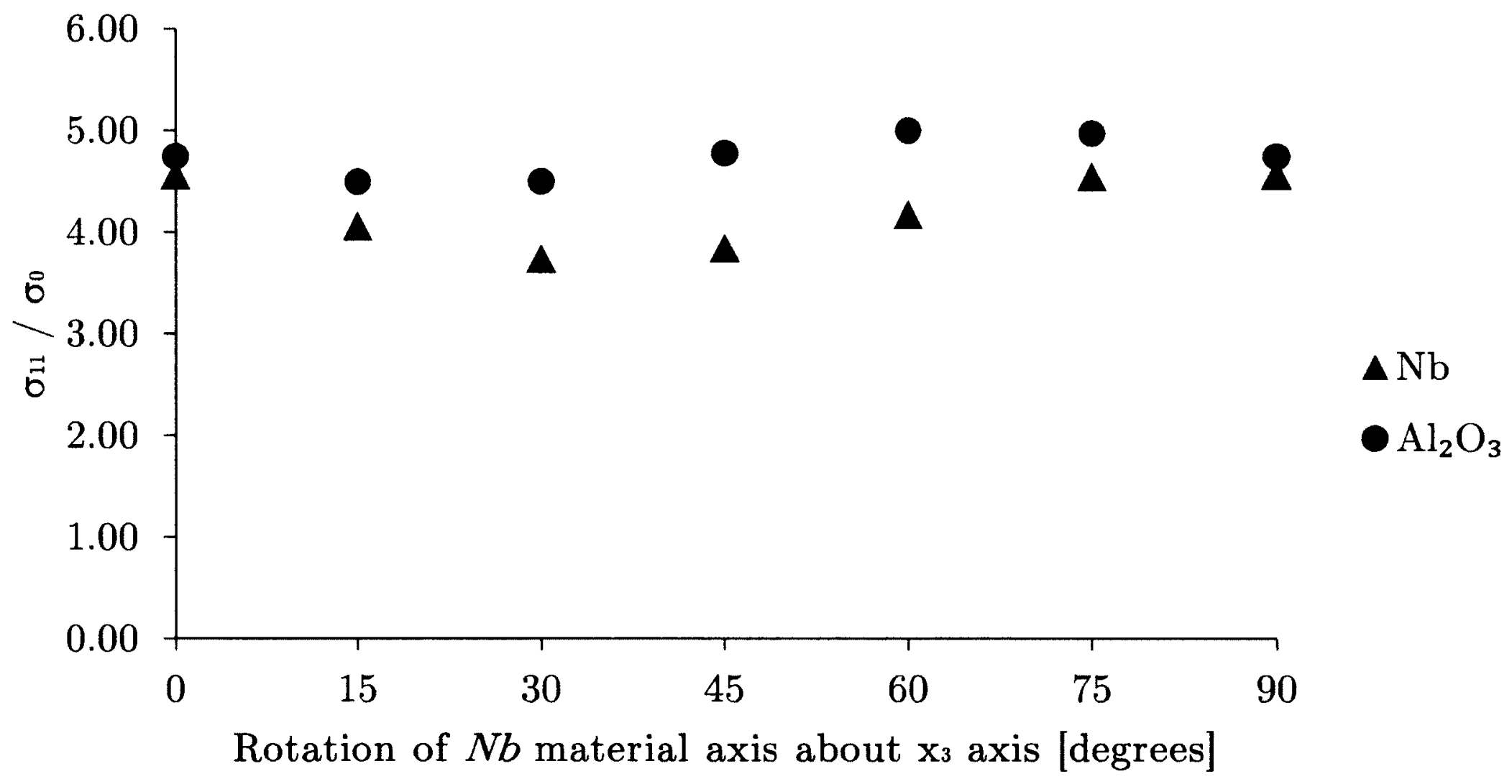

Figure 4.10: Variation of $\sigma_{11} / \sigma_{0}$ at point $\mathrm{C}$ of a $N b-A l_{2} O_{3}$ bicrystal bar with double U-notch for $x_{3}$-material axis rotations of the $N b$ crystal 


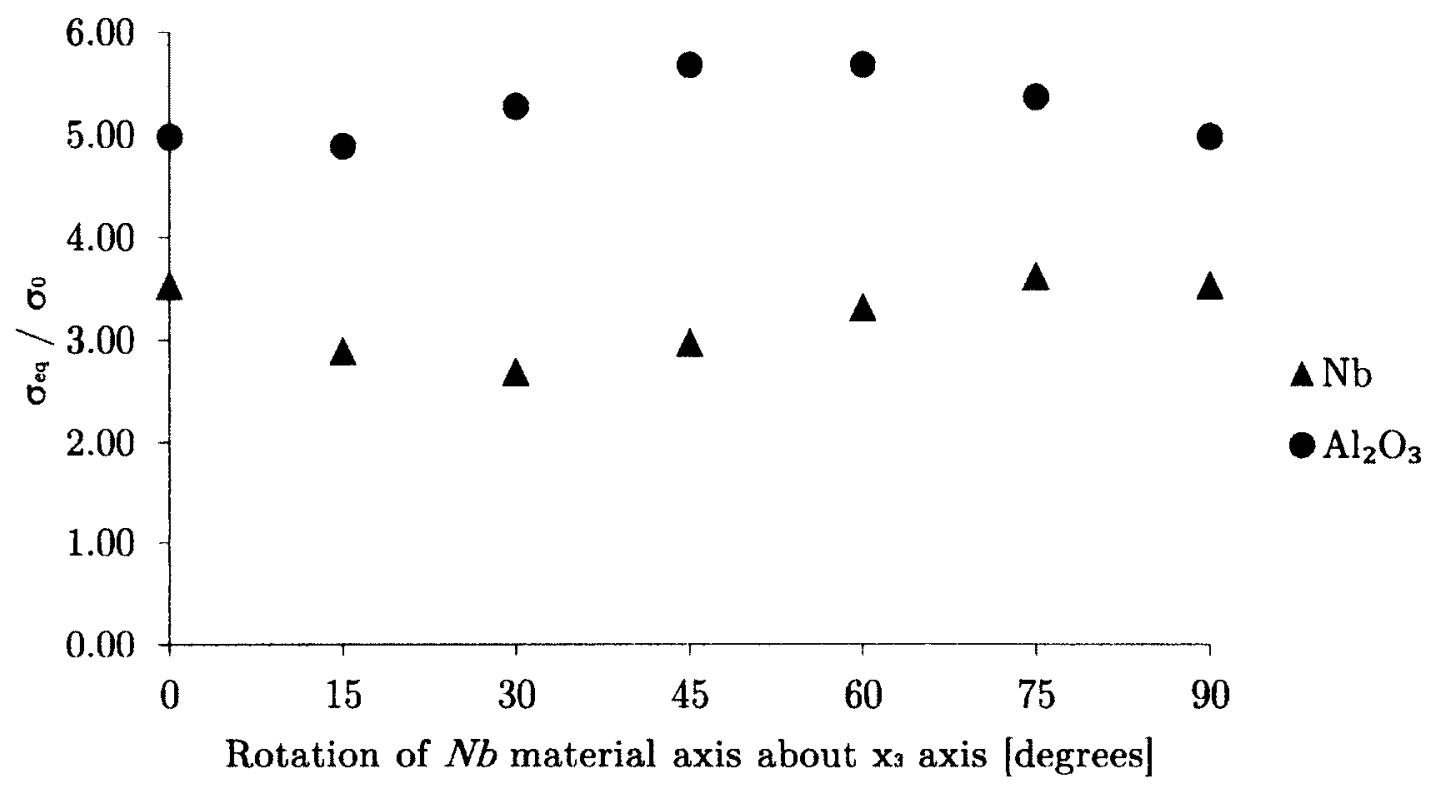

(a) At point $\mathrm{C}$

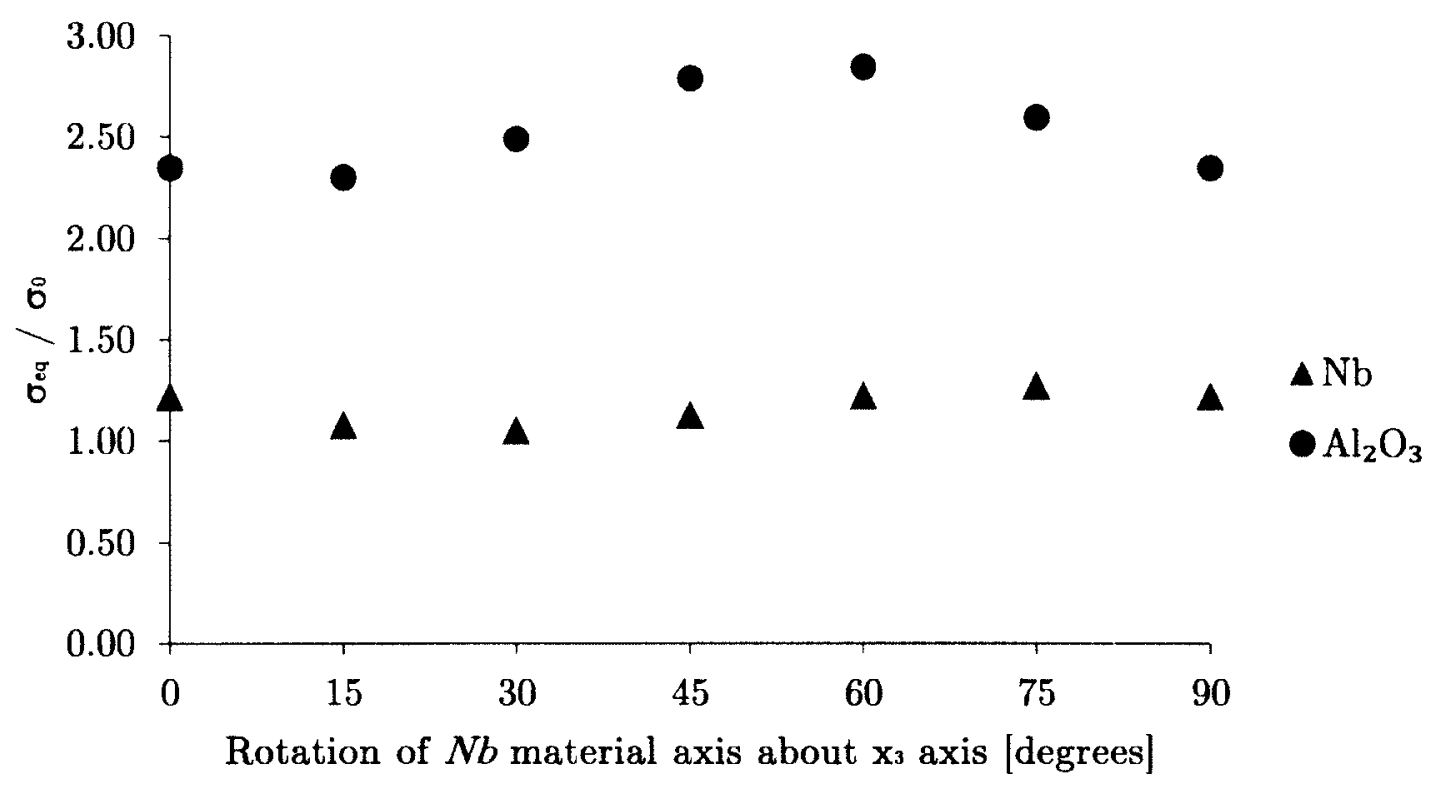

(b) At point $\mathrm{F}$

Figure 4.11: Variation of $\sigma_{e q} / \sigma_{0}$ of a $\mathrm{Nb}-\mathrm{Al}_{2} \mathrm{O}_{3}$ bicrystal bar with double U-notch for $x_{3}$-material axis rotations of the $N b$ crystal 


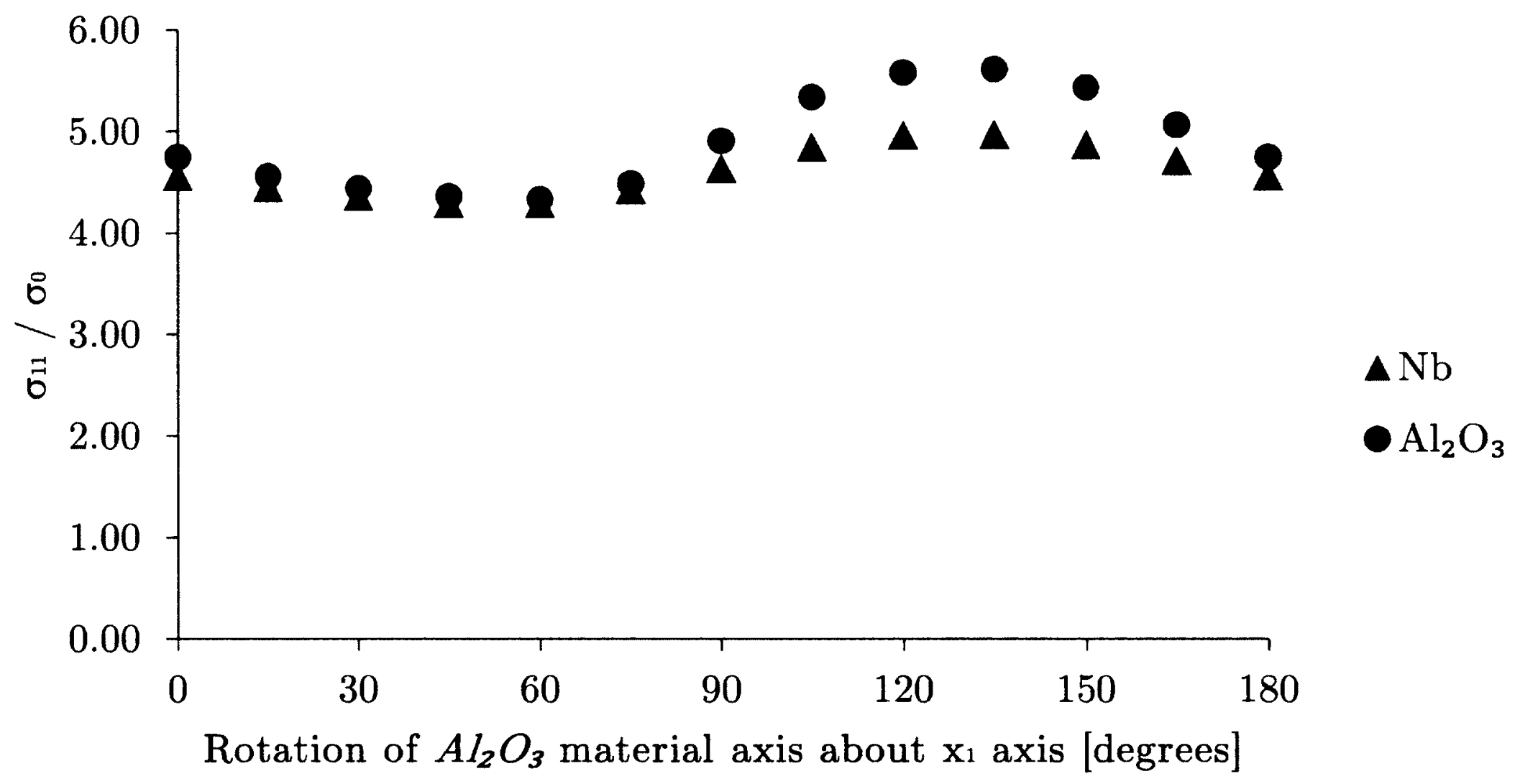

Figure 4.12: Variation of $\sigma_{11} / \sigma_{0}$ at point $\mathrm{C}$ of a $\mathrm{Nb}-\mathrm{Al}_{2} \mathrm{O}_{3}$ bicrystal bar with double U-notch for $x_{1}$-material axis rotations of the $N b$ crystal 


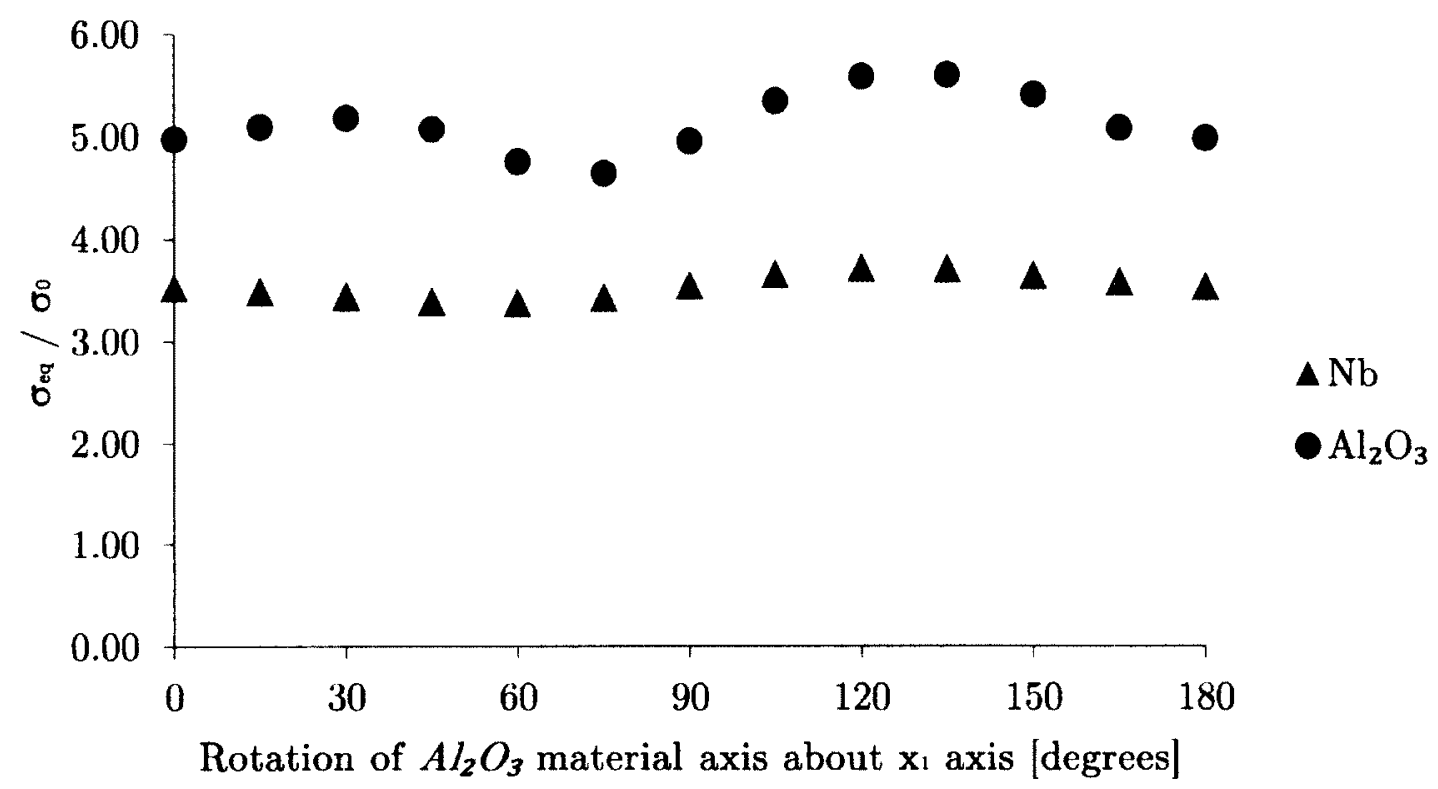

(a) At point $\mathrm{C}$

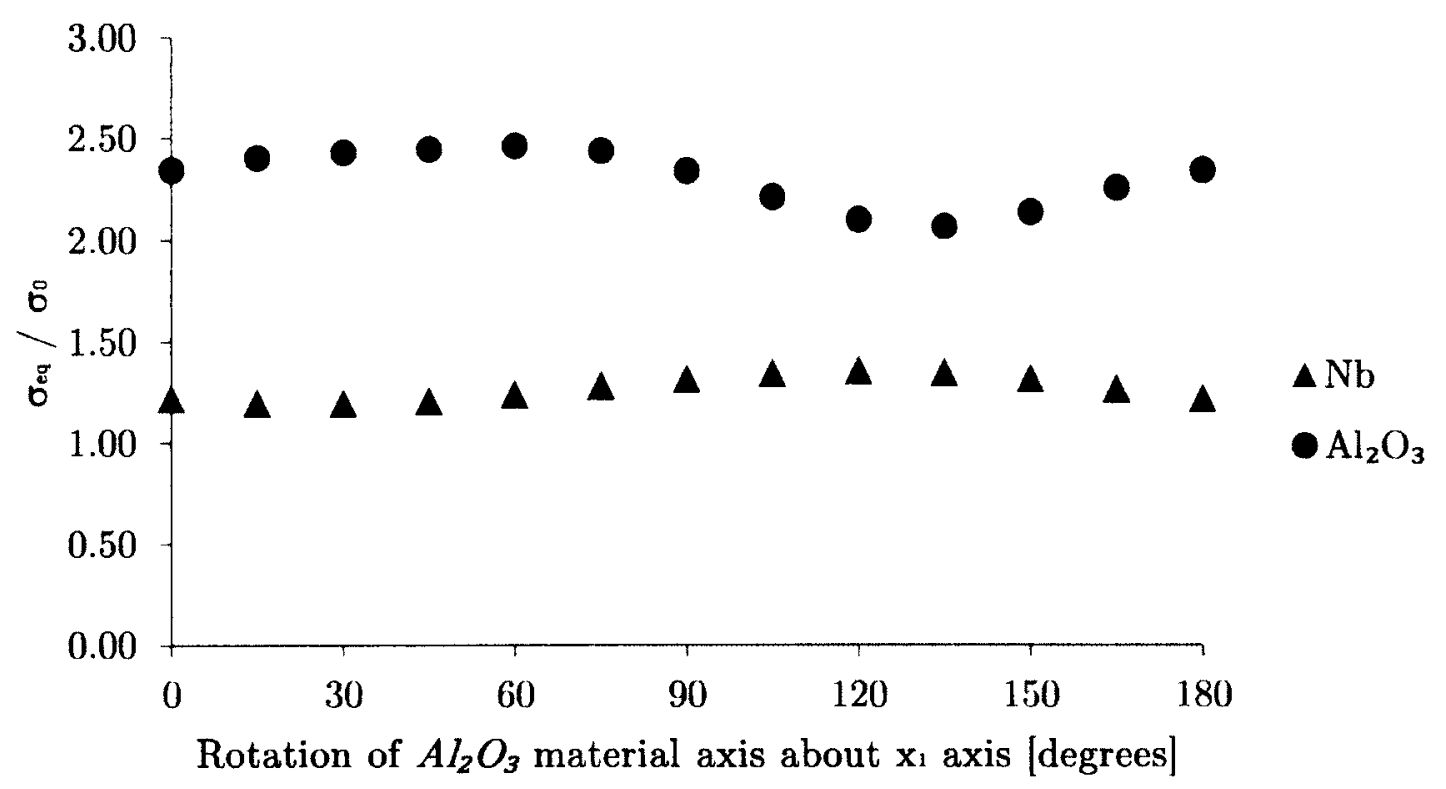

(b) At point $F$

Figure 4.13: Variation of $\sigma_{e q} / \sigma_{0}$ of a $\mathrm{Nb}-\mathrm{Al}_{2} \mathrm{O}_{3}$ bicrystal bar with double U-notch for $x_{1}$-material axis rotations of the $\mathrm{Al}_{2} \mathrm{O}_{3}$ crystal 


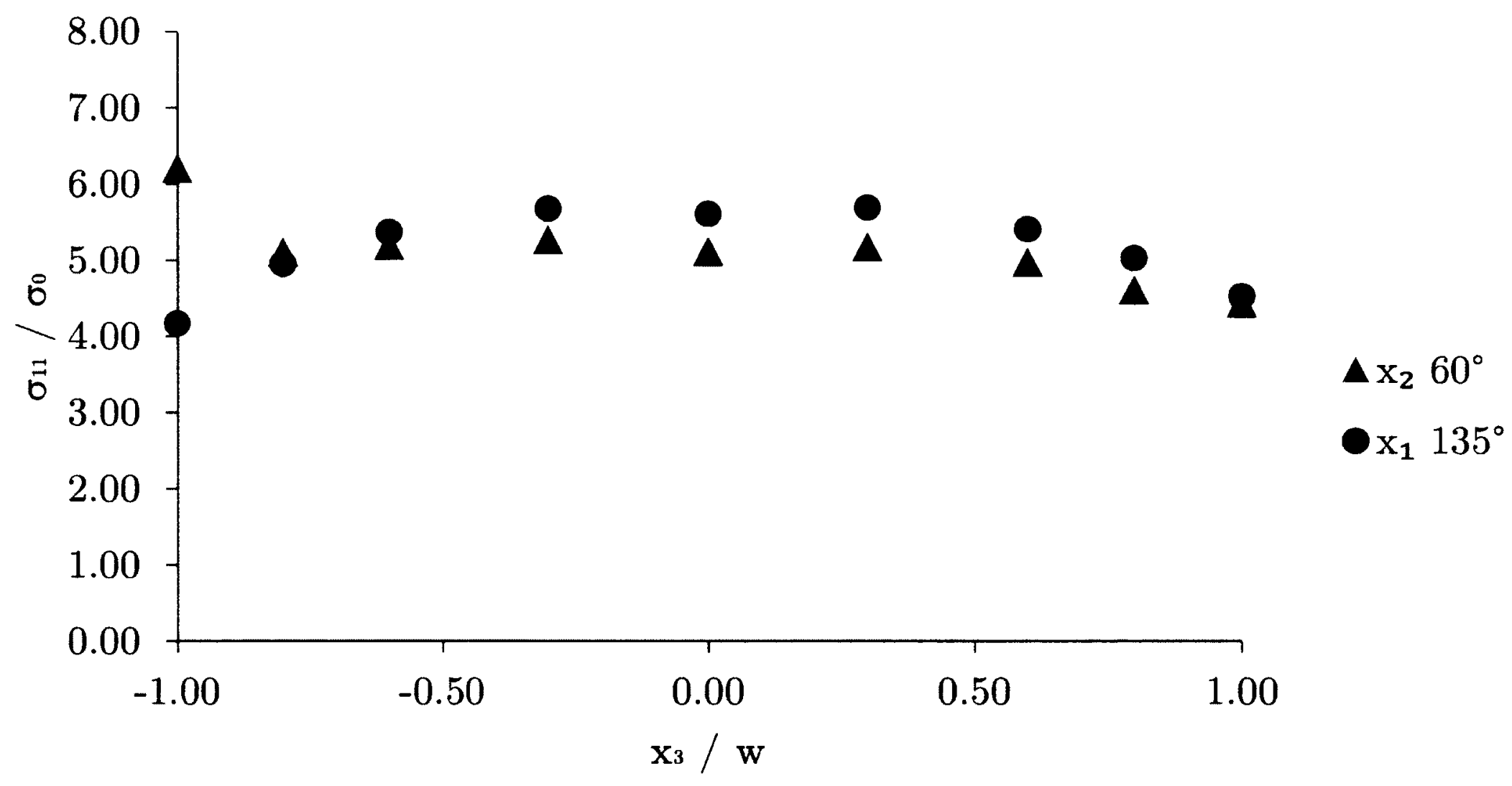

Figure 4.14: Variation of $\sigma_{11} / \sigma_{0}$ through the thickness along $\overline{A C B}$ at the interface of a $\mathrm{Nb}_{-} \mathrm{Al}_{2} \mathrm{O}_{3}$ bicrystal bar with double U-notch in the $\mathrm{Al}_{2} \mathrm{O}_{3}$ crystal for an $\mathrm{Al}_{2} \mathrm{O}_{3} x_{2}$-material axis rotation of $60^{\circ}$ and $x_{1}$-material axis rotation of $135^{\circ}$ 


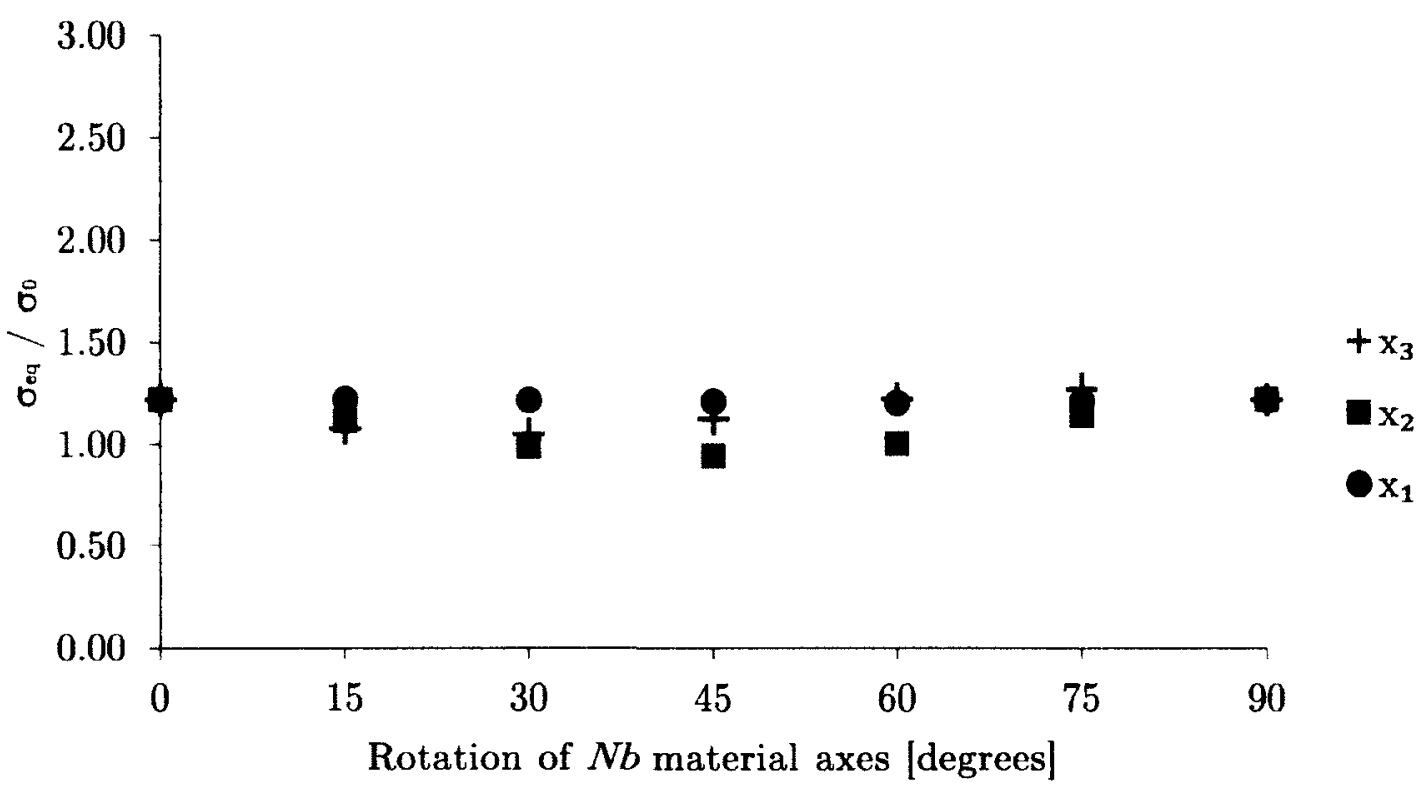

(a) Rotations of the $\mathrm{Nb}$ crystal

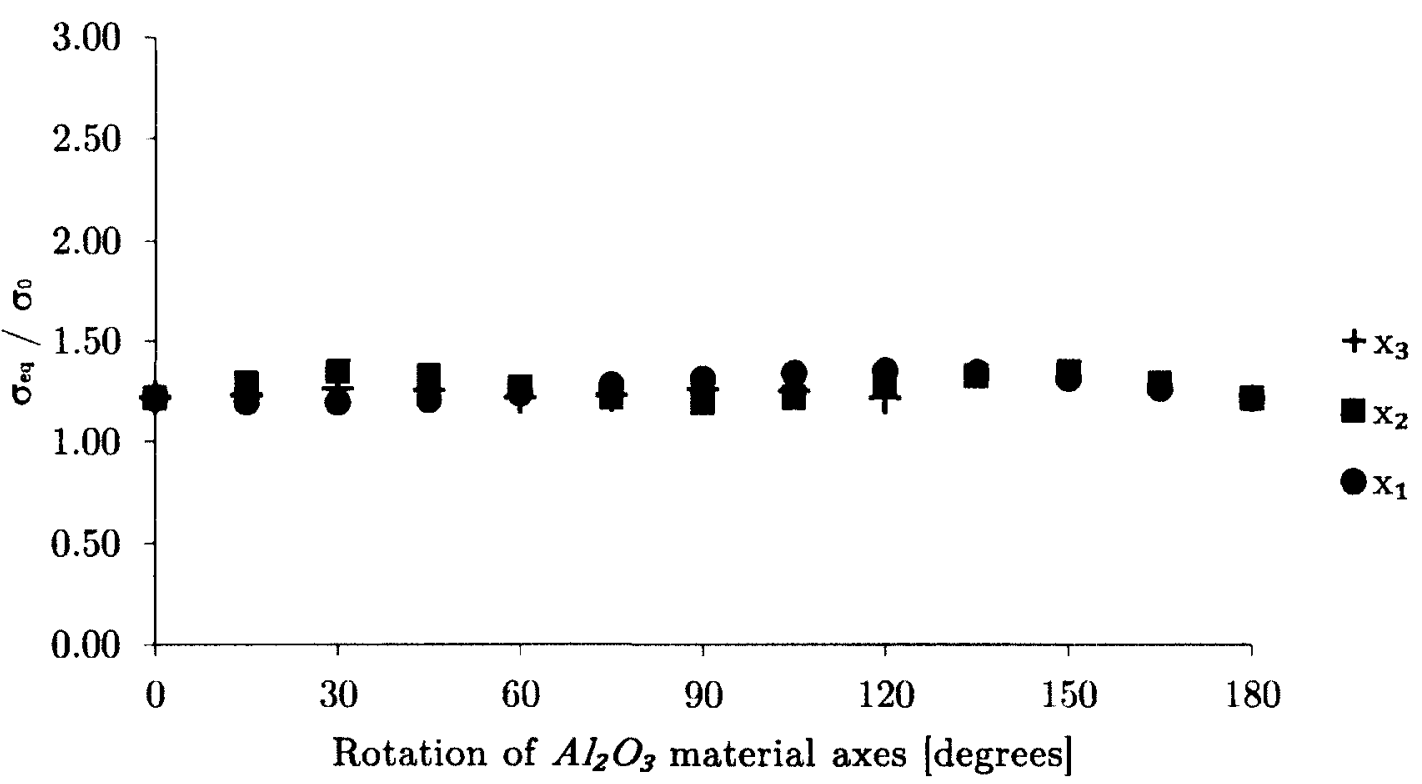

(b) Rotations of the $\mathrm{Al}_{2} \mathrm{O}_{3}$ crystal

Figure 4.15: Variation of $\sigma_{e q} / \sigma_{0}$ at point $\mathrm{F}$ in the $\mathrm{Nb}$ crystal of a $\mathrm{Nb}-\mathrm{Al}_{2} \mathrm{O}_{3}$ bicrystal bar with a double U-notch for $x_{1}, x_{2}$, and $x_{3}$-material axis rotations 


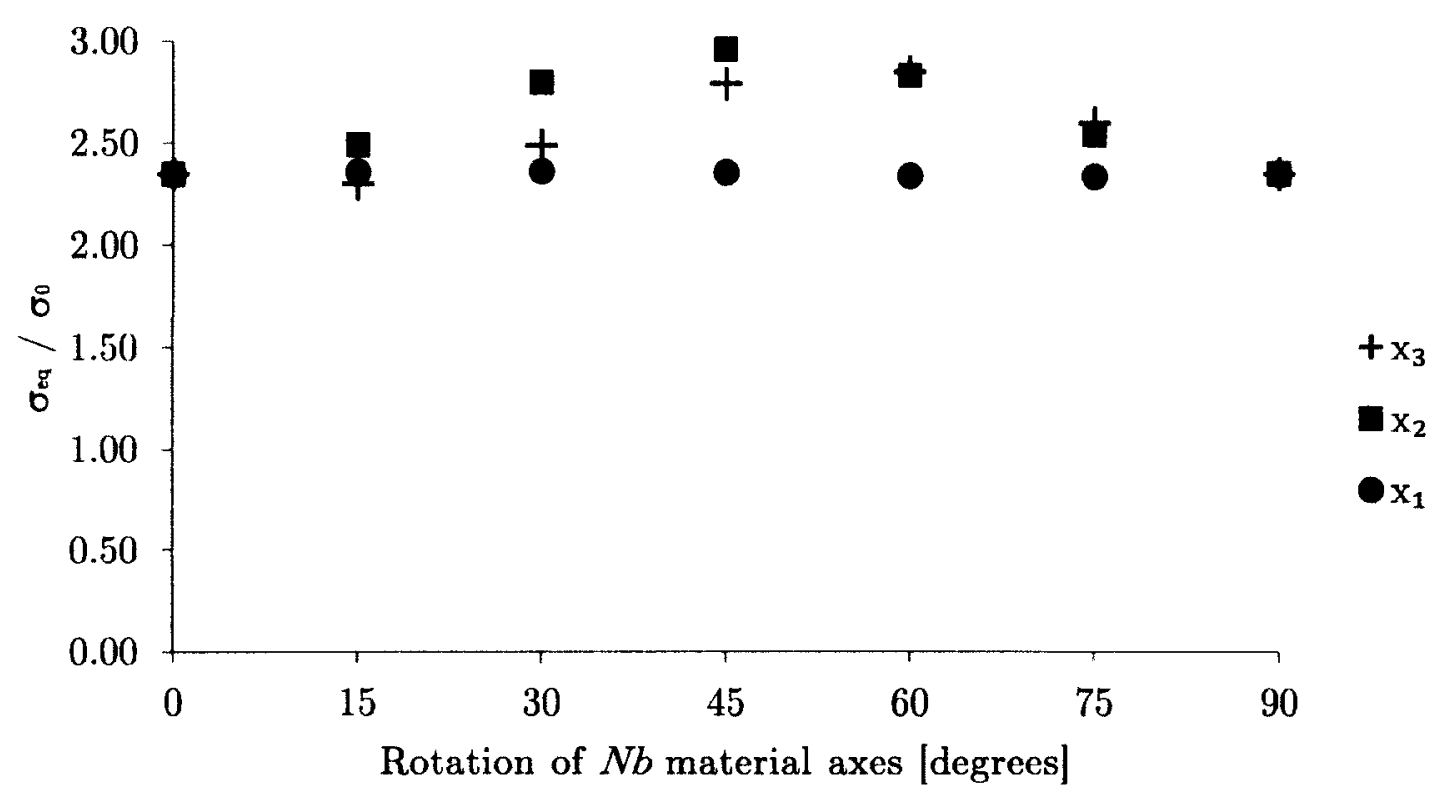

(a) Rotations of the $\mathrm{Nb}$ crystal

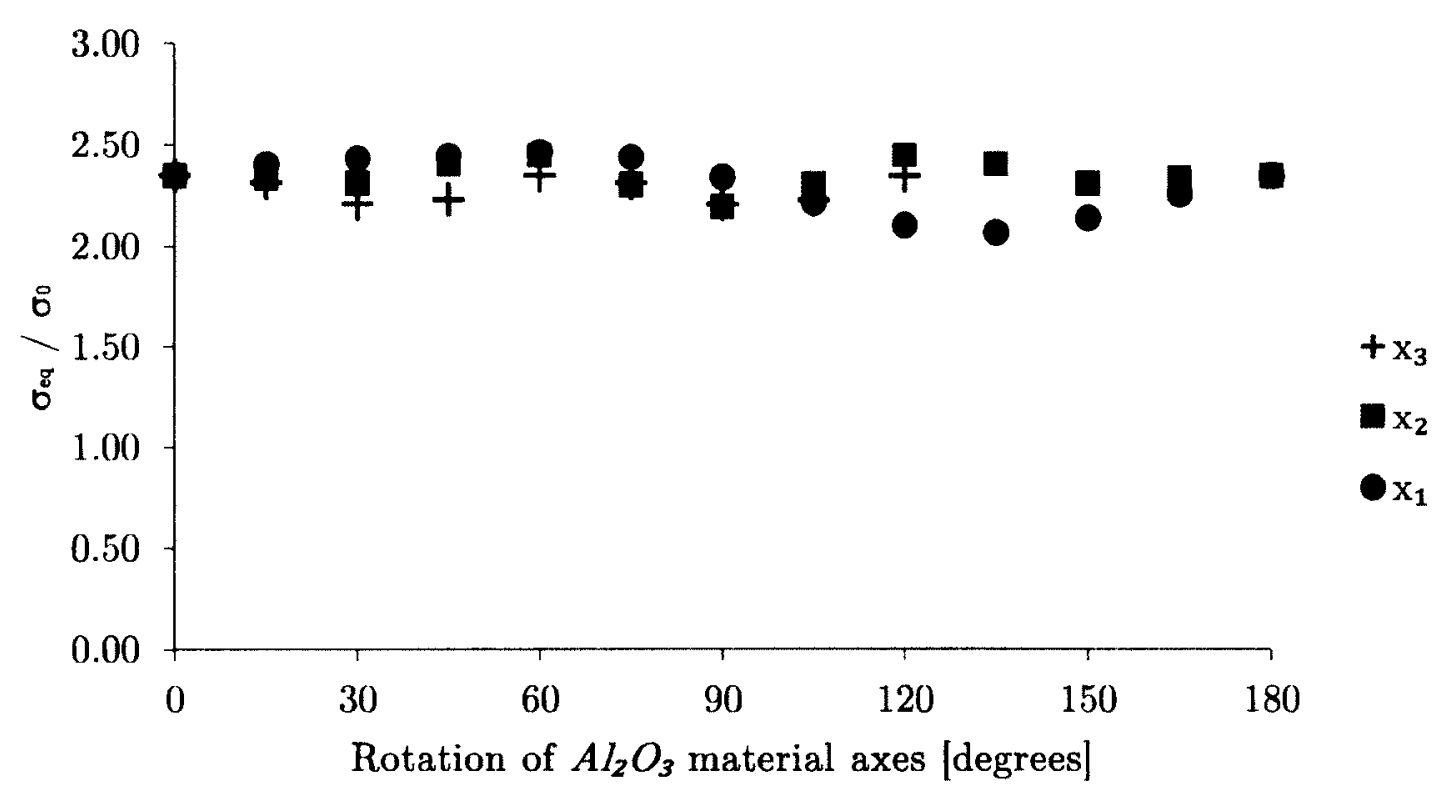

(b) Rotations of the $\mathrm{Al}_{2} \mathrm{O}_{3}$ crystal

Figure 4.16: Variation of $\sigma_{e q} / \sigma_{0}$ at point $\mathrm{F}$ in the $\mathrm{Al}_{2} \mathrm{O}_{3}$ crystal of a $\mathrm{Nb}-\mathrm{Al}_{2} \mathrm{O}_{3}$ bicrystal bar with a double U-notch for $x_{1}, x_{2}$, and $x_{3}$-material axis rotations 


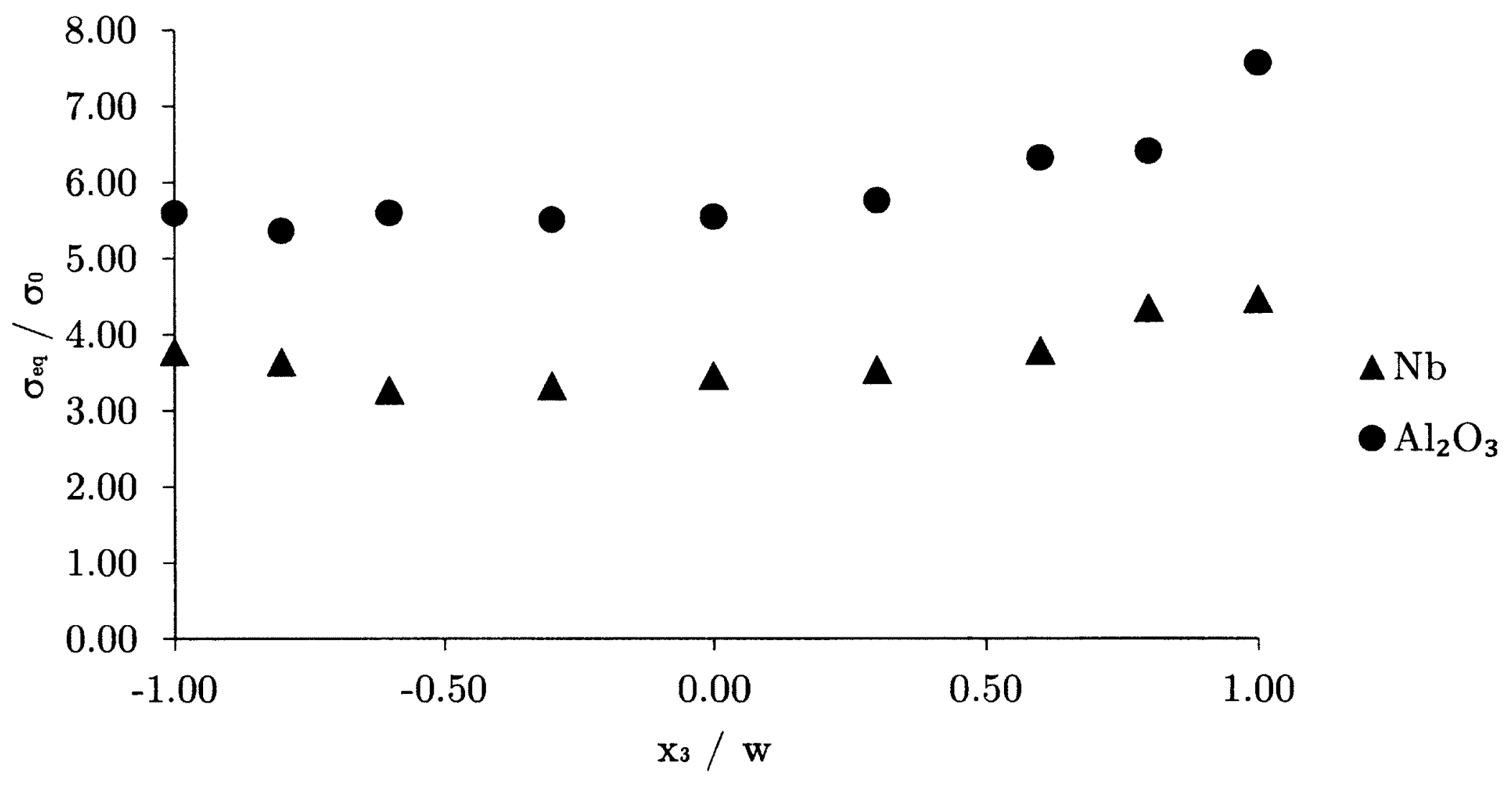

Figure 4.17: Variation of $\sigma_{e q} / \sigma_{0}$ through the thickness along $\overline{A C B}$ at the interface of a $\mathrm{Nb}_{-} \mathrm{Al}_{2} \mathrm{O}_{3}$ bicrystal bar with double U-notch for a $\mathrm{Nb} x_{2}$-material axis rotation of $45^{\circ}$ 


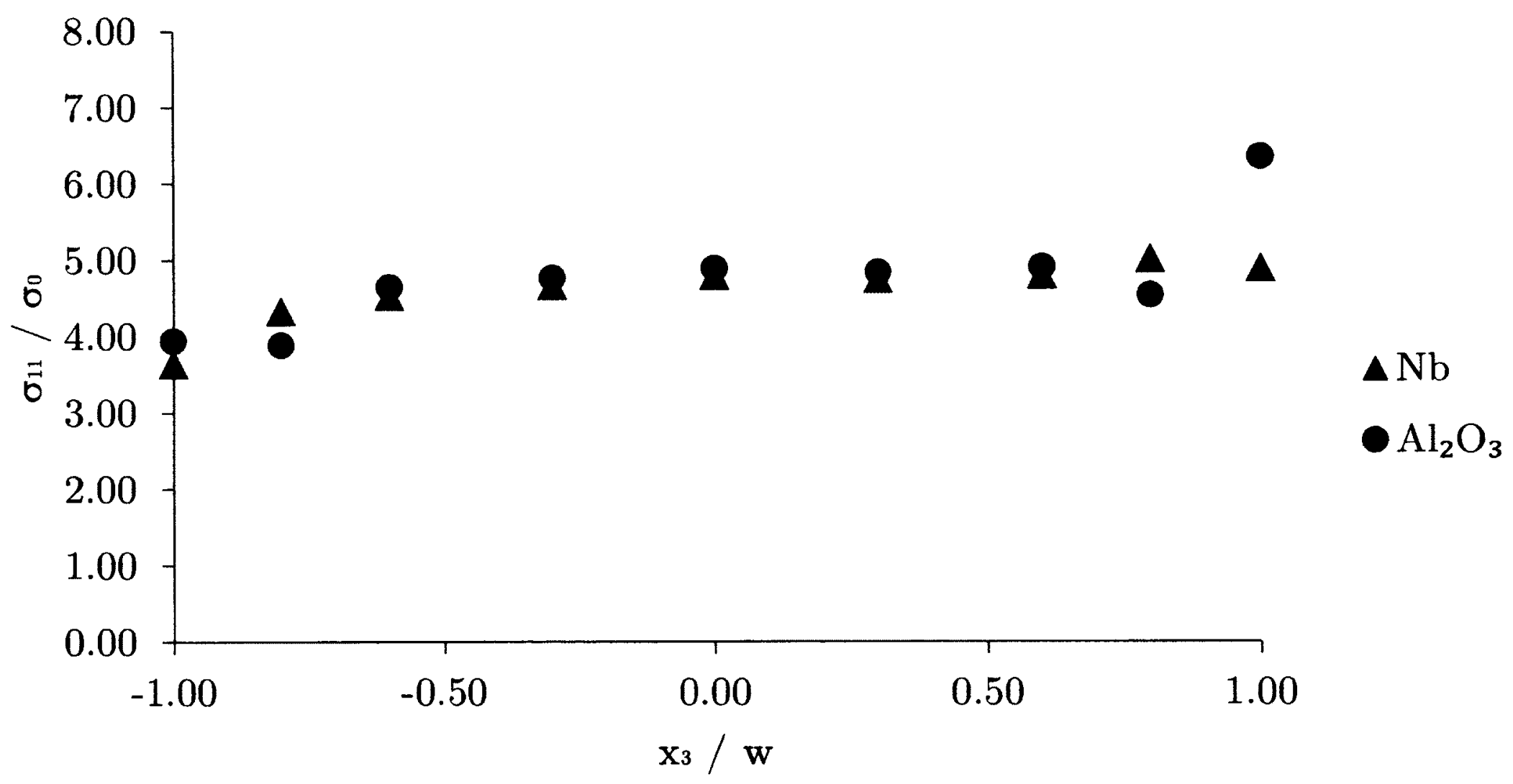

Figure 4.18: Variation of $\sigma_{11} / \sigma_{0}$ through the thickness along $\overline{A C B}$ at the interface of a $\mathrm{Nb}-\mathrm{Al}_{2} \mathrm{O}_{3}$ bicrystal bar with double U-notch for a $\mathrm{Nb} x_{2}$-material axis rotation of $60^{\circ}$ 


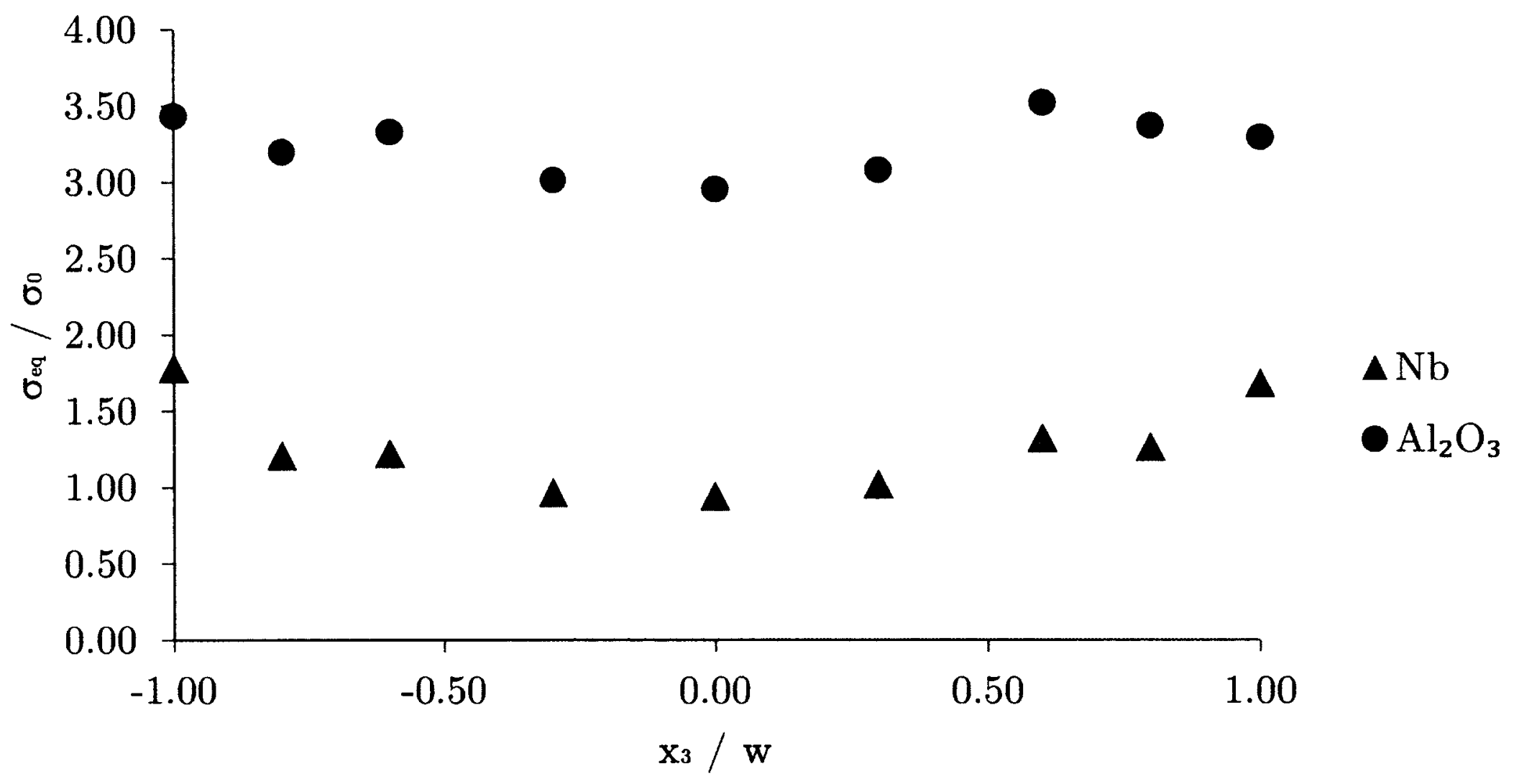

Figure 4.19: Variation of $\sigma_{e q} / \sigma_{0}$ through the thickness along $\overline{D F E}$ at the interface of a $\mathrm{Nb}_{-} \mathrm{Al}_{2} \mathrm{O}_{3}$ bicrystal bar with double U-notch for a $\mathrm{Nb} x_{2}$-material axis rotation of $45^{\circ}$ 


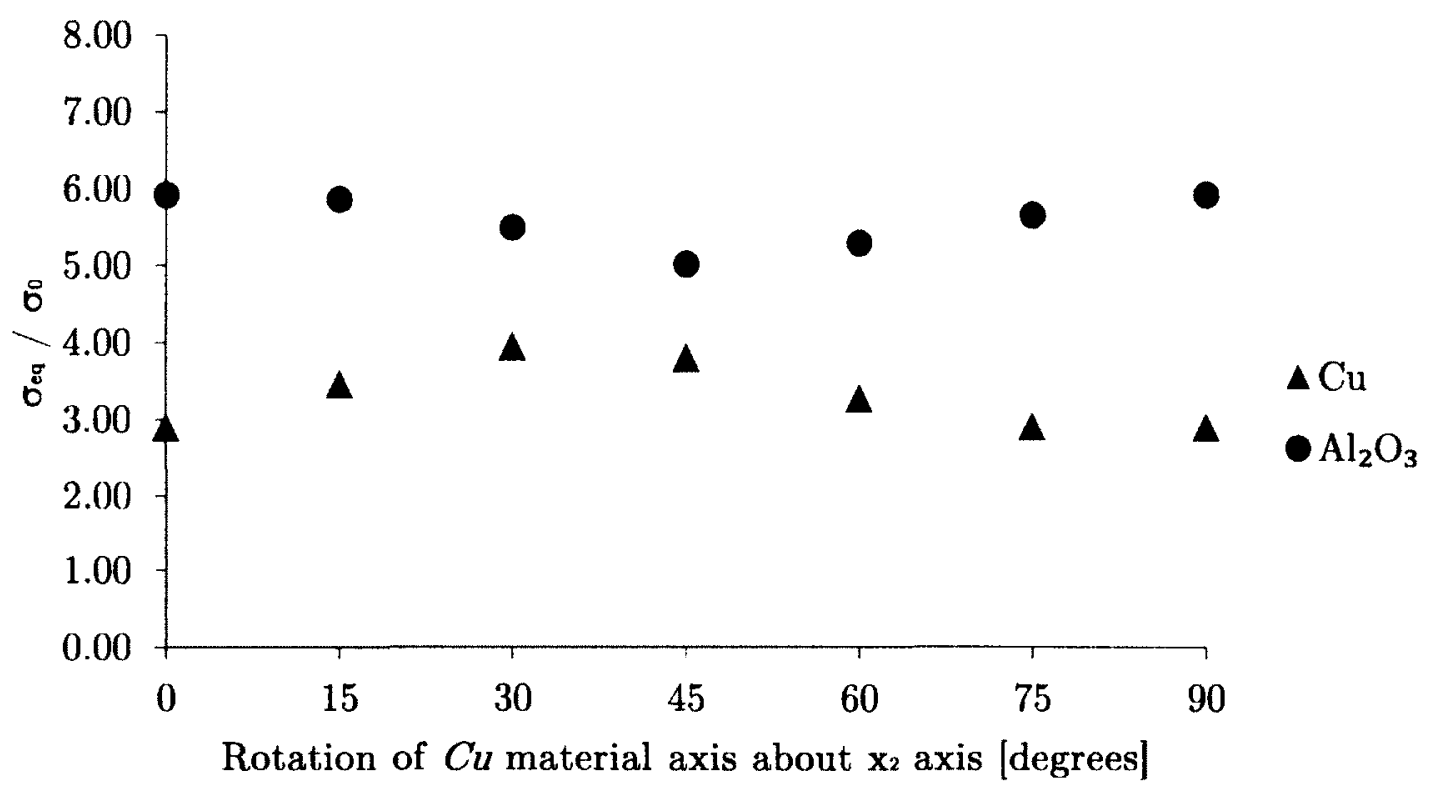

(a) At point $\mathrm{C}$

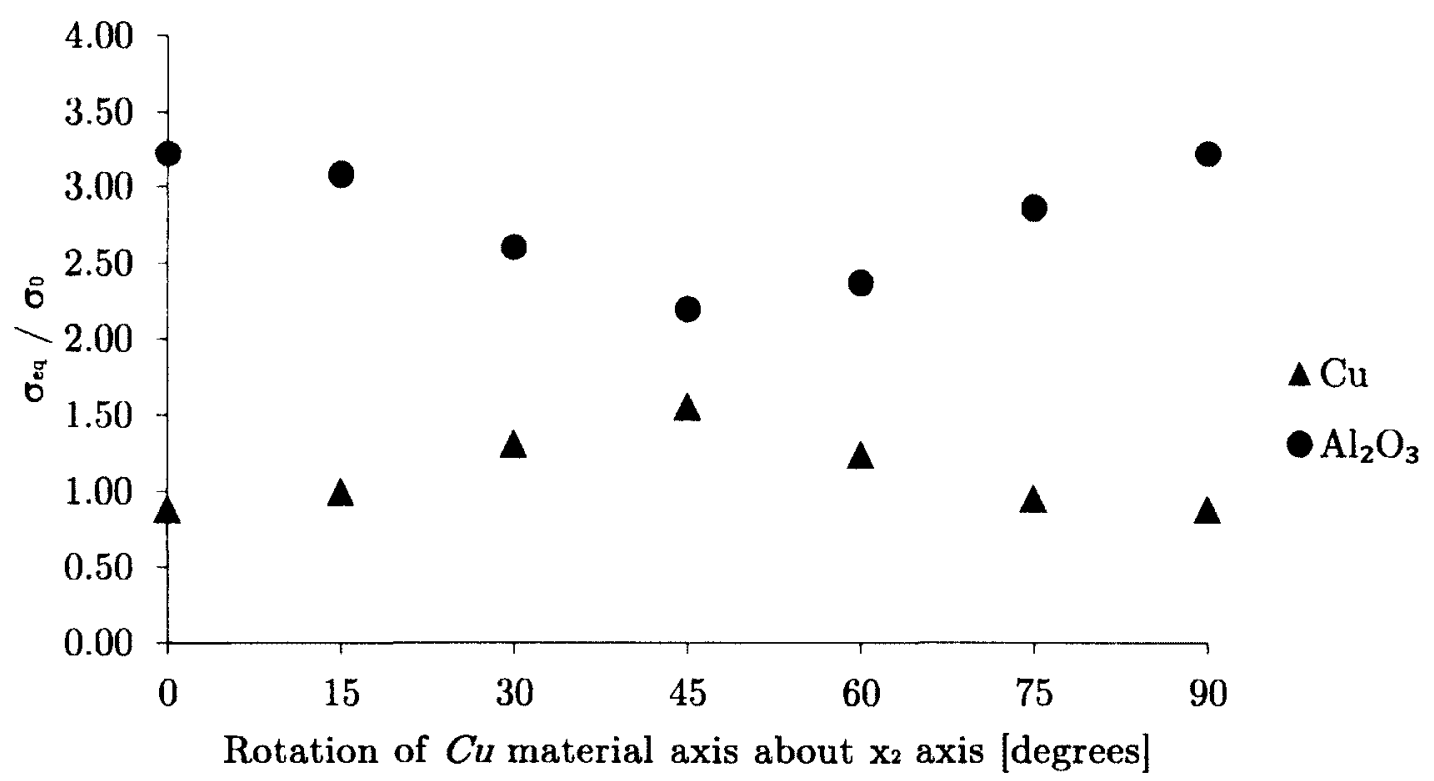

(b) At point $\mathrm{F}$

Figure 4.20: Variation of $\sigma_{e q} / \sigma_{0}$ of a $\mathrm{Cu}-\mathrm{Al}_{2} \mathrm{O}_{3}$ bicrystal bar with double U-notch for $x_{2}$-material axis rotations of the $C u$ crystal 


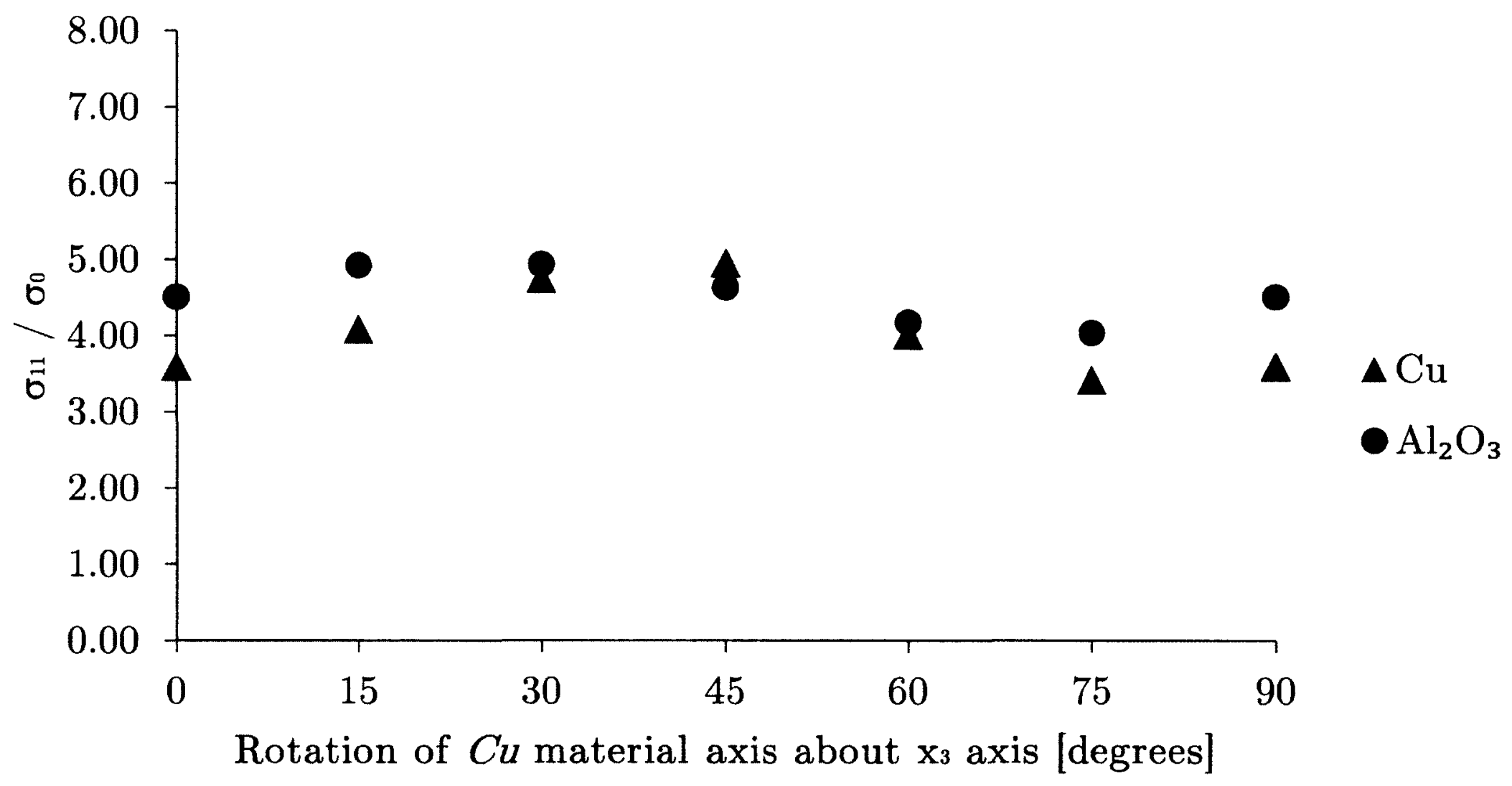

Figure 4.21: Variation of $\sigma_{11} / \sigma_{0}$ at point $\mathrm{C}$ of a $\mathrm{Cu}-\mathrm{Al}_{2} \mathrm{O}_{3}$ bicrystal bar with double U-notch for $x_{3}$-material axis rotations of the $C u$ crystal 


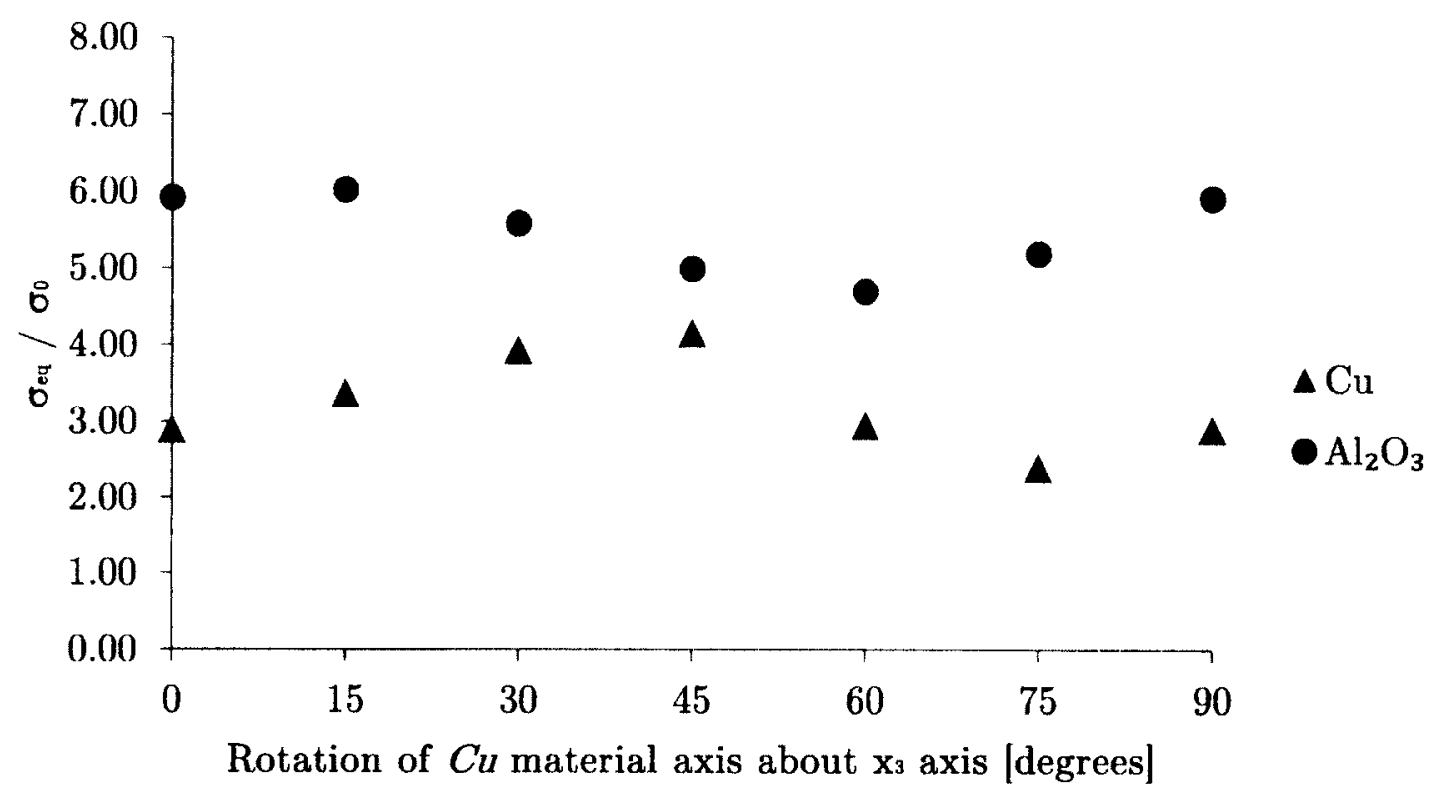

(a) At point $\mathrm{C}$

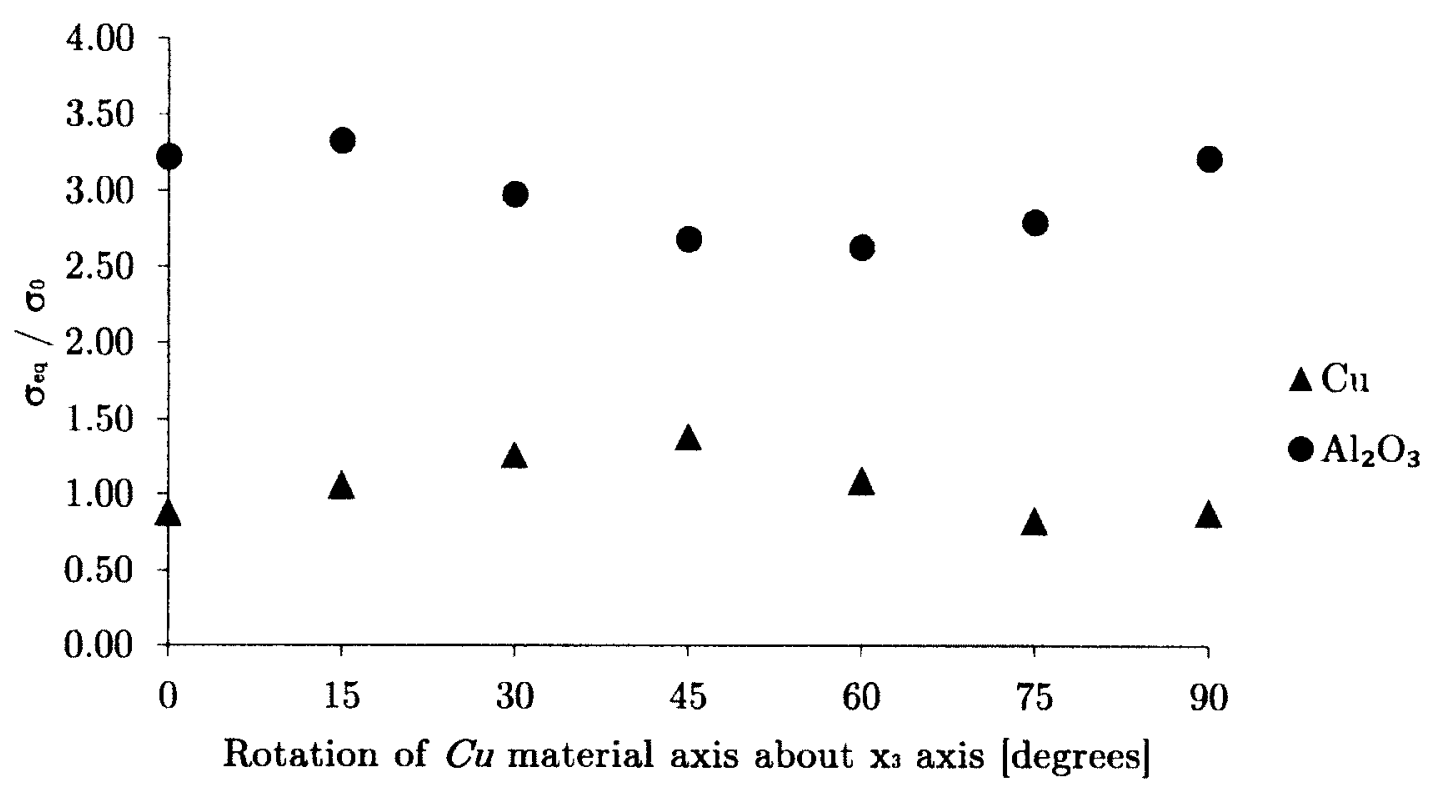

(b) At point $\mathrm{F}$

Figure 4.22: Variation of $\sigma_{e q} / \sigma_{0}$ of a $\mathrm{Cu}-\mathrm{Al}_{2} \mathrm{O}_{3}$ bicrystal bar with double U-notch for $x_{3}$-material axis rotations of the $C u$ crystal 


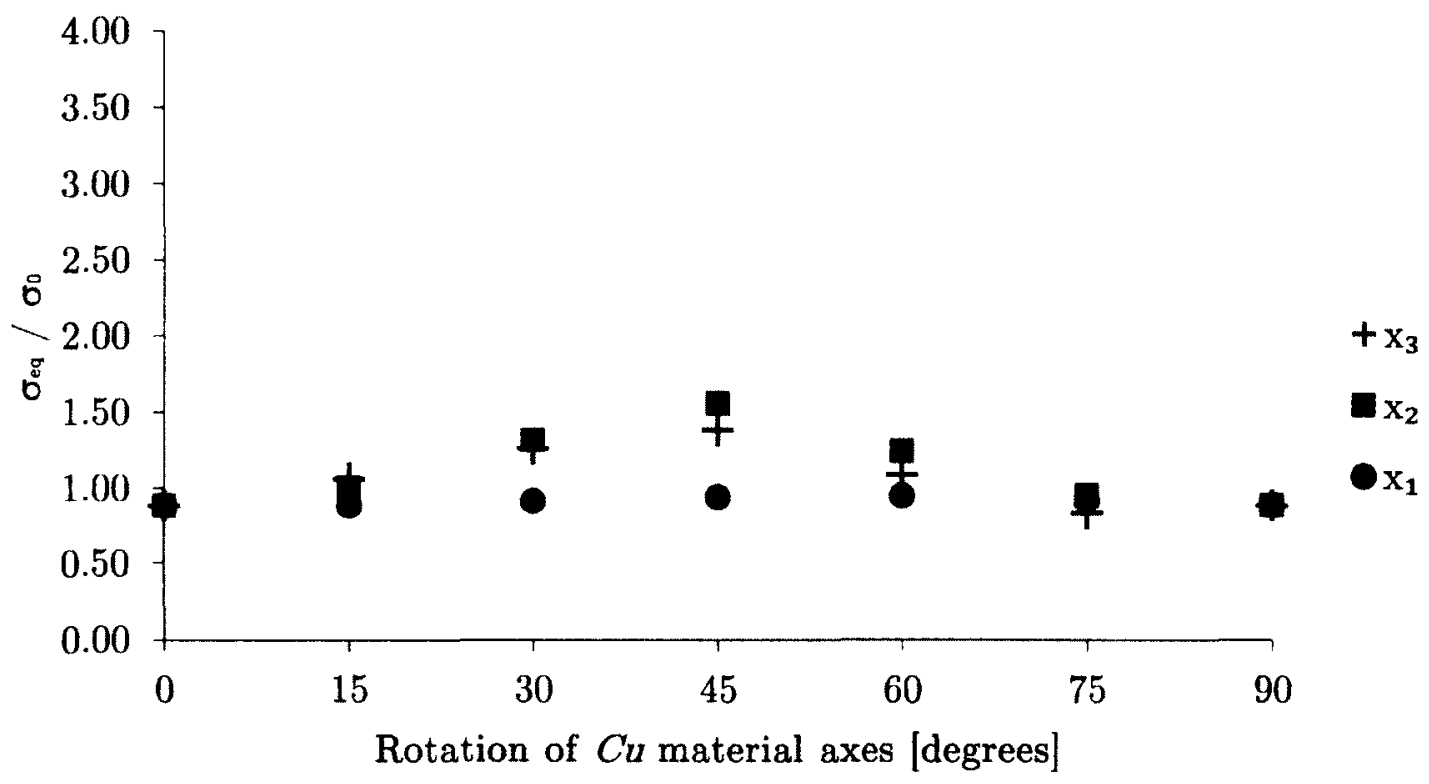

(a) Rotations of the $\mathrm{Cu}$ crystal

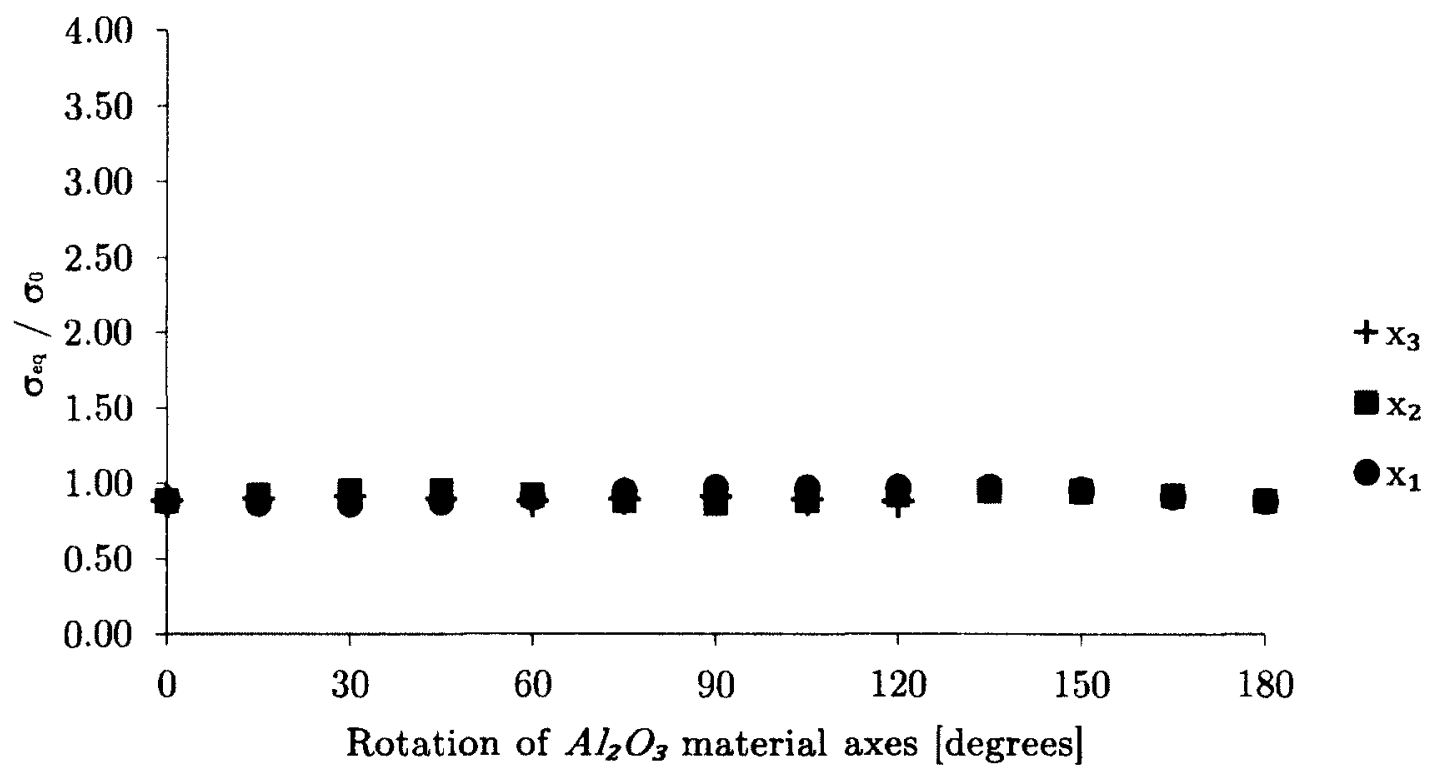

(b) Rotations of the $\mathrm{Al}_{2} \mathrm{O}_{3}$ crystal

Figure 4.23: Variation of $\sigma_{e q} / \sigma_{0}$ at point $\mathrm{F}$ in the $\mathrm{Cu}$ crystal of a $\mathrm{Cu}-\mathrm{Al}_{2} \mathrm{O}_{3}$ bicrystal bar with a double $\mathrm{U}$-notch for $x_{1}, x_{2}$, and $x_{3}$-material axis rotations 


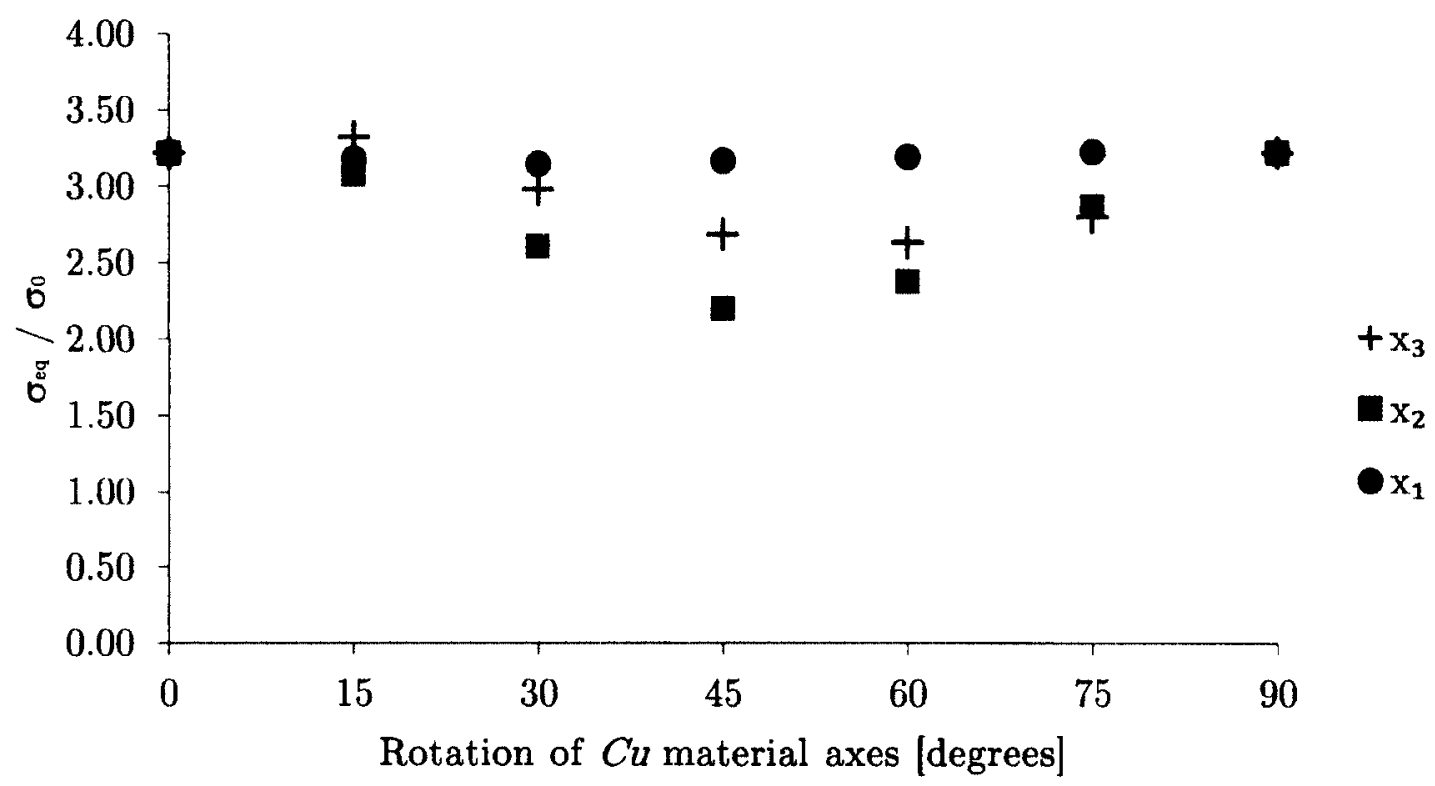

(a) Rotations of the $C u$ crystal

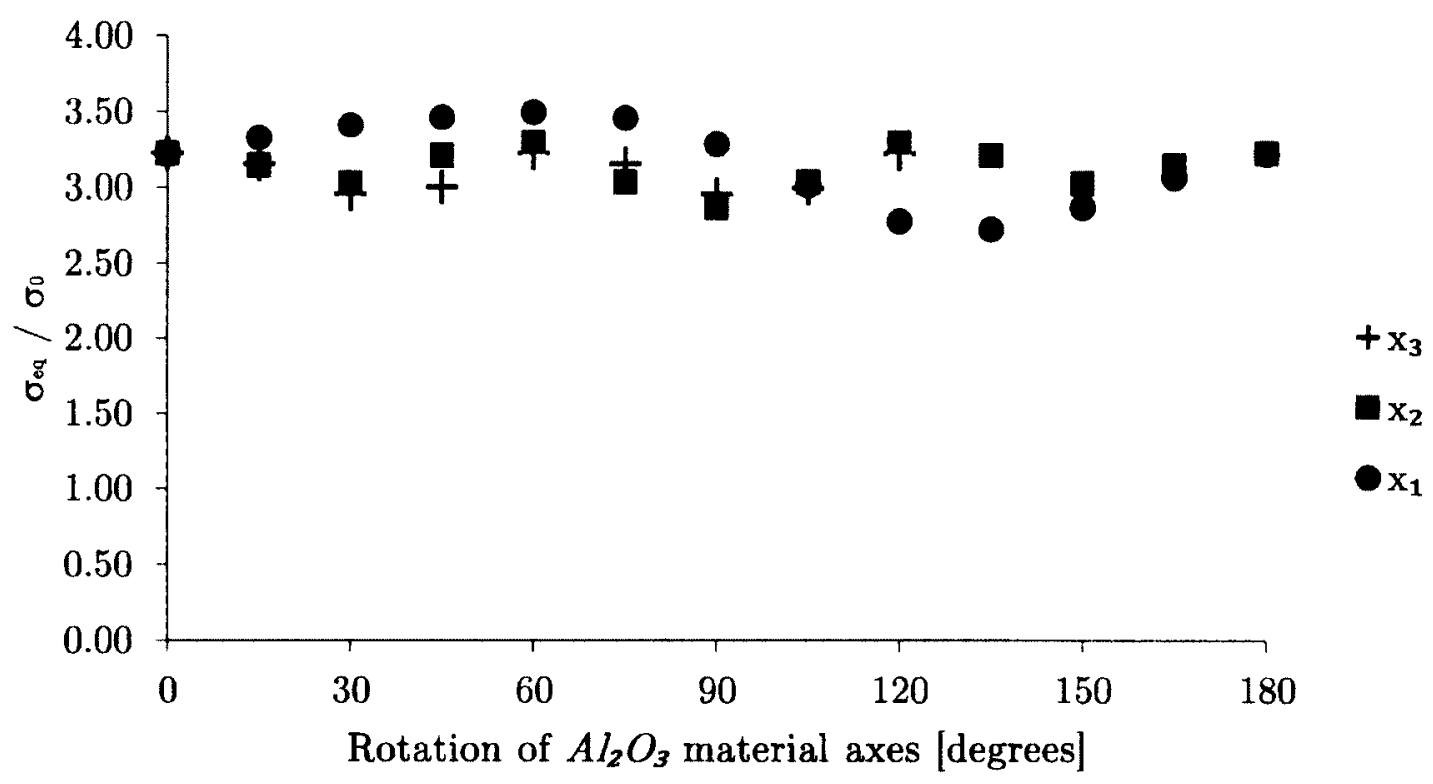

(b) Rotations of the $\mathrm{Al}_{2} \mathrm{O}_{3}$ crystal

Figure 4.24: Variation of $\sigma_{e q} / \sigma_{0}$ at point $\mathrm{F}$ in the $\mathrm{Al}_{2} \mathrm{O}_{3}$ crystal of a $\mathrm{Cu}-\mathrm{Al}_{2} \mathrm{O}_{3}$ bicrystal bar with a double U-notch for $x_{1}, x_{2}$, and $x_{3}$-material axis rotations 


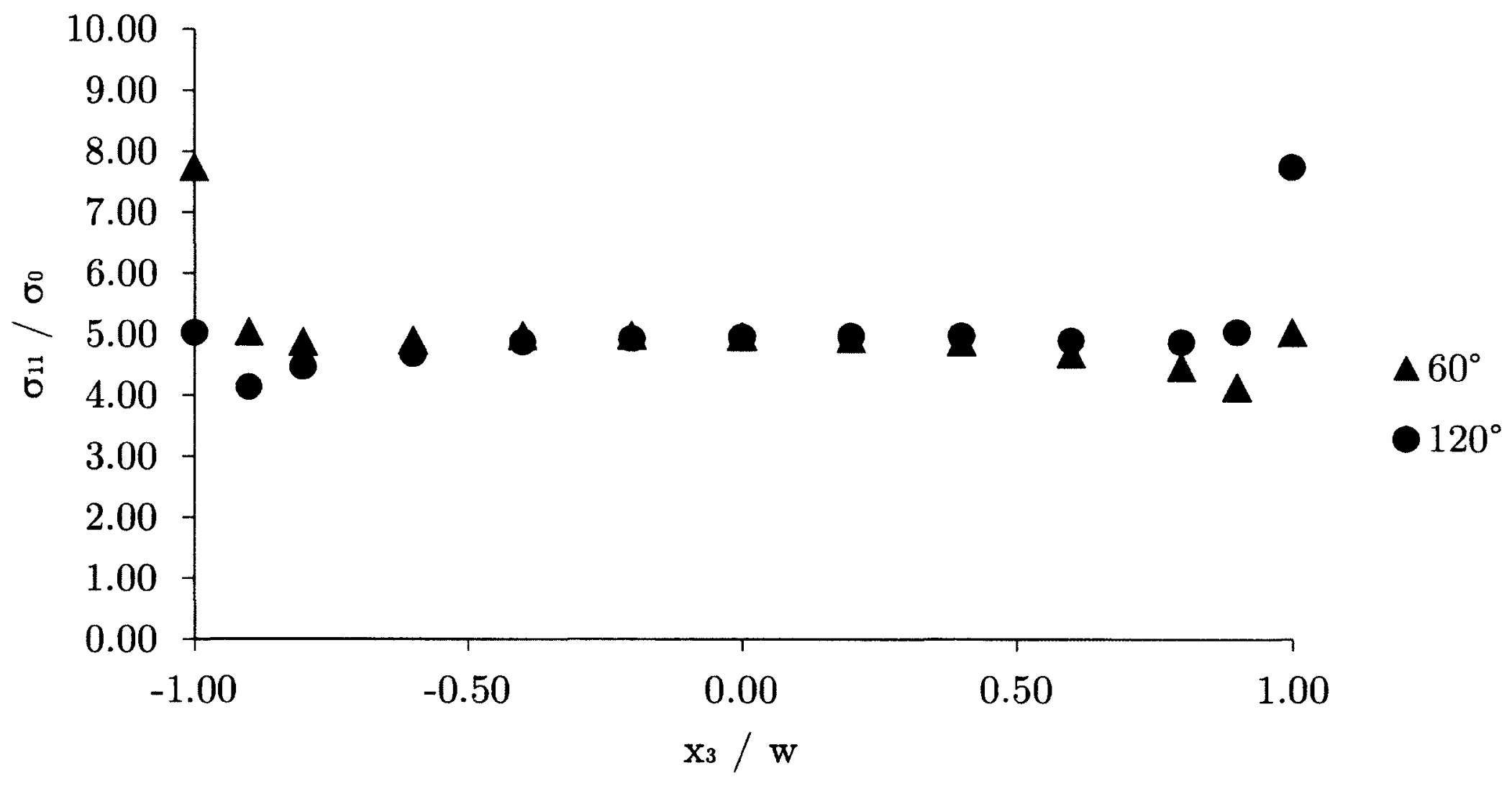

Figure 4.25: Variation of $\sigma_{11} / \sigma_{0}$ through the thickness along $\overline{A C B}$ at the interface of a $C u-A l_{2} O_{3}$ bicrystal bar with double U-notch in the $\mathrm{Al}_{2} \mathrm{O}_{3}$ crystal for $\mathrm{Al}_{2} \mathrm{O}_{3} x_{2}$-material axis rotations of $60^{\circ}$ and $120^{\circ}$ 


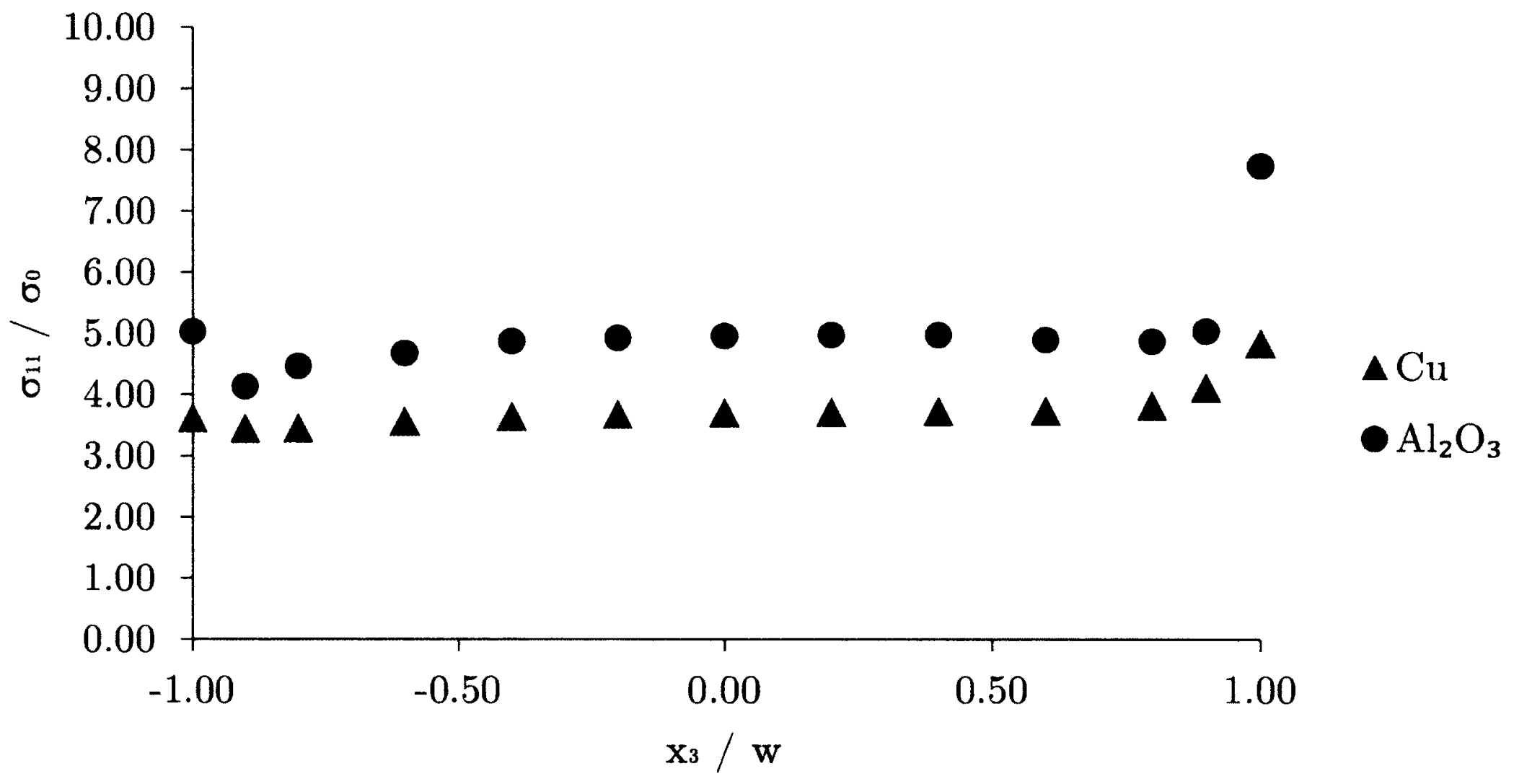

Figure 4.26: Variation of $\sigma_{11} / \sigma_{0}$ through the thickness along $\overline{A C B}$ at the interface of a $\mathrm{Cu}-\mathrm{Al}_{2} \mathrm{O}_{3}$ bicrystal bar with double U-notch for a $\mathrm{Al}_{2} \mathrm{O}_{3} x_{2}$-material axis rotation of $120^{\circ}$ 


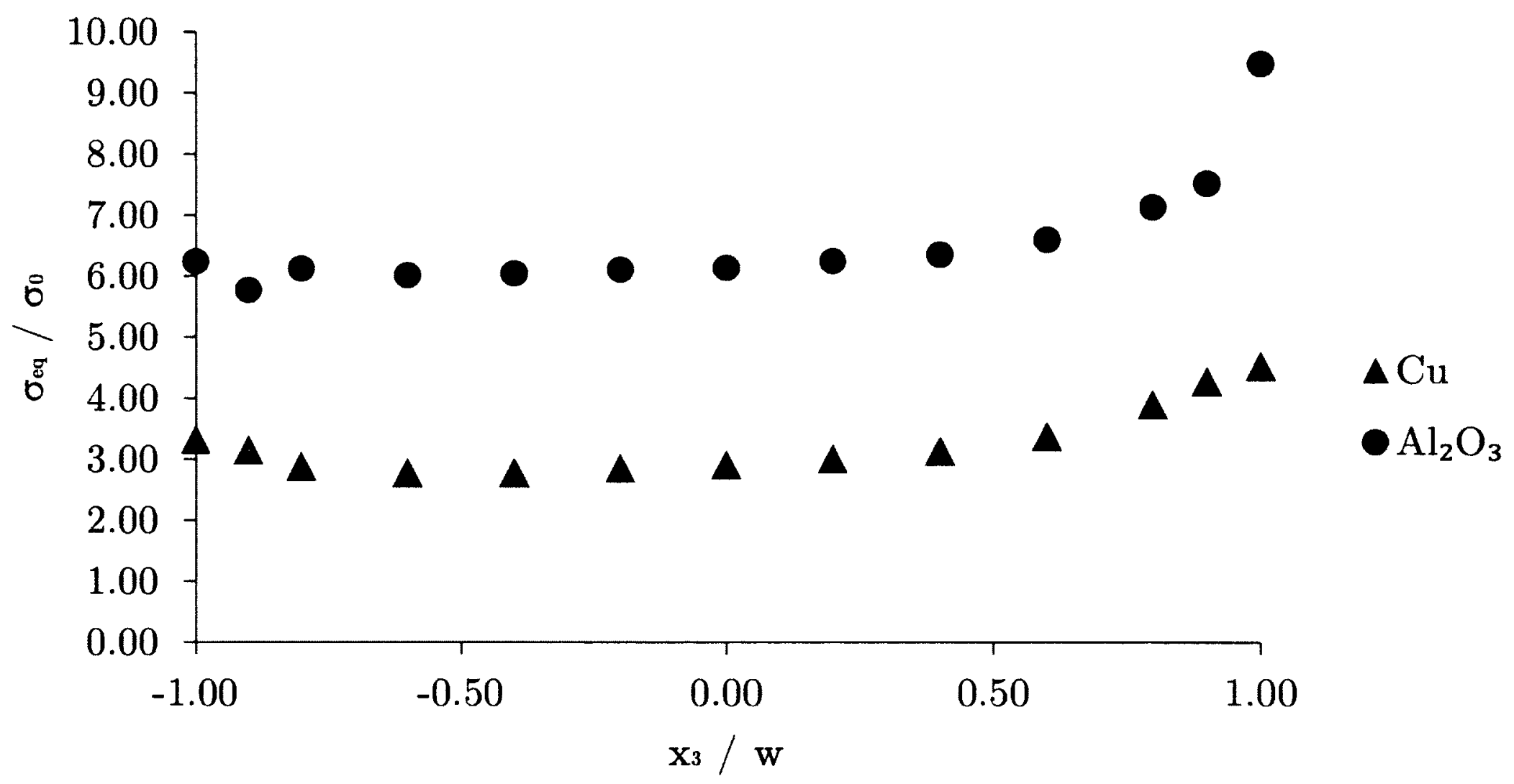

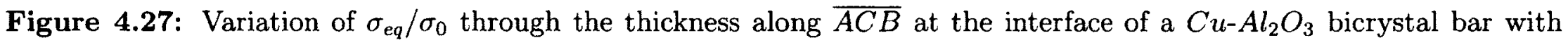
double $\mathrm{U}$-notch for a $\mathrm{Al}_{2} \mathrm{O}_{3} x_{2}$-material axis rotation of $120^{\circ}$ 


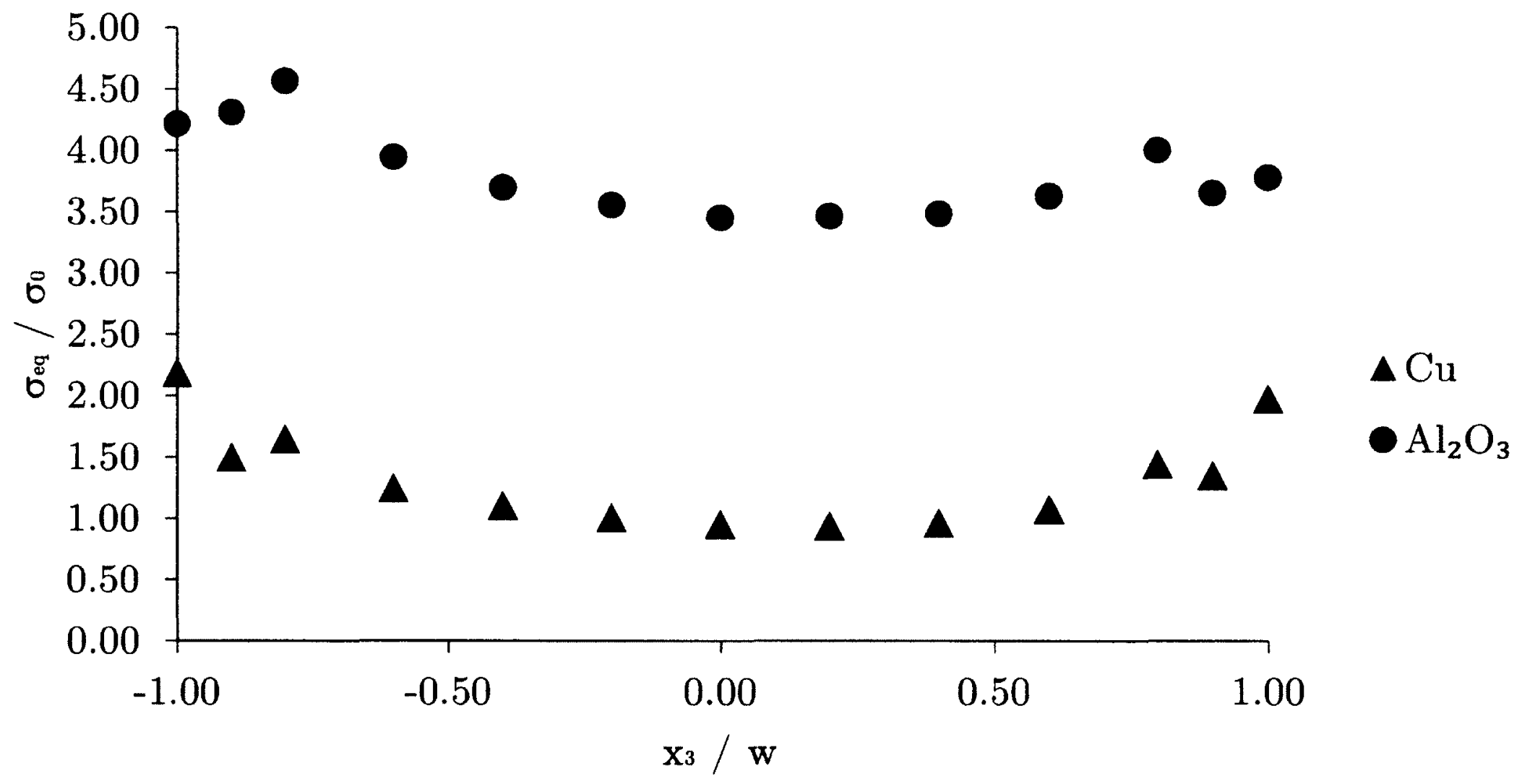

Figure 4.28: Variation of $\sigma_{e q} / \sigma_{0}$ through the thickness along $\overline{D F E}$ at the interface of a $\mathrm{Cu}-\mathrm{Al}_{2} \mathrm{O}_{3}$ bicrystal bar with double U-notch for a $C u x_{1}$-material axis rotation of $75^{\circ}$ 


\section{Chapter 5}

\section{On the Influence of Auxiliary Holes in a Bicrystal Plate with a Primary Circular Hole}

The focus of this chapter returns to the physical problem described in Chapter 3 of a plate with a circular hole in tension and adds a defence hole system (DHS), as described in Meguid (1986) for example, which uses auxiliary holes in the surrounding low stress area to reduce the stress at the main hole. The parametric study employed to investigate the effect of auxiliary hole size and location on the first principal stress, $\sigma_{1}$, within the structure is first described alongside the physical problem. The numerical models used are then presented. In order to gain a better understanding of the results from the bimaterial bicrystal analysis, the problem is first studied through increasing complexity from the corresponding homogeneous isotropic and anisotropic problems, and bimaterial isotropic problem. The stress concentrations in the main and auxiliary holes from the parametric study are presented, and hole placement, anisotropic effects, and the material interface are discussed. 


\subsection{Problem Review and Definition}

A DHS is designed around a geometrical discontinuity to reduce the maximum stress in the structure, specifically the stress concentration. Auxiliary holes are introduced in the areas of low stress near the main hole to smooth the flow of the tensile principal stress trajectories past the main hole. Haddon (1967) was the first with an explicit solution for two unequal holes in an infinite medium with stress boundary conditions. From this, a clearer understanding of the problem was obtained, including how the position of maximum stress changes about the inner face of the smaller hole depending on its relative size and distance from the main hole, when tension is applied in the direction of the line of holes. It also became apparent that substantial stress reductions could be obtained with these auxiliary holes, spurring further investigation.

The problem in question is an extension to that encountered in Chapter 3 of a plate with a circular hole in tension, beginning with the same initial physical problem, as shown in Figure 3.1, with a uniaxial tensile load, $\sigma_{0}$, applied at the ends of the plate. Circular auxiliary holes are added, similar to the study by Erickson \& Riley (1978), and their radii, $b / r=0.3,0.5,0.7,0.9$, and centre-to-centre distances from the main hole, $d / r=2.0,2.5,3.0$, as shown in Figure 5.1 ( $x_{3}$ dimension not shown), are varied in a parametric study, where $r$ is the radius of the main hole and $\theta$ is the angle along the inner surface of the auxiliary holes where the largest first principal stress occurs, where $\theta=0^{\circ}$ coincides with the $x_{2}=0$ plane. To differentiate the anisotropic effects in the bicrystal problem from those of the corresponding homogeneous isotropic problem, parametric studies were performed in increasing order of complexity: a homogeneous isotropic problem; homogeneous anisotropic problems with $\mathrm{Nb}, \mathrm{Cu}$, and $\mathrm{Al}_{2} \mathrm{O}_{3}$ crystals; bimaterial isotropic problems with $\mathrm{Nb}-\mathrm{Al}_{2} \mathrm{O}_{3}$ and $\mathrm{Cu}-\mathrm{Al}_{2} \mathrm{O}_{3}$ material combinations; and finally the anisotropic $\mathrm{Nb}-\mathrm{Al}_{2} \mathrm{O}_{3}$ and $\mathrm{Cu}-\mathrm{Al}_{2} \mathrm{O}_{3}$ bicrystal problems. The $x_{2}=0$ plane splits the bimaterial problem geometry into two material regions, 
as shown in Figure 5.2; also shown are the lines containing the largest first principal stress in the main, top, and bottom auxiliary holes, $\overline{A C B}, \overline{A^{\prime} C^{\prime} B^{\prime}}$, and $\overline{A^{\prime \prime} C^{\prime \prime} B^{\prime \prime}}$, respectively. The material principal axes of the anisotropic materials have been taken to coincide with the Cartesian axes. The material properties have previously been presented in Table 3.1.

\subsection{Numerical Models}

A separate BEM mesh was required for each case in the parametric study. For consistency, a base mesh, containing 488 quadratic surface elements and 1416 nodes, was used for most models by relocating nodes to their respective locations based on the $d / r$ and $b / r$ parameters, an example of which is presented in Figure 5.3. However, a number of cases required more elements as summarized in Table 5.1. Thus, three new base meshes with 480 elements and 1384 nodes; 488 elements and 1424 nodes; and 496 elements and 1456 nodes were used; examples of which are shown in Figures $5.4,5.5$ and 5.6, respectively. All models were fully constrained at one end of the plate while a uniform stress of unity, $\sigma_{0}$, was applied at the opposite end. Each mesh was used for all material cases investigated, while the bimaterial problems were treated as perfectly bonded along the interfacial plane.

\subsection{Defence Hole System}

The objective of a DHS is to reduce the stress concentrations in a structure to achieve a more efficient design and to retard the initiation of fatigue cracks under cyclic loading conditions. Small auxiliary holes, added in the low stress regions of the plate problem in question, contain lower stress concentrations than the main hole. The addition of these holes helps to smooth the flow of the principal stress trajectories past 
the main hole, thereby lowering the stress concentration at the main hole. However, inappropriate size and location parameters may result in transferring the largest stress concentration from the main to the auxiliary holes. It is, therefore, desirable to obtain the auxiliary hole parameters which result in the lowest stress concentration in the entire structure. Since the position where the largest stress occurs is known to vary around the face of the auxiliary holes depending on the parameters of the design, only the largest value of the first principal stress on the surface of each hole, as denoted by $\hat{\sigma}_{1}$, is examined. The "optimal" parameters discussed herein are those which produce the lowest stress concentrations within the range of parameters studied, and not necessarily the lowest attainable values.

\subsubsection{Homogeneous Plate with a Circular Hole}

\section{Isotropic Results}

A parametric study identifying the optimal DHS for a homogeneous isotropic plate was carried out first. A typical trend of $\sigma_{1} / \sigma_{0}$ through the thickness of the plate at both main and auxiliary holes is presented in Figure $5.7 ; \hat{\sigma}_{1} / \sigma_{0}$ occurs at the midthickness, at $\theta=0^{\circ}$. Examination of the changing stress concentration with respect to $d / r$ does not prove to be a satisfactory method in determining the parameters producing the lowest value. Figure 5.8 demonstrates this, as the stress concentration changes very little with $d / r$ in the main hole, and increases with $d / r$ in the auxiliary holes as expected, since the further the auxiliary hole is from the main hole, the less it will be located in the low stress region created by the main hole. The lowest stress concentration observed was for $d / r=2.0$ and $b / r=0.850$, a value of 2.55 , an $18.7 \%$ reduction from the case with no DHS. These stress results from the study are presented in Figure 5.9. It was also observed that in the auxiliary holes of small size, $b / r \leq 0.5$, close to the main hole, $d / r=2.0$, the largest stress concentration was 
shifted to the next node, ie. $\theta=15^{\circ}$, as expected from the results of Haddon (1967).

\section{Anisotropic Results}

The generic isotropic material was substituted for anisotropic $\mathrm{Nb}, \mathrm{Cu}$, and $\mathrm{Al}_{2} \mathrm{O}_{3}$. As with the previous case, very little variation of stress concentration is witnessed in the main hole for changing $d / r$, as shown in Figure 5.10 for $\mathrm{Nb}$ and $\mathrm{Al}_{2} \mathrm{O}_{3}$. The typical variation of $\sigma_{1} / \sigma_{0}$ through the thickness at the holes in the $N b$ plate, shown in Figure 5.11, follows a similar trend to the corresponding isotropic problem, but with a larger stress concentration. The lowest stress concentration, 2.93, was also observed for $d / r=2.0$ and at $b / r=0.843$, a $19.8 \%$ reduction with respect to the case of no DHS. These results are shown in Figure 5.12. All the nodes with the highest stress concentration were located at $\theta=0^{\circ}$. The values of $\hat{\sigma}_{1} / \sigma_{0}$ in the $C u$ crystal plate followed somewhat different trends. The largest stress concentrations in the auxiliary holes were all located at $\theta=30^{\circ}$, and it decreases by a larger amount towards the free surface, as shown in Figure 5.13 which depicts the variation of $\sigma_{1} / \sigma_{0}$ through the plate thickness at the holes. The lowest stress concentration, 2.58, occurred for $d / r=2.0$ at $b / r=0.558$ which was a $13.3 \%$ reduction, as shown in Figure 5.14 . The small increase in $\hat{\sigma}_{1} / \sigma_{0}$ with respect to $d / r$ in $C u$ previously shown in Figure $5.10 \mathrm{~b}$ suggests that a smaller $d / r$ parameter may produce a lower stress concentration. The effect of the location of the largest stress concentration changing position about the face of the auxiliary hole is also related to the anisotropic factor. $N b$ crystal has a low anisotropic factor; the shear stiffness coefficients are lower, relative to those from an isotropic material, and the position of the largest stress concentration location changes very little about the face of the hole. $C u$ crystal, on the other hand, has a high anisotropic factor and its shear coefficients are, relatively, much higher, causing the largest stress concentration location to occur at $\theta=30^{\circ}$ along the face of the auxiliary hole. Finally, a DHS parametric study of the $\mathrm{Al}_{2} \mathrm{O}_{3}$ crystal plate was conducted. As 
expected, the typical $\sigma_{1} / \sigma_{0}$ profile through the plate thickness, shown in Figure 5.15, was not symmetrical about the mid-thickness, since $\mathrm{Al}_{2} \mathrm{O}_{3}$ is a trigonal material. The lowest stress concentration observed in the parametric study, 2.78 , occurred again for $d / r=2.0$ and at $b / r=0.800$, a reduction of $18.1 \%$; the results are shown in Figure 5.16. The value of $\hat{\sigma}_{1} / \sigma_{0}$ in the auxiliary holes was consistently located at $\theta=15^{\circ}$.

\subsubsection{Bimaterial Plate with a Circular Hole}

As noted in the problem of a bimaterial plate with a circular hole in Chapter 3 , there is a relatively weak stress singularity, along $\overline{A C B}$ and along the other free edges at the interface. Thus, again, the stress results along these edges must be taken with caution. It is not possible here to determine the exact optimal hole parameters without implicitly treating the singularity in the BEM formulation, and developing further understanding for the relationship between the associated stress participation factor and possible crack initiation. Nevertheless, the changes in the numerical values of $\hat{\sigma}_{1} / \sigma_{0}$ at these locations with changing values of $b / r$ and $d / r$ could still provide useful information as to the likely optimal combination of these parameters to reduce the stress concentration factor.

\section{Isotropic Results}

The DHS parametric study was carried out first with the isotropic $\mathrm{Nb}_{-} \mathrm{Al}_{2} \mathrm{O}_{3}$ material pairing. A typical variation of $\sigma_{1} / \sigma_{0}$ through the thickness at the largest stress concentrations in the main and auxiliary holes for the $N b$ material is shown in Figure 5.17; $\hat{\sigma}_{1} / \sigma_{0}$ occurring at the mid-thickness. The stress concentrations are nearly constant with $d / r$ within the range studied, as shown in Figure 5.18. The case producing the lowest stress concentration, 2.44 , in $N b$ was found for $d / r=2.0$ and at $b / r=0.898$, a $17.7 \%$ reduction, as shown in Figure 5.19. The through-thickness $\sigma_{1} / \sigma_{0}$ variation for the $\mathrm{Al}_{2} \mathrm{O}_{3}$ material, presented in Figure 5.20, shows $\hat{\sigma}_{1} / \sigma_{0}$ occurring in the main 
hole at the free surface, instead of the mid-thickness, due to the localized transverse tensile stress which arises due to the incompatibility of the material properties at the interface, $\mathrm{Al}_{2} \mathrm{O}_{3}$ being the stiffer material. The stress results in the $\mathrm{Al}_{2} \mathrm{O}_{3}$ material from the parametric study, shown in Figure 5.21, suggest that the optimal hole size where the stress concentration in both main and auxiliary holes are equal, was not attained for the range of $b / r$ considered. However, for $d / r=2.0$ and $b / r=0.9$, the stress concentration in the main hole has been reduced to 2.86 , a reduction of $17.1 \%$. This result suggests that the optimal auxiliary hole in the $\mathrm{Al}_{2} \mathrm{O}_{3}$ material has to be larger than the corresponding hole in the $N b$ region.

The stress results from the isotropic $\mathrm{Cu}-\mathrm{Al}_{2} \mathrm{O}_{3}$ material pairing are very similar to those of the $\mathrm{Nb}-\mathrm{Al}_{2} \mathrm{O}_{3}$ bimaterial plate. The through-thickness values of $\sigma_{1} / \sigma_{0}$ in $C u$ at the stress concentration in the main and auxiliary holes, shown in Figure 5.22, illustrate the same trend seen in the $\mathrm{Nb}-\mathrm{Al}_{2} \mathrm{O}_{3}$ plate, including the insensitivity of the stress concentration to $d / r$ within the range studied, as shown in Figure 5.23. The stress concentrations in the $C u$ material, presented in Figure 5.24, are lowest for $d / r=2.0$ and $b / r=0.884$, signifying a reduction of $17.4 \%$ to 2.44 . Similarly, in the $\mathrm{Al}_{2} \mathrm{O}_{3}$ material, $\hat{\sigma}_{1} / \sigma_{0}$ occurs at the free surface, as shown in Figure 5.25. And the stress concentration results of the parametric study, shown in Figure 5.26, do not reach a minimum for the range of $b / r$ investigated, although the stress in the main hole is reduced by $17.2 \%$ to 2.74 for $d / r=2.0$ and $b / r=0.9$.

\section{Anisotropic Results}

The final DHS parametric studies were performed for the anisotropic $\mathrm{Nb}-\mathrm{Al}_{2} \mathrm{O}_{3}$ and $\mathrm{Cu}-\mathrm{Al}_{2} \mathrm{O}_{3}$ bimaterial bicrystal plates. For the $\mathrm{Nb}$ region of the first plate, the typical variation of $\sigma_{1} / \sigma_{0}$ through the thickness at the holes is plotted in Figure 5.27, showing expected trends: an unsymmetrical stress profile at the main hole caused by the interaction with anisotropic $\mathrm{Al}_{2} \mathrm{O}_{3}$, the largest stress occurring at the mid-thickness, 
and the weak variation of stress concentration with $d / r$, as shown in Figure 5.28. The lowest stress concentration observed in $N b, 2.81$, occurred for $d / r=2.0$ and $b / r=0.816$, a $17.3 \%$ reduction, as shown in Figure 5.29. The location of $\hat{\sigma}_{1} / \sigma_{0}$ through the thickness of $\mathrm{Al}_{2} \mathrm{O}_{3}$ is not constant for all cases. Shown in Figure 5.30 is the through the thickness $\sigma_{1} / \sigma_{0}$ variation for $d / r=2.5$ and $b / r=0.7$, where the maximum stress occurs at $\theta=0^{\circ}$ and is at the free edge of the main hole and at the mid-thickness of the auxiliary hole. In Figure 5.31, it is observed that $\hat{\sigma}_{1} / \sigma_{0}$ in the auxiliary hole occurs at $\theta=15^{\circ}$ and at the free surface. The lowest attainable stress concentration in the $\mathrm{Al}_{2} \mathrm{O}_{3}$ region is, strictly speaking, not determined, as shown in Figure 5.32. Nevertheless, at the main hole the stress concentration of 2.91, a reduction of $21.0 \%$, occurring for $d / r=2.0$ and $b / r=0.9$, is arguably within the numerical error of the stress in the auxiliary hole, a $3.4 \%$ discrepancy, recalling that the stress at the edge in the main hole should be treated with caution.

Examining the $\mathrm{Cu}$ region in the anisotropic $\mathrm{Cu}-\mathrm{Al}_{2} \mathrm{O}_{3}$ plate, it is again observed, as with the homogeneous $C u$ plate, that $\hat{\sigma}_{1} / \sigma_{0}$ in the auxiliary hole occurs at $\theta=30^{\circ}$ throughout the parametric study. The main and auxiliary hole through the thickness values of $\sigma_{1} / \sigma_{0}$ are plotted in Figure 5.33, showing a typical profile. The stress concentration varies very little with $d / r$ in the $C u$ crystal, as shown in Figure 5.34a, but the stress concentration in $\mathrm{Al}_{2} \mathrm{O}_{3}$ is shown to decrease, only marginally, by $2.3 \%$, relative to that of the case with no DHS, from $d / r=2.0$ to $d / r=2.5$, for $b / r=0.9$. The variation of stress concentration with $b / r$ in $C u$ is presented in Figure 5.35, showing the lowest value, 2.59 , for $d / r=2.0$ and $b / r=0.686$, a $13.2 \%$ reduction. Interestingly, $\hat{\sigma}_{1} / \sigma_{0}$ at the main hole in the $\mathrm{Al}_{2} \mathrm{O}_{3}$ does not occur at the interface, it is located $15^{\circ}$ from the $x_{2}=0$ plane. The effect is caused by the trigonal symmetry and properties of $\mathrm{Al}_{2} \mathrm{O}_{3}$ crystal, together with the interaction of the stress fields of the holes. The values of $\sigma_{1} / \sigma_{0}$ are plotted through the thickness for $d / r=2.5$ and $b / r=0.7$, and $d / r=2.0$ and $b / r=0.3$ cases in Figures 5.36 and 5.37 , respectively. 
$\hat{\sigma}_{1} / \sigma_{0}$ in the auxiliary hole occurs at the free surface when it coincides with the largest $\sigma_{1} / \sigma_{0}$ occurring along $\theta=15^{\circ}$, similar to the $\mathrm{Al}_{2} \mathrm{O}_{3}$ region in the previous $\mathrm{Nb}-\mathrm{Al}_{2} \mathrm{O}_{3}$ plate. The results of the parametric study are unable to determine the optimal auxiliary hole parameters for the range considered, as shown in Figure 5.38. A stress reduction of $11.7 \%$ is achieved at the main hole, with a stress concentration of 3.42 for $d / r=2.5$ and $b / r=0.9$. There is still a large discrepancy between the stress concentrations in the main and auxiliary holes, $22.5 \%$ with respect to the former, which can likely be reduced with a larger auxiliary hole in the $\mathrm{Al}_{2} \mathrm{O}_{3}$ material. Although, $\hat{\sigma}_{1} / \sigma_{0}$ occurs away from the material interface in $\mathrm{Al}_{2} \mathrm{O}_{3}$ crystal, $\sigma_{1} / \sigma_{0}$ at the interface is still within $10 \%$ and should not be disregarded since the interface is a probable site for crack development.

From interpolation of the results obtained in this parametric study, the lowest stress concentration factors that can be achieved are summarized in Table 5.2 with their corresponding $b / r$ ratio. As indicated previously, they would also occur at the smallest value of $d / r$ ratio considered, namely, $d / r=2.0$, with the exception of the $\mathrm{Cu}-\mathrm{Al}_{2} \mathrm{O}_{3}$ bicrystal. The percentage reduction of the stress concentration factor when compared to the problem of a plate with a single hole is also shown for each case.

\subsection{Concluding Remarks}

A DHS to reduce the stress concentration factor in a plate with a circular hole in tension using circular auxiliary holes was investigated in a parametric study. This involved altering the size and location of the auxiliary holes to find the lowest stress concentration attainable. Multiple materials and material combinations have been analysed: a homogeneous isotropic plate; homogeneous anisotropic $\mathrm{Cu}, \mathrm{Nb}$, and $\mathrm{Al}_{2} \mathrm{O}_{3}$ crystal plates; bimaterial isotropic $\mathrm{Nb}-\mathrm{Al}_{2} \mathrm{O}_{3}$ and $\mathrm{Cu}-\mathrm{Al}_{2} \mathrm{O}_{3}$ plates; and bimaterial anisotropic $\mathrm{Nb}-\mathrm{Al}_{2} \mathrm{O}_{3}$ and $\mathrm{Cu}-\mathrm{Al}_{2} \mathrm{O}_{3}$ bicrystal plates. Stress concentration 
reductions of $17 \%$ and greater have been obtained in all cases, except those involving anisotropic $C u$ crystal where $13 \%$ reductions are attained. The large relative shear stiffness coefficients of $C u$ crystal cause the material to have a lower stress concentration within the structure before the introduction of the DHS, possibly reducing its effectiveness. The location where the largest stress concentration occurred was found to change around the face of the holes, depending on the relative size and position of the main and auxiliary holes. It has also been observed that the location shifts from the $\theta=0^{\circ}$ position as the shear stiffness properties increase relative to the anisotropic coefficients responsible for normal stiffness properties. Also, similar percentage stress reductions have been attained across cases using the same material for homogeneous and bimaterial system.

Stress concentration factors were found to be lowest for the range of geometric parameters investigated, when the auxiliary holes are positioned at $d / r=2.0$. It is worthwhile to consider smaller values of $d / r$ in future studies, since this is at the edge of the parametric range investigated. Different auxiliary hole parameters for each material in a bimaterial system may need to be investigated as well to find the lowest attainable stress concentration. The exact auxiliary hole parameters for the $\mathrm{Al}_{2} \mathrm{O}_{3}$ material in all bimaterial cases were also not found since they lie outside of the range of parameters investigated. However, significant stress concentration reductions were still attained, except for $\mathrm{Al}_{2} \mathrm{O}_{3}$ in the $\mathrm{Cu}-\mathrm{Al}_{2} \mathrm{O}_{3}$ bicrystal where the results suggest a larger hole than those analysed is needed to further reduce the stress concentration. 


\begin{tabular}{|c|c|c|}
\hline Mesh & Nodes & Elements \\
\hline A & 1384 & 480 \\
\hline B & 1416 & 488 \\
\hline C & 1424 & 488 \\
\hline D & 1456 & 496 \\
\hline
\end{tabular}

(a) BEM mesh properties

\begin{tabular}{|c|c|c|c|c|}
\cline { 3 - 5 } \multicolumn{2}{c|}{} & \multicolumn{3}{c|}{$\mathrm{d} / \mathbf{r}$} \\
\cline { 2 - 5 } & 2.0 & 2.5 & 3.0 \\
\hline \multirow{5}{*}{$\mathbf{b} / \mathbf{r}$} & 0.3 & $\mathrm{~B}$ & $\mathrm{C}$ & $\mathrm{D}$ \\
\cline { 2 - 5 } & 0.5 & $\mathrm{~B}$ & $\mathrm{~B}$ & $\mathrm{C}$ \\
\hline & 0.7 & $\mathrm{~B}$ & $\mathrm{~B}$ & $\mathrm{C}$ \\
\hline & 0.9 & $\mathrm{~A}$ & $\mathrm{~B}$ & $\mathrm{~B}$ \\
\hline
\end{tabular}

(b) Meshes used with varying auxiliary hole geometry

Table 5.1: Reference of the various base meshes used to analyse all cases in the parametric study 


\begin{tabular}{|c|c|c|c|c|c|}
\cline { 3 - 6 } \multicolumn{2}{c|}{} & $d / r$ & $b / r$ & $\hat{\sigma}_{1} / \sigma_{0}$ & Reduction [\%] \\
\hline \multirow{4}{*}{ Isotropic } & $\begin{array}{c}E=1000 \mathrm{GPa} \\
\nu=0.3\end{array}$ & 2.0 & 0.850 & 2.55 & 18.7 \\
\cline { 2 - 6 } & $\mathrm{Nb}$ & 2.0 & 0.843 & 2.93 & 19.8 \\
\cline { 2 - 6 } & $\mathrm{Cu}$ & 2.0 & 0.558 & 2.58 & 13.3 \\
\cline { 2 - 6 } & $\mathrm{Al}_{2} \mathrm{O}_{3}$ & 2.0 & 0.800 & 2.78 & 18.1 \\
\hline
\end{tabular}

(a) Homogeneous Plate

\begin{tabular}{|c|c|c|c|c|c|}
\cline { 2 - 6 } \multicolumn{1}{c|}{} & $d / r$ & $b / r$ & $\hat{\sigma}_{1} / \sigma_{0}$ & Reduction [\%] \\
\hline \multirow{5}{*}{ Isotropic } & $\mathrm{Nb}$ & 2.0 & 0.898 & $2.44^{*}$ & 17.7 \\
& $\mathrm{Al}_{2} \mathrm{O}_{3}$ & 2.0 & 0.9 & $2.86^{*}$ & $17.1^{* *}$ \\
\cline { 2 - 6 } & $\mathrm{Cu}$ & 2.0 & 0.884 & $2.44^{*}$ & 17.4 \\
& $\mathrm{Al}_{2} \mathrm{O}_{3}$ & 2.0 & 0.9 & $2.74^{*}$ & $17.2^{* *}$ \\
\hline \multirow{5}{*}{ Anisotropic } & $\mathrm{Nb}$ & 2.0 & 0.816 & $2.81^{*}$ & 17.3 \\
& $\mathrm{Al}_{2} \mathrm{O}_{3}$ & 2.0 & 0.9 & $2.91^{*}$ & $21.0^{* *}$ \\
\cline { 2 - 6 } & $\mathrm{Cu}$ & 2.0 & 0.686 & $2.59^{*}$ & 13.2 \\
& $\mathrm{Al}_{2} \mathrm{O}_{3}$ & 2.5 & 0.9 & $3.42^{*}$ & $11.7^{* *}$ \\
\hline
\end{tabular}

(b) Bimaterial Plate

Table 5.2: Lowest stress concentrations and the corresponding auxiliary hole parameters

*Stress values affected by weak singularity

${ }^{* *}$ Larger stress concentration reductions may be possible with further investigation 


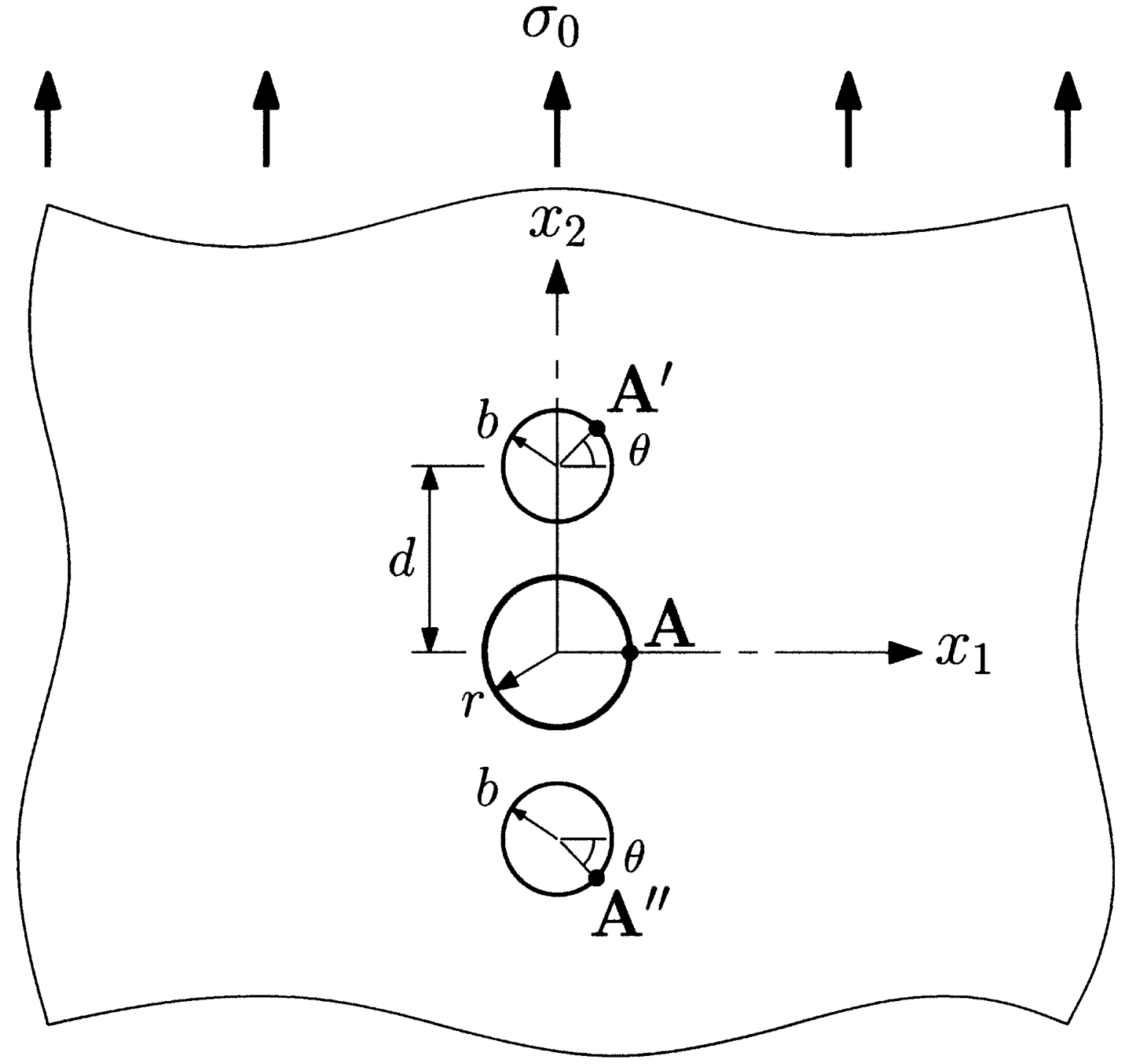

Figure 5.1: DHS of a plate with a circular hole in tension $\left(\mathrm{x}_{3}\right.$ dimension not illustrated) 


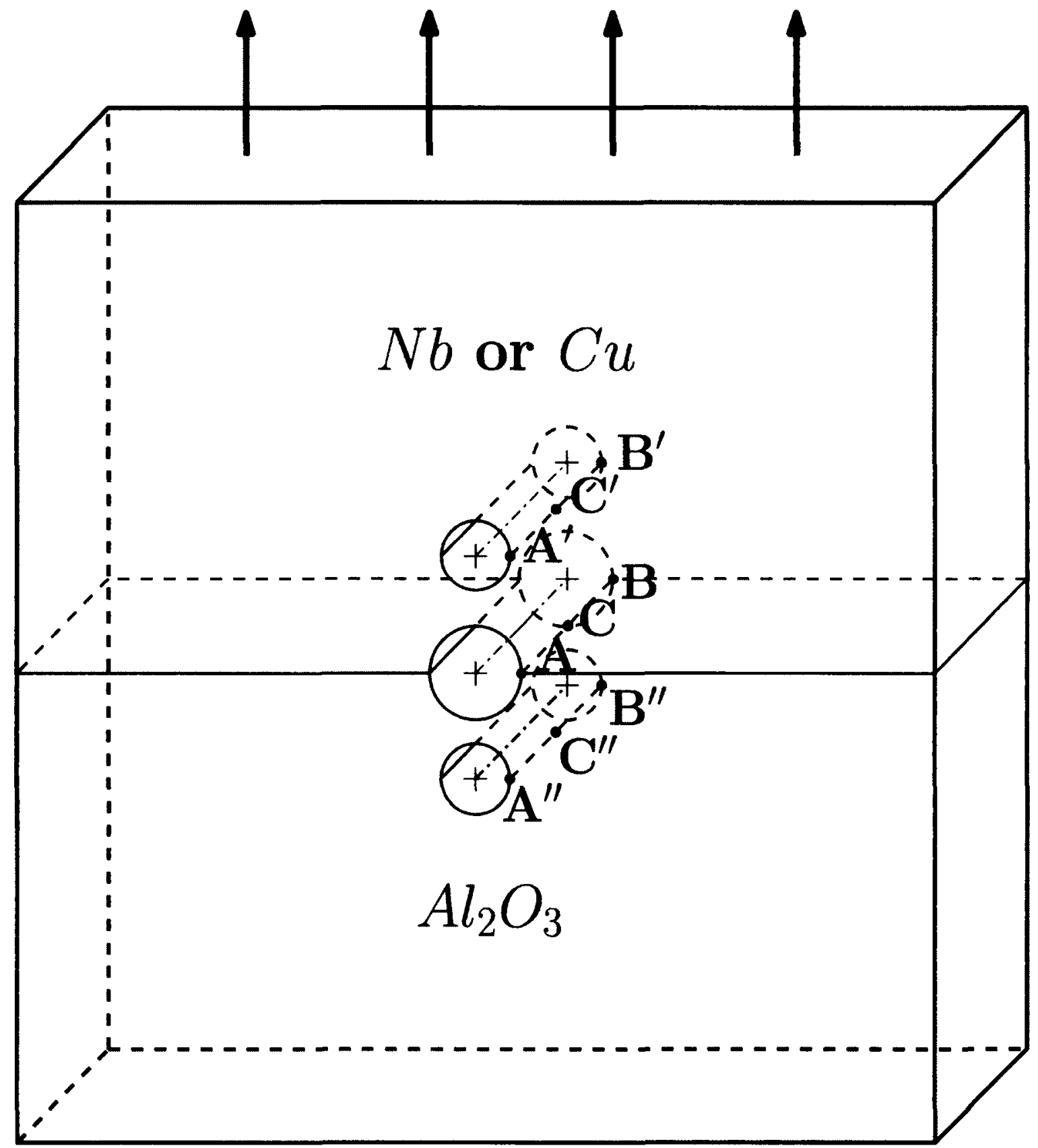

Figure 5.2: Bimaterial regioning of a plate with a circular hole at the interface with a DHS 


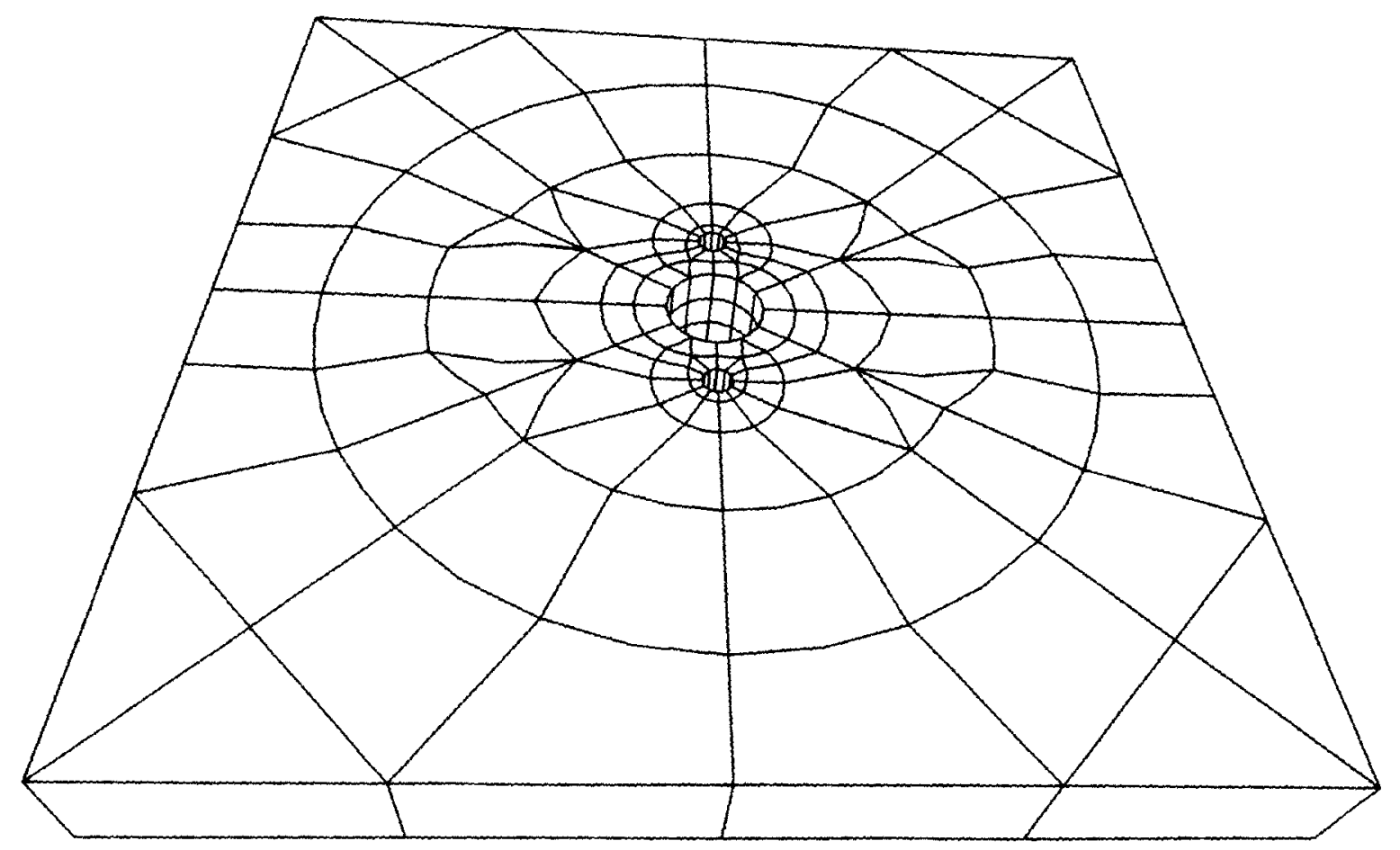

(a) Full Mesh

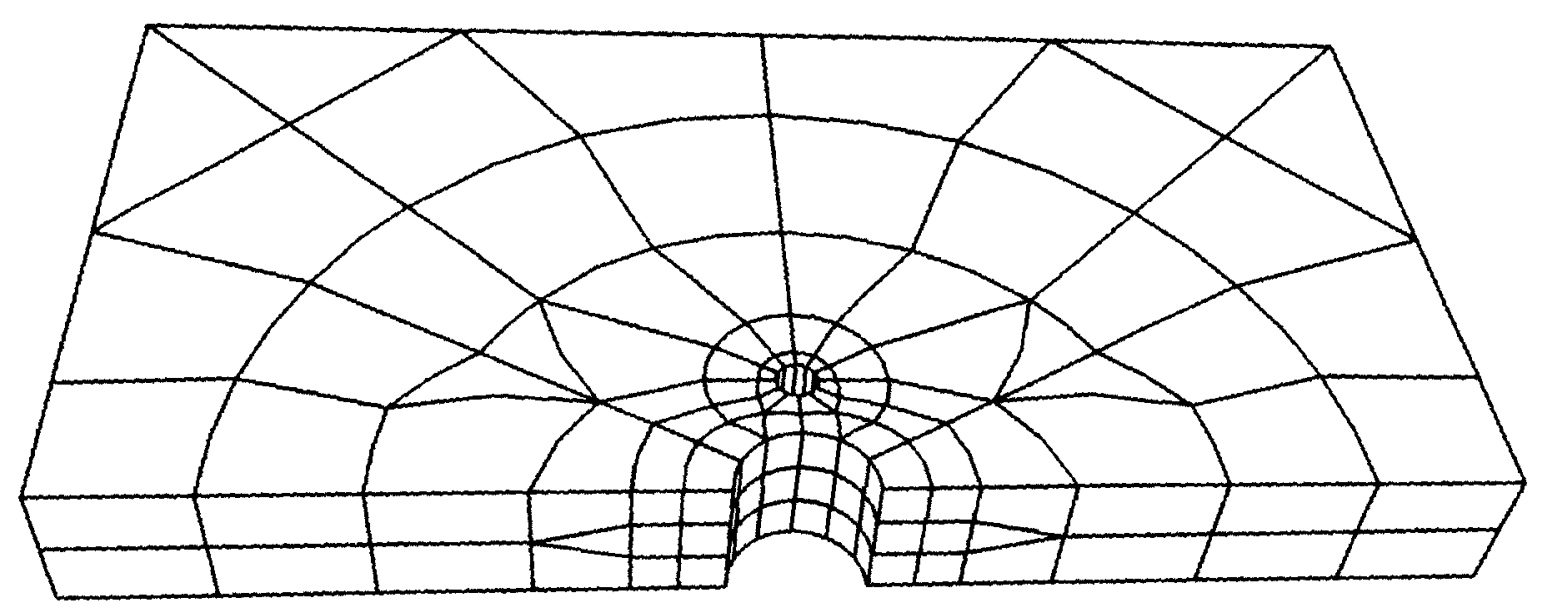

Figure 5.3: $B E M$ mesh (b) Interfacial Mesh

1416 nodes) 


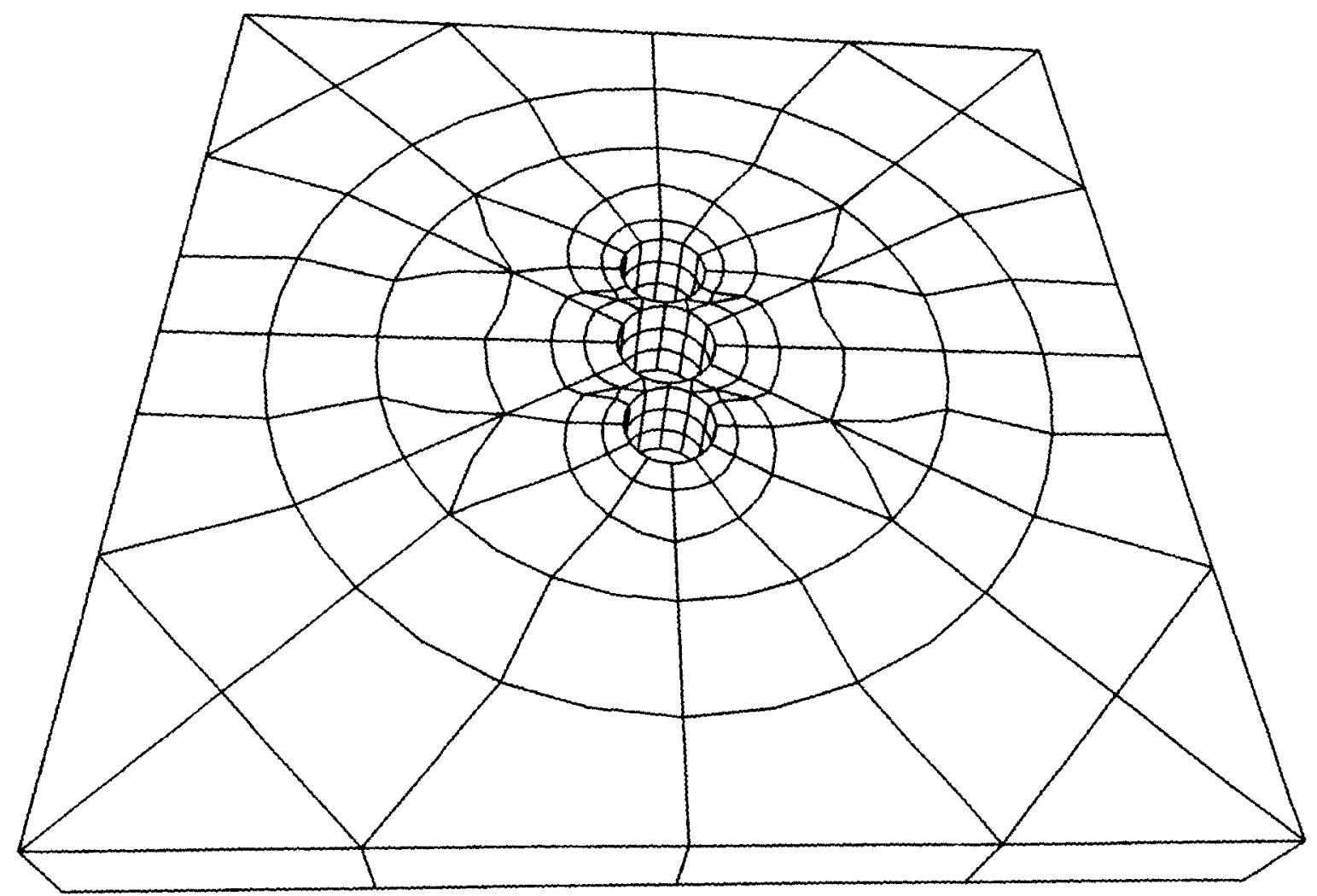

Figure 5.4:

1384 nodes)

(480 elements and 


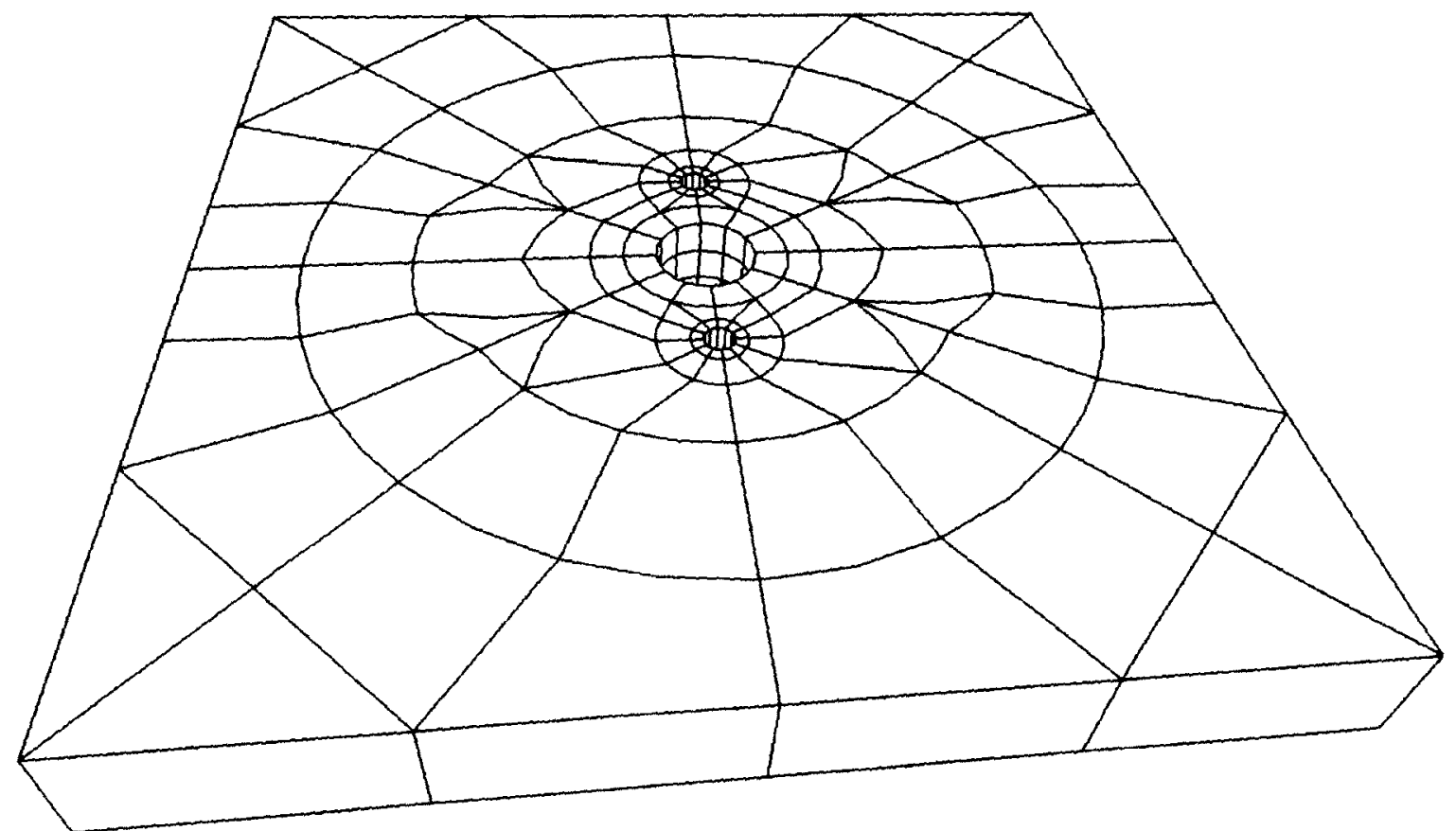

Figure 5.5: BEM mesh of plate with a circular hole and 1424 nodes)

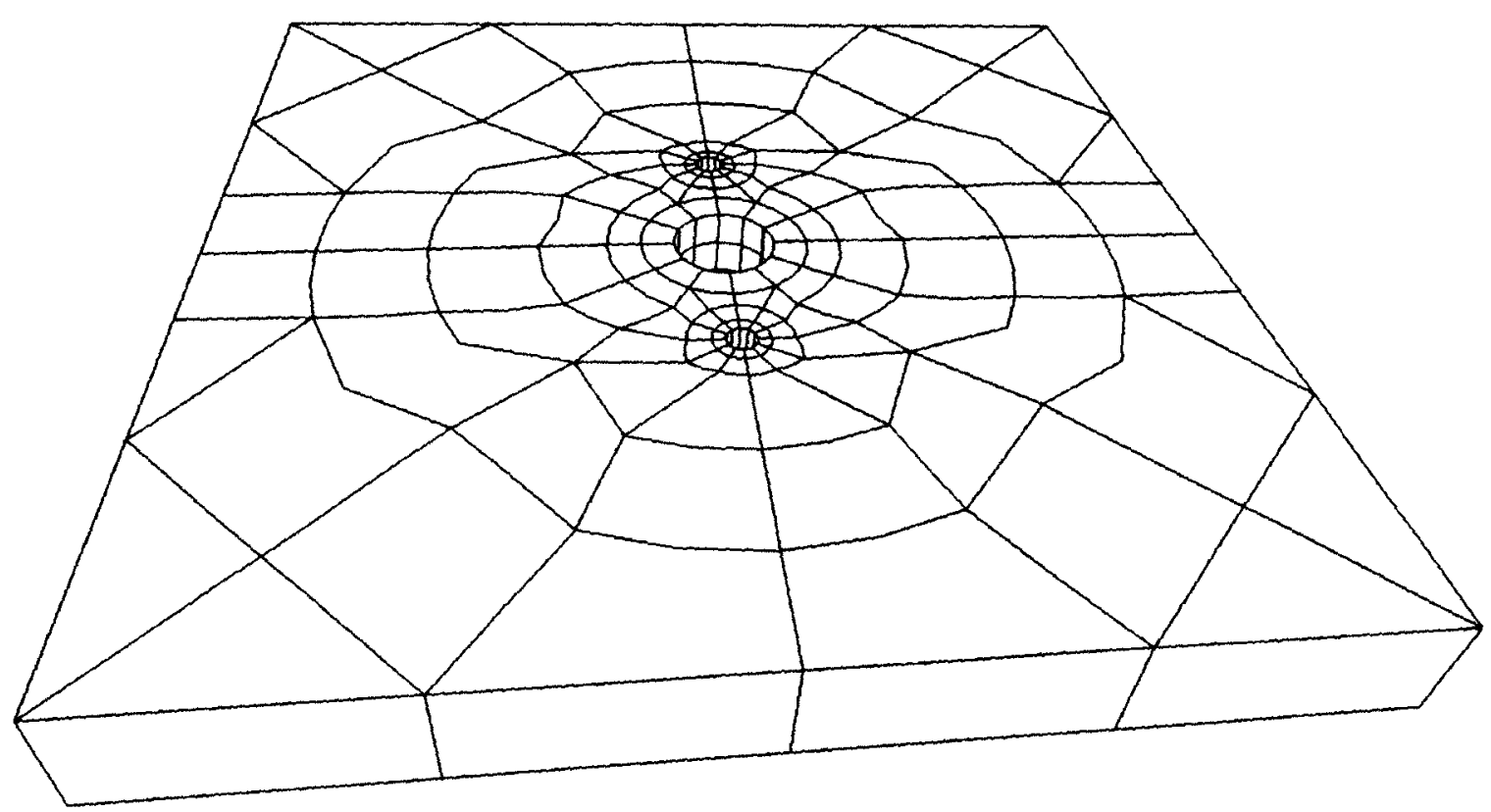

Figure 5.6: BEM mesh of plate with a circular hole and 1456 nodes)

HS (496 elements and 


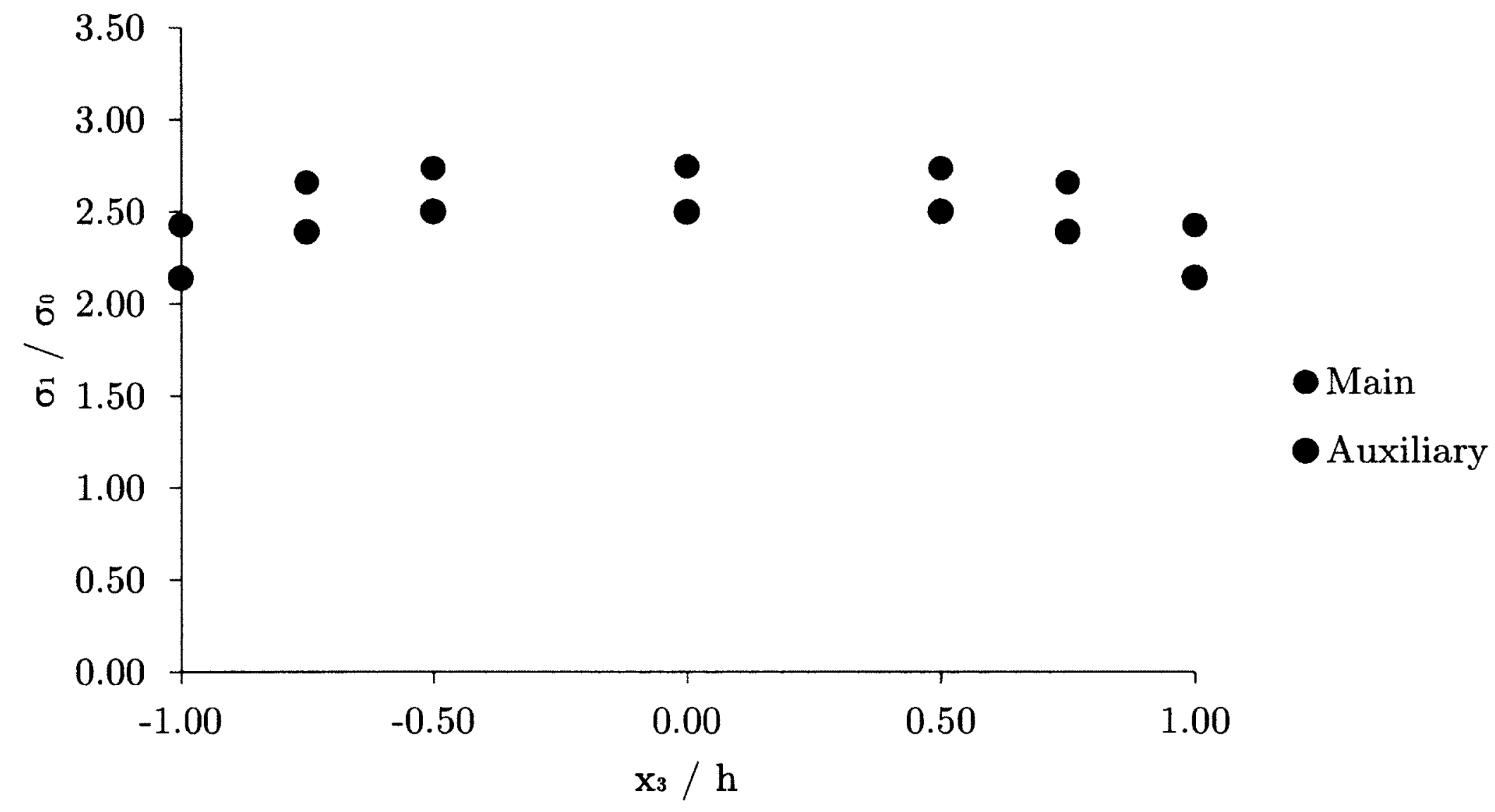

Figure 5.7: Variation of $\sigma_{1} / \sigma_{0}$ in a homogeneous isotropic plate with a circular hole and DHS, through the thickness along the main, $\overline{A C B}$, and auxiliary, $\overline{A^{\prime} C^{\prime} B^{\prime}}$ and $\overline{A^{\prime \prime} C^{\prime \prime} B^{\prime \prime}}$, holes for $d / r=2.5$ and $b / r=0.7$ 


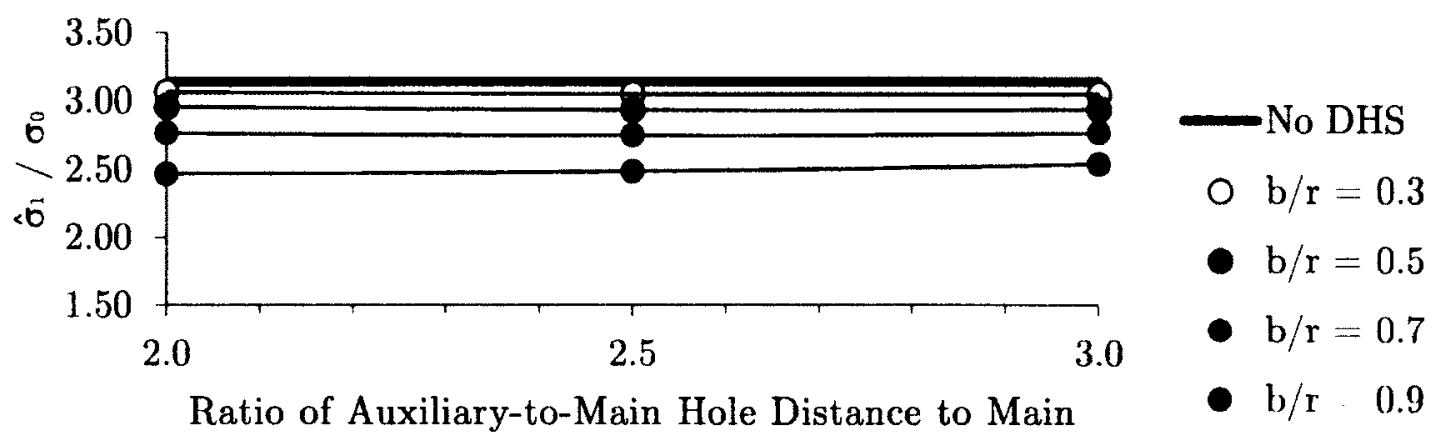

Hole Radius [d/r]

(a) Main Hole

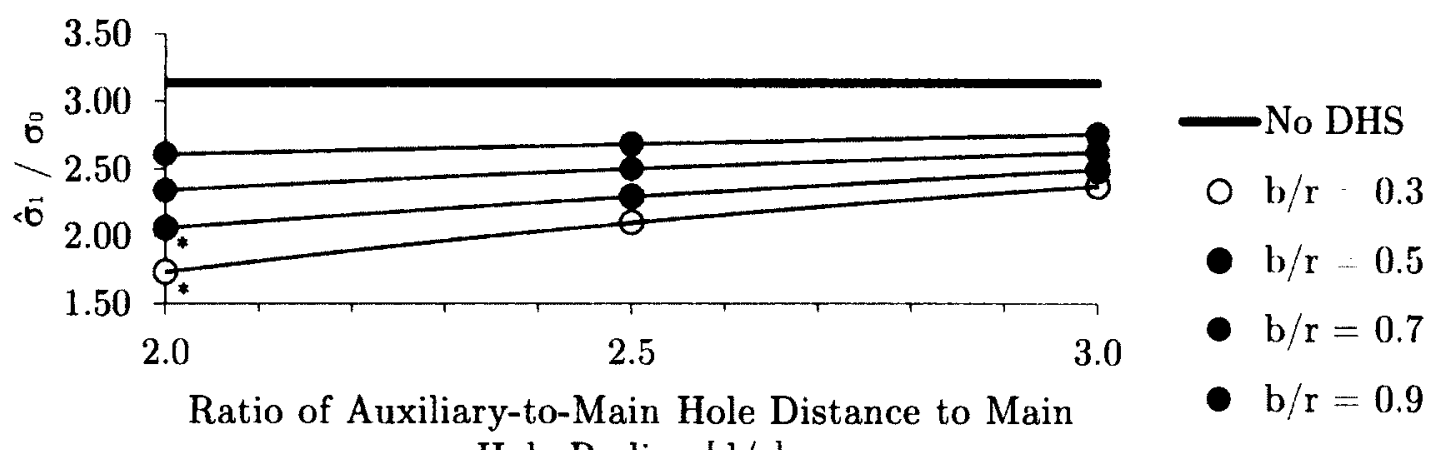

Hole Radius [d/r]

(b) Auxiliary Hole

Figure 5.8: Variation of stress concentration with $d / r$ in a homogeneous isotropic plate with a circular hole and DHS, along the main, $\overline{A C B}$, and auxiliary, $\overline{A^{\prime} C^{\prime} B^{\prime}}$ and $\overline{A^{\prime \prime} C^{\prime \prime} B^{\prime \prime}}$, holes

*Highest stress concentration located at $\theta=15^{\circ}$ 


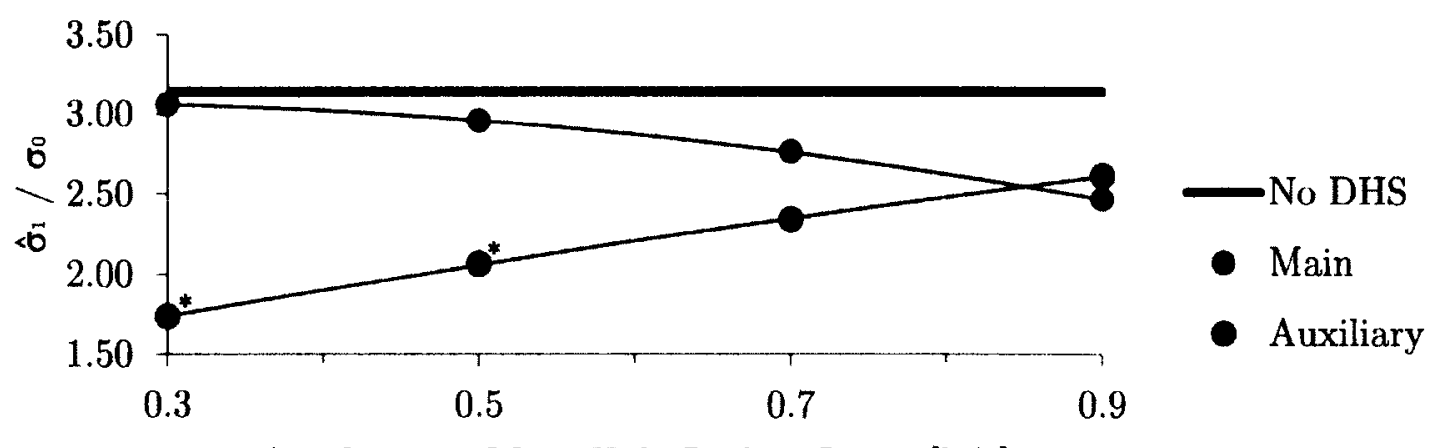

Auxiliary to Main Hole Radius Ratio [b/r]

(a) $d / r=2.0$

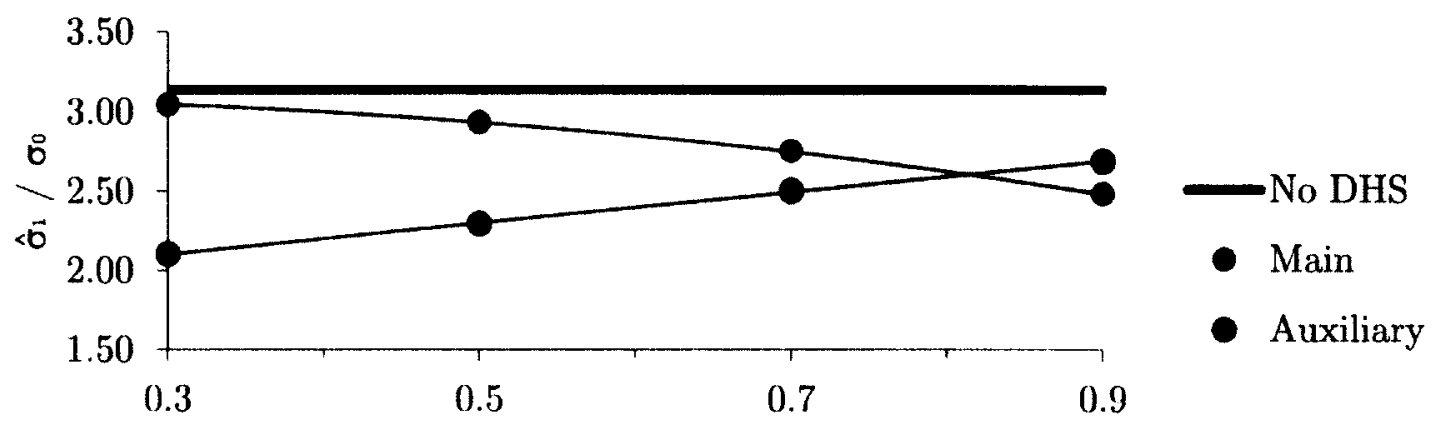

Auxiliary to Main Hole Radius Ratio [b/r]

(b) $d / r=2.5$

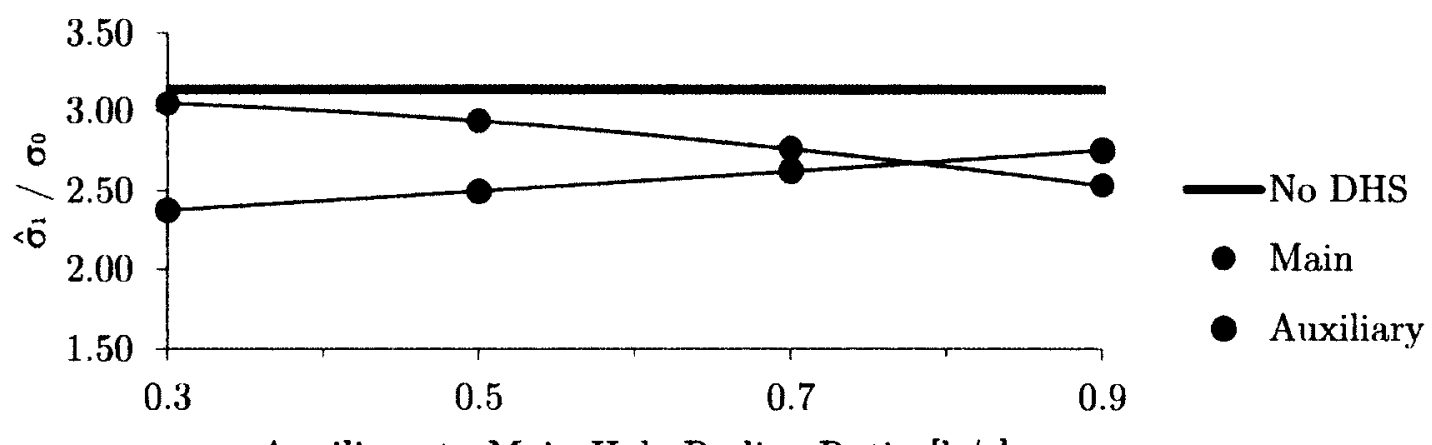

Auxiliary to Main Hole Radius Ratio [b/r]

(c) $d / r=3.0$

Figure 5.9: Variation of stress concentration in a homogeneous isotropic plate with a circular hole and DHS, along the main, $\overline{A C B}$, and auxiliary, $\overline{A^{\prime} C^{\prime} B^{\prime}}$ and $\overline{A^{\prime \prime} C^{\prime \prime} B^{\prime \prime}}$, holes

${ }^{*}$ Highest stress concentration located at $\theta=15^{\circ}$ 


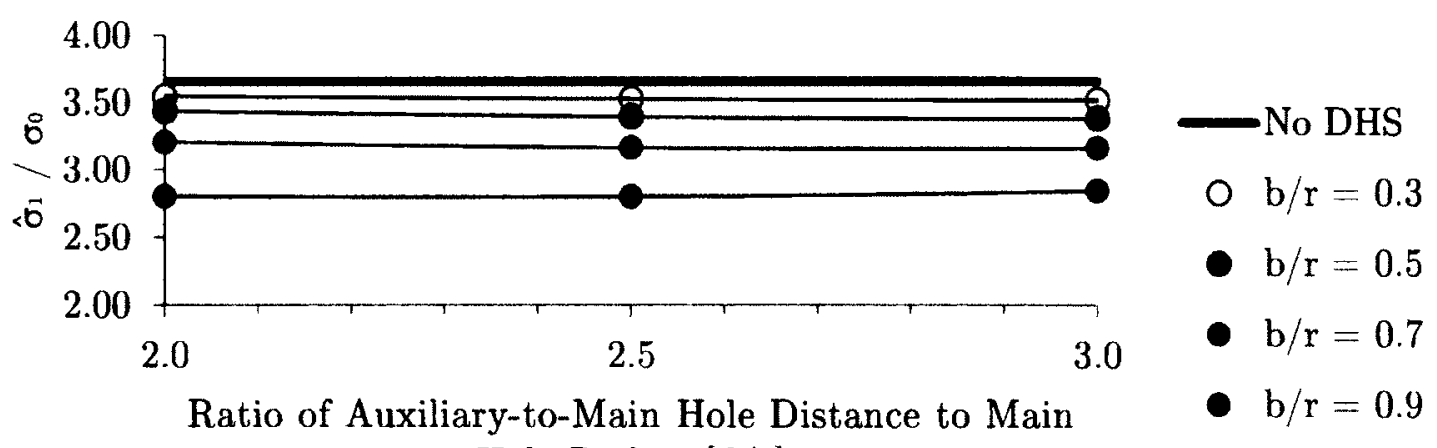

Hole Radius $[\mathrm{d} / \mathrm{r}]$

(a) Nb Plate

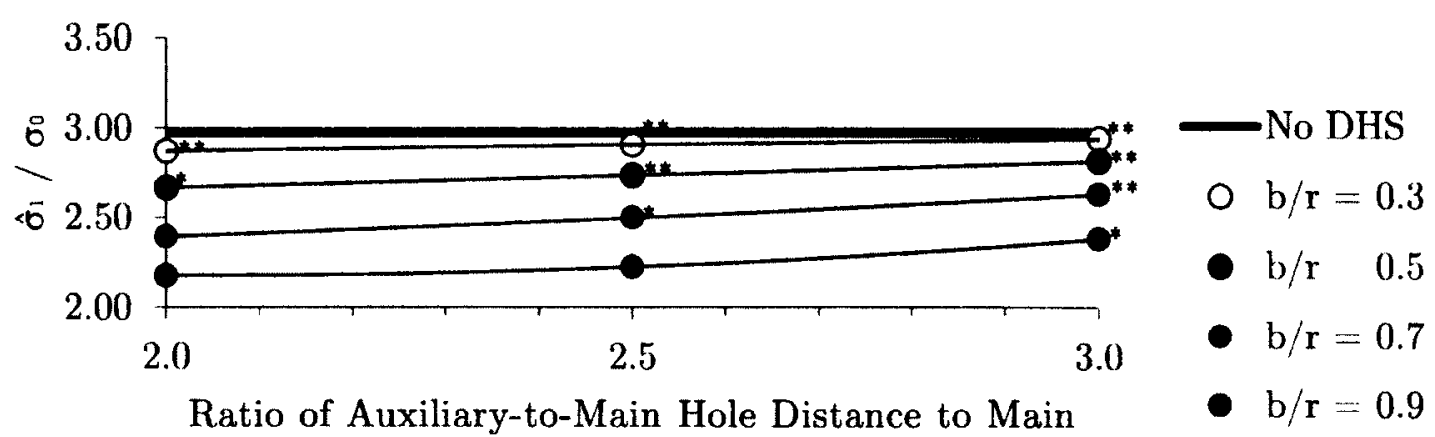

Hole Radius [d/r]

(b) Cu Plate

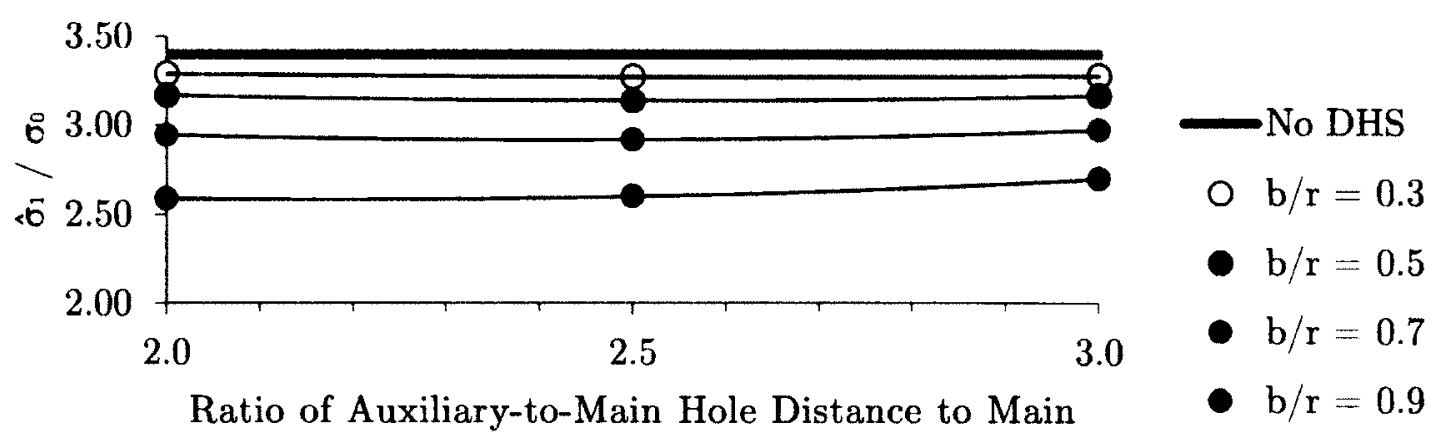

Hole Radius $[\mathrm{d} / \mathrm{r}]$

(c) $\mathrm{Al}_{2} \mathrm{O}_{3}$ Plate

Figure 5.10: Variation of stress concentration with $d / r$ in homogeneous anisotropic plates, each with a circular hole and DHS, along the main hole, $\overline{A C B}$

*Highest stress concentration located at $\theta=15^{\circ}$

**Highest stress concentration located at $\theta=30^{\circ}$ 


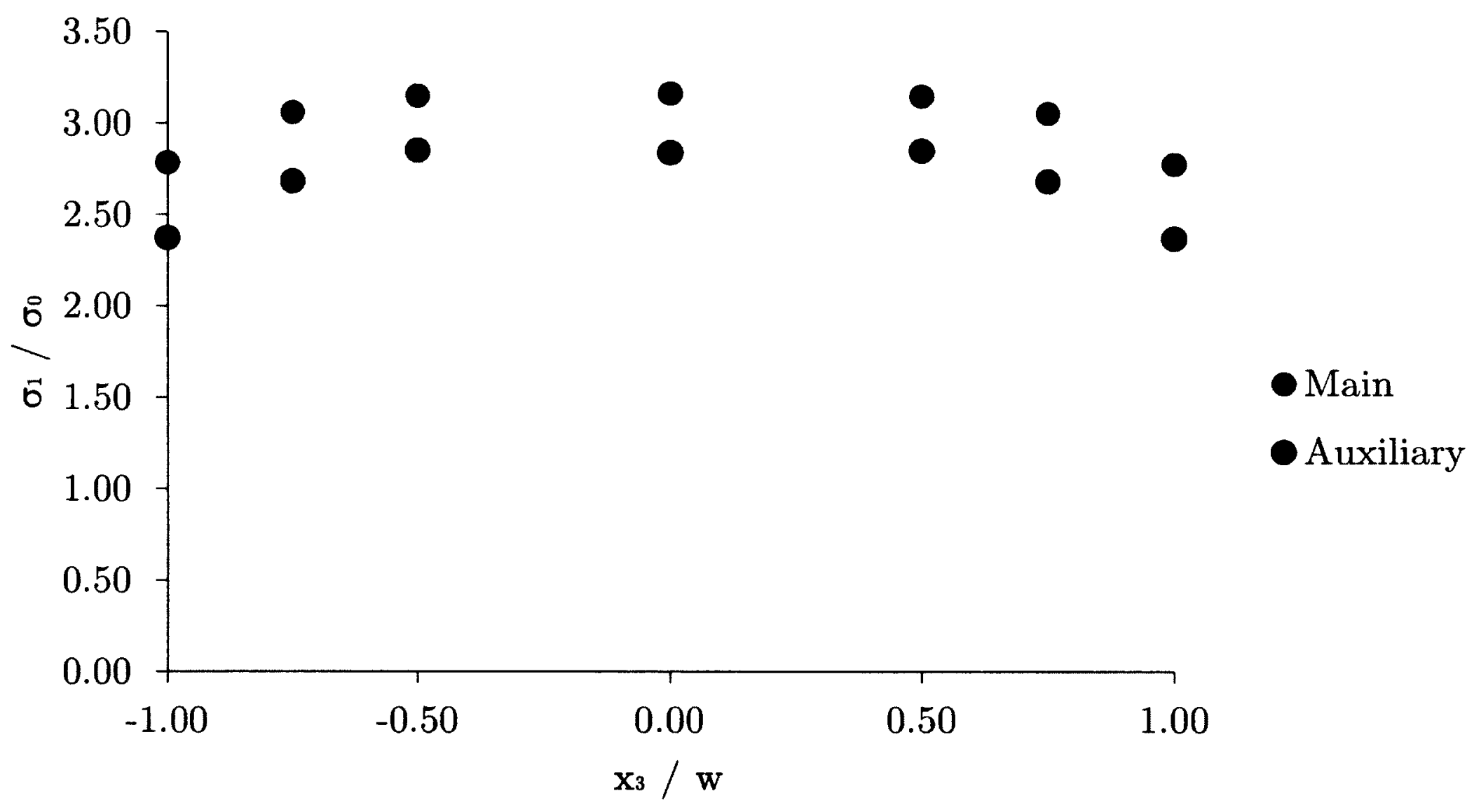

Figure 5.11: Variation of $\sigma_{1} / \sigma_{0}$ in a homogeneous anisotropic $N b$ plate with a circular hole and DHS, through the thickness along the main, $\overline{A C B}$, and auxiliary, $\overline{A^{\prime} C^{\prime} B^{\prime}}$ and $\overline{A^{\prime \prime} C^{\prime \prime} B^{\prime \prime}}$, holes for $d / r=2.5$ and $b / r=0.7$ 


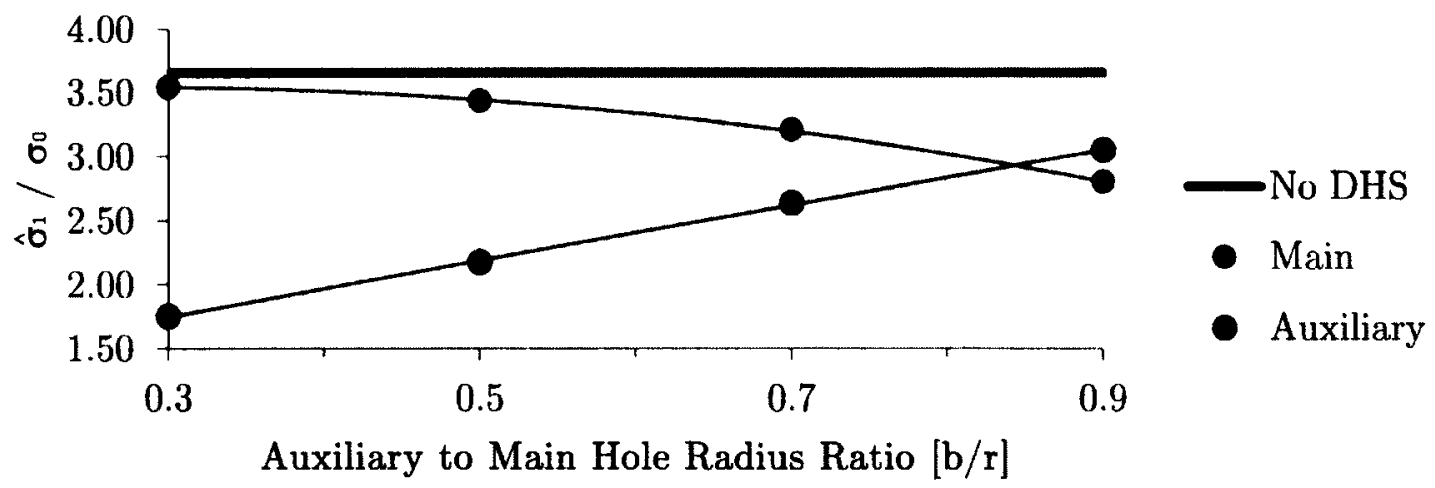

(a) $d / r=2.0$

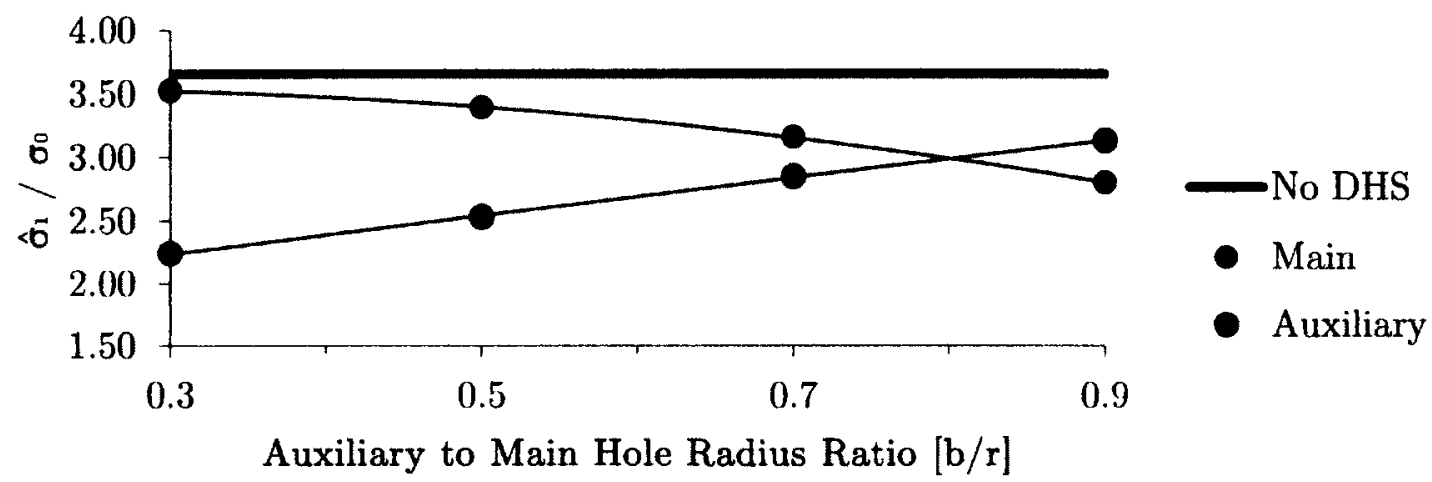

(b) $d / r=2.5$

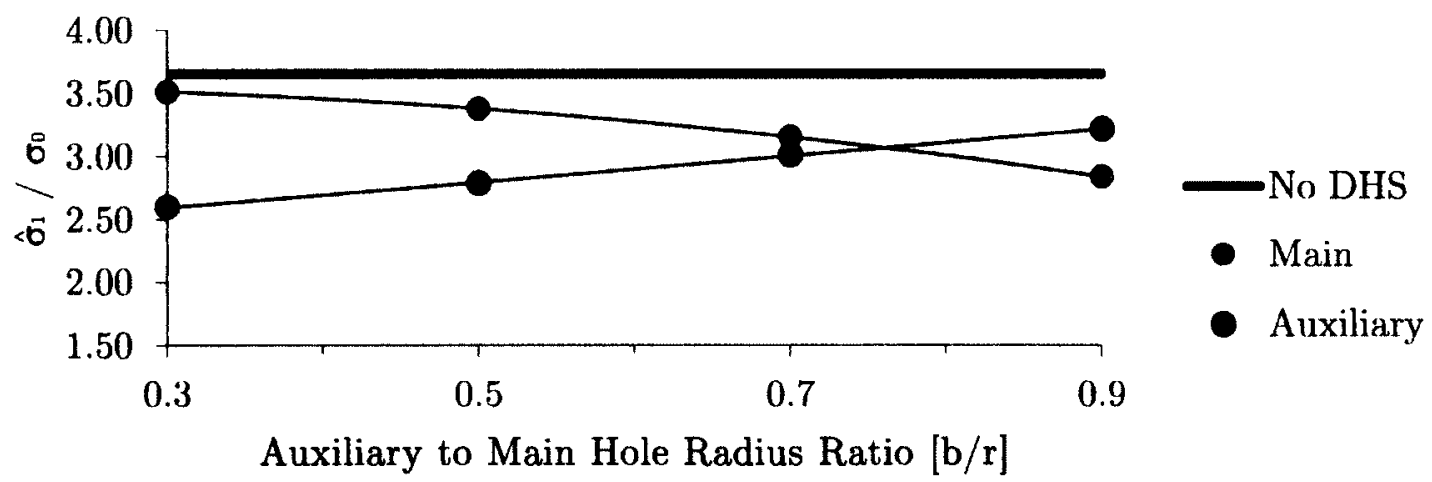

(c) $d / r=3.0$

Figure 5.12: Variation of stress concentration in a homogeneous anisotropic $N b$ plate with a circular hole and DHS, along the main, $\overline{A C B}$, and auxiliary, $\overline{A^{\prime} C^{\prime} B^{\prime}}$ and $\overline{A^{\prime \prime} C^{\prime \prime} B^{\prime \prime}}$, holes 


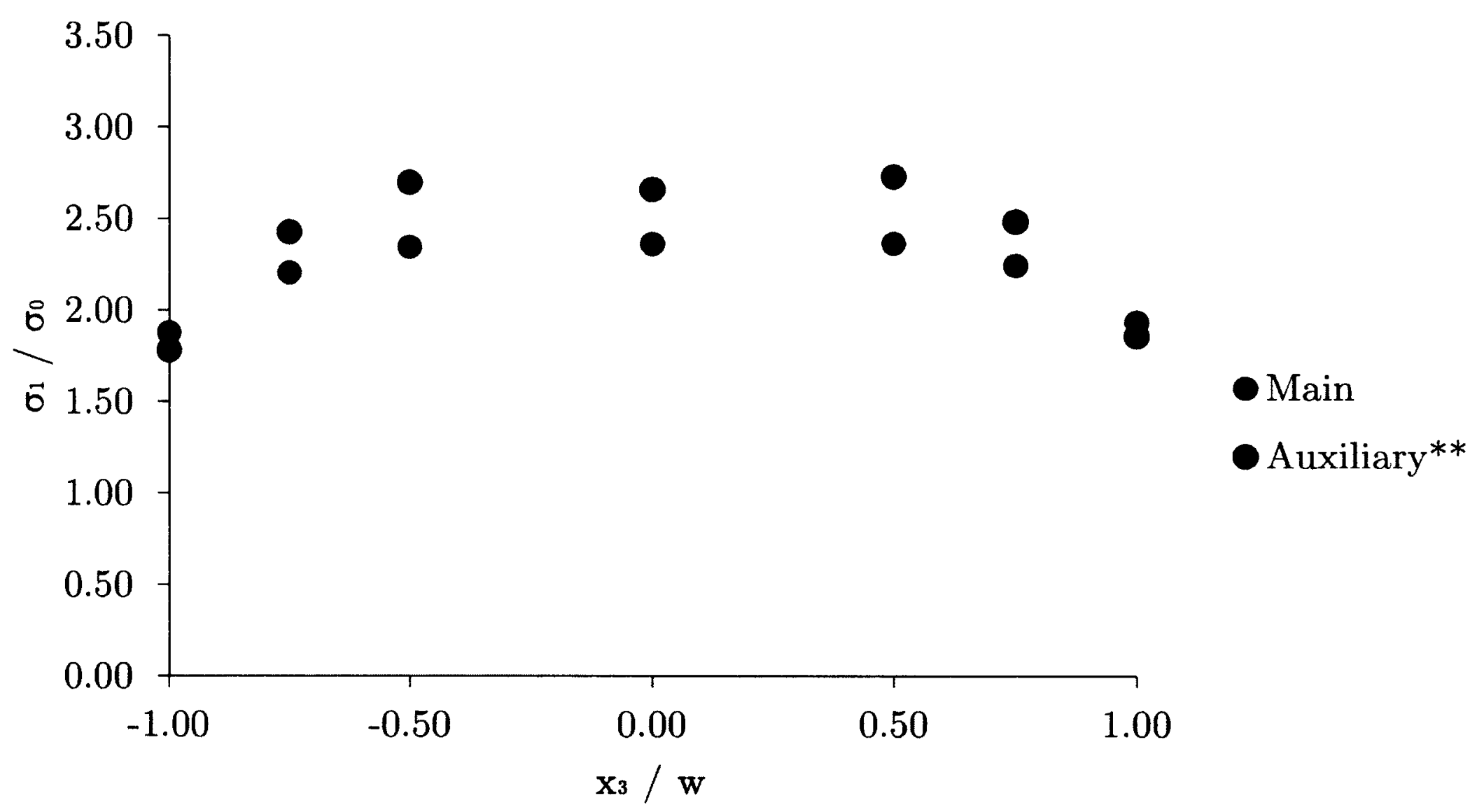

Figure 5.13: Variation of $\sigma_{1} / \sigma_{0}$ in a homogeneous anisotropic $C u$ plate with a circular hole and DHS, through the thickness along the main, $\overline{A C B}$, and auxiliary, $\overline{A^{\prime} C^{\prime} B^{\prime}}$ and $\overline{A^{\prime \prime} C^{\prime \prime} B^{\prime \prime}}$, holes for $d / r=2.0$ and $b / r=0.7$

\footnotetext{
${ }^{* *}$ Highest stress concentration located at $\theta=30^{\circ}$
} 


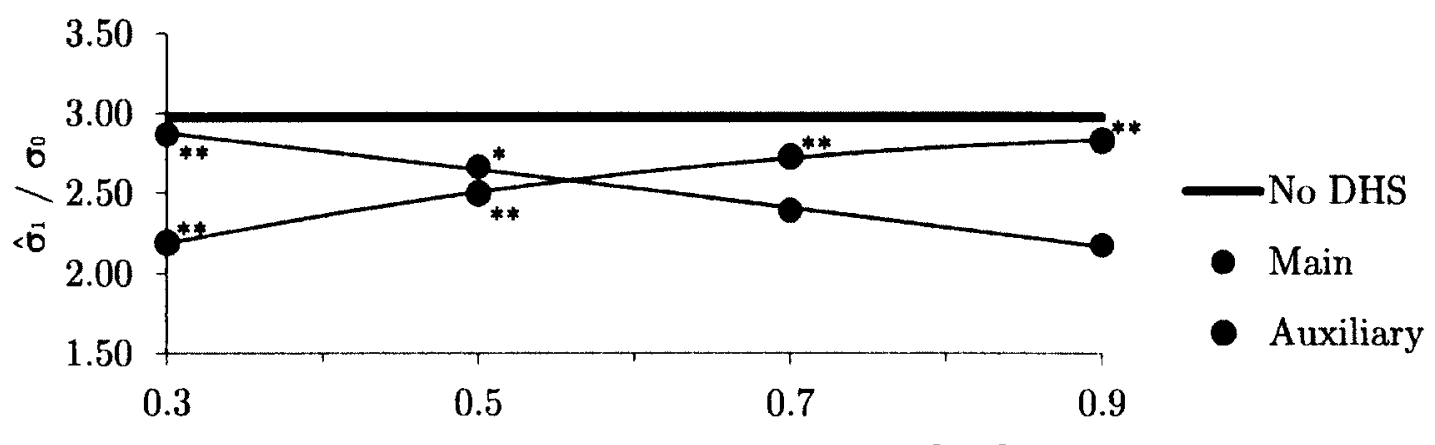

Auxiliary to Main Hole Radius Ratio [b/r]

(a) $d / r=2.0$

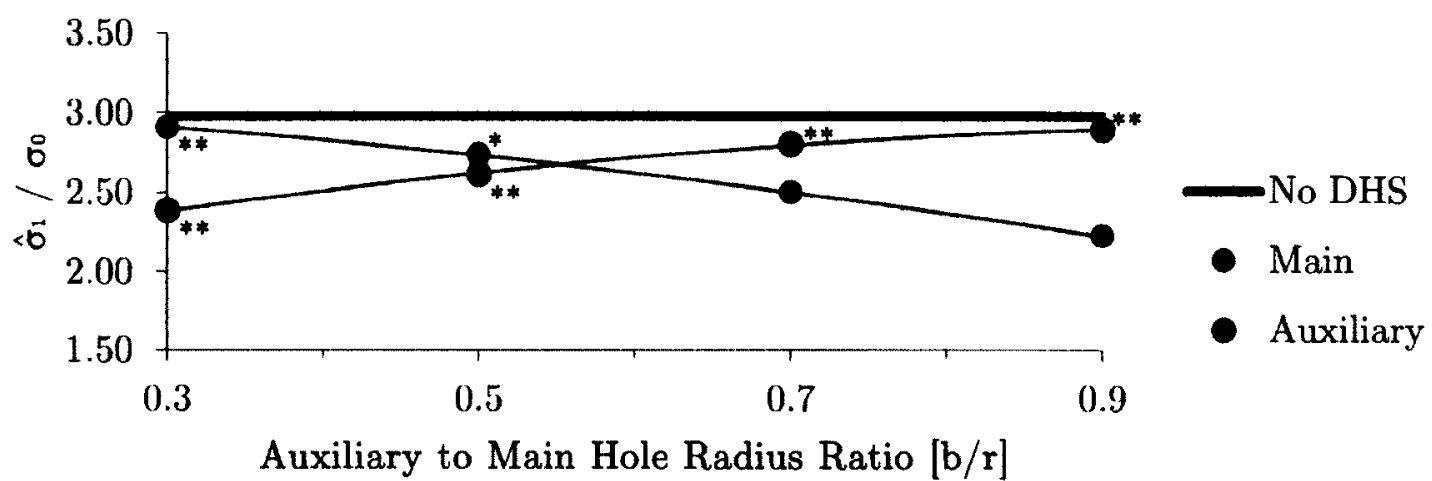

(b) $d / r=2.5$

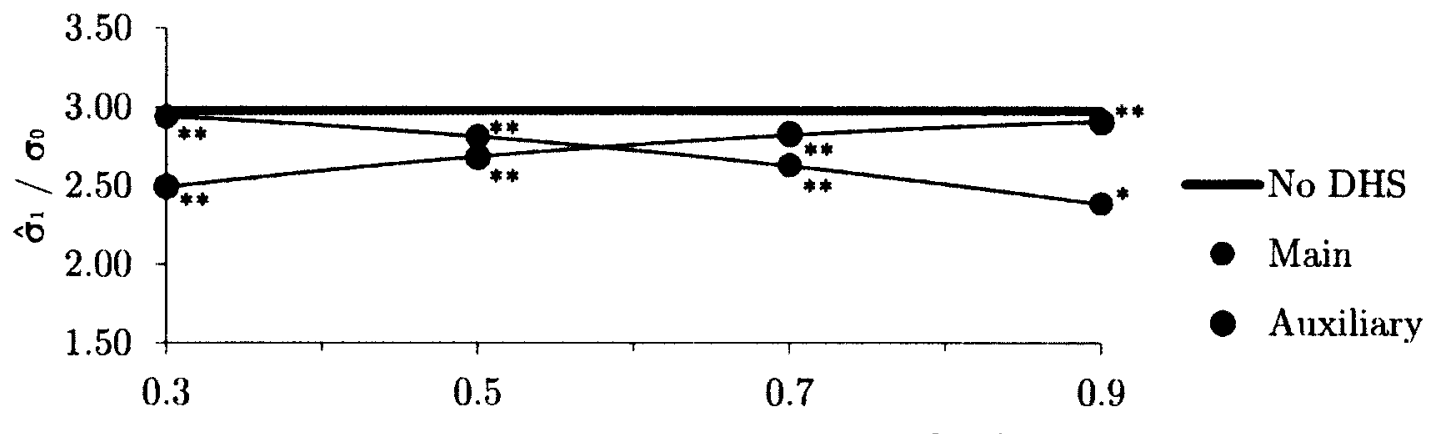

Auxiliary to Main Hole Radius Ratio [b/r]

(c) $d / r=3.0$

Figure 5.14: Variation of stress concentration in a homogeneous anisotropic $C u$ plate with a circular hole and DHS, along the main, $\overline{A C B}$, and auxiliary, $\overline{A^{\prime} C^{\prime} B^{\prime}}$ and $\overline{A^{\prime \prime} C^{\prime \prime} B^{\prime \prime}}$, holes

${ }^{*}$ Highest stress concentration located at $\theta=15^{\circ}$

${ }^{* *}$ Highest stress concentration located at $\theta=30^{\circ}$ 


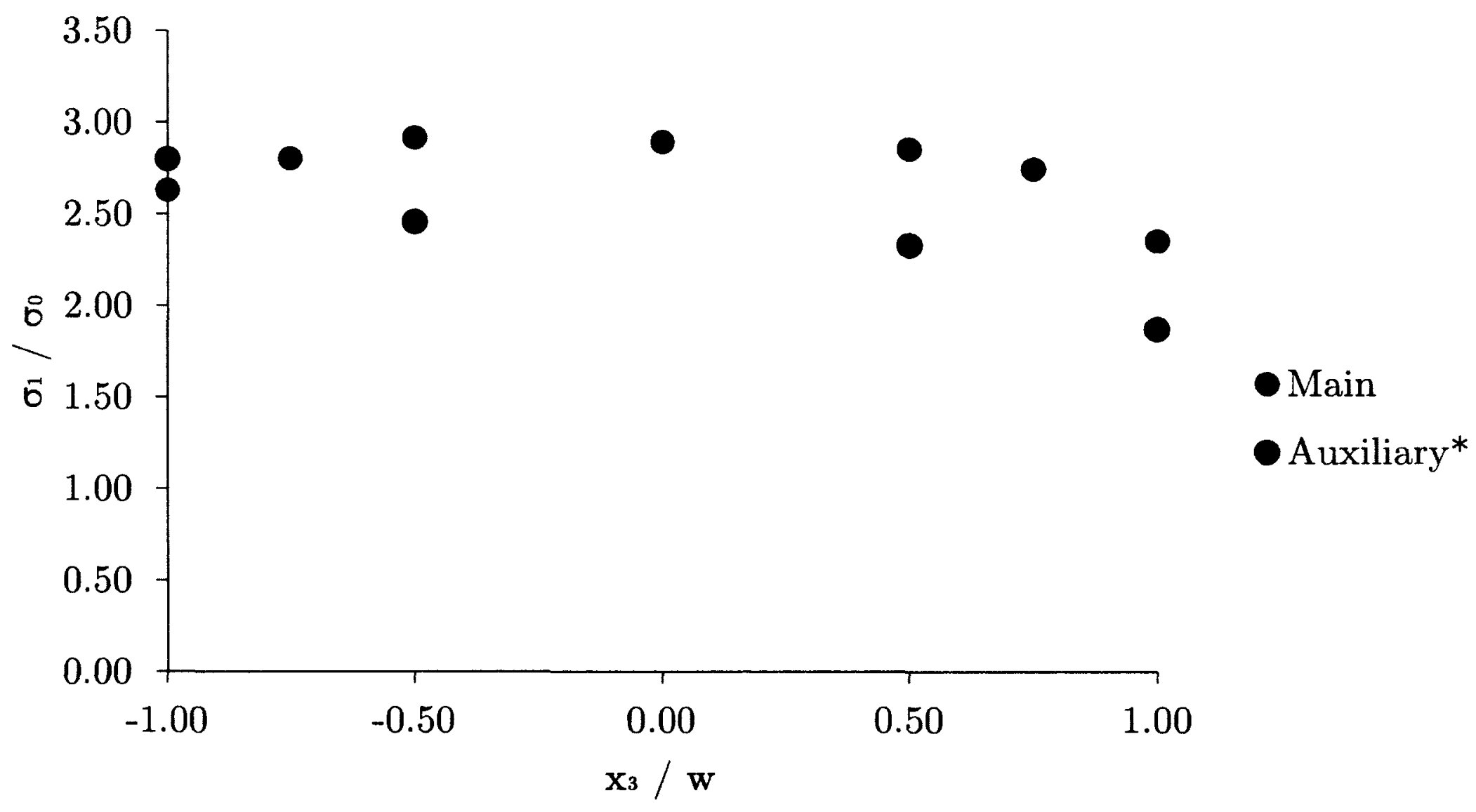

Figure 5.15: Variation of $\sigma_{1} / \sigma_{0}$ in a homogeneous anisotropic $A l_{2} O_{3}$ plate with a circular hole and DHS, through the thickness along the main, $\overline{A C B}$, and auxiliary, $\overline{A^{\prime} C^{\prime} B^{\prime}}$ and $\overline{A^{\prime \prime} C^{\prime \prime} B^{\prime \prime}}$, holes for $d / r=2.5$ and $b / r=0.7$ 


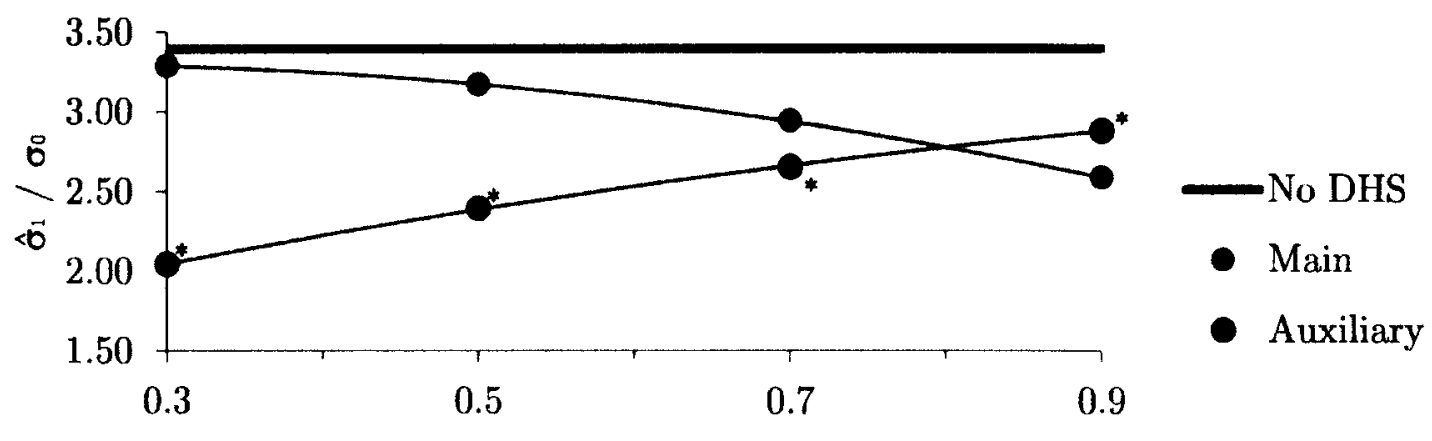

Auxiliary to Main Hole Radius Ratio [b/r]

(a) $d / r=2.0$

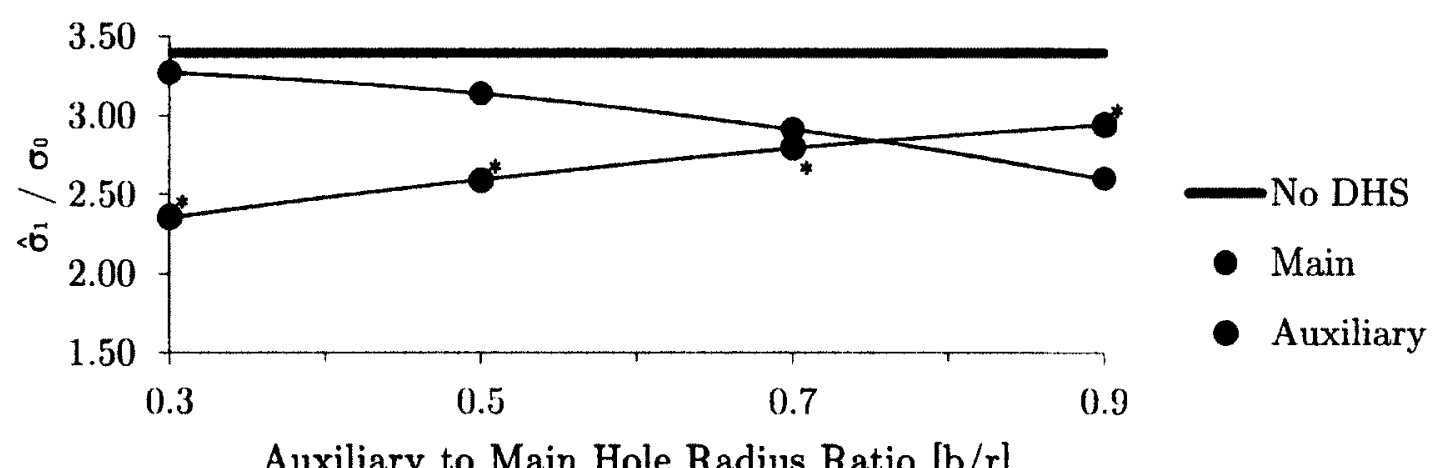

(b) $d / r=2.5$

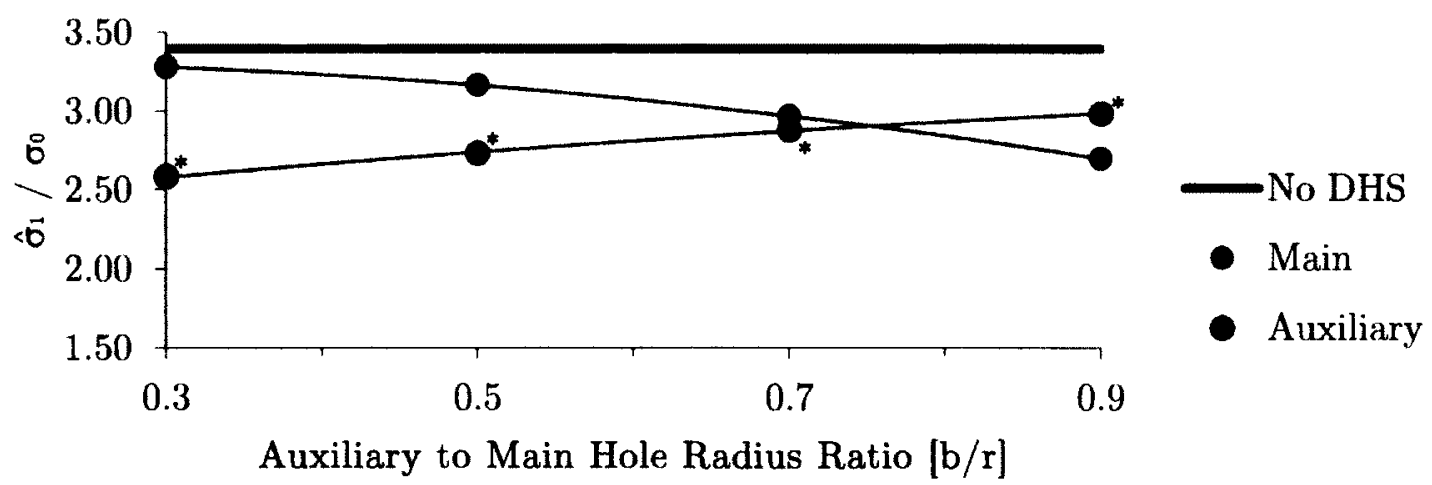

(c) $d / r=3.0$

Figure 5.16: Variation of stress concentration in a homogeneous anisotropic $\mathrm{Al}_{2} \mathrm{O}_{3}$ plate with a circular hole and DHS, along the main, $\overline{A C B}$, and auxiliary, $\overline{A^{\prime} C^{\prime} B^{\prime}}$ and $\overline{A^{\prime \prime} C^{\prime \prime} B^{\prime \prime}}$, holes

${ }^{*}$ Highest stress concentration located at $\theta=15^{\circ}$ 


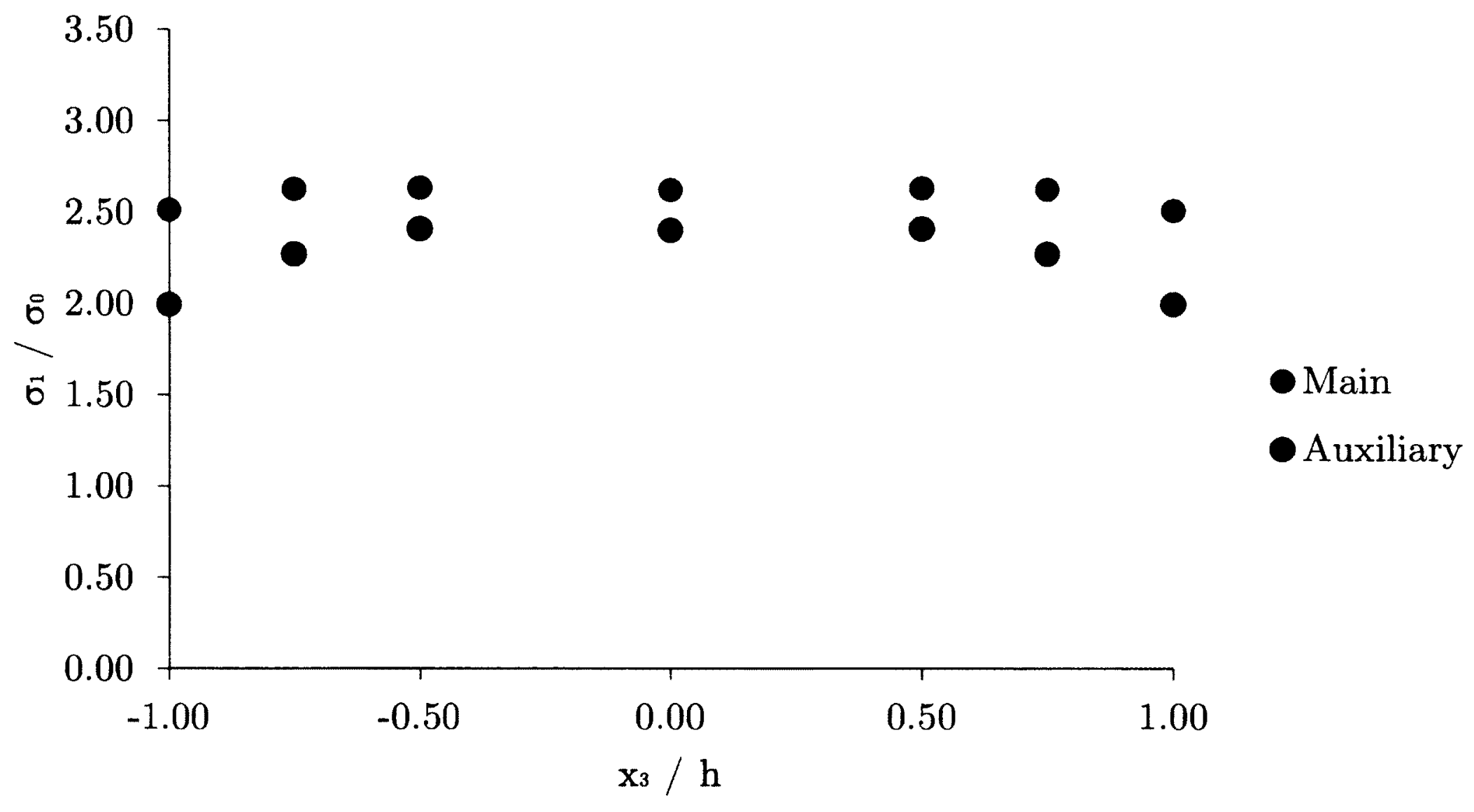

Figure 5.17: Variation of $\sigma_{1} / \sigma_{0}$ in the $N b$ material of an isotropic bimaterial $N b-A l_{2} O_{3}$ plate with a circular hole at the interface and DHS, through the thickness along the main, $\overline{A C B}$, and auxiliary, $\overline{A^{\prime} C^{\prime} B^{\prime}}$, holes for $d / r=2.5$ and $b / r=0.7$ 


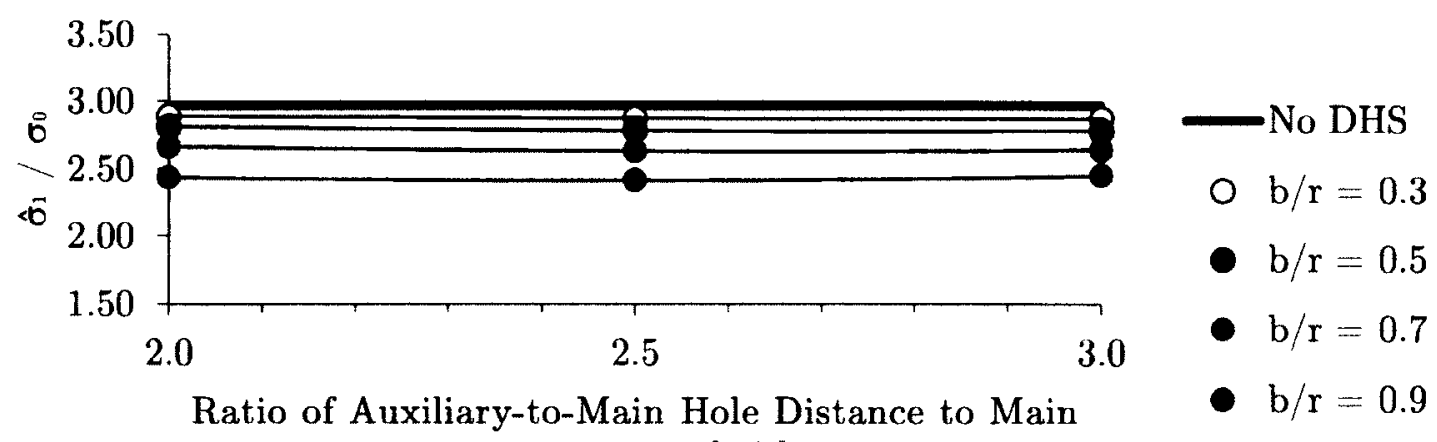

Hole Radius [d/r]

(a) $\mathrm{Nb}$ Plate

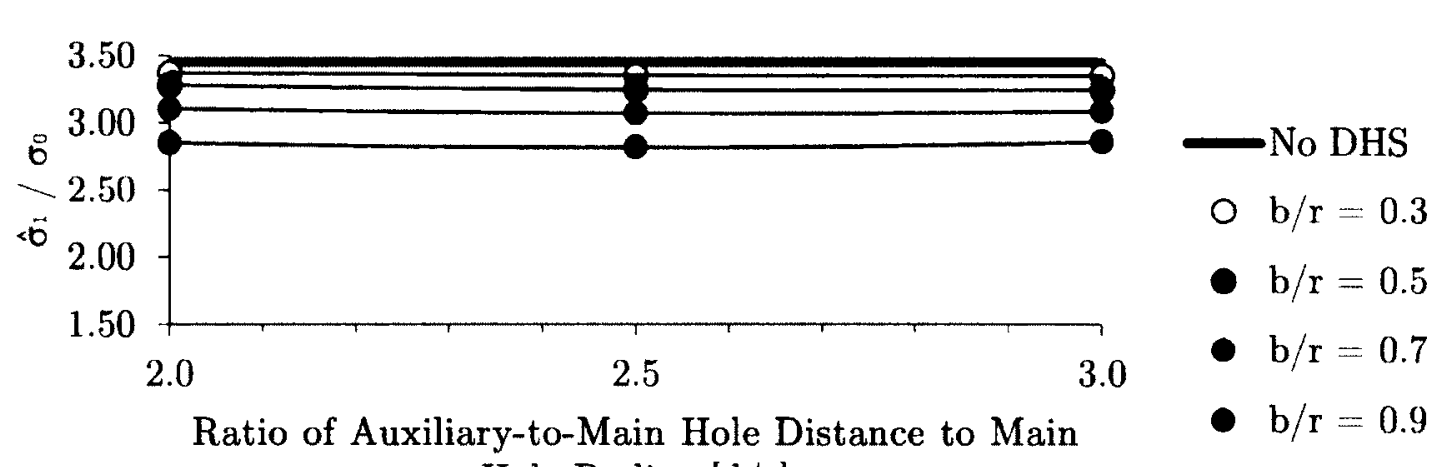

Hole Radius $[\mathrm{d} / \mathrm{r}$ ]

(b) $\mathrm{Al}_{2} \mathrm{O}_{3}$ Plate

Figure 5.18: Variation of stress concentration with $d / r$ in a $\mathrm{Nb}-\mathrm{Al}_{2} \mathrm{O}_{3}$ bimaterial isotropic plate with a circular hole and DHS, along the main hole, $\overline{A C B}$ 


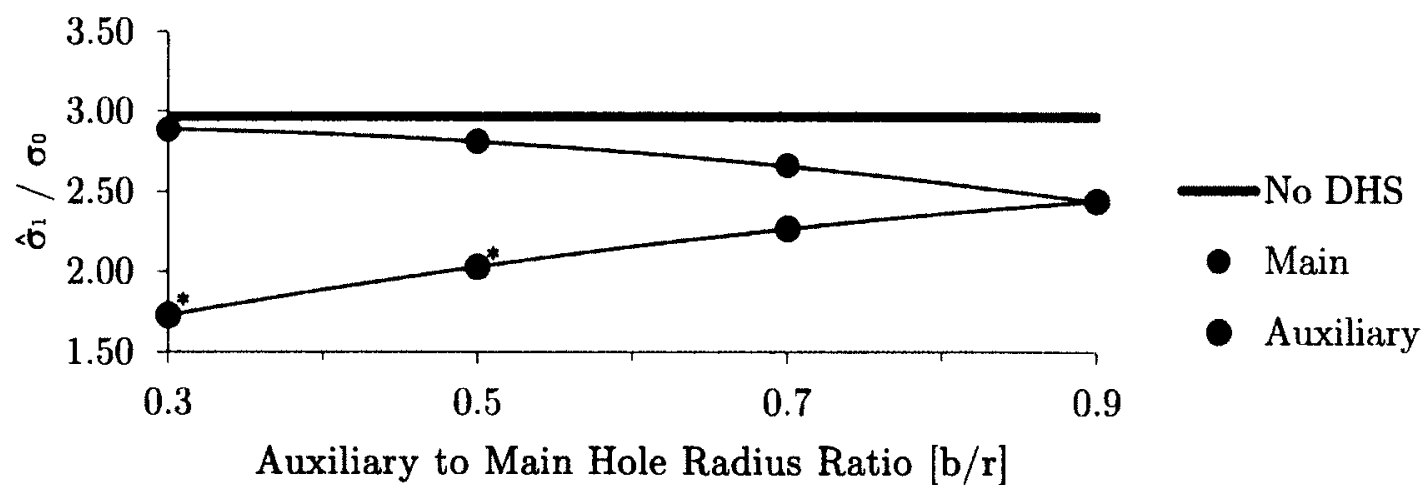

(a) $d / r=2.0$

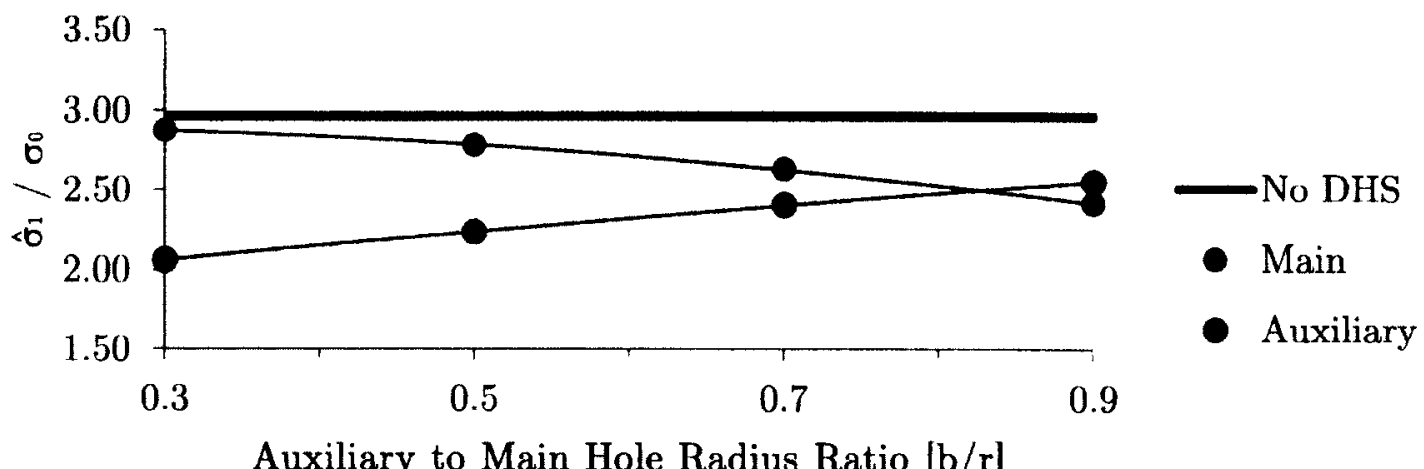

(b) $d / r=2.5$

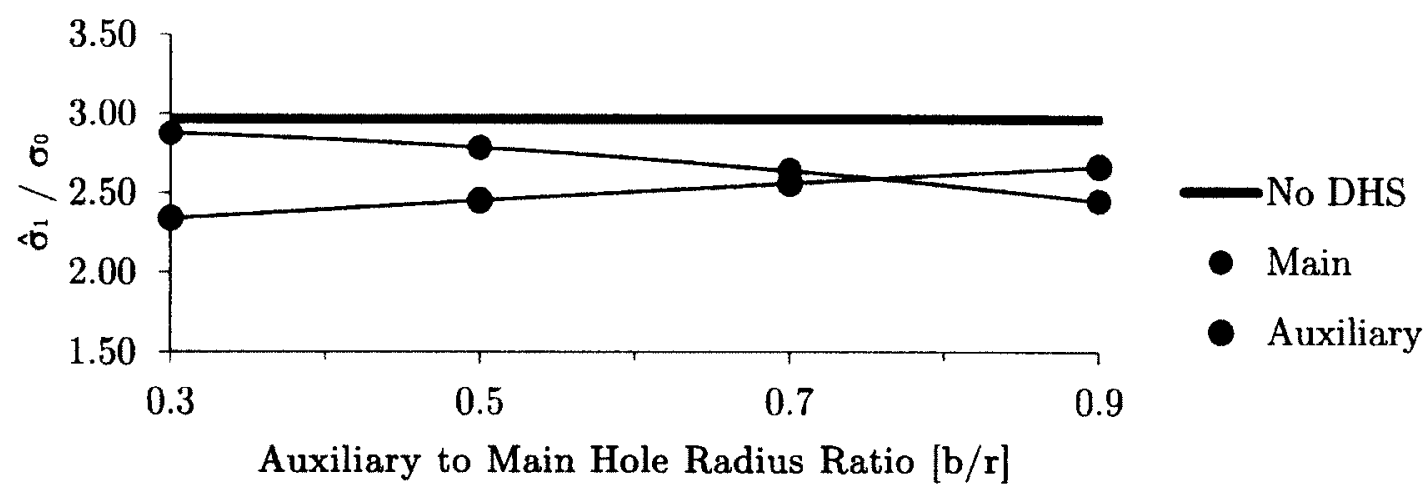

(c) $d / r=3.0$

Figure 5.19: Variation of stress concentration in the $N b$ material of an isotropic bimaterial $\mathrm{Nb}-\mathrm{Al}_{2} \mathrm{O}_{3}$ plate with a circular hole at the interface and DHS, along the main, $\overline{A C B}$, and auxiliary, $\overline{A^{\prime} C^{\prime} B^{\prime}}$, holes

*Highest stress concentration located at $\theta=15^{\circ}$ 


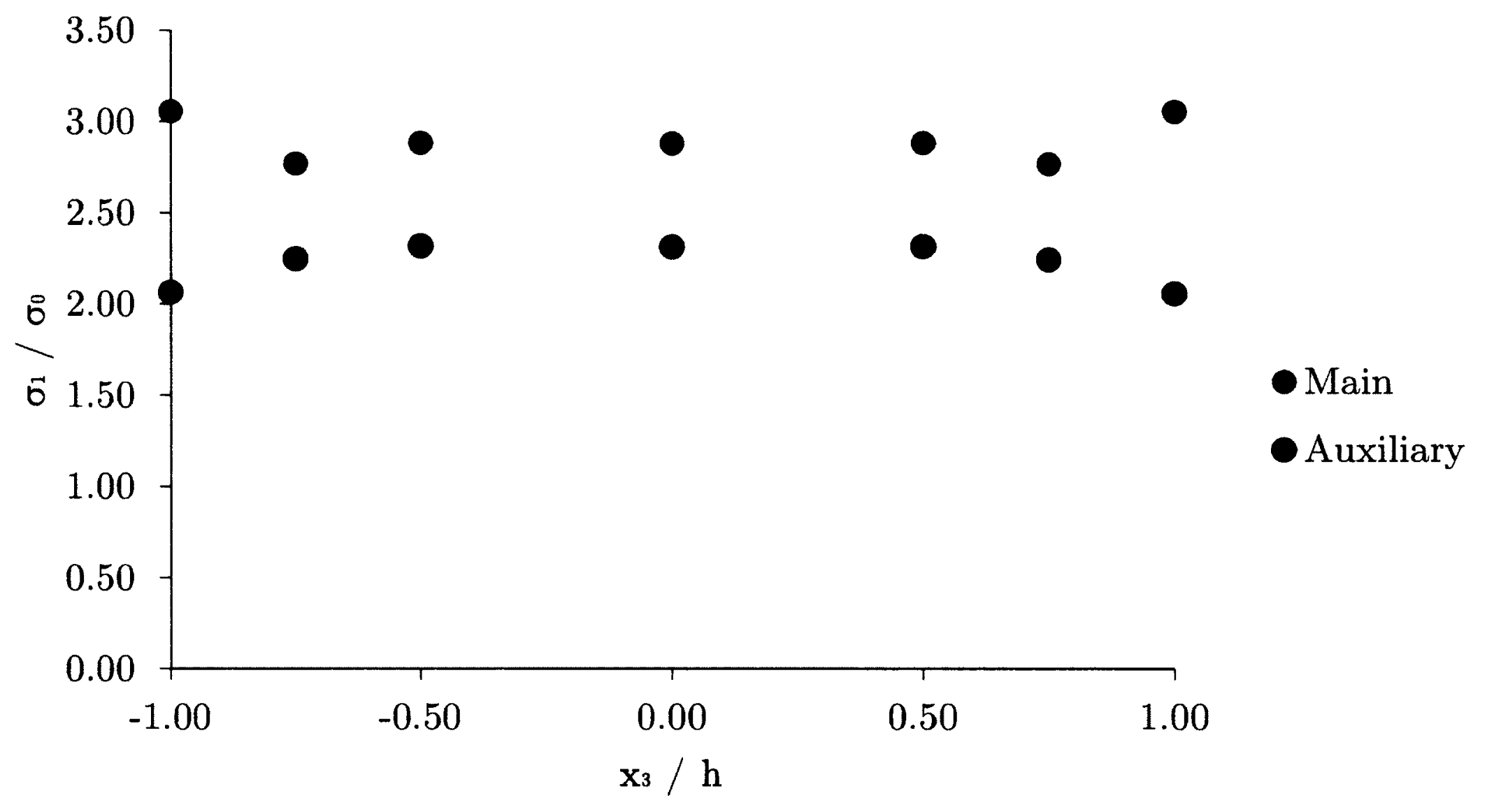

Figure 5.20: Variation of $\sigma_{1} / \sigma_{0}$ in the $\mathrm{Al}_{2} \mathrm{O}_{3}$ material of an isotropic bimaterial $\mathrm{Nb}-\mathrm{Al}_{2} \mathrm{O}_{3}$ plate with a circular hole at the interface and DHS, through the thickness along the main, $\overline{A C B}$, and auxiliary, $\overline{A^{\prime \prime} C^{\prime \prime} B^{\prime \prime}}$, holes for $d / r=2.5$ and $b / r=0.7$ 


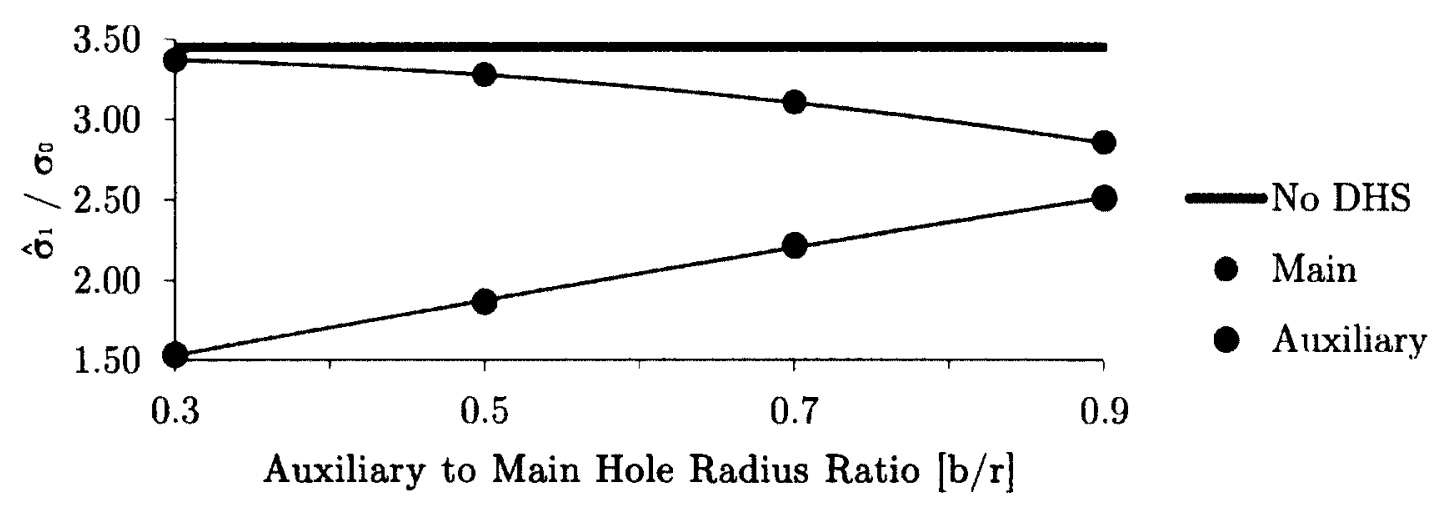

(a) $d / r=2.0$

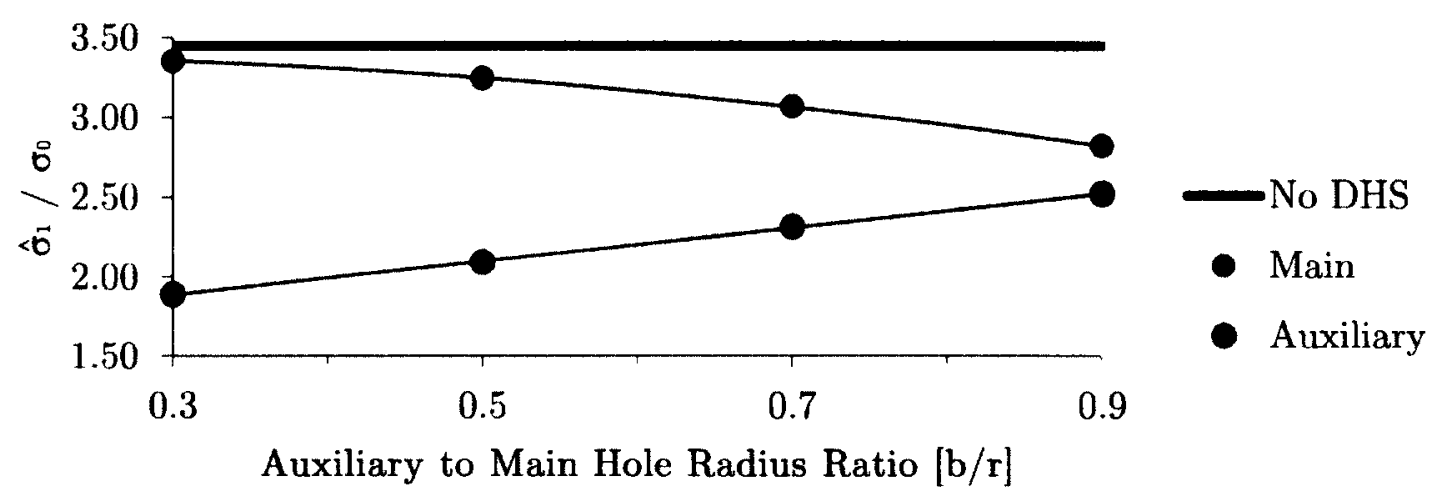

(b) $d / r=2.5$

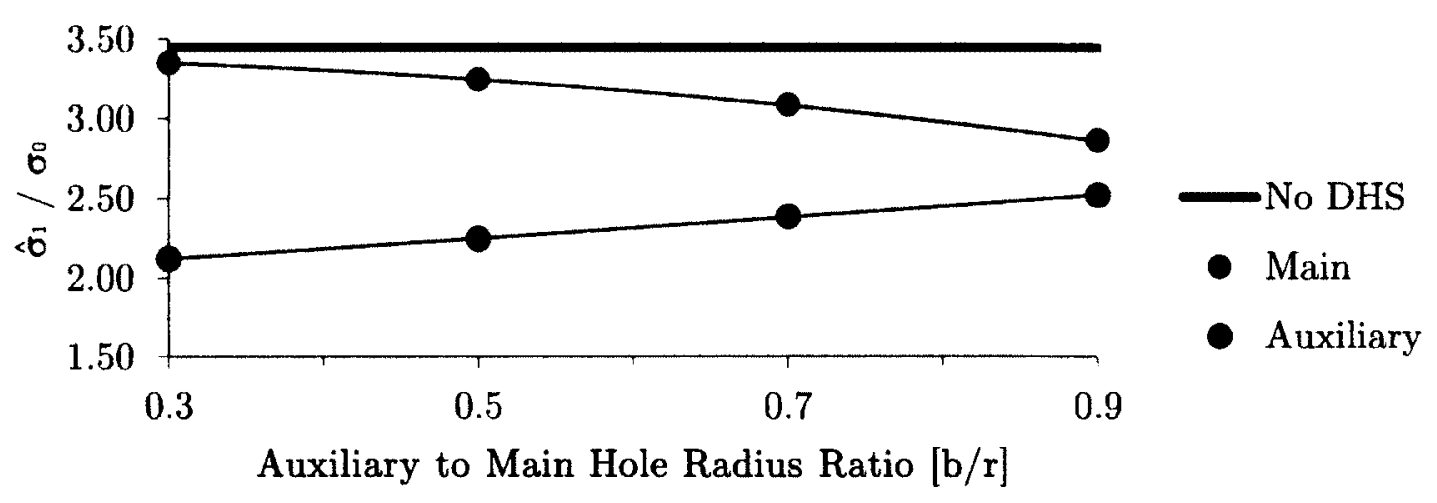

(c) $d / r=3.0$

Figure 5.21: Variation of stress concentration in the $\mathrm{Al}_{2} \mathrm{O}_{3}$ material of an isotropic bimaterial $\mathrm{Nb}-\mathrm{Al}_{2} \mathrm{O}_{3}$ plate with a circular hole at the interface and DHS, along the main, $\overline{A C B}$, and auxiliary, $\overline{A^{\prime \prime} C^{\prime \prime} B^{\prime \prime}}$, holes 


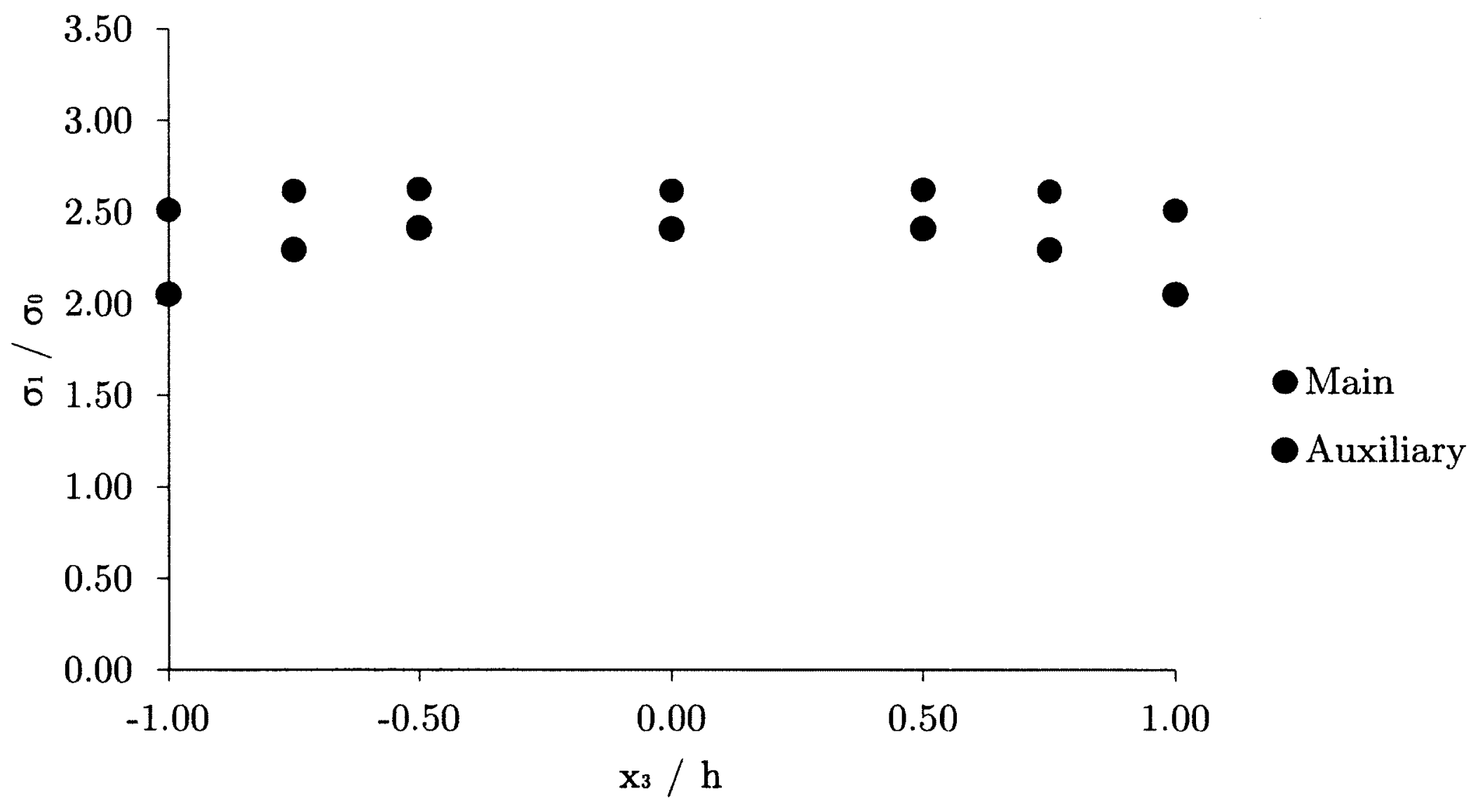

Figure 5.22: Variation of $\sigma_{1} / \sigma_{0}$ in the $\mathrm{Cu}$ material of an isotropic bimaterial $\mathrm{Cu}-\mathrm{Al}_{2} \mathrm{O}_{3}$ plate with a circular hole at the interface and DHS, through the thickness along the main, $\overline{A C B}$, and auxiliary, $\overline{A^{\prime} C^{\prime} B^{\prime}}$, holes for $d / r=2.5$ and $b / r=0.7$ 


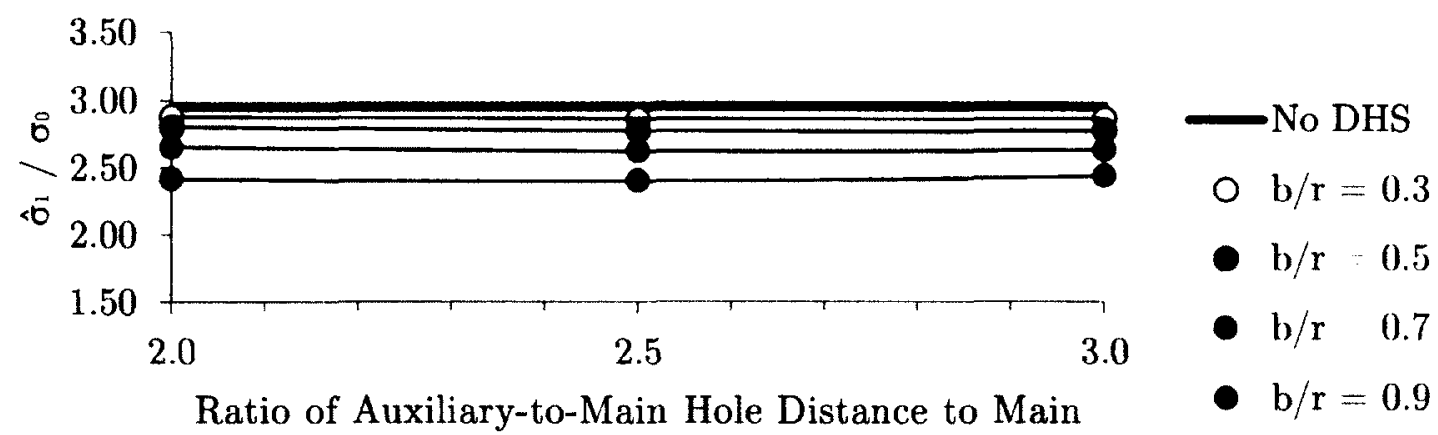

Hole Radius $[\mathrm{d} / \mathrm{r}]$

(a) $C u$ Plate

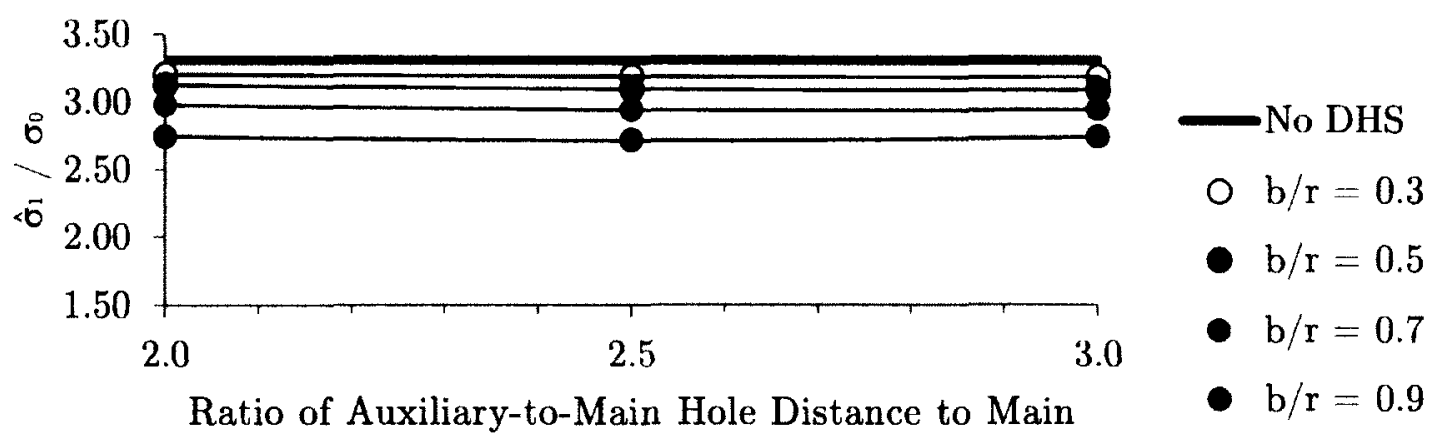
Hole Radius $[\mathrm{d} / \mathrm{r}]$

(b) $\mathrm{Al}_{2} \mathrm{O}_{3}$ Plate

Figure 5.23: Variation of stress concentration with $d / r$ in a $\mathrm{Cu}-\mathrm{Al}_{2} \mathrm{O}_{3}$ bimaterial isotropic plate with a circular hole and DHS, along the main hole, $\overline{A C B}$ 


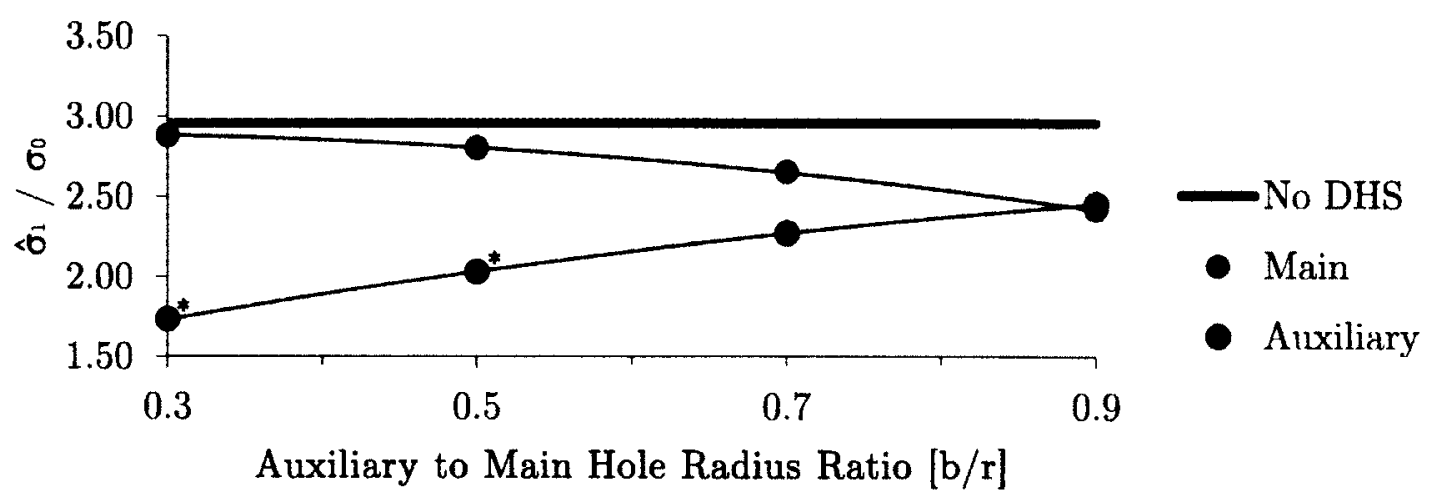

(a) $d / r=2.0$

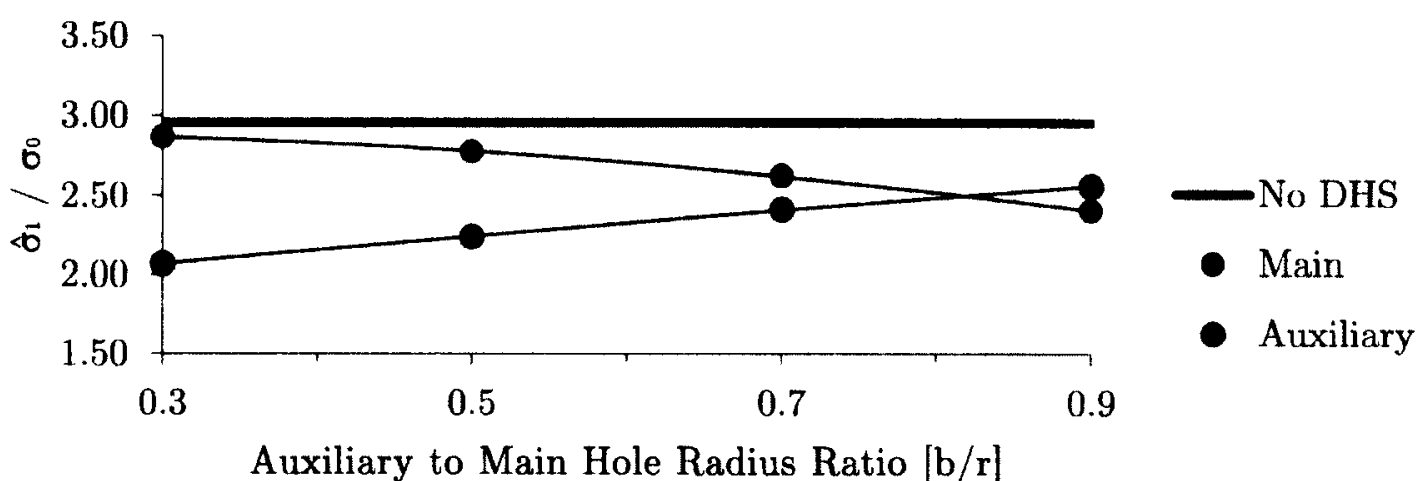

(b) $d / r=2.5$

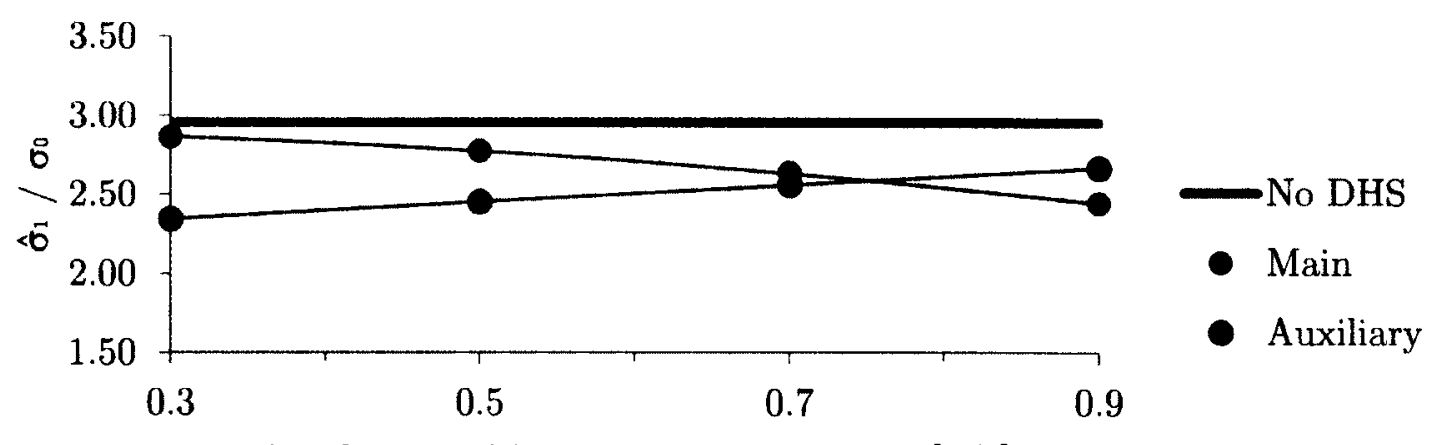

Auxiliary to Main Hole Radius Ratio [b/r]

(c) $d / r=3.0$

Figure 5.24: Variation of stress concentration in the $\mathrm{Cu}$ material of an isotropic bimaterial $\mathrm{Cu}-\mathrm{Al}_{2} \mathrm{O}_{3}$ plate with a circular hole at the interface and DHS, along the main, $\overline{A C B}$, and auxiliary, $\overline{A^{\prime} C^{\prime} B^{\prime}}$, holes

${ }^{*}$ Highest stress concentration located at $\theta=15^{\circ}$ 


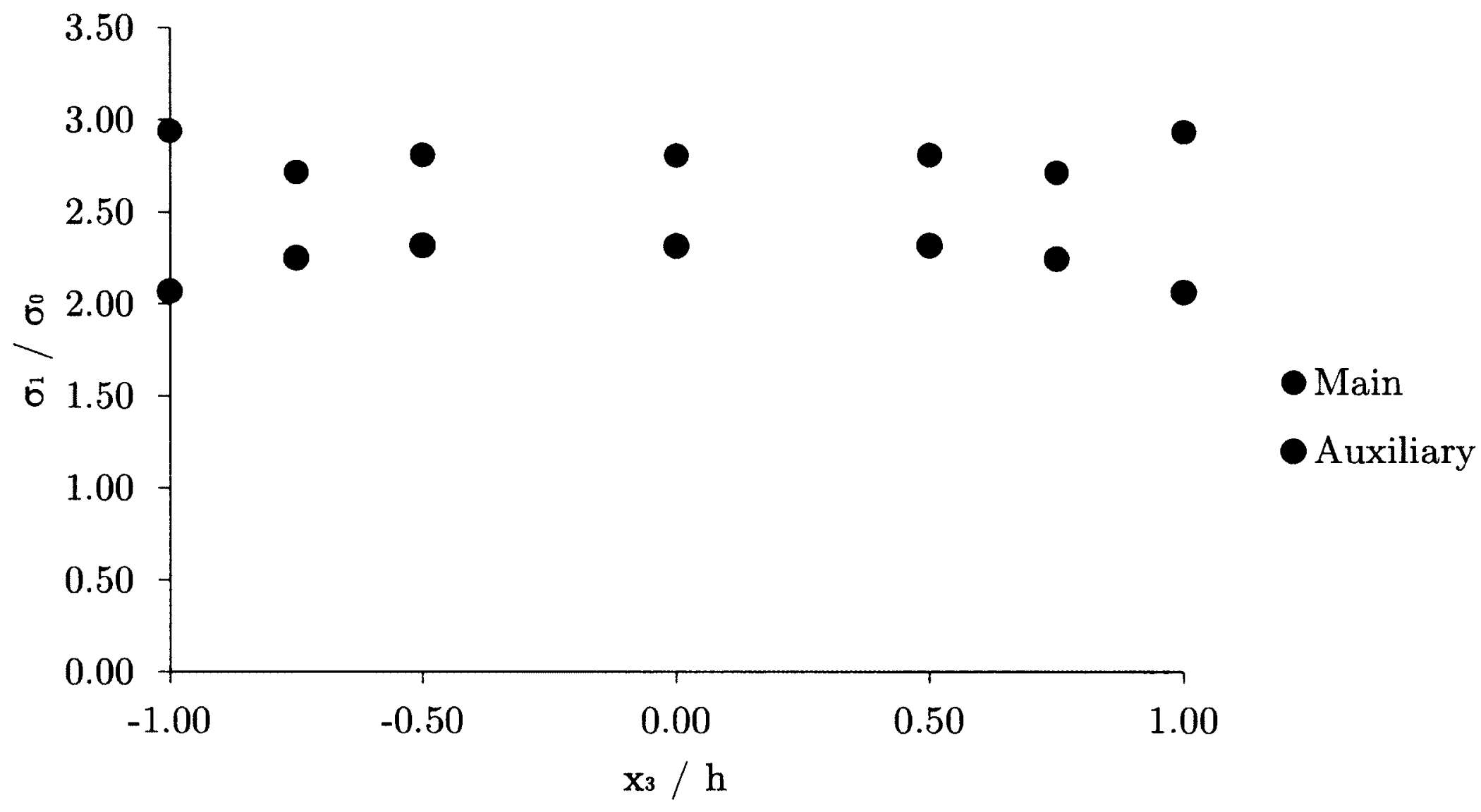

Figure 5.25: Variation of $\sigma_{1} / \sigma_{0}$ in the $\mathrm{Al}_{2} \mathrm{O}_{3}$ material of an isotropic bimaterial $\mathrm{Cu}-\mathrm{Al}_{2} \mathrm{O}_{3}$ plate with a circular hole at the interface and DHS, through the thickness along the main, $\overline{A C B}$, and auxiliary, $\bar{A}^{\prime \prime} C^{\prime \prime} B^{\prime \prime}$, holes for $d / r=2.5$ and $b / r=0.7$ 


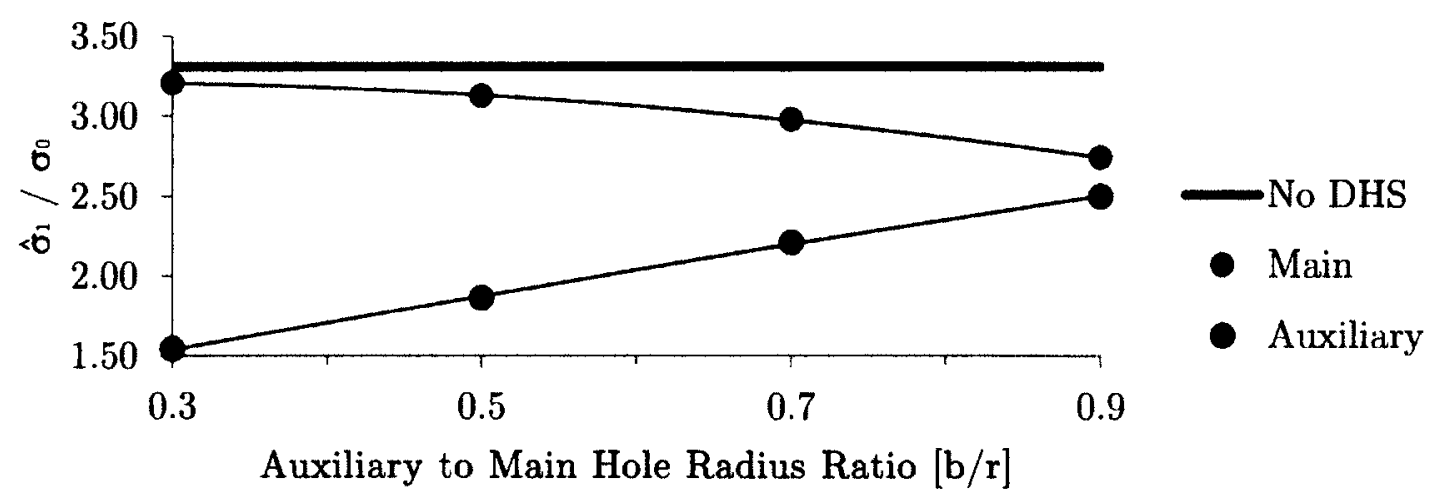

(a) $d / r=2.0$

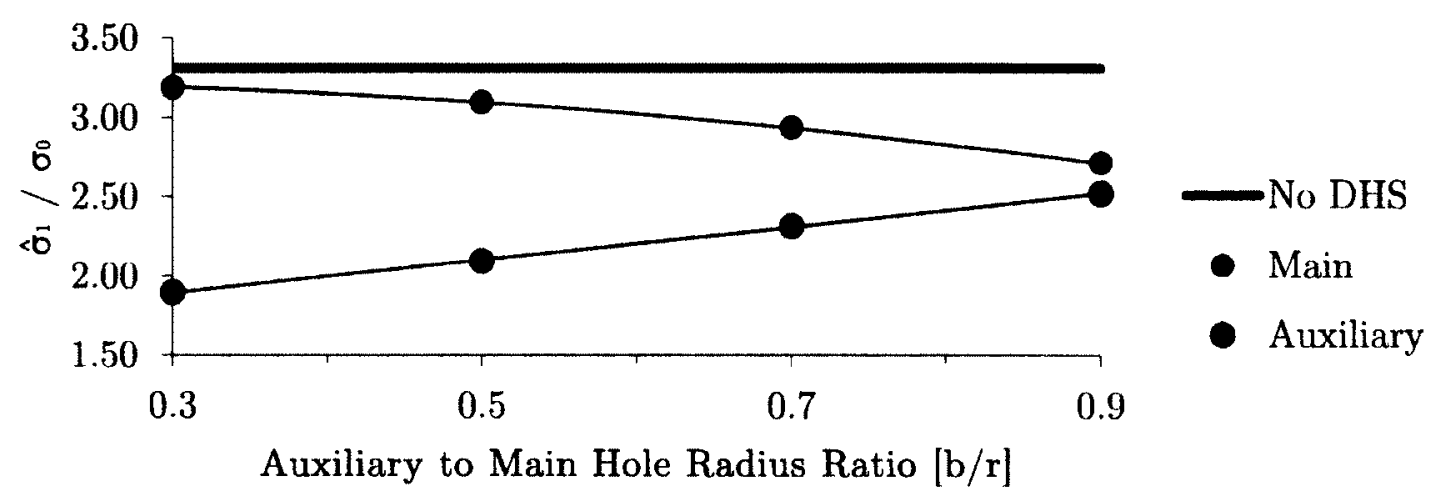

(b) $d / r=2.5$

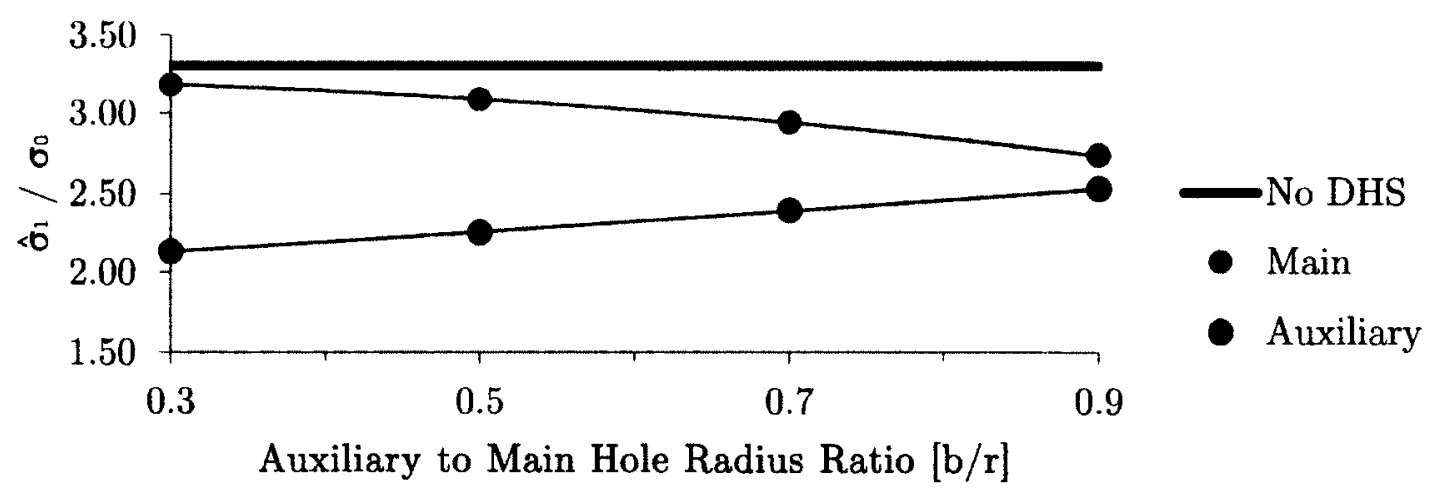

(c) $d / r=3.0$

Figure 5.26: Variation of stress concentration in the $\mathrm{Al}_{2} \mathrm{O}_{3}$ material of an isotropic bimaterial $\mathrm{Cu}-\mathrm{Al}_{2} \mathrm{O}_{3}$ plate with a circular hole at the interface and DHS, along the main, $\overline{A C B}$, and auxiliary, $\overline{A^{\prime \prime} C^{\prime \prime} B^{\prime \prime}}$, holes 


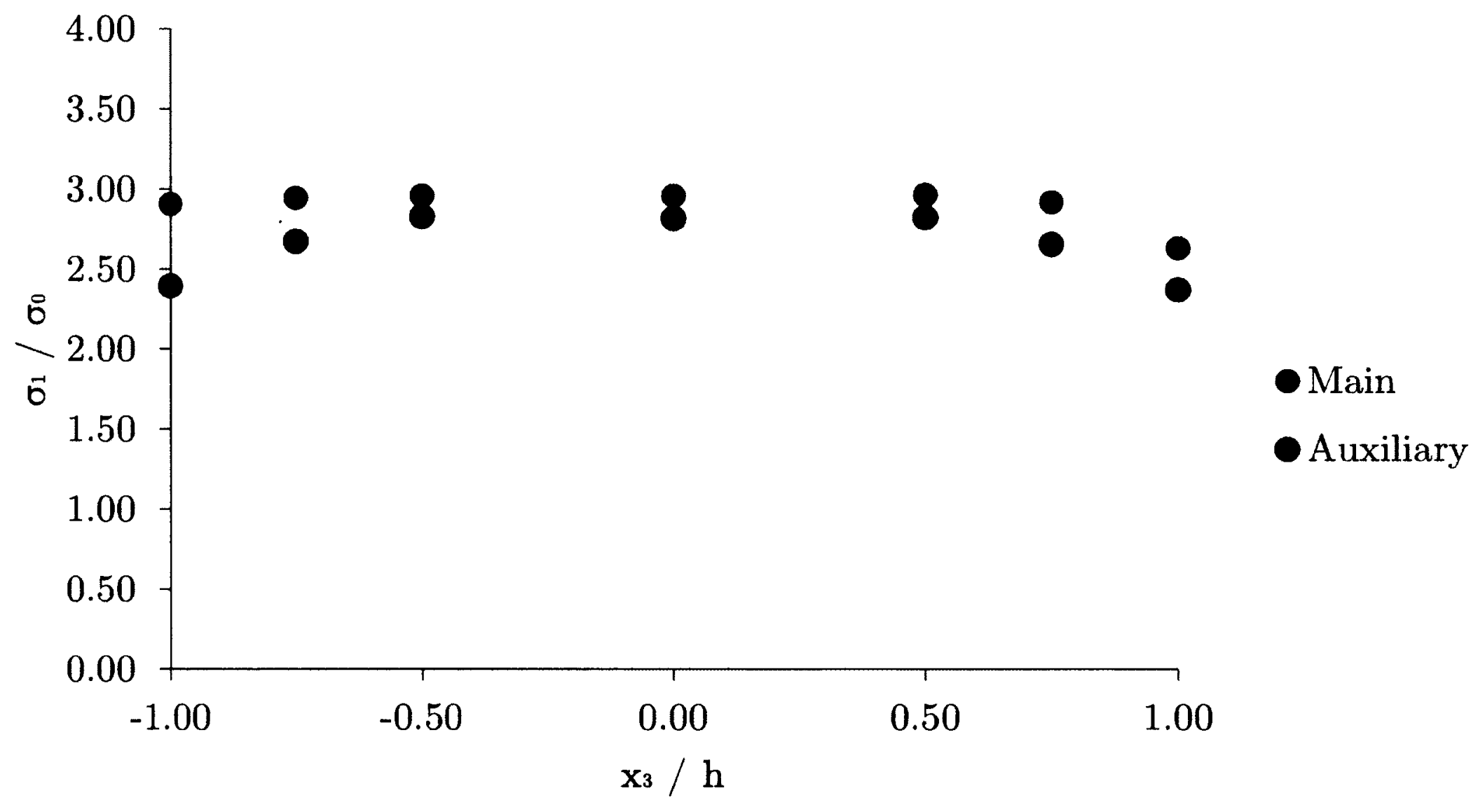

Figure 5.27: Variation of $\sigma_{1} / \sigma_{0}$ in the $\mathrm{Nb}$ material of an anisotropic bimaterial $\mathrm{Nb}-\mathrm{Al}_{2} \mathrm{O}_{3}$ plate with a circular hole at the interface and DHS, through the thickness along the main, $\overline{A C B}$, and auxiliary, $\overline{A^{\prime} C^{\prime} B^{\prime}}$, holes for $d / r=2.5$ and $b / r=0.7$ 


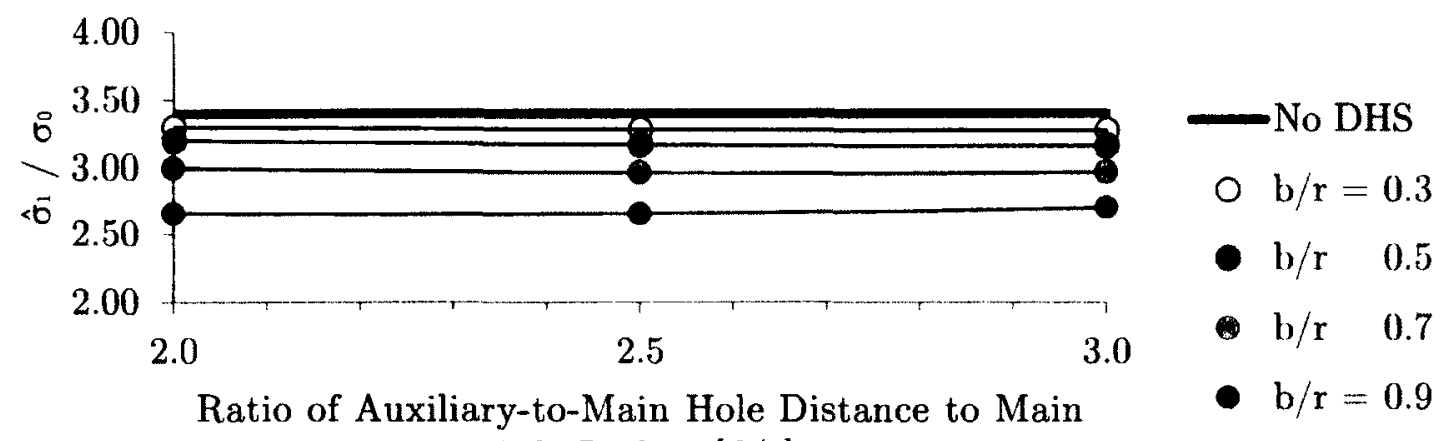
Hole Radius [d/r]

(a) Nb Plate

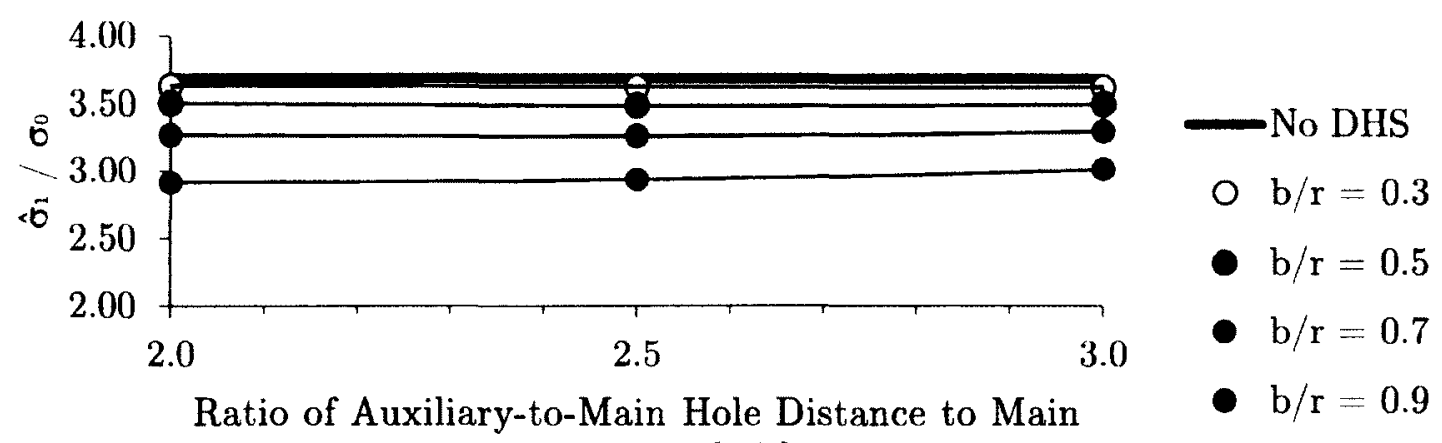
Hole Radius [d/r]

(b) $\mathrm{Al}_{2} \mathrm{O}_{3}$ Plate

Figure 5.28: Variation of stress concentration with $d / r$ in a $\mathrm{Nb}_{-} \mathrm{Al}_{2} \mathrm{O}_{3}$ bimaterial anisotropic plate with a circular hole and DHS, along the main hole, $\overline{A C B}$ 


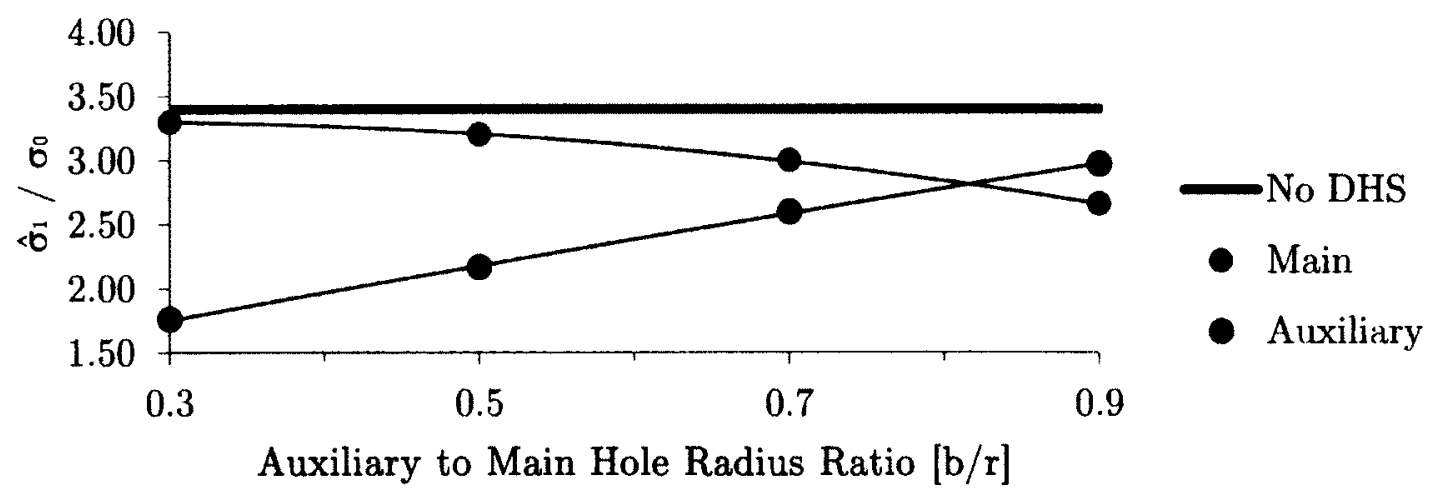

(a) $d / r=2.0$

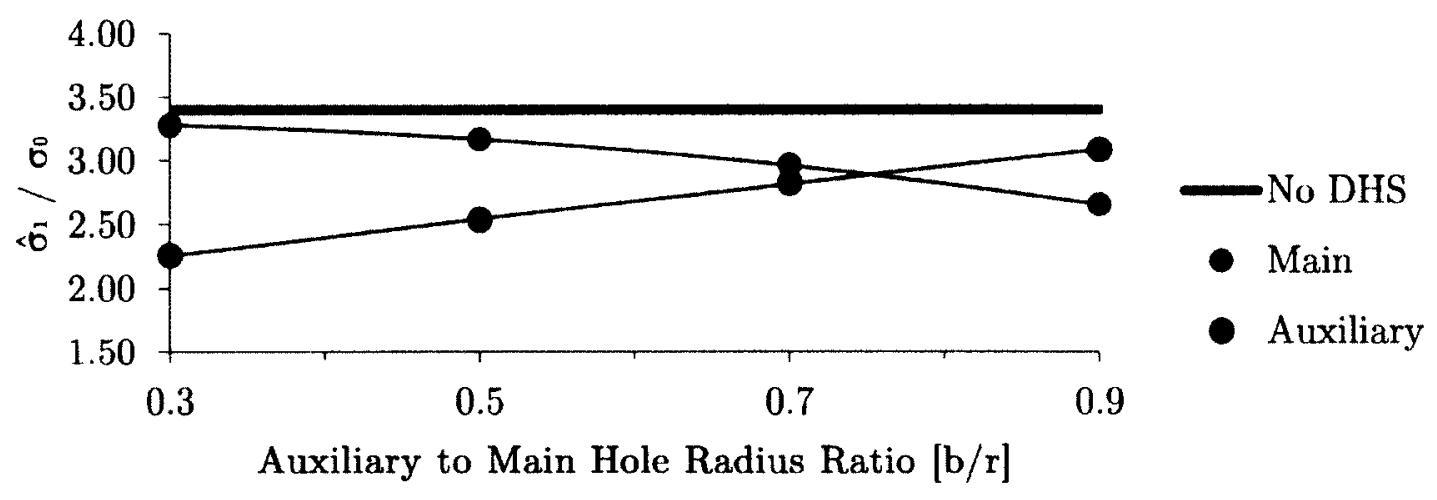

(b) $d / r=2.5$

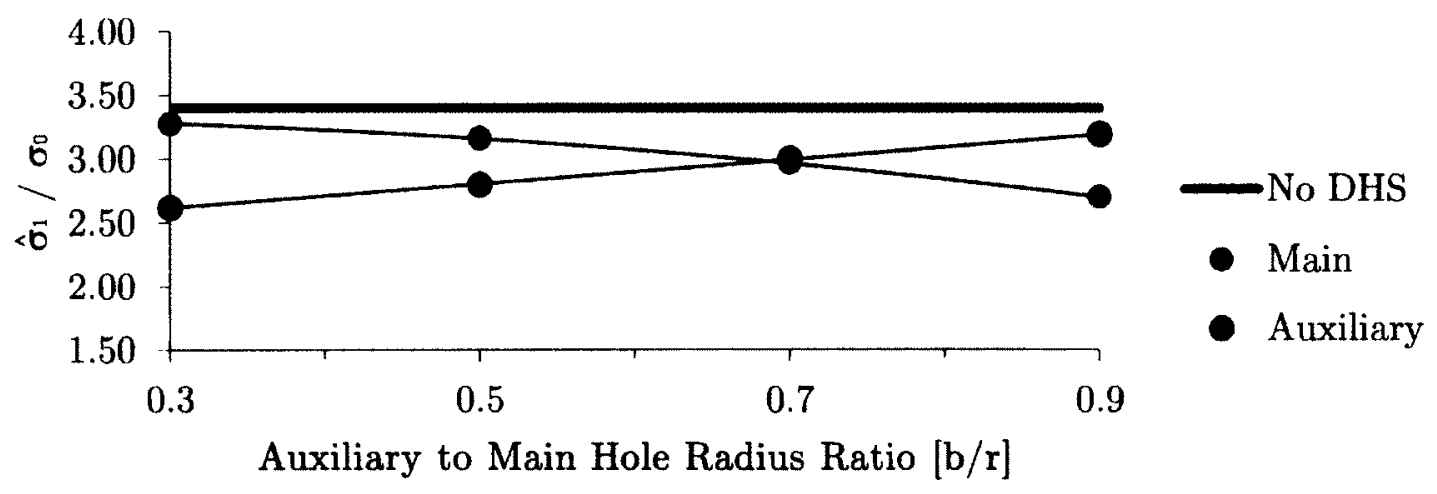

(c) $d / r=3.0$

Figure 5.29: Variation of stress concentration in the $N b$ material of an anisotropic bimaterial $\mathrm{Nb}-\mathrm{Al}_{2} \mathrm{O}_{3}$ plate with a circular hole at the interface and DHS, along the main, $\overline{A C B}$, and auxiliary, $\overline{A^{\prime} C^{\prime} B^{\prime}}$, holes 


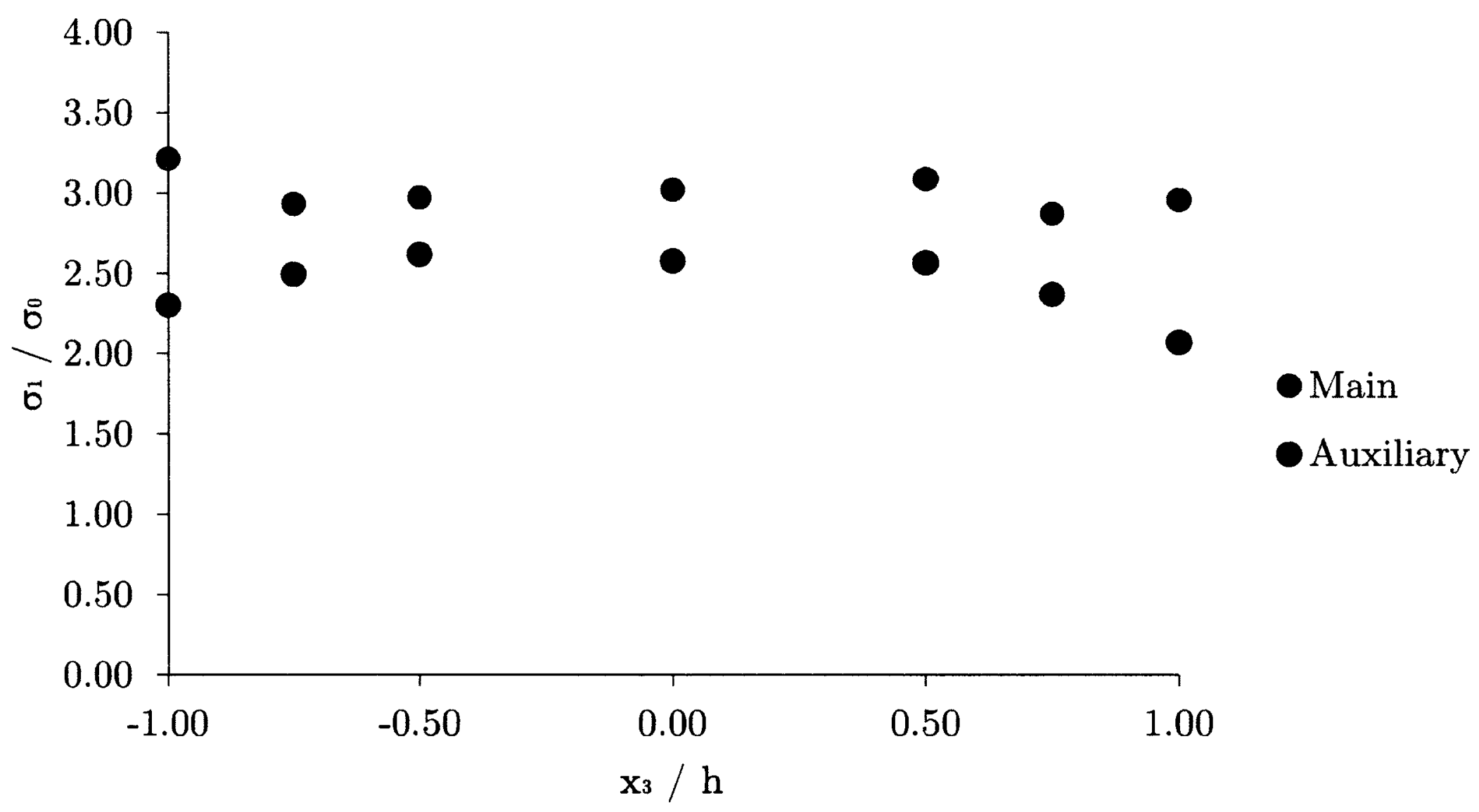

Figure 5.30: Variation of $\sigma_{1} / \sigma_{0}$ in the $\mathrm{Al}_{2} \mathrm{O}_{3}$ material of an anisotropic bimaterial $\mathrm{Nb}_{-} \mathrm{Al}_{2} \mathrm{O}_{3}$ plate with a circular hole at the interface and DHS, through the thickness along the main, $\overline{A C B}$, and auxiliary, $\overline{A^{\prime \prime} C^{\prime \prime} B^{\prime \prime}}$, holes for $d / r=2.5$ and $b / r=0.7$ 


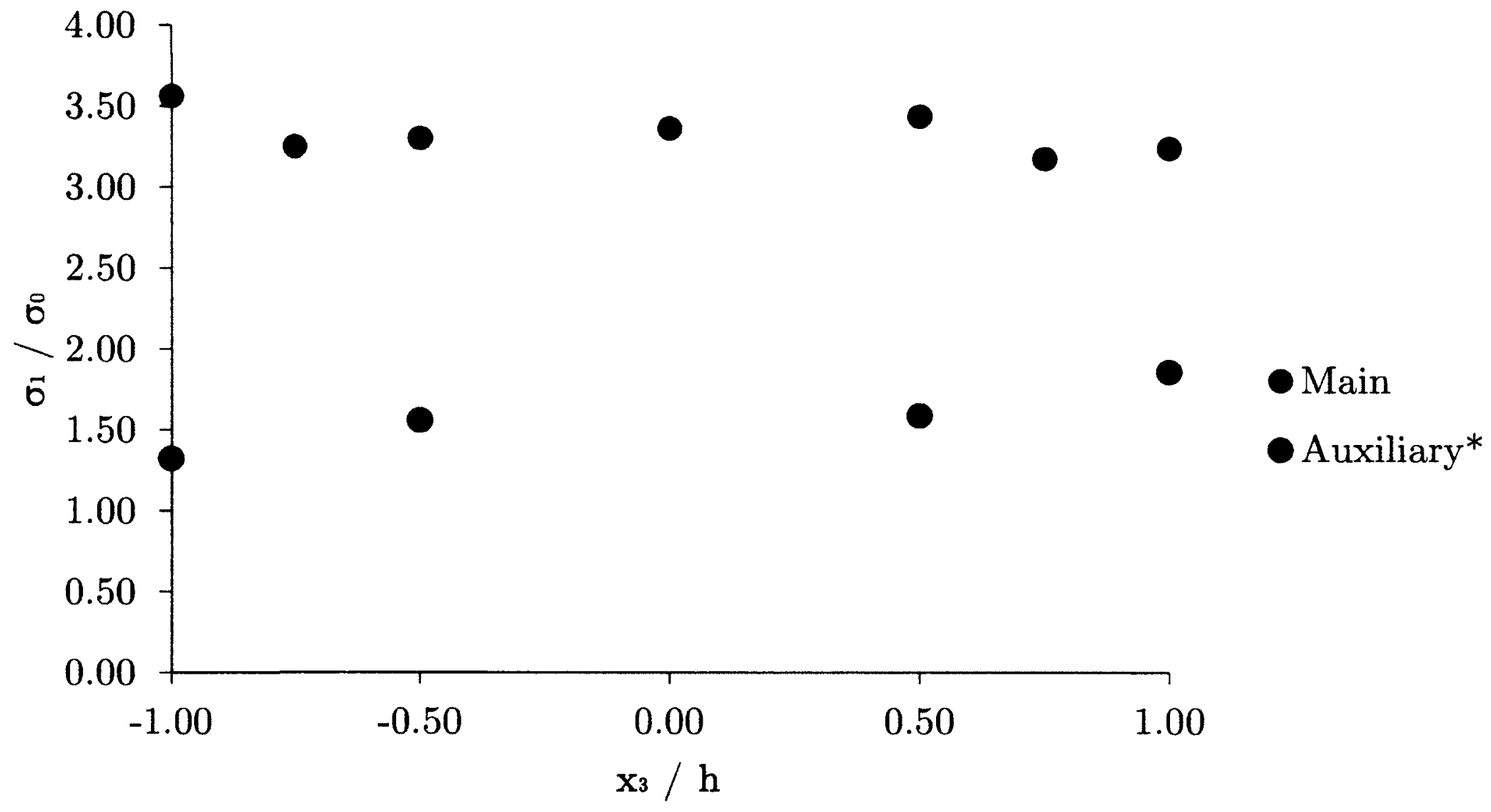

Figure 5.31: Variation of $\sigma_{1} / \sigma_{0}$ in the $\mathrm{Al}_{2} \mathrm{O}_{3}$ material of an anisotropic bimaterial $\mathrm{Nb}-\mathrm{Al}_{2} \mathrm{O}_{3}$ plate with a circular hole at the interface and DHS, through the thickness along the main, $\overline{A C B}$, and auxiliary, $\overline{A^{\prime \prime} C^{\prime \prime} B^{\prime \prime}}$, holes for $d / r=2.0$ and $b / r=0.3$

${ }^{*}$ Highest stress concentration located at $\theta=15^{\circ}$ 


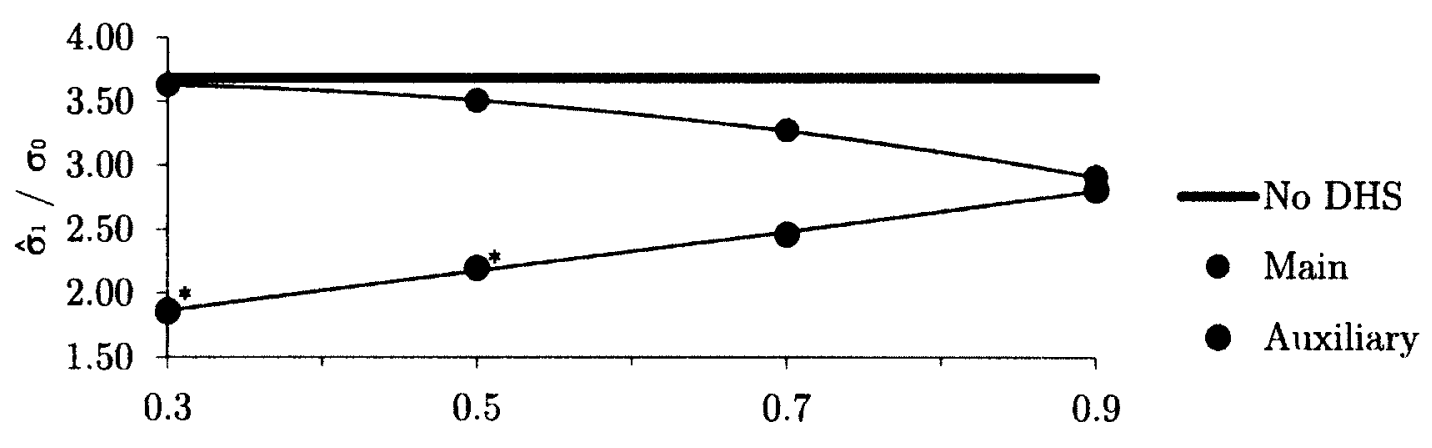

Auxiliary to Main Hole Radius Ratio [b/r]

(a) $d / r=2.0$

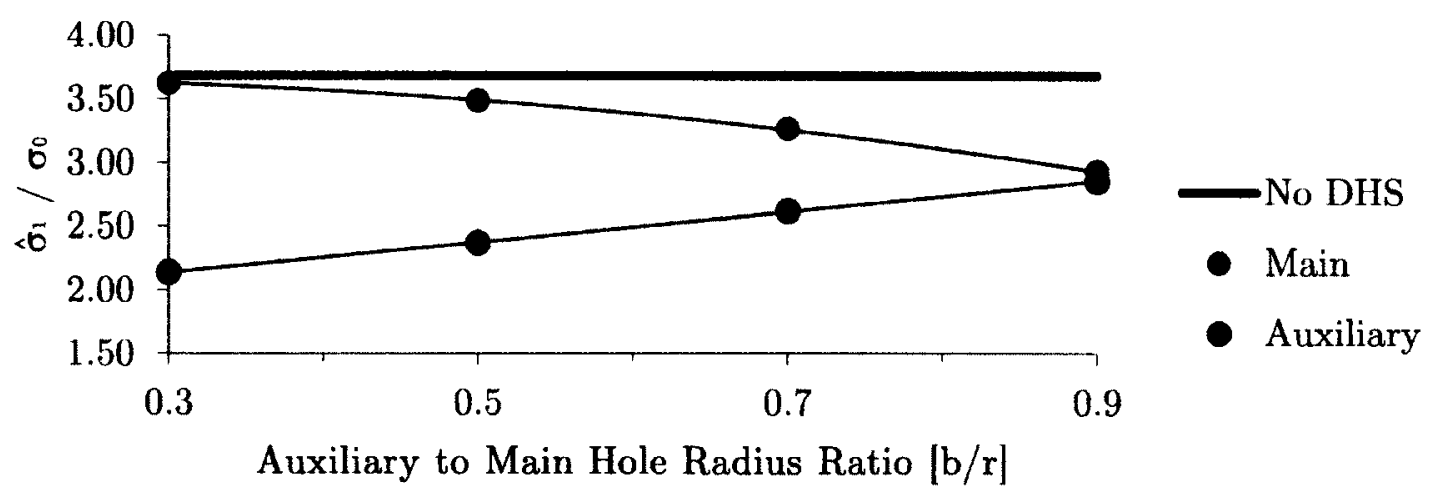

(b) $d / r=2.5$

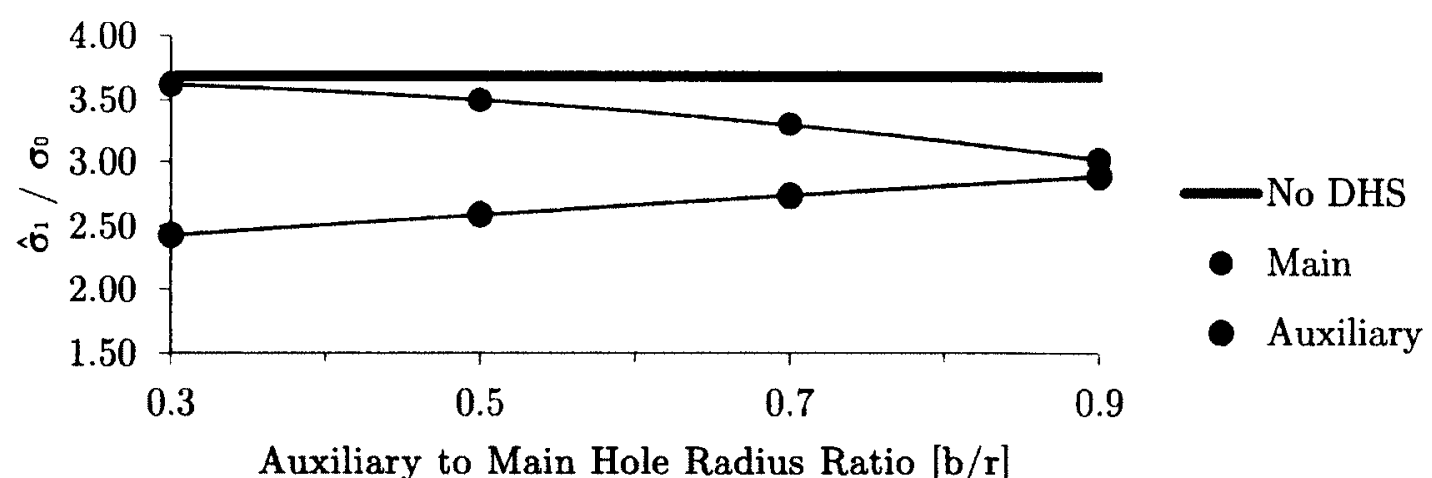

(c) $d / r=3.0$

Figure 5.32: Variation of stress concentration in the $\mathrm{Al}_{2} \mathrm{O}_{3}$ material of an anisotropic bimaterial $\mathrm{Nb}-\mathrm{Al}_{2} \mathrm{O}_{3}$ plate with a circular hole at the interface and DHS, along the main, $\overline{A C B}$, and auxiliary, $\overline{A^{\prime \prime} C^{\prime \prime} B^{\prime \prime}}$, holes

${ }^{*}$ Highest stress concentration located at $\theta=15^{\circ}$ 


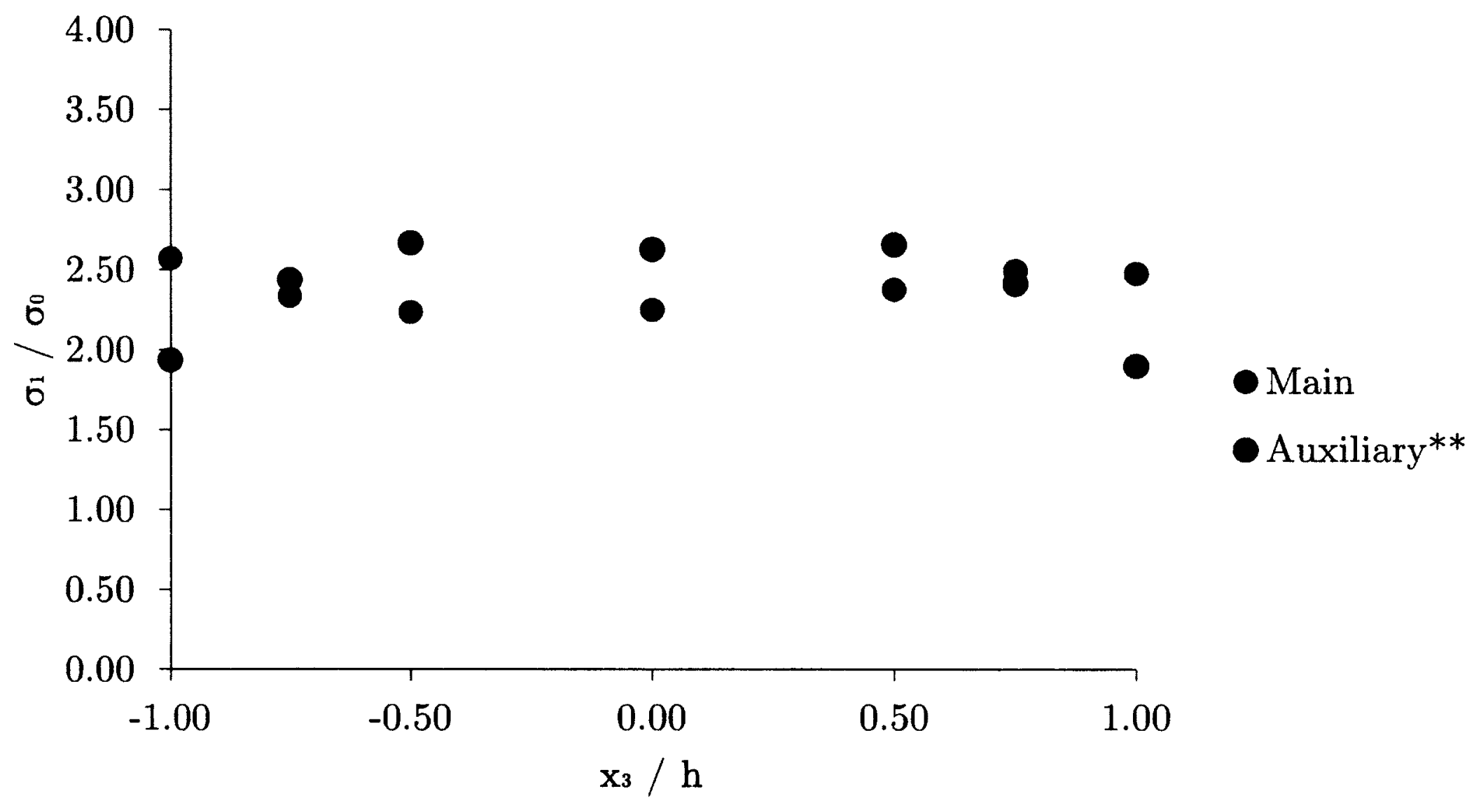

Figure 5.33: Variation of $\sigma_{1} / \sigma_{0}$ in the $C u$ material of an anisotropic bimaterial $C u-A l_{2} O_{3}$ plate with a circular hole at the interface and DHS, through the thickness along the main, $\overline{A C B}$, and auxiliary, $\overline{A^{\prime} C^{\prime} B^{\prime}}$, holes for $d / r=2.5$ and $b / r=0.7$ 


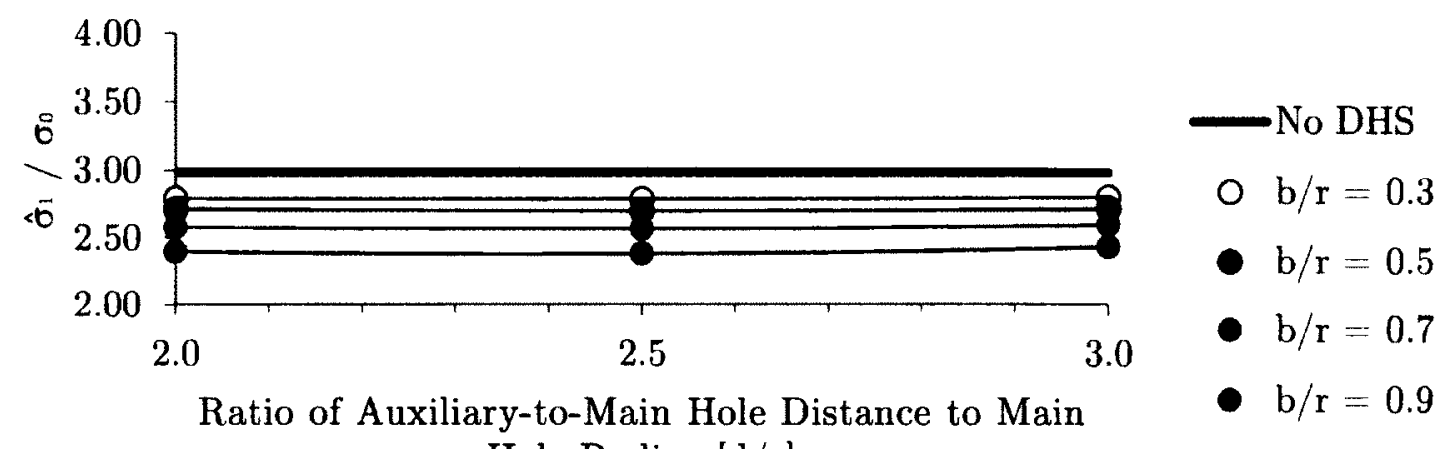
Hole Radius [d/r]

(a) $C u$ Plate

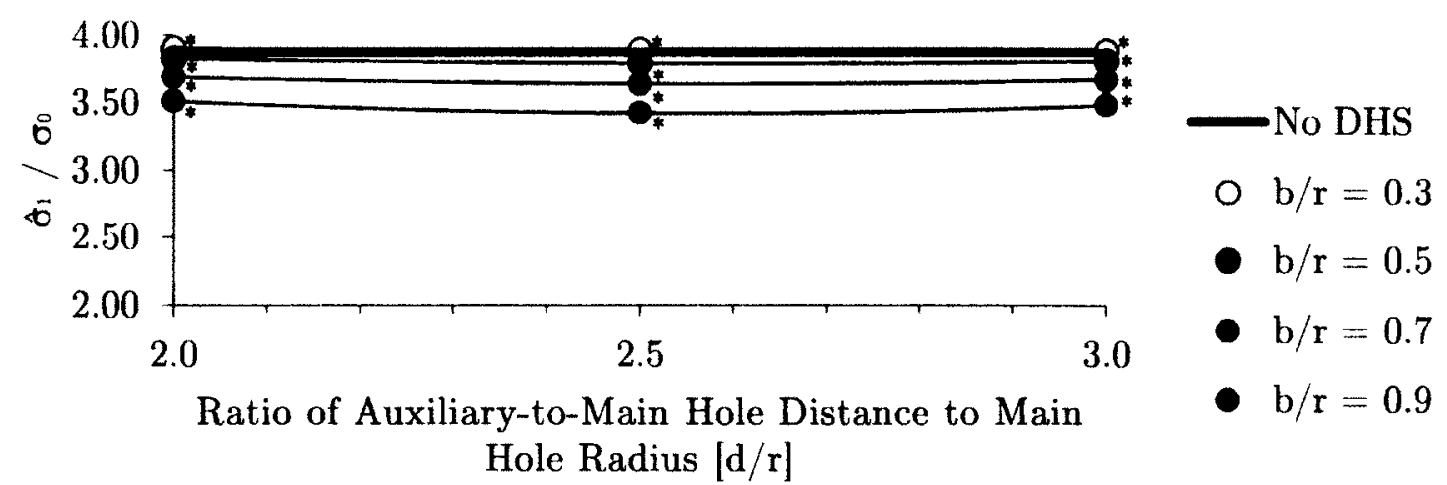

(b) $\mathrm{Al}_{2} \mathrm{O}_{3}$ Plate

Figure 5.34: Variation of stress concentration with $d / r$ in a $\mathrm{Cu}-\mathrm{Al}_{2} \mathrm{O}_{3}$ bimaterial isotropic plate with a circular hole and DHS, along the main hole, $\overline{A C B}$

${ }^{*}$ Highest stress concentration located at $\theta=15^{\circ}$ 


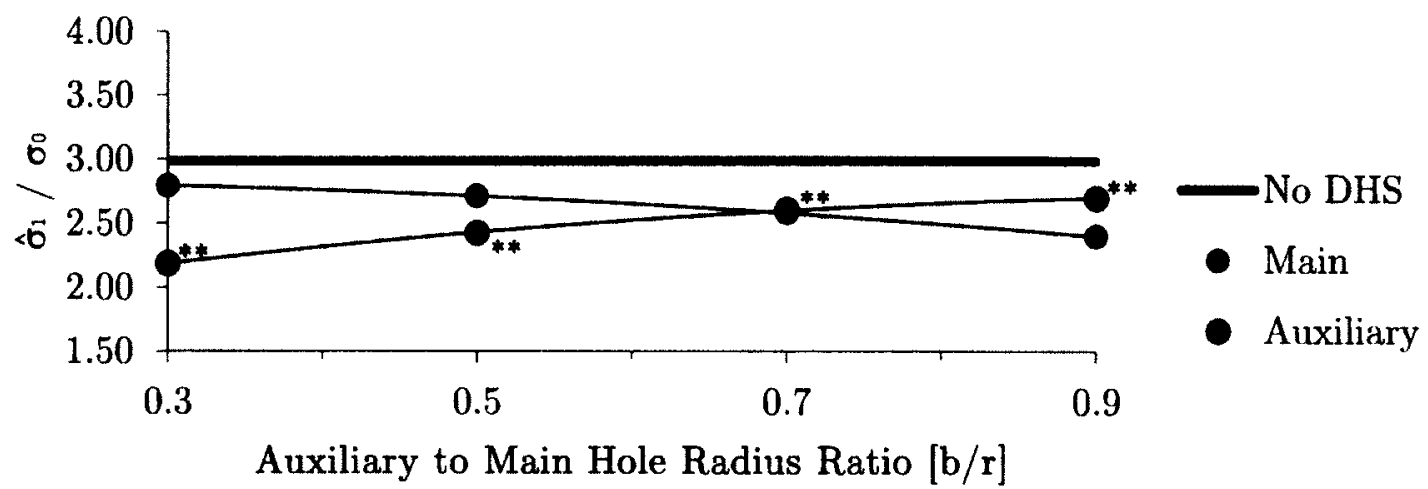

(a) $d / r=2.0$

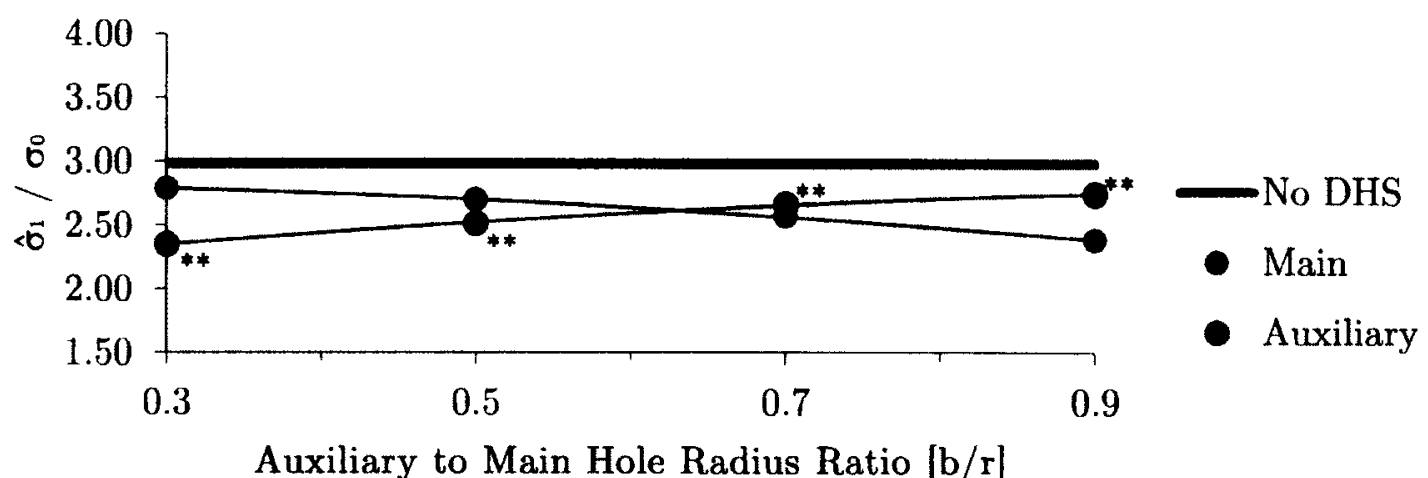

(b) $d / r=2.5$

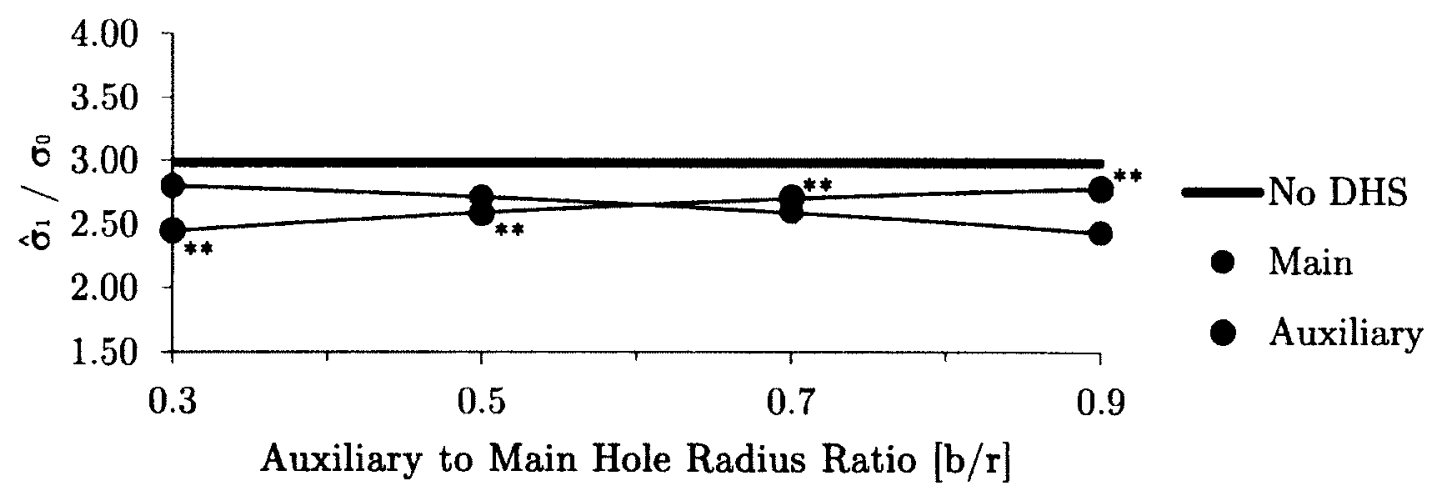

(c) $d / r=3.0$

Figure 5.35: Variation of stress concentration in the $C u$ material of an anisotropic bimaterial $\mathrm{Cu}-\mathrm{Al}_{2} \mathrm{O}_{3}$ plate with a circular hole at the interface and DHS, along the main, $\overline{A C B}$, and auxiliary, $\overline{A^{\prime} C^{\prime} B^{\prime}}$, holes

${ }^{* *}$ Highest stress concentration located at $\theta=30^{\circ}$ 


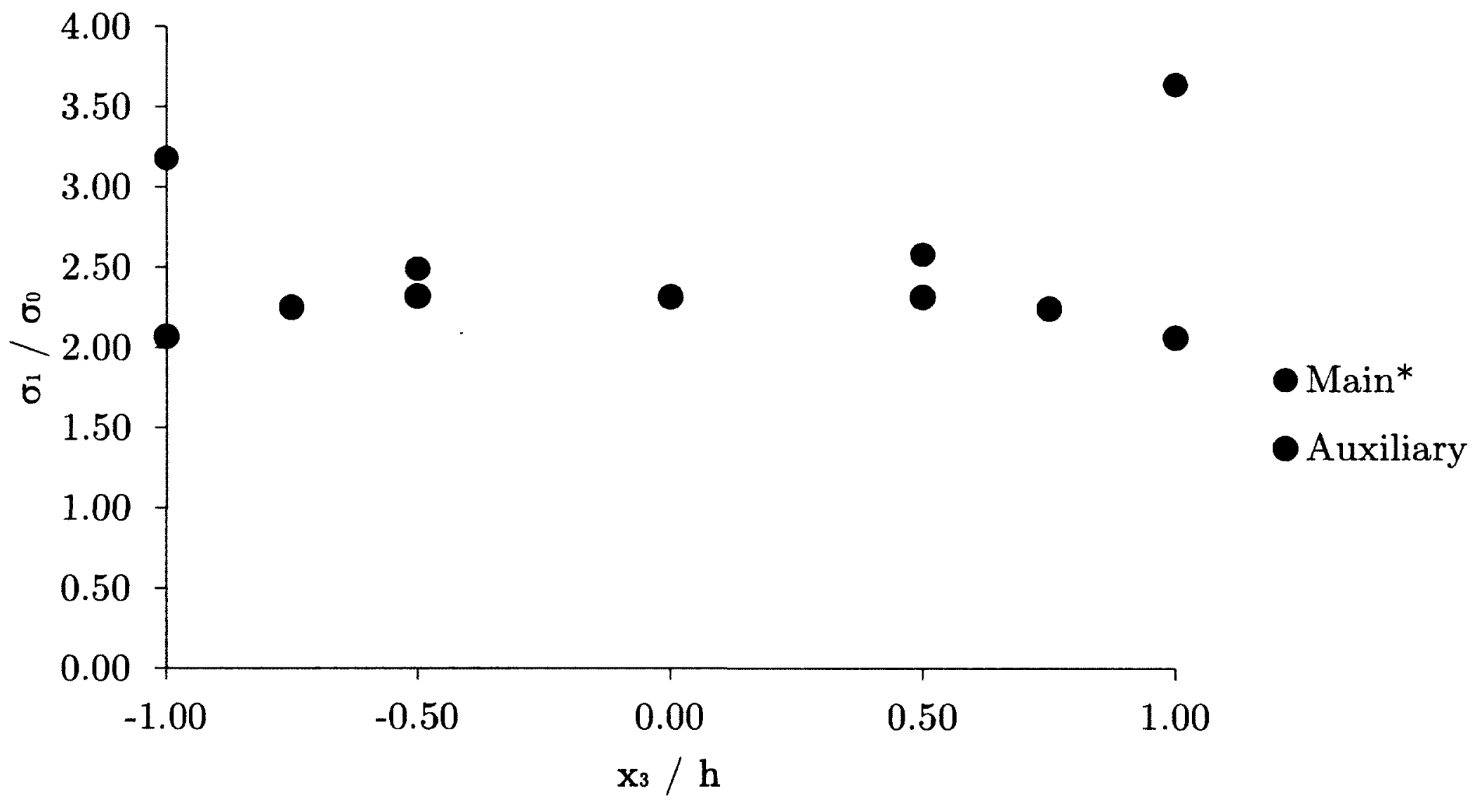

Figure 5.36: Variation of $\sigma_{1} / \sigma_{0}$ in the $\mathrm{Al}_{2} \mathrm{O}_{3}$ material of an anisotropic bimaterial $\mathrm{Cu}-\mathrm{Al}_{2} \mathrm{O}_{3}$ plate with a circular hole at the interface and DHS, through the thickness along the main, $\overline{A C B}$, and auxiliary, $\overline{A^{\prime \prime} C^{\prime \prime} B^{\prime \prime}}$, holes for $d / r=2.5$ and $b / r=0.7$ 


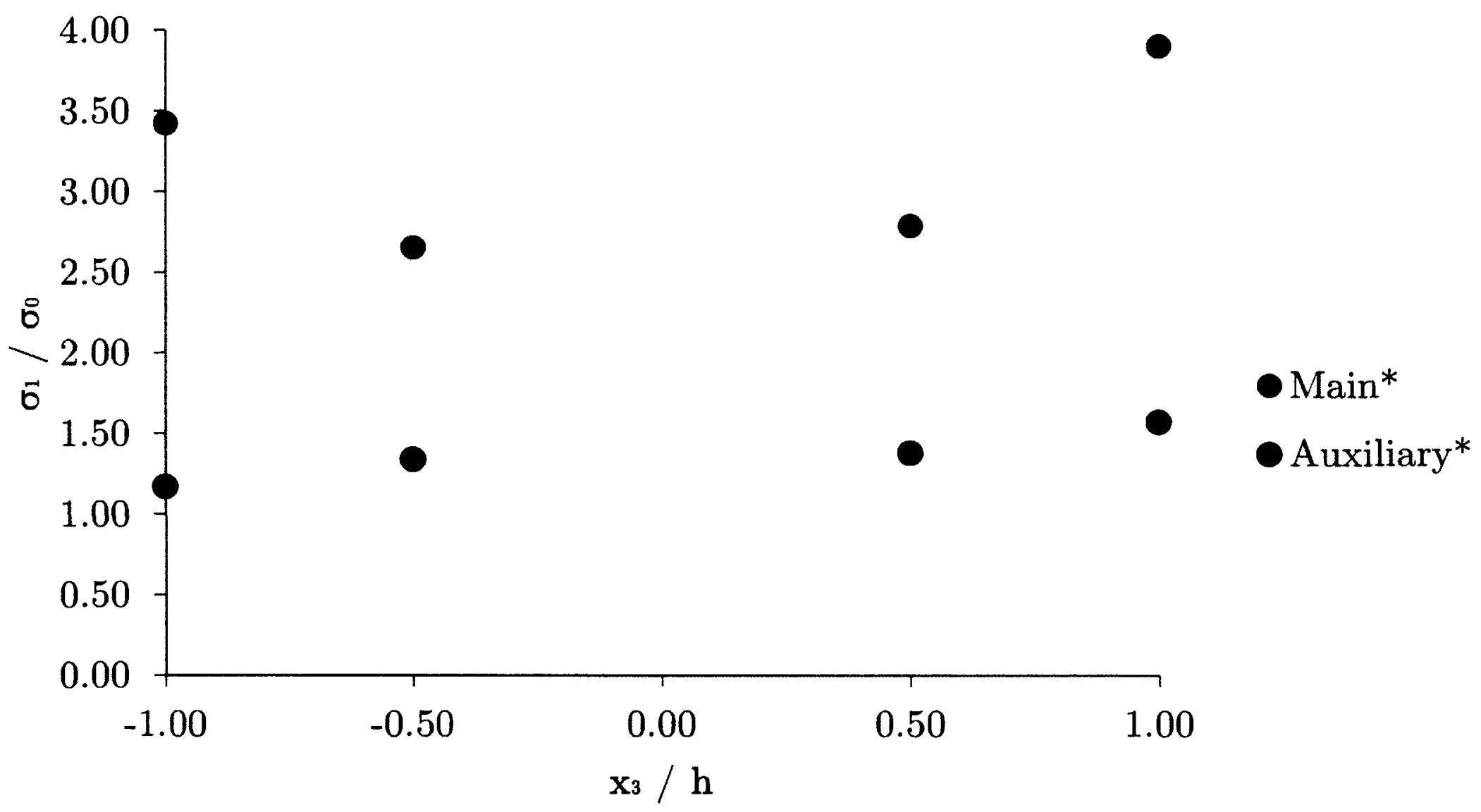

Figure 5.37: Variation of $\sigma_{1} / \sigma_{0}$ in the $\mathrm{Al}_{2} \mathrm{O}_{3}$ material of an anisotropic bimaterial $\mathrm{Cu}-\mathrm{Al}_{2} \mathrm{O}_{3}$ plate with a circular hole at the interface and DHS, through the thickness along the main, $\overline{A C B}$, and auxiliary, $\overline{A^{\prime \prime} C^{\prime \prime} B^{\prime \prime}}$, holes for $d / r=2.0$ and $b / r=0.3$ 


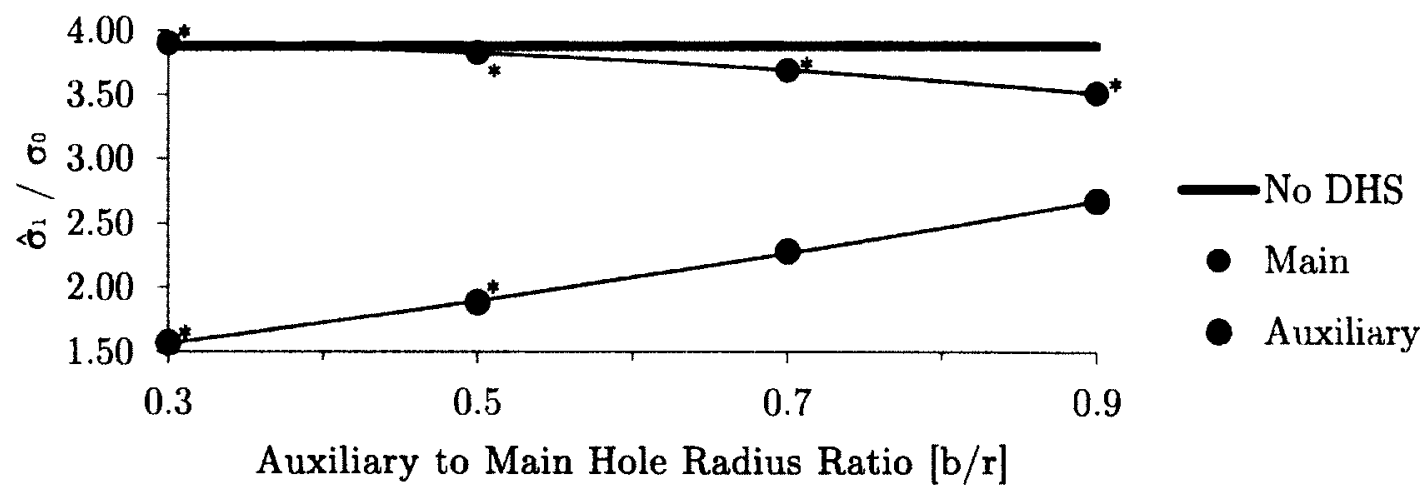

(a) $d / r=2.0$

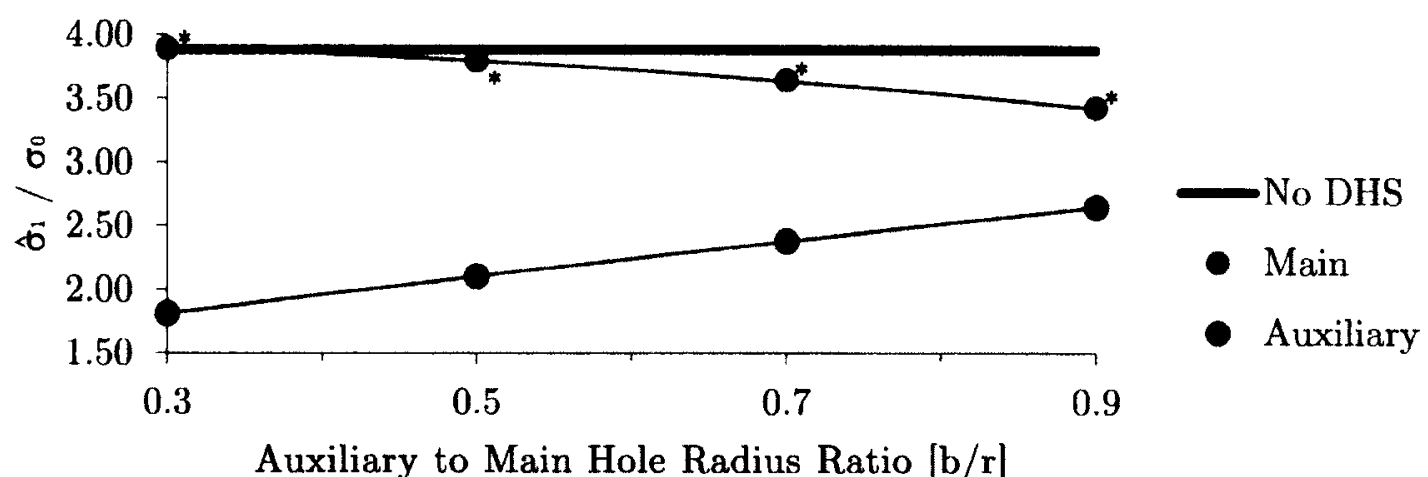

(b) $d / r=2.5$

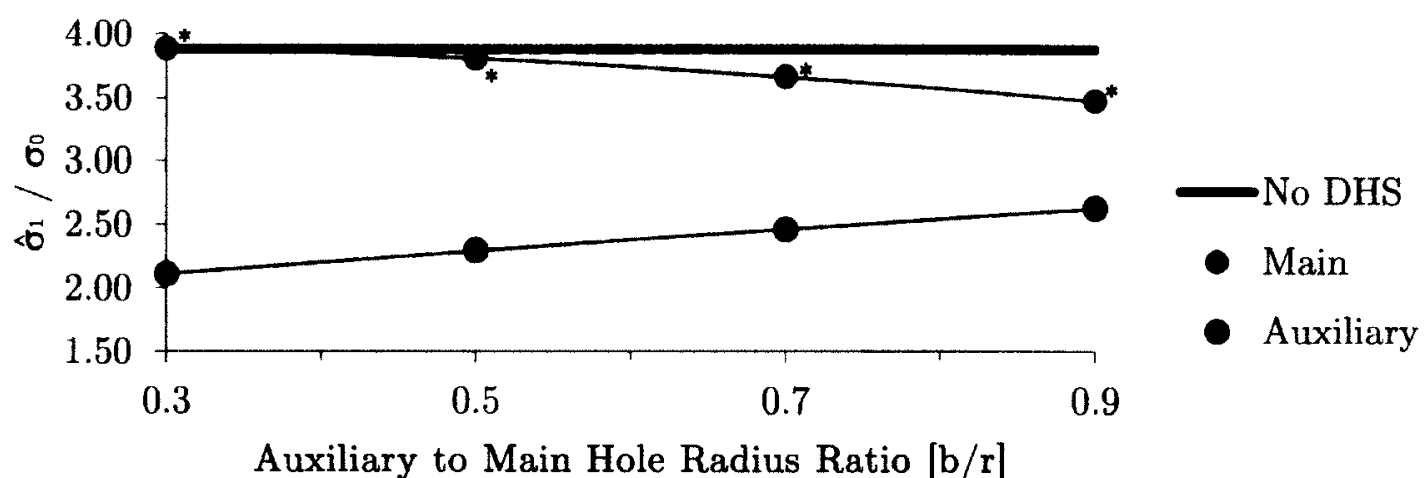

(c) $d / r=3.0$

Figure 5.38: Variation of stress concentration in the $\mathrm{Al}_{2} \mathrm{O}_{3}$ material of an anisotropic bimaterial $\mathrm{Cu}-\mathrm{Al}_{2} \mathrm{O}_{3}$ plate with a circular hole at the interface and DHS, along the main, $\overline{A C B}$, and auxiliary, $\overline{A^{\prime \prime} C^{\prime \prime} B^{\prime \prime}}$, holes

*Highest stress concentration located at $\theta=15^{\circ}$ 


\section{Chapter 6}

\section{Conclusions}

The stress concentrations within multiple bicrystal geometries have been investigated using the BEM in this study; $\mathrm{Nb}-\mathrm{Al}_{2} \mathrm{O}_{3}$ and $\mathrm{Cu}-\mathrm{Al}_{2} \mathrm{O}_{3}$ bicrystals were chosen for analysis. The material principal axes of each crystal, beginning as aligned with the global Cartesian axes, were rotated independently through their full range until a symmetrical state was reached. The change in the stress concentrations at the interface was analysed. A separate investigation into the reduction of the stress concentrations by adding auxiliary holes was also performed.

The first bicrystal geometry studied was that of a plate with a circular hole at the interface in tension along the $\mathrm{x}_{2}$-axis. The weak stress singularity at the material interface free edges was observed. Generally, reduction in the equivalent stress within the less stiff material was accompanied by an increase of equivalent stress in the stiffer material. This effect is more pronounced in the $\mathrm{Cu}-\mathrm{Al}_{2} \mathrm{O}_{3}$ bicrystal, as the differences in the relevant stiffness coefficients between the $C u$ crystal and the $\mathrm{Al}_{2} \mathrm{O}_{3}$ crystal are greater in comparison to those between $\mathrm{Nb}$ and $\mathrm{Al}_{2} \mathrm{O}_{3}$. From the crystallographic rotations of the cubic materials, $\mathrm{Nb}$ and $\mathrm{Cu}$, it was found that they follow opposite trends; equivalent stress increased in $\mathrm{Al}_{2} \mathrm{O}_{3}$ and decreased in $\mathrm{Nb}$ for rotation of the $\mathrm{Nb} \mathrm{x}_{1}$-material axis, and the stress decreased in $\mathrm{Al}_{2} \mathrm{O}_{3}$ and increased in $C u$ for the $C u \mathrm{x}_{1}$-material axis rotation. This opposing effect is a recurring trend 
for all $N b$ and $C u$ material axis rotation comparisons. It is explained by the difference in the anisotropic factor of the two materials, where $C u$ crystal has a higher anisotropic factor, indicating larger relative shear stress to normal stress coefficients. The material orientations producing the largest normal and von Mises equivalent stresses were found to produce stress concentrations up to $89 \%$ and $50 \%$ higher than the corresponding isotropic homogeneous and bimaterial problems, respectively.

The next bicrystal problem studied was a double U-notch bar in tension along the $\mathrm{x}_{1}$-axis, with the notch at the bicrystal interface. The study followed the same steps throughout the analysis and many observations of the stress interactions at the interface were quite similar to the first problem, such as the stress singularity, the effect caused by interaction of the stiffer and less stiff materials, and the opposing trends from $\mathrm{Nb}$ and $\mathrm{Cu}$ crystallographic rotations. Stress concentrations up to $134 \%$ and $82 \%$ larger than the corresponding isotropic homogeneous and bimaterial problems, respectively, were observed. Other interesting characteristics, common to the two bicrystals with different geometries and grain boundary orientations, are as follows: a) the normal stress in the loading direction, a short distance into the materials at the interface, is similar to that of the corresponding isotropic cases, although the other stress components differ significantly; $b$ ) the rotation of the cubic material axis which coincides with the load axis causes very little stress variation in relation to other material axis rotations; $c$ ) the equivalent stress changes significantly as the anisotropy of the materials cause large changes in normal and shear stresses; and $d$ ) rotation of the trigonal $\mathrm{Al}_{2} \mathrm{O}_{3}$ material axes, namely the $\mathrm{x}_{1}$-material axis, generally causes both increases and decreases of equivalent and normal stresses in the direction of loading depending on rotation.

The introduction of auxiliary holes in a bicrystal plate with a circular hole in tension was successful in significantly reducing the largest stress concentrations by at least $17 \%$ in all cases, except those involving $C u$ crystal which initially contained a 
lower stress concentration. The reductions in the latter are still at least $13 \%$. The percent reductions attained for each material are similar for both a bimaterial and homogenous structure. The auxiliary hole parameters investigated were auxiliary-tomain hole radius ratio, $b / r=0.3,0.5,0.7,0.9$, and the auxiliary-to-main hole distance to main hole radius ratio, $d / r=2.0,2.5,3.0$. The lowest stress concentrations were produced when the auxiliary holes were positioned at $d / r=2.0$ for all cases, except within the $\mathrm{Al}_{2} \mathrm{O}_{3}$ material of the $\mathrm{Cu}-\mathrm{Al}_{2} \mathrm{O}_{3}$ bicrystal where the results favour a hole located at $d / r=2.5$ and suggest a larger hole outside the range studied will further reduce the stress concentration. Moreover, the stress results, from the $\mathrm{Al}_{2} \mathrm{O}_{3}$ regions of all bimaterial cases investigated, suggest larger holes are necessary to attain the lowest possible stress concentrations. The location of the largest stress concentration was found to change position around the face of the holes depending on the relative size and position of the main and auxiliary holes. The location also occurs further away from the plane normal to the tensile axis, $\theta=0^{\circ}$, for materials with relatively larger shear stiffness coefficients in relation to the normal stiffness coefficients such as $C u$ crystal.

\subsection{Suggestions for Future Work}

This study has found qualitative trends of the stress concentrations located at the bicrystal interface for changing crystallographic orientations. However, exact details describing the stress field at the free edges, such as the stress participation factor, are outside the scope of this analysis. To this end, further research into modifying the formulation of a numerical method to capture the singular nature of the stress field at the interface free edges would be of great value.

It was observed that the rotation of the material principal axis coinciding with the tensile load axis of the cubic materials, paired with $\mathrm{Al}_{2} \mathrm{O}_{3}$, yielded significantly 
reduced variation of stress. This effect was maintained for different orientations of the grain boundary plane. An investigation into the parameters responsible would help explain the cause of this effect.

The DHS parametric study did not resolve all optimal auxiliary hole values within the ranges examined. Increased resolution of the auxiliary-to-main hole distance parameter is justified in all studies, as well as expanding the upper range of the auxiliary hole size parameter for bimaterial cases when there exists a significant discrepancy in material stiffness across the interface. With these modifications, further studies would provide the largest attainable stress concentration reductions. 


\section{List of References}

Akour, S. N., Nayfeh, J. F. \& Nicholson, D. W. (2003), 'Design of a defence hole system for a shear-loaded plate', The Journal of Strain Analysis for Engineering Design 38(6), 507-517.

Barroso, A., Mantič, V. \& Paris, F. (2003), 'Singularity analysis of anisotropic multimaterial corners', Intermational Journal of Fracture 119(1), 1-23.

Benthem, J. P. (1977), 'State of stress at the vertex of a quarter-infinite crack in a half-space', Intermational Journal of Solids and Structures 13(5), 479-492.

Bogy, D. B. (1968), 'Edge-bonded dissimilar orthogonal elastic wedges under normal and shear loading', Journal of Applied Mechanics 35, 460-466.

Chen, C. R., Li, S. X. \& Wang, Z. G. (1998), 'Characteristics of strain and resolved shear stress in a bicrystal with the grain boundary perpendicular to the tensile axis', Materials Science and Engineering A 247(1-2), 15-22.

Cruse, T. A. (1969), 'Numerical solutions in three dimensional elastostatics', International Journal of Solids and Structures 5(12), 1259-1274.

Delale, F. (1984), 'Stress singularities in bonded anisotropic materials', International Journal of Solids and Structures 20(1), 31-40.

Erickson, P. E. \& Riley, W. F. (1978), 'Minimizing stress concentrations around circular holes in uniaxially loaded plates', Experimental Mechanics 18(3), 97100 .

Folias, E. S. \& Wang, J. J. (1990), 'On the three-dimensional stress field around a circular hole in a plate of arbitrary thickness', Computational Mechanics 6(5), 379391.

Gagorik, J. E., Queeney, R. A. \& McKinstry, H. A. (1971), 'Stress distributions in Al2O3 bicrystal tensile specimens', Journal of The American Ceramic Society 54(12), 625-627. 
Gemperlová, J., Paidar, V. \& Kroupa, F. (1989), 'Compatibility stresses in deformed bicrystals', Czechoslovak Journal of Physics 39(4), 427-446.

Haddon, R. A. W. (1967), 'Stresses in an infinite plate with two unequal circular holes', The Quarterly Journal of Mechanics and Applied Mathematics 20(3), 277.

Heinzelmann, M. \& Kalamkarov, A. L. (2010), 'Stress concentration factors and weight functions in thin notched structures of equibiaxial anisotropic materials', Advanced Engineering Materials 12(7), 633-636.

Jindal, U. C. (1983), 'Reduction of stress concentration around a hole in a uniaxially loaded plate', The Journal of Strain Analysis for Engineering Design 18(2), 135141.

Lee, V. G. (2003), 'Explicit expression of derivatives of elastic Green's functions for general anisotropic materials', Mechanics Research Communications 30(3), 241249 .

Lee, V. G. (2009), 'Derivatives of the three-dimensional Green's functions for anisotropic materials', International Journal of Solids and Structures 46(1819), 3471-3479.

Lifshitz, I. M. \& Rozentsveĭg, L. N. (1947), 'On the construction of the Green's tensor for the fundamental equations of the theory of elasticity in the case of an unrestricted elastic-anisotropic medium', Zh. Ėksper. Teoret. Fiz 17, 783-791.

Meguid, S. A. (1986), 'Finite element analysis of defence hole systems for the reduction of stress concentration in a uniaxially-loaded plate with two coaxial holes', Engineering Fracture Mechanics 25(4), 403-413.

Pageau, S. S. \& Biggers Jr., S. B. (1996), 'A finite element approach to threedimensional singular stress states in anisotropic multi-material wedges and junctions', International Journal of Solids and Structures 33(1), 33-47.

Peralta, P., Schober, A. \& Laird, C. (1993), 'Elastic stresses in anisotropic bicrystals', Materials Science and Engineering: A 169(1-2), 43-51.

Phan, A.-V., Gray, L. J. \& Kaplan, T. (2004), 'On the residue calculus evaluation of the 3-D anisotropic elastic Green's function', Communications in Numerical Methods in Engineering 20(5), 335-341.

Pilkey, W. (1997), Peterson's Stress Concentration Factors, Vol. 2, Wiley Online Library. 
Qamar, I. \& Husain, W. (1989), 'Incompatibility stresses at the boundary of a bicrystal of an elastically anisotropic solid', Scripta Metallurgica 23(12), 2105-2110.

Reedy, E. D. J. (1990), 'Intensity of the stress singularity at the interface corner between a bonded elastic and rigid layer', Engineering Fracture Mechanics 36(4), 575-583.

Sales, M. A. \& Gray, L. J. (1998), 'Evaluation of the anisotropic Green's function and its derivatives', Computers \& structures 69(2), 247-254.

Shiah, Y. C., Tan, C. L. \& Chen, Y. H. (2009), Three dimensional BEM anisotropic stress analysis of bicrystals, in 'Advances in Boundary Element Techniques $\mathrm{X}$, Proc. BeTeq 2009 Conf., Athens', pp. 389-394.

Shiah, Y. C., Tan, C. L. \& Lee, V. G. (2008), 'Evaluation of explicit-form fundamental solutions for displacements and stresses in 3D anisotropic elastic solids', CMES: Computer Modeling in Engineering \& Sciences 34(3), 205-226.

Shiah, Y. C., Tan, C. L., Lee, V. G. \& Chen, Y. H. (2008), Evaluation of Green's functions for 3D anisotropic elastic solids, in 'Advances in Boundary Element Techniques IX, Proc. BeTeq 2008 Conf., Seville', EC Ltd.(UK), pp. 119-124.

Shiah, Y. C., Tan, C. L., Sun, W. X. \& Chen, Y. H. (2010), On the displacement derivatives of the three-dimensional Green's function for generally anisotropic bodies, in 'Advances in Boundary Element Techniques XI, Proc. BeTeq 2010 Conf., Berlin', pp. 426-432.

Tan, C. L., Shiah, Y. C. \& Lin, C. W. (2009), 'Stress analysis of 3D generally anisotropic elastic solids using the boundary element method', CMES: Computer Modeling in Engineering \& Sciences 41(3), 195-214.

Ting, T. C. T. \& Lee, V. G. (1997), 'The three-dimensional elastostatic Green's function for general anisotropic linear elastic solids', The Quarterly Journal of Mechanics and Applied Mathematics 50(3), 407.

Tvergaard, V. \& Hutchinson, J. W. (1988), 'Microcracking in ceramics induced by thermal expansion or elastic anisotropy', Journal of the American Ceramic Society 71(3), 157-166.

Wan, J. \& Yue, Z. (2004), 'Stress distributions near grain boundary in anisotropic bicrystals and tricrystals', Applied Mathematics and Mechanics 25(1), 39-46. 
Wang, C. Y. (1997), 'Elastic fields produced by a point source in solids of general anisotropy', Journal of Engineering Mathematics 32(1), 41-52.

Wang, C. Y. \& Denda, M. (2007), '3D BEM for general anisotropic elasticity', International Journal of Solids and Structures 44(22-23), 7073-7091.

Wilson, R. B. \& Cruse, T. A. (1978), 'Efficient implementation of anisotropic three dimensional boundary-integral equation stress analysis', International Journal for Numerical Methods in Engineering 12(9), 1383-1397. 


\section{Appendix A}

\section{Fundamental Solutions of Three}

\section{Dimensional Anisotropic Elasticity}

Only the final forms of the fundamental solutions for three dimensional anisotropic elasticity are presented here. For more details about their derivation, refer to Ting \& Lee (1997), Lee (2003), and Lee (2009); and for more details on their numerical evaluation refer to Shiah, Tan \& Lee (2008), Tan et al. (2009), and Shiah, Tan, Sun \& Chen (2010).

Recall the boundary integral equation (BIE) which relates nodal displacements, $u_{j}$, and tractions, $t_{j}$, over the boundary, $S$, of a homogeneous elastic domain

$$
C_{j i}(P) u_{i}(P)+\int_{S} u_{i}(Q) T_{j i}^{*}(P, Q) d S(Q)=\int_{S} t_{i}(Q) U_{j i}(P, Q) d S(Q)
$$

where body forces have been omitted.

$$
U_{i j}(P, Q) \equiv \mathbf{U}(\mathbf{x}) \text { and } T_{i j}^{*}(P, Q) \equiv \mathbf{T}^{*}(\mathbf{x}) \text { represent the fundamental solutions }
$$

of displacements and tractions, respectively; these are also known as the Green's functions. Now consider a source point, $P$, at the local origin $\mathbf{x}=0$ where a unit load is applied in an infinite anisotropic elastic body. The field point, $Q$, is at $\mathbf{x}=$ $\left(x_{1}, x_{2}, x_{3}\right)$ and is a distance $r$ away from $P$. For a unit circle $\left|\mathbf{n}^{*}\right|=1$ on an oblique 
plane normal to $\mathbf{x}_{Q}$, the unit vector, $\mathbf{n}^{*}$, can be written in terms of an arbitrary parameter, $\psi$, as

$$
\mathbf{n}^{*}=\mathbf{n} \cos \psi+\mathbf{m} \sin \psi
$$

where the vectors $\mathbf{n}$ and $\mathbf{m}$, along with $\mathbf{x} / r$, form a right-handed $\operatorname{triad}[\mathbf{n}, \mathbf{m}, \mathbf{x} / r]$, see Figure A.1. The Green's displacements can be expressed as (Ting \& Lee 1997)

$$
\mathbf{U}(\mathbf{x})=\frac{1}{4 \pi r} H_{i j}=\frac{1}{4 \pi r} \frac{1}{|\mathbf{T}|} \sum_{n=0}^{4} q_{n} \hat{\Gamma}^{(n)}
$$

where $\hat{\Gamma}$, with components $\hat{\Gamma}^{(n)}$, is the adjoint of $\Gamma$ and

$$
\boldsymbol{\Gamma}(p)=\mathbf{Q}+p\left(\mathbf{R}+\mathbf{R}^{T}\right)+p^{2} \mathbf{T}
$$

In equation A.4,

$$
\begin{aligned}
& \mathbf{Q} \equiv Q_{i k}=C_{i j k s} n_{j} n_{s}, \\
& \mathbf{R} \equiv R_{i k}=C_{i j k s} n_{j} m_{s}, \\
& \mathbf{T} \equiv T_{i k}=C_{i j k s} m_{j} m_{s},
\end{aligned}
$$

where $C_{i j k s}$ is the material stiffness matrix, and $p=\tan \psi$. A sextic equation in $p$ is obtained by equating the determinant, $|\Gamma(p)|$, to zero. The six independent roots are the Stroh's eigenvalues. The roots of this equation are complex conjugate pairs, $p_{v}=\alpha_{v}+\imath \beta_{v}, \beta_{v}>0,(v=1,2,3)$. Also, $q_{n}$ is given as

$$
q_{n}= \begin{cases}\frac{-1}{2 \beta_{1} \beta_{2} \beta_{3}}\left[\operatorname{Re}\left\{\sum_{t=1}^{3} \frac{p_{t}^{n}}{\left(p_{t}-\bar{p}_{t+1}\right)\left(p_{t}-\bar{p}_{t+2}\right)}\right\}-\delta_{n 2}\right] & \text { for } n=0,1,2 \\ \frac{-1}{2 \beta_{1} \beta_{2} \beta_{3}}\left[\operatorname{Re}\left\{\sum_{t=1}^{3} \frac{p_{t}^{n-2} \bar{p}_{t+1} \bar{p}_{t+2}}{\left(p_{t}-\bar{p}_{t+1}\right)\left(p_{t}-\bar{p}_{t+2}\right)}\right\}\right] & \text { for } n=3,4\end{cases}
$$


where $\bar{p}_{t}$ denotes the complex conjugate, $\delta_{i j}$ is the Kronecker delta, and the subscript $t$ follows the cyclic rule, $t=(t-3)$ if $t>3$. The Green's function for tractions, $\mathbf{T}^{*}(\mathbf{x})$, is obtained from the first derivative of equation A.3, the displacements function, and utilizing Hooke's law and the relationship between the stress tensor and traction vector. The displacements derivative of $\mathbf{U}(\mathbf{x})$ is

$$
U_{i j, l}=\frac{1}{4 \pi^{2} r^{2}}\left[-\pi y_{l} H_{i j}+C_{p q r s}\left(y_{s} M_{l q i p r j}+y_{q} M_{s l i p r j}\right)\right]
$$

where $y_{i}$ are the components of the unit position vector $\mathbf{y}=\frac{\mathbf{x}}{r}$ in a spherical coordinate system. $M_{i j k l m n}$ is given explicitly in terms of the Stroh's eigenvalues, $p_{t}$, as

$$
\begin{aligned}
M_{i j k l m n}= & \frac{2 \pi \imath}{|T|^{2}} \sum_{t=1}^{3} \frac{1}{\left(p_{t}-p_{t+1}\right)^{2}\left(p_{t}-p_{t+2}\right)^{2}} \\
& {\left[\Phi_{i j k l m n}^{\prime}\left(p_{t}\right)-2 \Phi_{i j k l m n}\left(p_{t}\right) \times\left(\frac{1}{p_{t}-p_{t+1}}+\frac{1}{p_{t}-p_{t+2}}\right)\right], }
\end{aligned}
$$

where $\Phi_{i j k l m n}(p)$ can be shown to be

$$
\Phi_{i j k l m n}(p)=\frac{\left[n_{i} n_{j}+\left(n_{i} m_{j}+m_{i} n_{j}\right) p+m_{i} m_{j} p^{2}\right]\left[\hat{\Gamma}_{k l}(p) \hat{\Gamma}_{m n}(p)\right]}{\left(p-\bar{p}_{1}\right)^{2}\left(p-\bar{p}_{2}\right)^{2}\left(p-\bar{p}_{3}\right)^{2}}
$$

In equation A.8, $p_{t+1}$ and $p_{t+2}$ follow the cyclic rule for $t>2$ as discussed earlier. It is also not necessary to provide the explicit expression of $\Phi_{i j k l m n}^{\prime}\left(p_{t}\right)$ since it is relatively simple to program the constituent functions of $\Phi_{i j k l m n}$ and their derivatives and subsequently apply the chain rule in the differentiation. 


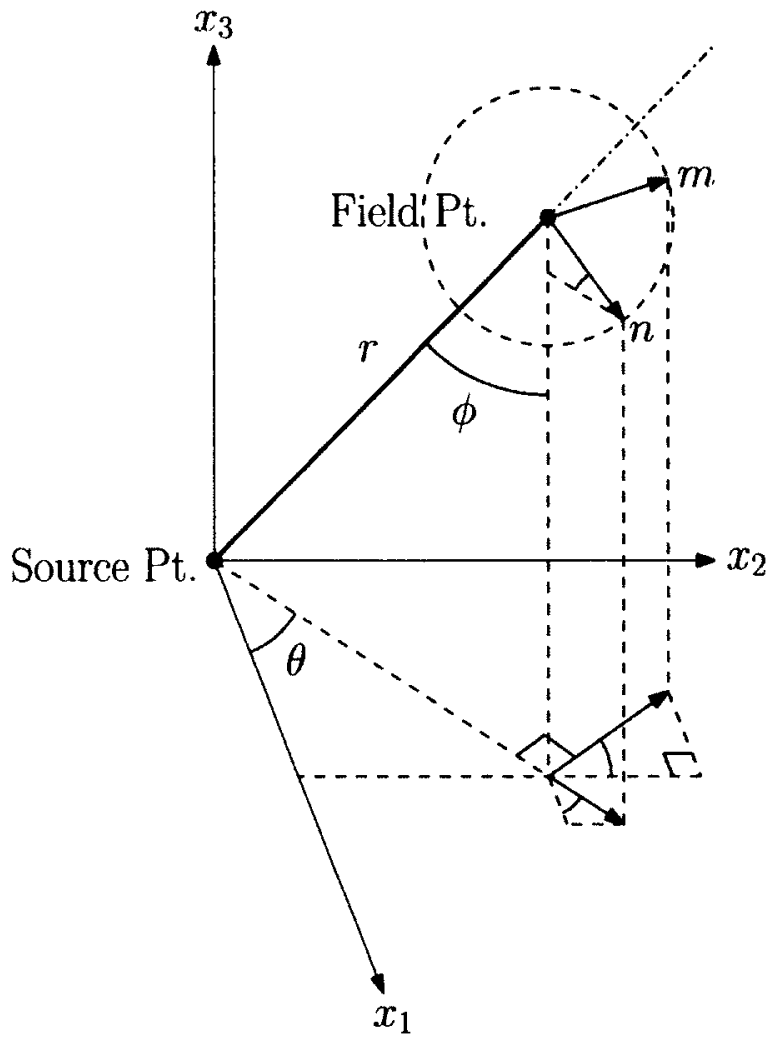

Figure A.1: Definition of the unit vectors $\mathbf{n}$ and $\mathbf{m}$ 


\section{Appendix B}

\section{Quadratic Shape Functions of BEM}

\section{Elements}

\section{B.1 Quadrilateral Elements}

$$
\begin{aligned}
& N^{1}\left(\xi_{1}, \xi_{2}\right)=-\frac{1}{4}\left(1-\xi_{1}\right)\left(1-\xi_{2}\right)\left(1+\xi_{1}+\xi_{2}\right) \\
& N^{2}\left(\xi_{1}, \xi_{2}\right)=\frac{1}{2}\left(1-\xi_{1}^{2}\right)\left(1-\xi_{2}\right) \\
& N^{3}\left(\xi_{1}, \xi_{2}\right)=-\frac{1}{4}\left(1+\xi_{1}\right)\left(1-\xi_{2}\right)\left(1-\xi_{1}+\xi_{2}\right) \\
& N^{4}\left(\xi_{1}, \xi_{2}\right)=\frac{1}{2}\left(1-\xi_{1}\right)\left(1-\xi_{2}^{2}\right) \\
& N^{5}\left(\xi_{1}, \xi_{2}\right)=\frac{1}{2}\left(1+\xi_{1}\right)\left(1-\xi_{2}^{2}\right) \\
& N^{6}\left(\xi_{1}, \xi_{2}\right)=-\frac{1}{4}\left(1-\xi_{1}\right)\left(1+\xi_{2}\right)\left(1+\xi_{1}-\xi_{2}\right) \\
& N^{7}\left(\xi_{1}, \xi_{2}\right)=\frac{1}{2}\left(1-\xi_{1}^{2}\right)\left(1+\xi_{2}\right) \\
& N^{8}\left(\xi_{1}, \xi_{2}\right)=-\frac{1}{4}\left(1+\xi_{1}\right)\left(1+\xi_{2}\right)\left(1-\xi_{1}-\xi_{2}\right)
\end{aligned}
$$




\section{B.2 Triangular Elements}

$$
\begin{aligned}
& N^{1}\left(\xi_{1}, \xi_{2}\right)=\left(1-\xi_{1}-\xi_{2}\right)\left(1-2 \xi_{1}-2 \xi_{2}\right) \\
& N^{2}\left(\xi_{1}, \xi_{2}\right)=4 \xi_{1}\left(1-\xi_{1}-\xi_{2}\right) \\
& N^{3}\left(\xi_{1}, \xi_{2}\right)=\xi_{1}\left(2 \xi_{1}-1\right) \\
& N^{4}\left(\xi_{1}, \xi_{2}\right)=4 \xi_{1} \xi_{2} \\
& N^{5}\left(\xi_{1}, \xi_{2}\right)=\xi_{2}\left(2 \xi_{2}-1\right) \\
& N^{6}\left(\xi_{1}, \xi_{2}\right)=4 \xi_{2}\left(1-\xi_{1}-\xi_{2}\right)
\end{aligned}
$$




\section{Appendix C}

\section{Numerical Results}

Because of the voluminous amount of numerical results obtained in this study, a digital medium (CD) is included here in this thesis. It contains the complete set of all the processed results of the numerical analyses carried out. Instructions and details of each case considered are described in the files on the CD. 